Aus dem Fachgebiet Allgemeine Phytopathologie und Pflanzenschutz des Departments für Nutzpflanzenwissenschaften der Georg-August-Universität Göttingen

\title{
Europäisches Rassen-Monitoring und Pathogenesestudien zur Turcicum-Blattdürre (Exserohilum turcicum) an Mais (Zea mays L.)
}

\author{
Dissertation \\ zur Erlangung des Doktorgrades \\ der Fakultät für Agrarwissenschaften \\ der Georg-August-Universität Göttingen
}

vorgelegt von

Hendrik Hanekamp

geboren in Löningen

Göttingen, im März 2016 
D 7

1. Referent: Prof. Dr. Andreas von Tiedemann

2. Referent: Prof. Dr. Heiko Becker

Tag der mündlichen Prüfung: 25. April 2016 
"We're going to teach you to be rebels. Not with guns and daggers, but with science and technology." Norman Borlaug 


\section{Inhaltsverzeichnis}

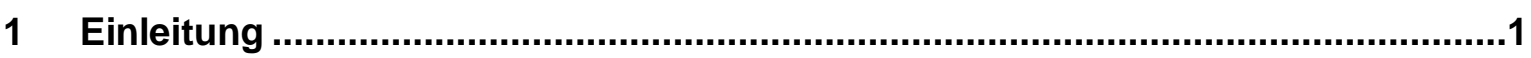

1.1 Bedeutung des Maisanbaus in Europa und Deutschland ...................................

1.2 Turcicum-Blattdürre: Das Pathosystem Mais und E. turcicum ..............................

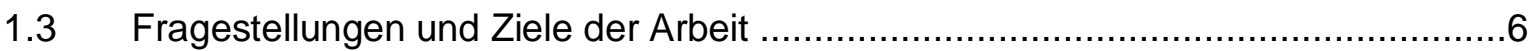

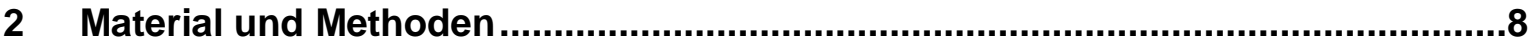

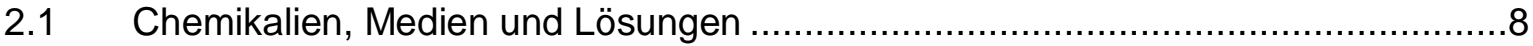

2.2 Exserohilum turcicum Isolate ..................................................................... 11

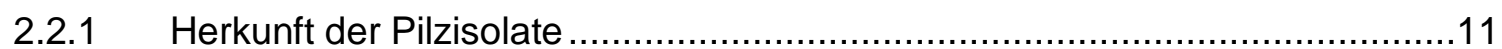

2.2.2 Gewinnung und Lagerung der Einsporisolate ..........................................13

2.3 Untersuchungen zu Kultureigenschaften von E. turcicum ...............................15

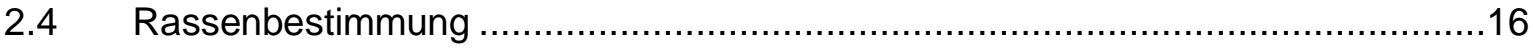

2.4.1 Pflanzenmaterial und Anzuchtbedingungen ..........................................16

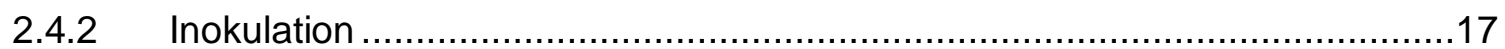

2.4.3 Klimabedingungen ab Inokulation .........................................................

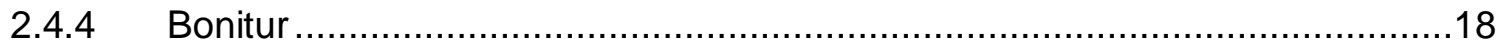

2.4.5 Regionale Diversität und Komplexität der E. turcicum Sammlungen ..............20

2.4.6 Regionale Virulenzhäufigkeiten von E. turcicum in Europa ..........................21

2.4.7 Anbau und Bonitur verschiedener $\mathrm{Ht}$-Differentialsortimente im Feld .............21

2.5 Temperatureinfluss auf die Wirksamkeit der untersuchten Resistenzgene ...........23

2.5.1 Einfluss der Temperatur auf die Wirksamkeit von $\mathrm{Ht}$-Genen .........................23

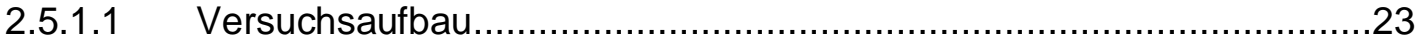

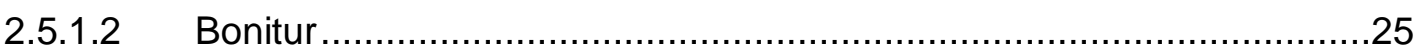

2.5.2 Spezifischer Einfluss der Temperatur auf die Wirksamkeit von $H$ t2 ...............26

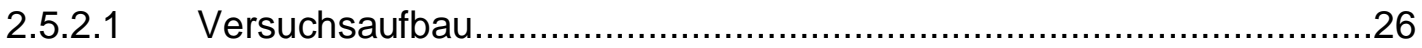

2.5.2.2 Bonitur und Probenahme zur DNA Quantifizierung ...........................27

2.5.2.3 DNA - Quantifizierung durch Real-Time-PCR .............................27

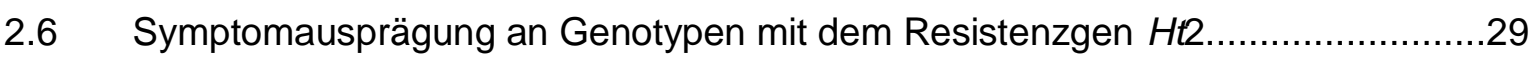




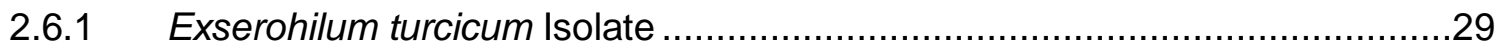

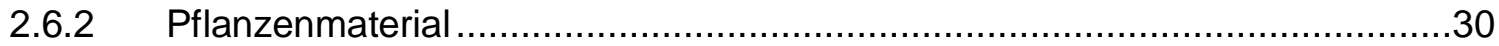

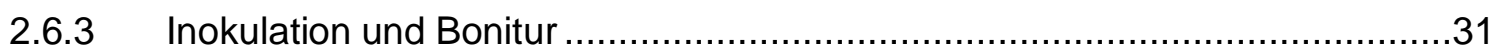

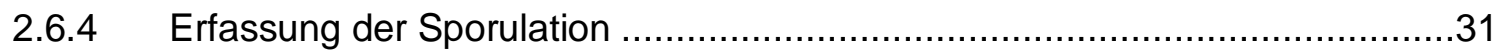

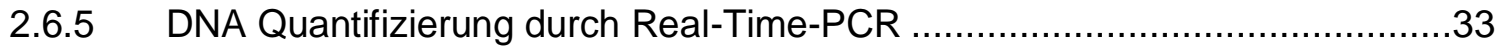

2.7 Histologische Untersuchungen zur Pathogenese von E. turcicum.......................33

2.7.1 E. turcicum Isolate und Pflanzenmaterial .....................................................33

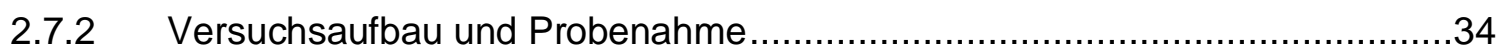

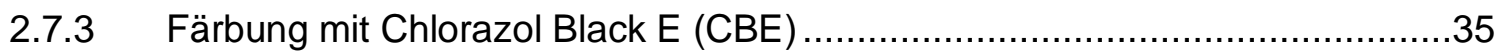

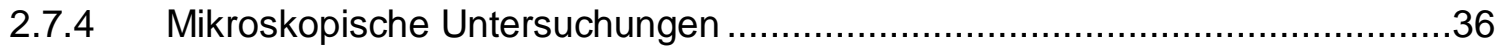

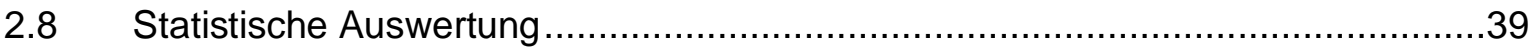

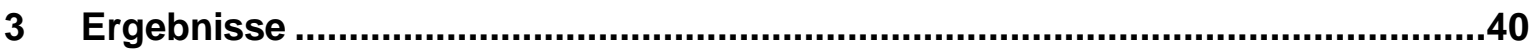

3.1 Kultur- und Lagereigenschaften von E. turcicum ...........................................40

3.2 Rassencharakterisierung europäischer E. turcicum Isolate ...............................42

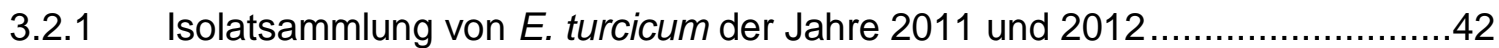

3.2.2 Regionale Rassenspektren der Jahre 2011 und $2012 \ldots \ldots \ldots \ldots \ldots \ldots \ldots \ldots \ldots \ldots . . . . . . . . \ldots \ldots$

3.2.3 Regionale Diversität und Komplexität der Rassen ....................................45

3.2.4 Regionale Wirksamkeit der Resistenzgene ...............................................49

3.2.5 Feldbonitur verschiedener $\mathrm{Ht}$-Differentialsortimente..................................51

3.3 Temperatureinfluss auf die Wirksamkeit der Resistenzgene gegen E. turcicum...53

3.3.1 Temperatureinfluss auf die Wirksamkeit der Gene $H t 1, H t 2, H t 3$ und $H t N \ldots . .53$

3.3.2 Spezifischer Temperatureinfluss auf das Resistenzgen $\mathrm{Ht2}$..........................55

3.4 Symptomausprägung von E. turcicum an Genotypen mit dem Resistenzgen Ht2 60

3.4.1 Symptomausprägungen verschiedener E. turcicum Isolate auf den nahisogenen Inzuchtlinien B37 und B37-Ht2

3.4.2 Epidemiepotential als Grundlage der Symptombeurteilung von E. turcicum am Genotyp B37-Ht2. .65

3.4.3 Korrelation der Merkmale zur Ht2-Symptomatik am Genotyp B37 .67 
3.4.4 Symptome von E. turcicum auf den nah-isogenen Inzuchtlinien Pa91 und Pa91$H t 2$ bzW. KWS und KWS-Ht2 ............................................................. 71

3.5 Histologische Untersuchungen zur Pathogenese von E. turcicum an Mais ..........77

3.5.1 Infektionsprozess von E. turcicum an Mais ..............................................

3.5.2 Vergleichende Auswertung der mikroskopischen Untersuchungen ...............81

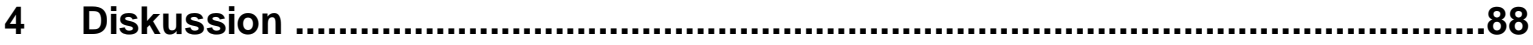

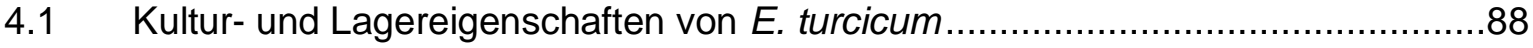

4.2 Rassencharakterisierung europäischer E. turcicum Isolate ................................89

4.3 Temperatureinfluss auf die Wirksamkeit der Resistenzgene ............................108

4.4 Ht2 Symptomatik und Epidemiepotential....................................................111

4.5 Histologische Untersuchungen............................................................ 114

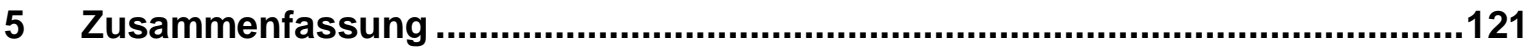

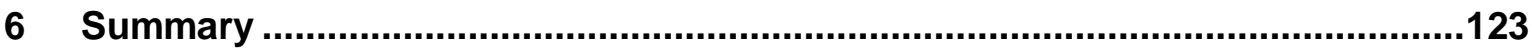

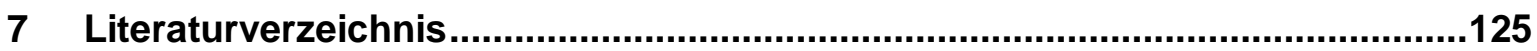

Anhang

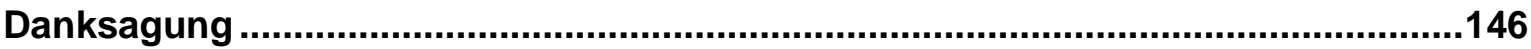

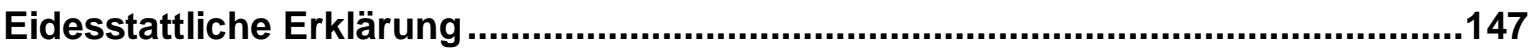

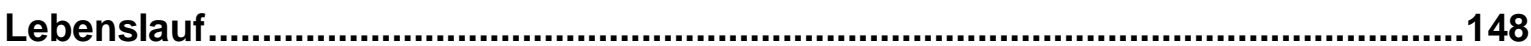


Abkürzungen und Symbole

Abb.

Abbildung

${ }^{\circ} \mathrm{C}$

Grad Celsius

$\mathrm{cm}$

Zentimeter

d. h.

das heißt

$\mathrm{dp}$

Tage nach Inokulation (days past inoculation)

DNA

Desoxyribonukleinsäure

et al.

und andere

ggf.

gegebenenfalls

h

Stunde(n)

ha

Hektar

M

molare Masse

$\min$

Minute(n)

Mio.

Millionen

$\mathrm{ml}$

Milliliter

mg

Milligramm

$\mu \mathrm{l}$

Mikroliter

ng

Nanogramm

$\mathrm{pg}$

Pikogramm

RPM

Umdrehungen pro Minute (rounds per minute)

S

Sekunde

TM

Trockenmasse

u. a.

unter anderem

Z. B.

zum Beispiel

+/- Stbw

+/- Standardabweichung 


\section{$1 \quad$ Einleitung}

\subsection{Bedeutung des Maisanbaus in Europa und Deutschland}

Mais (Zea mays L.) wurde in Europa (EU-28) im Jahr 2014 auf einer Fläche von etwa 15,7 Mio. ha angebaut und stellt damit nach Weizen flächenmäßig die zweitwichtigste Fruchtart dar. Die Maisfläche in Europa wurde 2014 zu 60\% für die Körnermaiserzeugung und zu 40\% zur Produktion von Silomais genutzt. Der Körnermaisanbau ist auf die südlichen Maisanbauregionen in Südwestfrankreich, Ungarn und Italien konzentriert, wohingegen knapp 60\% der europäischen Silomaisfläche auf Deutschland und die nördlichen Regionen in Frankreich entfallen (EUROSTAT, 2016). Aufgrund des hohen Temperaturbedarfs der ersten wenig kältetoleranten Sorten etablierte sich in den 1950er Jahren zunächst nur in den warmen südlichen Regionen ein nennenswerter Maisanbau. Sortenbezeichnung wie „Inntaler Mais“, „Badener Mais“ oder „Rheintaler Mais“ belegen die historische Bedeutung der Maisnutzung in den heute durch intensiven Maisanbau gekennzeichneten Regionen. Insbesondere die Regionen Südwestfrankreich, Italien, die Oststeiermark und die Oberrheinregion, aber auch nördliche Küstenregionen, wie z. B. in den Niederlanden sind durch sehr enge Fruchtfolgen von zum Teil über 50\% Mais gekennzeichnet. Darüber hinaus findet der Maisanbau in den warm-trockenen südlichen Regionen vermehrt unter dem Einsatz von Beregnung statt (Meissle et al., 2010; WIFO, 2015; AGPM, 2016)

Als wichtige Einflussfaktoren auf die regional verschiedenen Nutzungsrichtungen sind vor allem die vorherrschenden Temperaturen und die Niederschlagsmengen zu nennen. Generell werden die kühl-nassen Bedingungen in den nordwestlichen Regionen Europas vorwiegend für die Silomaiserzeugung und die warm-trockenen südlichen Regionen verstärkt zur Körnermaiserzeugung genutzt (Meissle et al., 2010). Darüber hinaus ist die Möglichkeit zur innerbetrieblichen Verwendung für die Wahl der Nutzungsrichtung von ebenso großer Bedeutung. Insbesondere in der Wiederkäuerfütterung in den nördlichen Küstenregionen spielt Silomais zur direkten Verwertung als energiereiches Futtermittel eine wichtige Rolle. Körnermais wird zum überwiegenden Teil als Futtermittel in der Schweine- und Geflügelhaltung verwendet, wobei Körnermais nicht an eine innerbetriebliche Verwertung gebunden ist, sondern oft wie Getreide als Marktfrucht vermarktet wird (Weiss, 2002).

Neben der Nutzung als Futtermittel wird Mais aufgrund der hohen Biomasseerträge bevorzugt auch als Energiepflanze in der Biogaserzeugung verwendet. Durch Vorgaben der Europäischen Union zur Förderung der Stromerzeugung aus erneuerbaren Energiequellen (Anonymus 1, 2001) kam es daraufhin in der EU zu einer Ausweitung der Silomaisfläche um etwa 25\% (EUROSTAT, 2016). Die Umsetzung dieser Vorgaben in nationales Recht 
erfolgte in Deutschland durch das Gesetz für den Vorrang Erneuerbarer Energien (Erneuerbare-Energien-Gesetz, EEG). Jedoch erst mit der Novellierung des EEGs im Jahr 2004 wurde die Attraktivität der Nutzung von Biomasse zur Strom- bzw. Gaserzeugung deutlich erhöht. Im Rahmen dieser Novellierung wurde in Deutschland ein Bonus eingeführt, der speziell den Einsatz nachwachsender Rohstoffe (NawaRo-Bonus) finanziell fördert (Anonymus 2, 2004). Den Erzeugern von Energie aus Biomasse wurden mit dieser Novellierung feste Vergütungssätze für 20 Jahre garantiert. Nach Einführung des EEGs hat die Anbaufläche von Mais in Deutschland zwischen 2000 und 2014 um etwa 1 Mio. ha bzw. 70\% zugenommen (DESTATIS, 2016). Der in Europa verzeichnete Anstieg der Maisfläche ist demnach zum überwiegenden Teil auf die Anbauausweitung in Deutschland zurückzuführen.

Der beschriebene Anstieg des Maisanbaus in Verbindung mit hohen Anbauintensitäten kann als Ursache für ein höheres Aufkommen von Blattkrankheiten im Mais in den vergangenen Jahren angesehen werden (Imgraben, 2002). Die ertragsrelevanteste Blattkrankheit im Mais ist die Turcicum-Blattdürre, die durch den Pilz Exserohilum turcicum hervorgerufen wird. Im Folgenden werden der Erreger, dessen Bedeutung und die Bekämpfungsmöglichkeiten näher erläutert.

\subsection{Turcicum-Blattdürre: Das Pathosystem Mais und E. turcicum}

Der Ascomycet Setosphaeria turcica (Luttrel) Leonard \& Suggs, anamorph Exserohilum turcicum (Pass.) Leonard \& Suggs ist der Erreger der Turcicum-Blattdürre an Mais (engl. Northern corn leaf blight). Die Turcicum-Blattdürre ist in Maisanbaugebieten weltweit sowohl in tropischen als auch in gemäßigten Regionen als bedeutende Blattkrankheit bekannt (Welz, 1998). Die Symptome beginnen meist an den unteren Bereichen der Pflanze auf den Blattspreiten mit grau-grünen, länglich-ovalen Läsionen mit einer Größe von 2 bis $3 \mathrm{~cm}$. Im weiteren Krankheitsverlauf dehnen sich die Läsionen auf 15 bis $20 \mathrm{~cm}$ aus, um schließlich zu großflächigen braunen Nekrosen zu verschmelzen. Dies führt zum Absterben großer Teile der Blattfläche. Dunkle, grau-schwarze Zonen in den Läsionen sind ein Indikator für Sporulation. Die Sporen sind oliv-grau, spindelförmig und drei- bis achtfach septiert. Das eindeutige Charakteristikum der Sporen von E. turcicum ist das herausragende Hilum der bis zu $120 \mu$ m langen Konidien (Abbildung 2). Die Sporen werden durch Wind und Regenspritzer innerhalb des Bestandes, aber auch über größere Distanzen in andere Bestände verbreitet und können so zur epidemischen Ausbreitung beitragen. Temperaturen zwischen $18^{\circ}$ und $25^{\circ} \mathrm{C}$ in Verbindung mit Nebel- oder Tauphasen von mehreren Stunden sind Voraussetzung sowohl für eine optimale Infektion als auch für die Sporenbildung (Carson, 
1999). Die Überwinterung des Erregers erfolgt als Spore oder Myzel an bzw. in Pflanzenresten, die im folgenden Jahr als Inokulum dienen. Bei kühlen Temperaturen zum Ende der Vegetationsperiode kommt es darüber hinaus zur Bildung von Chlamydosporen als Überdauerungsform (Levy, 1984). Die Beseitigung von Pflanzenresten durch entsprechende Bodenbearbeitung kann somit als wirksame vorbeugende Maßnahme zur Reduktion des Inokulums im Folgejahr dienen. Der Lebenszyklus von E. turcicum ist in Abbildung 1 dargestellt.

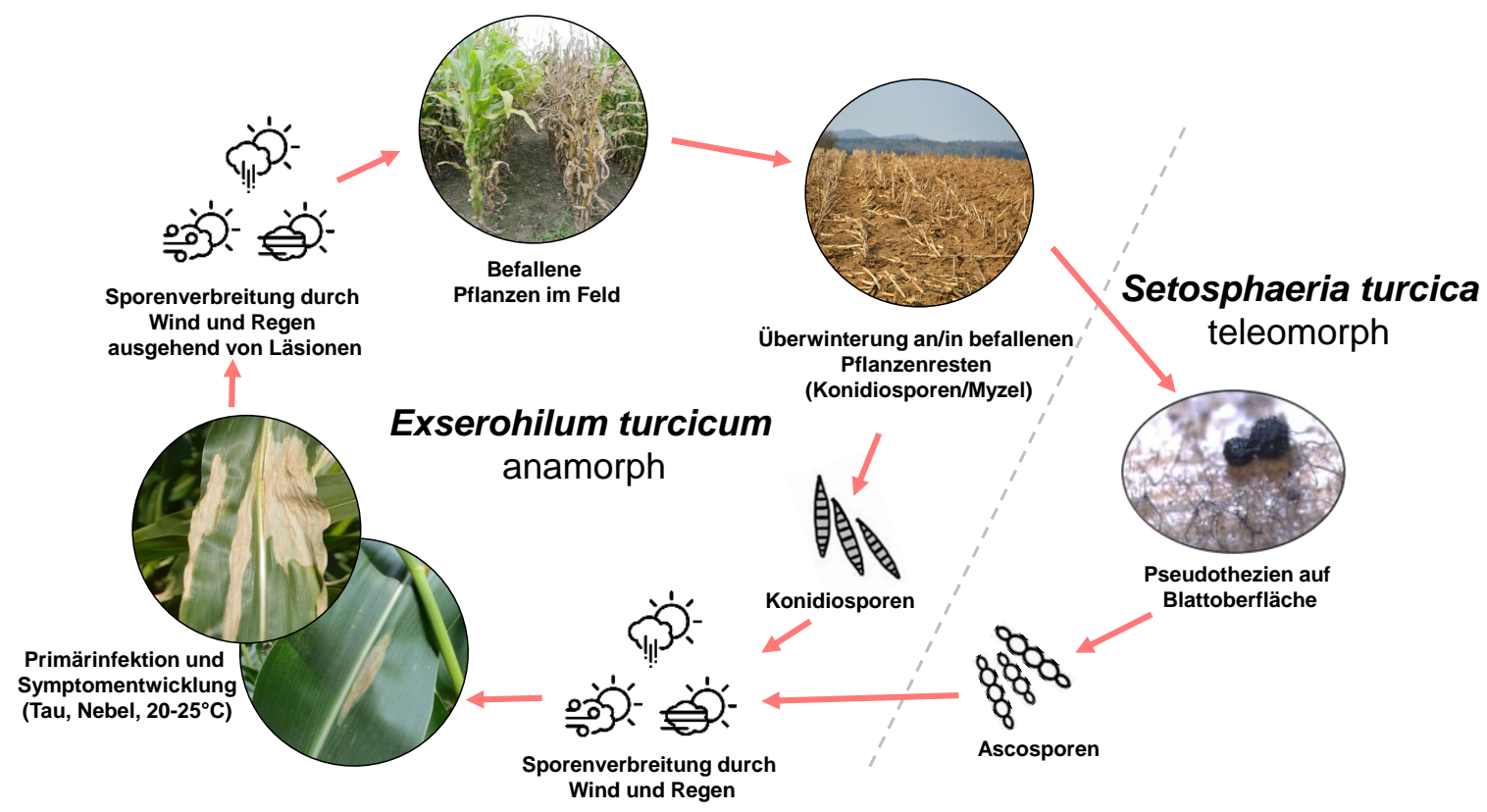

Abb. 1: Lebenszyklus von E. turcicum dem Erreger der Turcicum-Blattdürre an Mais
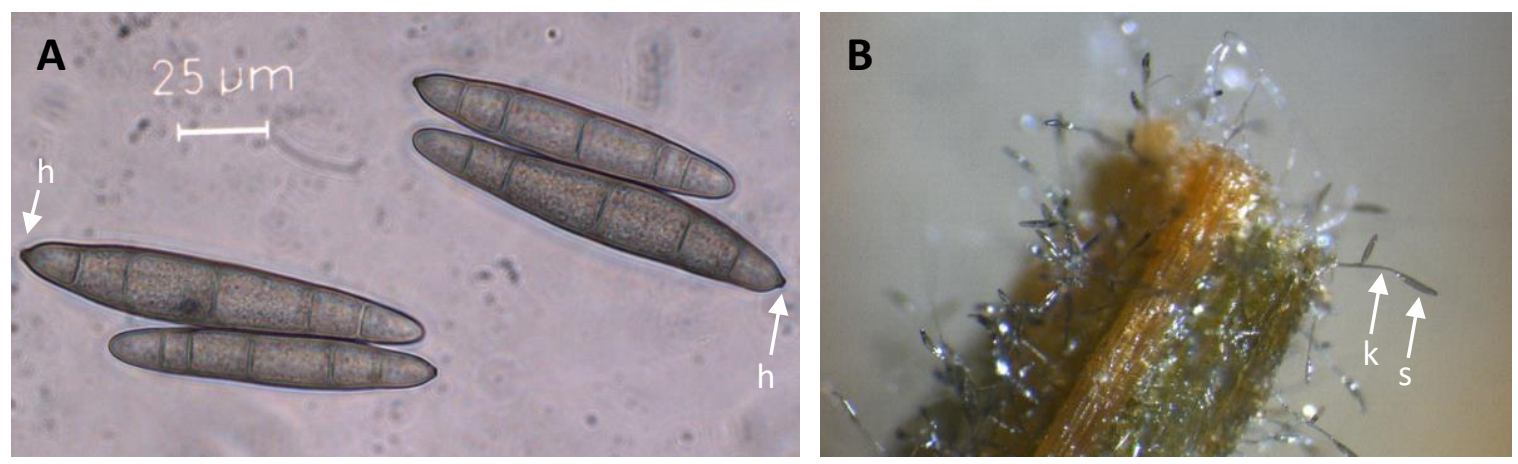

Abb. 2: (A) Konidiosporen von E. turcicum, mehrfach septiert mit herausragendem Hilum (h); (B) Konidienträger (k) mit Konidiosporen (s) auf Maisblatt 
Ertragsausfälle bzw. Ertragsreduktionen sind vor allem eine Folge der verringerten photosynthetisch aktiven Blattfläche. Darüber hinaus kann starker Befall zu hohen Trockensubstanzgehalten in der Maispflanze führen und somit die Futterqualität der Maissilage herabsetzen (Weiss, 2002). Wenn es zu frühem Befall auf anfälligen Sorten unter günstigen Bedingungen für den Pilz kommt, sind Ertragsverluste von über $60 \%$ bis hin zu Totalausfällen dokumentiert (Raymundo et al., 1981; Bowen \& Pedersen, 1988). Tritt der Befall hingegen erst später in der Vegetationsperiode auf, d. h. nach der Blüte, sind die Auswirkungen auf den Ertrag deutlich reduziert. Levy \& Leonard (1990) konnten in Versuchen in den USA zeigen, dass je 10\% Befallsstärke etwa 4\% Kornertragsverluste zur Folge haben

In den Maisanbauregionen der USA tritt die Turcicum-Blattdürre bereits seit den 1950er Jahren immer wieder in Form von Epidemien auf. In dokumentierten Fällen werden vor allem feuchte und milde Bedingungen in den frühen Sommermonaten in Verbindung mit großflächigem Anbau anfälliger Sorten als Ursache für die Entstehung von Turcicum-Epidemien genannt. Epidemien sind für die Turcicum-Blattdürre in den 1950er und 1960er Jahren im nördlichen Wisconsin und in den 1980er Jahren in North Carolina an der Ostküste dokumentiert. In den 1990er Jahren trat E. turcicum auch im südlichen Texas epidemisch auf und verursachte in anfälligen Sorten Ertragsverluste von bis zu $50 \%$, wohingegen resistente Sorten kaum Ertragsverluste aufwiesen (Meredith, 1966; Leonard \& Leath, 1986; Krausz et al., 1993).

In Europa nimmt seit Anfang der 1990er Jahre die Bedeutung der Turcicum-Blattdürre zu. So trat E. turcicum zu Beginn der 1990er Jahre in der Schweiz und 1995 vor allem in Österreich in epidemischer Form auf. Im Jahr 1995 ist E. turcicum erstmalig auch in Deutschland im Rheintal in einem Maisbestand zur Saatgutvermehrung nachgewiesen worden. In der Region Südwestfrankreich trat die Turcicum-Blattdürre bereits vor 1990 gelegentlich auf (Welz et al., 1996; Welz, 1998). Im Jahr 2002 ist erstmals ein epidemisches Auftreten der Turcicum-Blattdürre in der Oberrheinregion beschrieben, wobei auch in diesem Fall neben den Wetterbedingungen anfällige Sorten als Hauptursache für das starke Auftreten genannt wurden (Imgraben, 2002). In mehreren Versuchen konnte gezeigt werden, dass resistente bzw. weniger anfällige Sorten in den meisten Fällen in der Lage sind, Ertragsverluste vollständig zu verhindern oder zumindest deutlich zu reduzieren (Raymundo et al., 1981; Pataky, 1992; Pataky \& Ledencan, 2006). Die beschriebenen Fälle belegen, dass der Einsatz resistenter Sorten sowohl unter ökologischen als auch unter ökonomischen Gesichtspunkten die effektivste Methode zur Bekämpfung der Turcicum-Blattdürre im Mais darstellt.

Seit 2014 sind in Deutschland zwei Fungizide für die Anwendung im Mais gegen die Turicucm-Blattdürre zugelassen (BVL, 2016). In einer Meta-Analyse, die einen Zeitraum von acht Jahren im Corn-Belt der USA berücksichtigt, konnte gezeigt werden, dass durch den 
Anbau resistenter bzw. toleranter Maissorten der Einsatz von Fungiziden unter ökonomischen Gesichtspunkten in den meisten Fällen nicht gerechtfertigt ist (Paul et al., 2011). Dennoch unterstreicht die erstmalige Zulassung von Fungiziden gegen die Turcicum-Blattdürre dessen gestiegene Bedeutung in Deutschland.

Grundsätzlich gibt es zwei Formen der Resistenz gegen E. turcicum im Mais. Die quantitative, rassenunspezifische Resistenz wird durch viele Gene (polygen) vererbt und wird als dauerhaft wirksam beschrieben. Im Pathosystem Mais - E. turcicum sind in vielen Genotypen quantitative Resistenzen nachgewiesen (Freymark, 1993; Dingerdissen et al., 1996; Welz et al., 1999; Chung et al., 2010). Die Eigenschaft der polygenen Vererbung ist einerseits ein Vorteil für die Dauer der Wirksamkeit, andererseits stellt diese Eigenschaft eine Herausforderung für eine gezielte Nutzung in der Pflanzenzüchtung dar (Becker, 1993). Die qualitative, rassenspezifische Resistenz wird durch ein (monogen) oder sehr wenige Gene vererbt. Dadurch ist sie einerseits relativ einfach züchterisch zu nutzen, andererseits besteht die Gefahr der Entstehung virulenter Rassen, die in der Lage sind, diese Resistenz zu überwinden. Die Wirkungsdauer der qualitativen Resistenz wird deshalb im Vergleich zur quantitativen Resistenz als kurzweilig beschrieben. Das Konzept der qualitativen Resistenz wurde erstmals von Flor (1955) mit monogenen Resistenzen in Flachs gegen Rost beschrieben. Basierend auf der Beschreibung nach Flor (1955) steht bei monogen vererbter Resistenz jedem Resistenzgen im Wirt ein korrespondierendes Avirulenzgen im Pathogen gegenüber. Die vom Avirulenzgen codierten Elicitoren werden durch die vom korrespondierenden Resistenzgen codierten Rezeptoren erkannt, woraufhin Abwehrmechanismen im Wirt eingeleitet werden. In diesem Fall ist das Pathogen avirulent. Bei einer Defektmutation im Avirulenzgen wird daraufhin kein Elicitor synthetisiert und eine Erkennung durch den Rezeptor im Wirt ist nicht mehr möglich. In diesem Fall ist das Pathogen virulent und das Resistenzgen unwirksam. Aufgrund der einzelnen korrespondierenden Gene wird dieses Modell als Gen-für-Gen-Konzept beschrieben und ist in vielen Pathosystemen bekannt (Agrios, 2008).

Gegen die Turcicum-Blattdürre im Mais sind acht monogene Resistenzen als $\mathrm{Ht}$-Gene beschrieben ( $H t$ für die ehemalige Bezeichnung: Helminthosporium turcicum). Vier dieser HtGene $(H t 1, H t 2, H t 3$ und $H t \mathbb{N})$ wurden bereits intensiv vor allem in den USA in der Maiszüchtung verwendet. Informationen zur Nutzung der Ht-Gene in europäischen Maiszuchtprogrammen stehen bisher nicht öffentlich zur Verfügung. Für die vier weiteren Resistenzgene ht4, Htm1, Htp und rt (Carson, 1995; Robbins \& Warren, 1993; Ogliari et al., 2007) ist bisher eine züchterische Nutzung nicht dokumentiert. Das Gen Ht1 wurde von Hooker (1963) zeitgleich in der amerikanischen Linie GE440 und der peruanischen Popcornsorte "Ladyfinger" in den USA beschrieben. Hooker beschrieb die Resistenzreaktion durch $\mathrm{Ht1}$ als „chlorotic- 
lesion-resistance“, also als chlorotische Nekrosen mit deutlich verminderter Sporulation. Das Gen Ht2 wurde ebenfalls durch Hooker (1977) in der australischen Linie NN14B beschrieben. Dieses Gen ist auch durch chlorotische Reaktionen charakterisiert, allerdings mit deutlich größeren Anteilen an Nekrosen, verglichen mit $H t 1$. Die Resistenzreaktionen des Gens $H t 3$ sind ebenfalls durch chlorotische Nekrosen gekennzeichnet und unterscheiden sich nicht wesentlich von $H t 2$. Das Gen $H t 3$ wurde von Hooker (1981) beschrieben und ist das einzige $\mathrm{Ht}$-Gen, das aus der verwandten Art Tripsacum floridanum in Mais übertragen wurde (Welz \& Geiger, 2000). Grundsätzlich verschieden zu den Genen Ht1, Ht2 und $H t 3$ ist das von Gevers (1975) beschriebene Gen $H t \mathbb{N}$. Es reagiert nicht durch Chlorosen als Resistenzreaktion, sondern ist durch eine Verlängerung der Inkubationszeit und der Reduktion der Anzahl an Läsionen beschrieben (Raymundo et al., 1981).

Für einige $\mathrm{Ht}$-Gene konnten ein Einfluss der Temperatur auf die Wirksamkeit und somit veränderte Resistenzreaktionen nachgewiesen werden (Leonard et al., 1989). Die vier HtGene $(H t 1, H t 2, H t 3$ und $H t N)$ wurden insbesondere in den USA, aber auch in anderen Maisanbauregionen der Welt in Maiszuchtprogrammen genutzt, um die Resistenz der Sorten zu erhöhen. Die $H t$-Gene wurden in mehrere Linien über Rückkreuzungsschritte eingebracht, um mit Hilfe von isogenen Differentialsortiments Virulenzuntersuchungen durchführen zu können (Welz \& Geiger, 2000). Die Kenntnis über das Auftreten von virulenten Rassen in einer Pathogenpopulation ist eine Voraussetzung für die effektive Nutzung von entsprechenden Resistenzgenen in der Resistenzzüchtung. Umfangreiche Untersuchungen zu Virulenzspektren von E. turcicum in den Maisanbauregionen konnten zeigen, dass heute für jedes der Resistenzgene virulente Rassen in vielen Anbaugebieten bekannt sind und die Resistenzgene damit regional deutlich an Wirkung verloren haben (Bigirwa et al., 1993; Welz \& Geiger, 1995; Ferguson \& Carson, 2007). Eine flächendeckende Untersuchung zum Virulenzspektrum von E. turcicum in den wichtigen Maisanbauregionen in Zentral- und Westeuropa wurde bisher nicht durchgeführt. Es liegen also bisher in Bezug auf das Auftreten von Virulenzen gegenüber den genannten $\mathrm{Ht}$-Genen in Europa keine Erkenntnisse vor.

\subsection{Fragestellungen und Ziele der Arbeit}

Im Rahmen der vorliegenden Arbeit sollte versucht werden, die Wissenslücke in Bezug auf das Auftreten von virulenten Rassen von E. turcicum in den wichtigen europäischen Maisanbaugebieten zu schließen. Durch die Zusammenarbeit mit der Abteilung Mais der Gemeinschaft zur Förderung von Pflanzeninnovation e. V. (GFPi) sollte zunächst die Erstellung einer umfangreichen, repräsentativen Isolatsammlung realisiert werden. Das Hauptziel bestand darin, durch Virulenzanalysen auf der Erregerseite konkrete Aussagen 
über die Wirksamkeit der $\mathrm{Ht}$-Gene an den verschiedenen Standorten zu treffen und dadurch Impulse für eine gezielte und effektive Resistenzzüchtung im Mais gegen die TurcicumBlattdürre zu geben. Darüber hinaus sollten die Ergebnisse dazu dienen, standortangepasste Anbauempfehlungen für Sorten mit entsprechenden $\mathrm{Ht}$-Genen aussprechen zu können. Die Virulenzanalysen sollten mit Hilfe eines Differentialsortiments aus nah-isogenen Inzuchtlinien unter kontrollierten Bedingungen stattfinden. Durch den Anbau von Differentialsortimenten im Feld an verschiedenen Standorten der untersuchten Regionen sollten schließlich die Ergebnisse der Virulenzanalysen aus dem Gewächshaus validiert werden. In einem weiteren Schwerpunkt sollte in Klimakammerversuchen überprüft werden, wie die untersuchten $\mathrm{Ht}$-Gene in isogenen Maislinien durch verschiedene Temperaturen in ihrer Wirksamkeit beeinflusst werden. Aufgrund des bekannten Temperatureinflusses auf die Wirksamkeit sollte insbesondere das Resistenzgen Ht2 Gegenstand vertiefender Untersuchungen sein. Vor dem Hintergrund der sehr unterschiedlichen Temperaturbedingungen in den europäischen Maisanbaugebieten können diese Ergebnisse zu einer effektiveren standortangepassten Nutzung der entsprechenden $\mathrm{Ht}$-Gene beitragen.

Zudem sollte anhand mikroskopischer Studien die Pathogenese von E. turcicum in Maisblättern verfolgt und die Wirkung der untersuchten Resistenzgene zytologisch analysiert werden. Die Ergebnisse der histologischen Untersuchungen sollen zu einem besseren Verständnis der genetischen Interaktion zwischen E. turcicum und Mais im Kontext von kompatiblen und inkompatiblen Interaktionen beitragen. 


\section{Material und Methoden}

\subsection{Chemikalien, Medien und Lösungen}

\section{Chemikalien}

Agar-Agar

Merck, Darmstadt

Calciumcarbonat $\left(\mathrm{CaCO}_{3}\right)$

Carl Roth, Karlsruhe

Chlorazol Black E (CBE)

Sigma-Aldrich, St. Lois, USA

Czapek Dox

Duchefa Biochemie, Haarlem NL

Essigsäure $>99 \%$

Sigma-Aldrich, St. Lois, USA

Ethanol $>96 \%$

Merck, Darmstadt

Ethylendiamintetraacetat (EDTA)

AppliChem, Darmstadt

Formaldehyd-Lösung 36\%

Merck, Darmstadt

Gemüsesaft

Granini Deutschland, Nieder-Olm

Glucose

AppliChem, Darmstadt

Glycerin $97 \%$

Carl Roth, Karlsruhe

Kaliumhydroxid $(\mathrm{KOH})$

Merck, Darmstadt

Kaliumchlorid (KCL)

Merck, Darmstadt

Kaliumdihydrogenphosphat $\left(\mathrm{KH}_{2} \mathrm{PO}_{4}\right)$

AppliChem, Darmstadt

Kaliumnitrat $\left(\mathrm{KNO}_{3}\right)$

Carl Roth, Karlsruhe

Magnesiumsulfat $\left(\mathrm{MgSO}_{4}\right)$

Carl Roth, Karlsruhe

Midori Green

Nippon Genetics, Düren

Milchsäure $80 \%$

Carl Roth, Karlsruhe

Natriumhypochlorit (NaOCl)

Carl Roth, Karlsruhe

Polyethermodifiziertes Trisiloxan (Silwet Gold ${ }^{\circledR}$ ) Spiess Urania, Hamburg

Rifampicin

AppliChem, Darmstadt

Saccharose

AppliChem, Darmstadt

SensiFAST TM SYBR No-ROX Kit,

Bioline Reagents, UK

Streptomycinsulfat

Duchefa Biochemie, Haarlem NL 
TRIS-Borat-EDTA-Puffer (TBE)

Trishydroxyaminomethan (TRIS)
AppliChem, Darmstadt

Merck, Darmstadt

\section{Nährmedien}

Die verwendeten Nährmedien wurden 15 Minuten bei $121^{\circ} \mathrm{C}$ autoklaviert. Antibiotika wurden ggf. nach Abkühlung auf $55^{\circ} \mathrm{C}$ zugesetzt und die Festmedien in Polystyrol Petrischalen (Fa. Sarstedt) mit $9 \mathrm{~cm}$ Durchmesser ausplattiert.

Festmedien:

Synthetischer nährstoffarmer Agar SNA

$\mathrm{KH}_{2} \mathrm{PO}_{4}$

$\mathrm{KNO}_{3}$

$\mathrm{MgSO}_{4}$

KCL

Glucose

Saccharose

Agar-Agar

Streptomycinsulfat

Aqua bidest.

\section{V8 Gemüsesaftagar}

$\mathrm{CaCO}_{3}$

Agar-Agar

Gemüsesaft V8

Aqua bidest.

Streptomycinsulfat

Rifampicin
$1 \mathrm{~g}$

$1 \mathrm{~g}$

$0,5 \mathrm{~g}$

$0,5 \mathrm{~g}$

$0,2 \mathrm{~g}$

$0,2 \mathrm{~g}$

$15 \mathrm{~g}$

$0,2 \mathrm{~g}$

Ad $1000 \mathrm{ml}$

$2 \mathrm{~g}$

$15 \mathrm{~g}$

$100 \mathrm{ml}$

$900 \mathrm{ml}$

$0,2 \mathrm{~g}$

$0,04 \mathrm{~g}$ 
Flüssigmedium:

Czapek Dox

Czapek Dox

$33,4 \mathrm{~g}$

Aqua bidest

Ad $1000 \mathrm{ml}$

\section{Puffer und Lösungen}

$\underline{\text { TBE-Puffer (10x) }}$

TBE-Puffer (10x)

$100 \mathrm{ml}$

Aqua bidest

Ad $1900 \mathrm{ml}$

$\underline{\text { TE-Puffer, } \mathrm{pH}: 8}$

TRIS

$0,1 \mathrm{M}$

EDTA

$10 \mathrm{mM}$

$\underline{\text { AFE-Fixierungslösung }(100 \mathrm{ml})}$

Ethanol (70\%) $\quad 90 \mathrm{ml}$

Formaldehyd-Lösung (36\%) $5 \mathrm{ml}$

Essigsäure (99\%) $5 \mathrm{ml}$

2M Kaliumhydroxid Lauge

Kaliumhydroxid $\mathrm{KOH}$

$56,2 \mathrm{~g}$

Aqua bidest.

Ad $500 \mathrm{ml}$

Chlorazol Black E (CBE) - Färbelösung (100 ml)

Chlorazol Black E

$0,03 \mathrm{~g}(0,03 \%[\mathrm{w} / \mathrm{v}])$

Aqua bidest.

$33,3 \mathrm{ml}$

Milchsäure (80\%)

$33,3 \mathrm{ml}$ 
Glycerin (97\%) $\quad 33,3 \mathrm{ml}$

Beim Ansetzen der Färbelösung ist es vorteilhaft, das Chlorazol Black E (CBE) Pulver zunächst in Wasser aufzulösen und dann die beiden weiteren Komponenten hinzuzufügen. Beim Umgang mit CBE sollten aufgrund der Toxizität unbedingt Schutzmaßnahmen, wie Laborhandschuhe, Kittel und Schutzbrille beachtet werden.

\section{Trenngel}

Agarosegel (1\%)

Agarose $1 \mathrm{~g}$

TBE Puffer $(0,5 \mathrm{x})$

Midori Green $\quad 5 \mu \mathrm{l}$

\subsection{Exserohilum turcicum Isolate}

\subsubsection{Herkunft der Pilzisolate}

In den Jahren 2011 und 2012 wurden mit Exserohilum turcicum befallene Mais-Blattproben gesammelt. Die Blattproben wurden durch Mitarbeiter der kooperierenden Zuchtfirmen auf dem Postweg versandt. An den Zuchtstandorten der beteiligten Firmen wurden Fangpflanzen angebaut. Diese Fangpflanzen verfügten über keine bekannten monogenen Resistenzen und waren darüber hinaus durch die Zuchtfirmen als anfällige Genotypen gegenüber E. turcicum eingestuft. Von diesen Pflanzen erfolgte die Probenahme. Die befallenen Blätter wurden getrocknet und in Papierumschlägen versandt. Nach Abstimmung unter den Zuchtfirmen wurde die Standortauswahl entsprechend des Befallsauftretens in den verschiedenen Regionen der beiden Jahre vorgenommen. Durch die Verteilung der Zuchtstandorte in den bedeutenden europäischen Maisanbaugebieten sollte eine möglichst repräsentative Sammlung an E. turcicum-Isolaten als Grundlage für die Untersuchungen in dieser Arbeit erstellt werden. Insgesamt wurden in den Jahren 2011 und 2012 Blattproben von 168 Standorten aus zwölf verschiedenen europäischen Ländern eingesandt. Das Probenahmegebiet wurde über Ländergrenzen hinweg in zehn geographische Regionen aufgeteilt. In Tabelle 1 sind die Regionen und die Standorte mit den zugehörigen Ländern für beide Jahre dargestellt. 
Tab. 1: Regionen und Länder mit der Anzahl und dem Anteil aufgenommener Standorte in den Jahren 2011 und 2012. Die Standorte in der Türkei bzw. Spanien wurden gesondert betrachtet. Die Regionen sind absteigend sortiert nach der Gesamtanzahl der Standorte.

\begin{tabular}{lllrrrr} 
& & \multicolumn{4}{c}{ Anzahl/Anteil Standorte } \\
\cline { 3 - 7 } Nr. & Region & Land & 2011 & 2012 & Gesamt & $\%$ \\
\hline 1 & Niederlande/Belgien & D/NL/B & 12 & 18 & 30 & 17,9 \\
2 & Süddeutschland/Österreich (Inntal) & D/A & 19 & 10 & 29 & 17,3 \\
3 & Südwest Frankreich & $\mathrm{F}$ & 18 & 6 & 23 & 13,7 \\
4 & Oberrheinregion & $\mathrm{D} / \mathrm{F} / \mathrm{CH}$ & 11 & 12 & 23 & 13,7 \\
5 & Norddeutschland & $\mathrm{D}$ & 5 & 9 & 14 & 8,3 \\
6 & Zentralfrankreich & $\mathrm{F}$ & 7 & 6 & 14 & 8,3 \\
7 & Bretagne/Normandie & $\mathrm{F}$ & 9 & 2 & 11 & 6,5 \\
8 & Norditalien & $\mathrm{I}$ & 6 & 1 & 7 & 4,2 \\
9 & Österreich (Steiermark)/Ungarn & $\mathrm{A} / \mathrm{HU}$ & 4 & 2 & 6 & 3,6 \\
10 & Tschechien/Polen & $\mathrm{PL} / \mathrm{CZ}$ & 1 & 5 & 6 & 3,6 \\
& Türkei (Adana) & $\mathrm{TR}$ & & 3 & 3 & 1,8 \\
& Spanien (Galicien) & $\mathrm{ES}$ & 2 & & 2 & 1,2 \\
\hline & Summe & & $\mathbf{9 4}$ & $\mathbf{7 4}$ & $\mathbf{1 6 8}$ & $\mathbf{1 0 0}$
\end{tabular}

Für die Gesamtheit an Isolaten aus beiden Jahren, die aus einer der geographisch definierten Regionen stammt, wird im Folgenden der Begriff „Population“verwendet. Die Einteilung des gesamten Herkunftsgebietes in zehn Regionen erfolgte auf Basis der Standorte der eingesandten Isolate, wie in Abbildung 3 dargestellt. Die Standorte der Länder Türkei und Spanien wurden gesondert betrachtet. Aufgrund der geringen Anzahl der Standorte in diesen beiden Ländern wäre es wenig sinnvoll gewesen, für die Isolate dieser beiden Länder eigene Regionen zu bilden. Für eine Zuordnung zu bestehenden Regionen war die Distanz zu groß. 


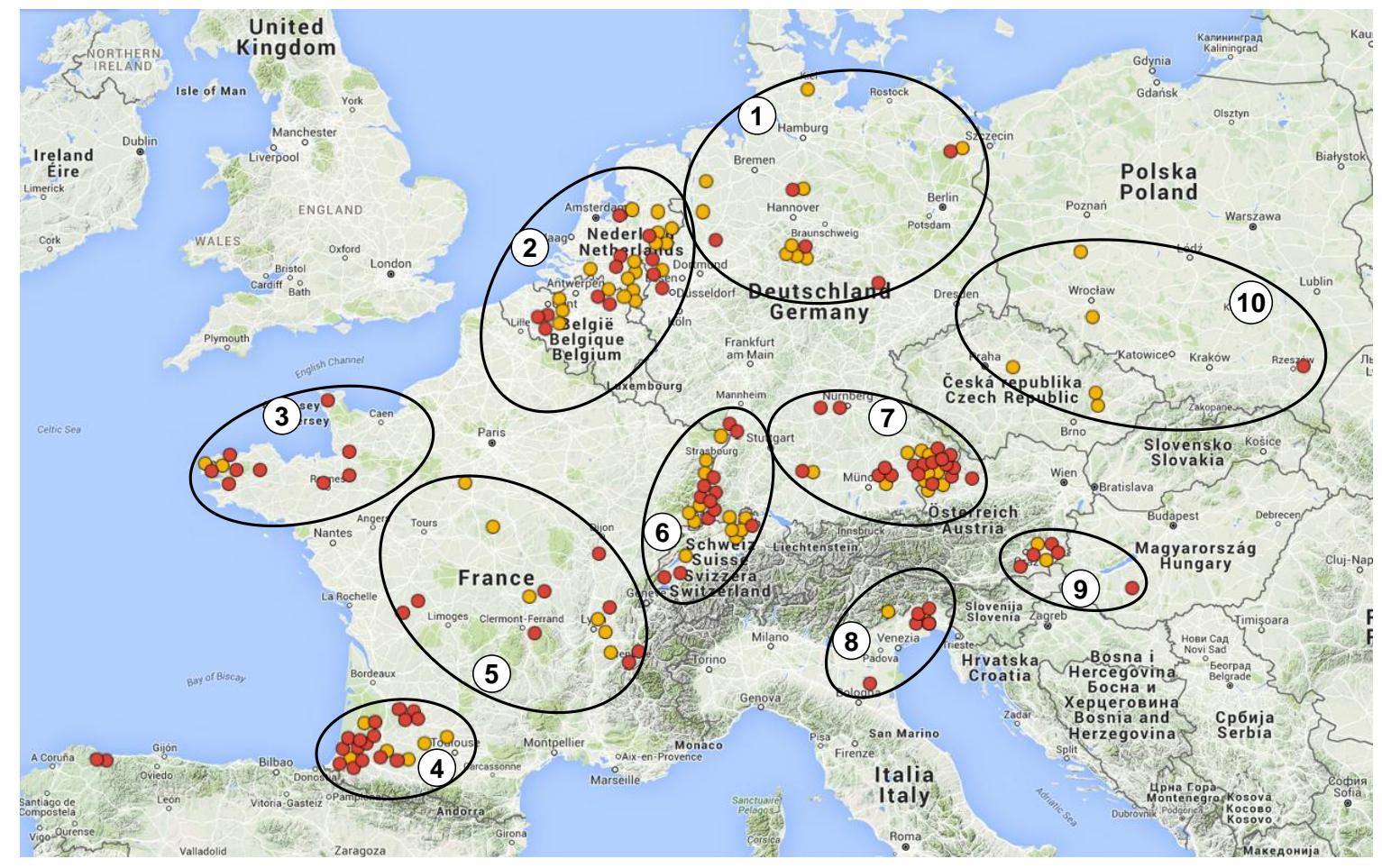

Abb. 3: Standorte der Probenahme von E. turcicum befallenem Blattmaterial in den Jahren $2011(\odot)$ und $2012(\bigcirc)$ eingeteilt in zehn Regionen auf Basis der Isolatherkünfte: 1 Norddeutschland, 2 Niederlande/Belgien, 3 Bretagne/Normandie, 4 Südwestfrankreich, 5 Zentralfrankreich, 6 Oberrheinregion, 7 Niederbayern/Österreich (Inntal), 8 Norditalien, 9 Österreich (Steiermark)/Ungarn, 10 Tschechien/Polen; Kartendaten: Google 2015, INEGI, ORION-ME

\subsubsection{Gewinnung und Lagerung der Einsporisolate}

Zunächst wurden die Blattproben unter trockenen Bedingungen dunkel bei $4^{\circ} \mathrm{C}$ bis zur Weiterverarbeitung gelagert. Aus jeder Blattprobe wurden kleine Blattsegmente mit einzelnen, abgegrenzten E. turcicum Läsionen herausgeschnitten. Nach einer Oberflächensterilisation für $30 \mathrm{~s}$. in $2 \% \mathrm{NaOCl}$ und zwei Waschschritten in autoklaviertem Leitungswasser für je 30 s. wurden die Blattsegmente in einer Petrischale auf feuchtem Filterpapier bei Raumtemperatur und Tageslicht für 48 Stunden zur Sporenbildung inkubiert. Sobald Sporenbildung auf den Blattsegmenten (grau-schwarze Bereiche) zu erkennen war, wurden mit Hilfe einer Impfnadel unter dem Stereomikroskop wenige Sporen abgenommen und auf synthetischem nährstoffarmem Agar (SNA) ausgestrichen. Im nächsten Schritt wurden von den ausgestrichenen Sporen drei einzelne Sporen auf markierte Bereiche derselben SNA-Petrischale vereinzelt. Die Inkubation erfolgte bei Raumtemperatur $\left(\approx 20-22^{\circ} \mathrm{C}\right)$ und Tageslicht für ca. sieben Tage, bis an den markierten Stellen graue Pilzkolonien gewachsen waren. 

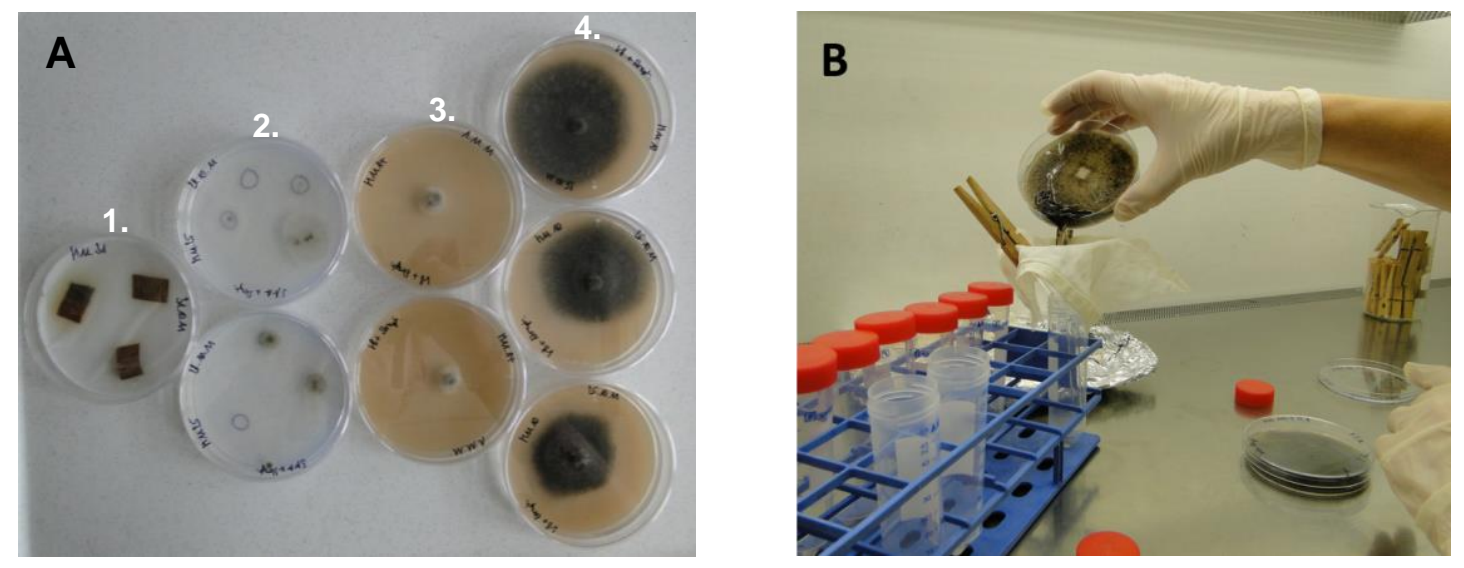

Abb. 4: (A) Schritte der Erstellung der Einsporisolate, 1. Blattsegmente auf feuchtem Filterpapier, 2. Kolonien von einzelnen Sporen auf SNA, 3. und 4. Subkultivierung auf V8-Agar. (B) Gewinnung von Sporensuspensionen durch Abschwämmen der Sporen und Filtern mit Hilfe einer Nylon Gaze.

Aus einer einzelnen Kolonie wurden kleine Bereiche mit einer Lanzettnadel ausgeschnitten und auf V8-Nährmedium übertragen. Um eine Bakterienkontamination zu vermeiden, wurden den Medien Antibiotika (Rifampicin \& Streptomycin) beigemischt. Die Inkubation erfolgte bei Raumtemperatur und Tageslicht für ca. zehn Tage, bis die Petrischalen vollständig bis an den Rand mit typischen grau-schwarz erscheinenden Konidiophoren bewachsen waren. Im nächsten Schritt wurden die Sporen unter sterilen Bedingungen durch Zugabe von $15 \mathrm{ml}$ autoklaviertem 25\% Glycerin mit Hilfe eines Objektträgers abgewaschen, durch Nylon-Gaze gefiltert und in einem $50 \mathrm{ml}$ Reaktionsgefäß gesammelt (siehe Abbildung 4). Nachdem die Isolation und Herstellung der Sporensuspension abgeschlossen waren, erfolgte die abschließende Identifizierung von E. turcicum anhand der Sporenmorphologie. Die Konidiosporen von E. turcicum sind unter dem Mikroskop anhand ihrer länglich ovalen Form mit einer Größe von ca. 20 × $120 \mu \mathrm{m}$, der oliv-grauen Farbe und den drei bis acht Septen leicht zu erkennen. Die eindeutige Bestimmung als $E$. turcicum erfolgte letztlich anhand des charakteristisch herausragenden Hilums (Abb. 2). Dadurch lässt sich E. turcicum eindeutig von den anderen Arten des Helminthosporium-Blattflecken-Erreger-Komplexes unterscheiden.

Für die mittelfristige Lagerung wurden von jedem Einsporisolat zehn Reaktionsgefäße $(1,5 \mathrm{ml})$ mit je einem Milliliter der Suspension befüllt und anschließend bei $-23^{\circ} \mathrm{C}$ bis zur weiteren Verwendung tiefgefroren gelagert. Zum Zweck der Lagerung wurde keine Bestimmung der Sporenkonzentration vorgenommen. 


\subsection{Untersuchungen zu Kultureigenschaften von E. turcicum}

\section{Optimaltemperatur}

Zunächst wurde untersucht, welche Temperatur für ein optimales Wachstum von E. turcicum benötigt wird. Dazu wurden folgende fünf Isolate aus verschiedenen Regionen Europas ausgewählt: M11.11 (Südwest Frankreich), M11.13 (Niederbayern/Österreich), M11.91 (Norddeutschland), M11.99 (Oberrheinregion) und M11.113 (Bretagne/Normandie). Im ersten Schritt wurden je $150 \mu \mathrm{l}$ der Sporensuspension von jedem der Isolate auf V8 Nährmedium mit Hilfe eines Drigalskispatel in Petrischalen ausplattiert. Nach ca. zehn Tagen wurden kreisrunde bewachsene Agarstücke aus dem bewachsenen Nährmedium mit Hilfe eines Korkbohrers (Durchmesser: $5 \mathrm{~mm}$ ) ausgeschnitten. Diese wurden anschließend mittig auf V8 Nährmedium in Kunststoff-Petrischalen platziert. Insgesamt wurden vier Platten je Isolat, bei zweifacher Durchführung des gesamten Versuchs, beimpft. Die Platten wurden bei fünf verschiedenen Temperaturstufen $\left(16^{\circ}, 20^{\circ}, 24^{\circ}, 28^{\circ}\right.$ und $\left.32^{\circ} \mathrm{C}\right)$ ohne Licht inkubiert. Die Durchmesser der Kolonien wurden jeden zweiten Tag mit Hilfe eines Lineals in mm erfasst, bis in einer Variante die Petrischalen vollständig bis an den Rand bewachsen waren. Für jedes Isolat und jede Temperatur wurde der Koloniezuwachs in mm pro Tag berechnet.

\section{Lagerfähigkeit}

Zunächst wurden Sporensuspensionen, wie unter Punkt 2.2.2 beschrieben, hergestellt. Die Konzentration der Suspension wurde mit Hilfe einer Fuchs-Rosenthal Zählkammer bestimmt und auf 1.000 Sporen/ml eingestellt. Es wurden sechs Isolate unterschiedlicher geografischer Herkunft verwendet: M11.24 (Italien, Po-Ebene), M11.28 (Südwestfrankreich), M11.38 (Süddeutschland), M11.91 (Norddeutschland), M11.96 (Niederlande/Belgien). Die Basis für die Sporensuspension bildete autoklaviertes 25\%iges Glycerin mit 125 ppm Silwet Gold ${ }^{\circledR}$. Die Suspensionen wurden bei $-23^{\circ} \mathrm{C}$ gelagert. Für die Bestimmung der Lagerfähigkeit diente das Merkmal Keimfähigkeit der Sporen auf Nährmedium. Um dieses Merkmals zu bestimmen, wurden $100 \mu \mathrm{l}$ der Sporensuspension mit einer Konzentration von 1.000 Sporen/ml auf V8 Nährmedium ausplattiert (=100 Sporen je Petrischale). Dieser Vorgang wurde in vierfacher Wiederholung für jedes Isolat durchgeführt. Die Inkubation erfolgte in einem Klimaschrank (WB $750 \mathrm{KFL}$, Fa. Mytron, Heiligenstadt) bei $24^{\circ} \mathrm{C}, 80 \%$ rel. Luftfeuchtigkeit und einem Tag/Nachtrhythmus von 12 Stunden. Nach fünf Tagen wurde die Anzahl entstandener Kolonien je Petrischale gezählt. Die Bestimmung der Keimfähigkeit erfolgte an fünf Zeitpunkten. Zunächst wurde die Keimfähigkeit direkt nach der Herstellung der Suspensionen ohne Einfluss von Frost bestimmt. Im Anschluss daran erfolgte die Bestimmung der Keimfähigkeit nach einer, zehn, 50 und 100 Wochen. 


\subsection{Rassenbestimmung}

\subsubsection{Pflanzenmaterial und Anzuchtbedingungen}

Im Rahmen der Rassenbestimmung wurden vier dominant vererbte Resistenzgene untersucht. Dabei handelt es sich um die Resistenzgene Ht1 (Hooker, 1963), Ht2 (Hooker, 1977), Ht3 (Hooker, 1981) und Htn1/HtN (Gevers, 1975). Die Resistenzgene wurden in den genetischen Hintergrund der Inzuchtlinie B37 eingebracht, die aus der sogenannten „lowa Stiff Stalk Synthetic“ (ISSS) Population der 1930er Jahre in den USA hervorgegangen ist (Hallauer, 2008). Über klassische Rückkreuzungsschritte wurden die einzelnen Resistenzgene eingekreuzt, sodass ein Differentialsortiment aus nah-isogenen Inzuchtlinien zur Verfügung stand. Das Differentialsortiment bestand mit der Linie B37 als Ausganglinie $(H t 0)$ und B37$H t 1$, B37-Ht2, B37-Ht3 und B37-HtN aus fünf Linien. Die Vermehrung und Bereitstellung des Saatguts wurde während der gesamten Projektphase durch die kooperierenden Zuchtfirmen der GFPi-Abteilung Mais gewährleistet. Weitere Informationen zu den untersuchten Resistenzgenen sind in Tabelle 2 dargestellt.

Tab. 2: Untersuchte Resistenzgene, ihre Quellen und die Art der Vererbung.

\begin{tabular}{lllll} 
Resistenzgen & Quelle & Resistenzreaktion & Referenz & Vererbung \\
\hline$H t 1$ & "Ladyfinger" GE440 & Chlorose & Hooker 1963 & dominant \\
$H t 2$ & NN14B & Chlorose & Hooker 1977 & dominant \\
$H t 3$ & Tripsacum floridanum & Chlorose & Hooker 1981 & dominant \\
$H t n 1 / H t N$ & "Pepitilla" & Verlängerte Latenzzeit & Gevers 1975 & dominant
\end{tabular}

Die Aussaat erfolgte in Multitopfplatten in einer Mischung von Einheitserde (T25) und Sand (1:1). Bei der Einheitserde handelt es sich um handelsübliche Blumenerde auf Torfbasis mit einem Anteil von 25\% Ton. Nachdem das zweite Laubblatt sichtbar war, wurden je zwei Pflanzen in einen Plastikpflanztopf $(11 \mathrm{~cm} \times 11 \mathrm{~cm})$ pikiert. Das verwendete Substrat bestand aus gedämpfter Komposterde, Einheitserde (T25) und Sand im Verhältnis 3:3:1. Nach dem Pikieren wurde auf die Oberfläche des Substrats eine dünne Sandschicht aufgebracht, was sich zuvor als effektiver Schutz gegen Trauermückenbefall herausgestellt hatte. Die Bewässerung erfolgte zurückhaltend, da Maispflanzen besonders empfindlich auf Staunässe reagieren. Die Düngung wurde wöchentlich entsprechend des Bedarfs der Pflanzen mit dem Ammonium betonten Universaldünger Hakaphos ${ }^{\circledR}$ Blau (Fa. Compo, Deutschland) mit allen notwendigen Makro- und Mikronährstoffen durchgeführt. Die Temperaturbedingungen während der Anzuchtphase lagen zwischen $19^{\circ}$ und $28^{\circ} \mathrm{C}$. Da die Anzucht in einem Glasgewächshaus durchgeführt wurde, entsprachen die Lichtbedingungen 
in den Sommermonaten dem Tagesrhythmus. In den Wintermonaten wurden zusätzliche Lichtquellen mit einem Tag/Nacht-Rhythmus von 14h/10h zugeschaltet (Natriumdampflampen, Typ: HPS400 SON-T Agro, Fa. Philips, Niederlande). Zum Zeitpunkt der vollen Ausbildung des fünften Blattes wurde die Inokulation durchgeführt. Dieses Pflanzenstadium war in der Regel nach fünf bis sechs Wochen erreicht. Für jedes zu testende Isolat wurden pro Durchgang vier Pflanzen von jeder der fünf Linien des Differentialsortiments verwendet. Bei einem wöchentlichen Durchsatz von 13 bis 15 Isolaten wurden 260 bis 300 Pflanzen pro Woche für die Inokulation benötigt. Um genügend Pflanzen zum Zeitpunkt der Inokulation bereit zu haben, war es sehr wichtig, bereits bei der Aussaat die zum Teil unterschiedlichen Keimfähigkeiten der Linien des Differentialsortiments zu berücksichtigen.

\subsubsection{Inokulation}

Zur Herstellung der Sporensuspensionen für die Inokulation wurde ein Teil der tiefgefrorenen Suspensionen der Einsporisolate zunächst zur Vermehrung auf V8-Nährmedien ausplattiert. Dazu wurde von drei Reaktionsgefäßen eines Isolates der Wasserüberstand verworfen und die verbleibenden Reste gemischt. Dadurch wurde eine höhere Sporenkonzentration erreicht, wodurch die Wahrscheinlichkeit reduziert wurde, dass keine oder nur wenige keimfähige Sporen in der Suspension vorhanden waren. Je Isolat wurden drei Petrischalen mit je ca. $150 \mu$ laufkonzentrierter Sporensuspension mit Hilfe eines Drigalskispatels ausplattiert. Nach zehn Tagen Inkubation waren die Petrischalen vollständig mit grau-schwarzen Strukturen, bestehend aus Hyphen, Sporenträgern und Sporen bewachsen. Die Temperatur- und Lichtbedingungen während der Inkubation entsprachen Raumtemperatur $\left(22^{\circ} \mathrm{C} \pm 2^{\circ} \mathrm{C}\right)$ und Tageslichtrhythmus im Labor. Im nächsten Schritt wurden die Sporen je Petrischale zweimal mit jeweils $10 \mathrm{ml}$ Leitungswasser mit Hilfe eines Objektträgers abgewaschen und durch Nylon Gaze gefiltert. Durch das Filtern sollten Agar- und Myzelreste von der Sporensuspension getrennt werden. Das Wasser war mit 125 ppm des Benetzungsmittels Silwet Gold ${ }^{\circledR}$ versetzt. Die Bestimmung der Sporenkonzentration erfolgte unter dem Mikroskop mit Hilfe einer Fuchs-Rosenthal-Zählkammer. Die Sporenkonzentration wurde durch Zugabe von Wasser mit 125 ppm Silwet Gold ${ }^{\circledR}$ auf 3.000 Sporen/ml eingestellt. Von jedem Isolat wurden $150 \mathrm{ml}$ Sporensuspension hergestellt. Bei 20 Pflanzen je Isolat entspricht das einer Suspensionsmenge von ca. 7,5 ml je Isolat und Pflanze. Es wurde eine Ganzpflanzeninokulation durchgeführt, bei der mindestens die oberen beiden voll ausgebildeten Blätter (4. und 5. Blatt) gleichmäßig mit Sporensuspension bis kurz vor der Tropfenbildung benetzt wurden. Die Inokulation erfolgte mit Hilfe eines Druckluftzerstäubers aus Glas (Handanfertigung, Fa. Ochs, Bovenden). Für jedes Isolat wurden die benötigten 20 Pflanzen (5 Genotypen x 4 Pflanzen) vor der Inokulation in Gruppen bereitgestellt. Jede 
Gruppe wurde abgeschirmt von den anderen Pflanzen mit einem neuen Zerstäuber und unter Verwendung neuer Einweghandschuhe inokuliert. Um eine Mischinfektion zwischen den Isolaten zu verhindern, wurden die einzelnen Gruppen separat mit Abstand zueinander unter einem Folienzelt zur Inkubation aufgestellt.

\subsubsection{Klimabedingungen ab Inokulation}

Durch Befeuchtung der im Folienzelt befindlichen Vliesunterlage und Beleuchtung des geschlossenen Zeltes mittels darüber angebrachten Lichtquellen wurde bereits vor dem Zeitpunkt der Inokulation eine Erhöhung der Luftfeuchtigkeit auf über $90 \%$ sowie eine gleichzeitige Erwärmung der Luft im Folienzelt realisiert. Ab dem Zeitpunkt der Inokulation wurden die Pflanzen in das Folienzelt gestellt. Die Beleuchtung wurde abgeschaltet und zudem durch Sonnenschutztücher für eine Beschattung des Zeltes gesorgt. Die inokulierten Pflanzen wurden im Folienzelt für 24 Stunden bei 17 bis $25^{\circ} \mathrm{C}$ und einer rel. Luftfeuchtigkeit von mind. 90\% inkubiert. Die Pflanzen wurden ca. zwei Stunden nach der Inokulation mit Hilfe eines Handzerstäubers zusätzlich mit einem feinen Wassernebel befeuchtet. Nach 24 Stunden im Folienzelt wurden die Pflanzen, in den separierten Gruppen verbleibend, in einen vollklimatisierten Raum gebracht. In diesem Raum betrugen die Tag/Nacht-Temperaturen $24^{\circ} \mathrm{C} / 19^{\circ} \mathrm{C}$ und die rel. Luftfeuchtigkeit $75 \%$. Der Tag/Nacht-Rhythmus lag bei $14 \mathrm{~h} / 10 \mathrm{~h}$ mit einer Beleuchtungsintensität von $150 \mu \mathrm{mol} \mathrm{m} \mathrm{m}^{-2} \mathrm{~s}^{-1}$ (Natriumdampflampen, Typ: HPS400 SON-T Agro, Fa. Philips, Niederlande). Bis zum Zeitpunkt der Bonitur wurden die Pflanzen unter diesen Bedingungen für 14 Tage inkubiert.

\subsubsection{Bonitur}

Die Bonitur erfolgte 14 Tage nach Inokulation. Zunächst wurden die Befallsreaktionen auf den Blättern der Maispflanzen nach einer definierten Boniturskala eingestuft. In Tabelle 3 ist die veränderte Boniturskala nach Bigirwa et al. (1993) dargestellt. Die Note 0 wurde vergeben, wenn keine Reaktionen auf der Pflanze sichtbar waren. In diesem Fall wurde für das betreffende Isolat der gesamte Inokulationsprozess wiederholt. Die Noten 1 bis 3 wurden vergeben, wenn chlorotische Reaktionen mit zunehmendem Anteil nekrotisierter Blattfläche sichtbar waren. Chlorotische Reaktionen in Verbindung mit nekrotischen Bereichen sind als klassische Resistenzreaktionen in diesem Pathosystem bekannt. Die Noten 4 bis 6 wurden mit zunehmender Befallsstärke vergeben, wenn grau-grünliche, welkeähnliche Symptome ohne chlorotische Bereiche auftraten. Diese Art von Läsionen ist für die unter- 
Tab. 3: Boniturskala zur phänotypischen Einstufung von Befallsreaktionen auf Mais gegen E. turcicum, verändert nach Bigirwa et al. (1993).

\begin{tabular}{lcl} 
Befallsreaktion & Note & Phänotyp \\
\hline resistent & 0 & keine Symptome \\
resistent & 1 & Chlorosen ohne nekrotische Läsionen, chlorotische Punkte \\
resistent & 2 & Chlorosen mit wenigen, begrenzten Nekrosen \\
resistent & 3 & beträchtliche Nekrosen mit Chlorosen \\
anfällig & 4 & grau/grünliche Welkesymptome ohne Chlorosen \\
anfällig & 5 & Nekrosen mit deutlichen Welkesymptomen ohne Chlorosen \\
anfällig & 6 & alle inokulierten Blattbereiche abgestorben, Welkesymptome
\end{tabular}

suchten Resistenzgene als Anfälligkeitsreaktion im Mais gegen E. turcicum definiert. In Abbildung 5 sind ausgewählte Symptombilder nach Gewächshausinokulation dargestellt. Bei unklarem Befund zur Einstufung der Befallsreaktionen zum Zeitpunkt 14 dpi bei mindestens einer der vier Pflanzen auf einer Linie des Differentialsortiments wurde die Bonitur dieses Isolates nach einer Woche (21 dpi) wiederholt. Wenn der Befund auch zu diesem Zeitpunkt unklar blieb, wurde der gesamte Inokulationsprozess für das betreffende Isolat wiederholt.

Die finale Rassencharakterisierung erfolgte nach der beschriebenen Nomenklatur auf Basis der phänotypischen Einstufung der Befallsreaktionen (Leonard et al., 1989). Die verwendete Rassennomenklatur ist in Tabelle 4 dargestellt.
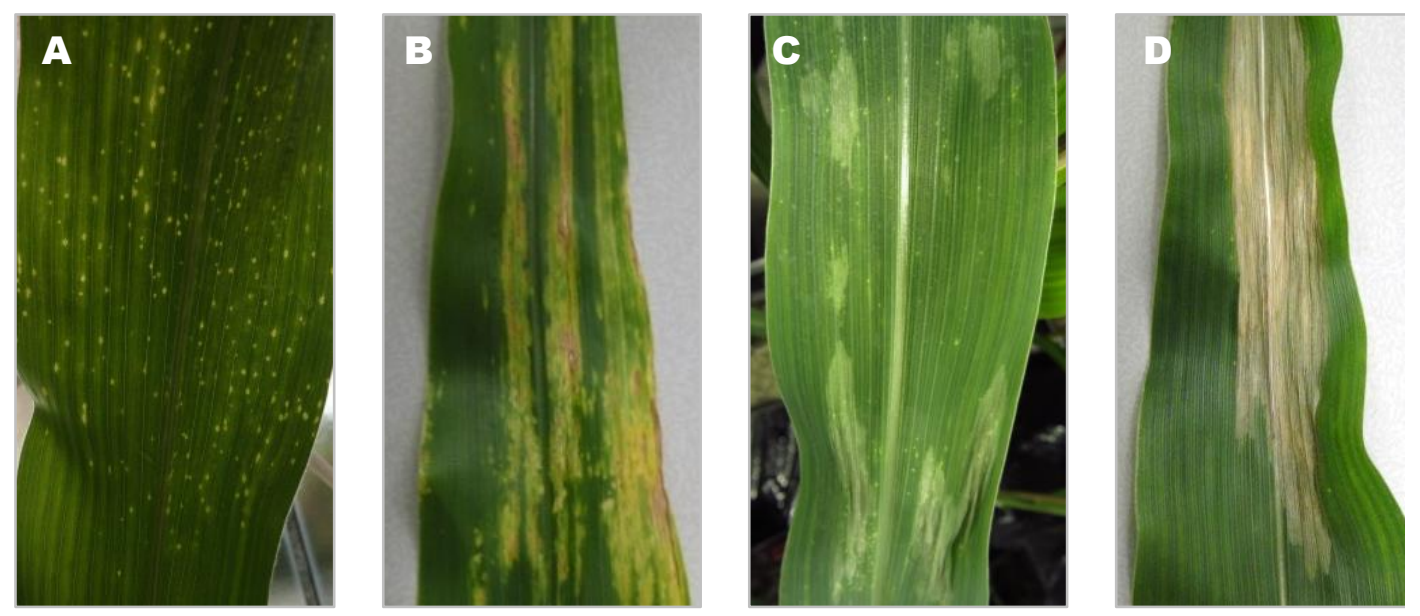

Abb. 5: Befallsreaktionen an Mais nach E. turcicum Inokulation im Gewächshaus. (A) Penetrationsstellen als chlorotische Punkte sichtbar, Note 1 (12 hpi); (B) Chlorosen mit begrenzten Nekrosen, Note 2 (14 dpi); (C) graugrünliche Welkesymptome ohne Chlorosen, Note 4 (14 dpi); (D) Nekrosen ohne Chlorosen, Note 5 (14 dpi). 
Tab. 4: Rassennomenklatur für E. turcicum an Mais auf Basis der Befallsreaktion auf den getesteten Differentiallinien B37, B37-Ht1, B37-Ht2, B37-Ht3 und B37-HtN, nach Leonard et al. (1989) ( ${ }^{*} \mathrm{R}=$ resistent, $A=$ anfällig).

\begin{tabular}{|c|c|c|c|c|c|}
\hline \multirow[b]{2}{*}{ Rasse } & \multicolumn{5}{|c|}{ Befallsreaktion* } \\
\hline & B37 & $\mathrm{B} 37-\mathrm{Ht} \mathbf{1}$ & B37-Ht2 & B37-Ht3 & B37- HtN \\
\hline 0 & $A$ & $R$ & $R$ & $R$ & $R$ \\
\hline 1 & A & A & $\mathrm{R}$ & $R$ & $\mathrm{R}$ \\
\hline 2 & A & $\mathrm{R}$ & A & $\mathrm{R}$ & $\mathrm{R}$ \\
\hline 13 & A & A & $\mathrm{R}$ & A & $\mathrm{R}$ \\
\hline 23 & A & $\mathrm{R}$ & A & A & $\mathrm{R}$ \\
\hline $23 \mathrm{~N}$ & A & $\mathrm{R}$ & A & A & A \\
\hline
\end{tabular}

\subsubsection{Regionale Diversität und Komplexität der E. turcicum Sammlungen}

Um die Diversität der Rassenspektren zu beschreiben, wurden die Verteilung, der Anteil, die Diversität und die Komplexität der vorkommenden Rassen in den einzelnen Regionen berechnet. In diesen Berechnungen wurden die Jahre 2011 und 2012 zusammen betrachtet. Zunächst wurden die Rassenverteilung bzw. die unterschiedlichen Rassenanteile beschrieben. Das Merkmal „Anzahl Rassen“ $\left(N_{r}\right)$ beschreibt die Anzahl verschiedener Rassen in der jeweiligen Region. Die Merkmale $R_{1}$ bzw. $R_{2}$ beschreiben den Anteil der häufigsten Rasse $\left(R_{1}\right)$ bzw. den kumulierten Anteil der zwei häufigsten Rassen $\left(R_{2}\right)$ in der jeweiligen Region. Mit Hilfe der Indizes $V_{i}$ und $V_{v}$ wurde die Anzahl an Virulenzen je Isolat (Virulenzkomplexität) beschrieben. Der Index $V_{i}$ beschreibt die Anzahl an Virulenzen als Mittelwert aller in der Region untersuchten Isolate. Der Index $V_{v}$ beschreibt die Virulenzkomplexität als Mittel aller als virulent eingestuften Isolate, das heißt ohne die Isolate der Rasse 0. Die Indizes zur Virulenzkomplexität wurden wie folgt berechnet:

$$
V_{\mathrm{i}}=\frac{\sum j(p j * v j)}{N i} \text { und } V_{\mathrm{v}}=\frac{\sum j(p j * v j)}{N v i}
$$

wobei $p_{j}$ der Anteil der j-ten Rasse in der jeweiligen Region und $v_{j}$ die Virulenzkomplexität der j-ten Rasse beschreibt. $N_{i}$ ist die Gesamtzahl an Isolaten in der i-ten Region und $N_{v i}$ beschreibt die Anzahl virulenter Isolate in der i-ten Region.

Zur Erfassung der Rassendiversität innerhalb der Regionen wurden zwei weitere Indizes verwendet: Der Gleason Index $H_{G}$ und der Shannon Index $H_{S}$ wurden wie folgt berechnet: 


$$
\mathrm{H}_{\mathrm{G}}=\frac{(N r-1)}{\ln N i} \text { und } \mathrm{H}_{\mathrm{S}}=\sum j[p j * \ln (p j)]
$$

wobei $N_{r}$ und $N_{i}$ bzw. $p_{j}$ wie bereits oben beschrieben verwendet wurden. Der Gleason Index ist für seine Anfälligkeit gegenüber einer hohen Anzahl an verschiedenen Rassen bekannt, wohingegen der Shannon Index sowohl die Anzahl als auch die Verteilung, also den Anteil der jeweiligen Rassen berücksichtigt (Andrivon \& Vallavieille-Pope, 1995). Um eine Verzerrung aufgrund unterschiedlicher Anzahlen an Isolaten zwischen den Regionen zu vermeiden, wurden ebenfalls der relative Gleason Index $\left(H_{G R}\right)$ und der relative Shannon Index $\left(H_{S R}\right)$ berechnet. Die Berechnungen erfolgten nach den untenstehenden Formeln:

$$
H_{G R}=\frac{(N r-1)}{(N i-1)} \text { und } H_{S R}=\frac{\sum j[p j * \ln (p j)]}{\ln N i}
$$

\subsubsection{Regionale Virulenzhäufigkeiten von E. turcicum in Europa}

Zur Beurteilung der regionalen Wirksamkeit der einzelnen Resistenzgene wurden die Virulenzfrequenzen für jedes der Resistenzgene in den untersuchten Regionen bestimmt. Die Virulenzfrequenz beschreibt den Anteil virulenter Isolate für ein bestimmtes Resistenzgen in einer definierten Region oder Population. Mit Hilfe dieses Merkmals lässt sich die Wirksamkeit der Resistenzgene in den untersuchten Regionen beschreiben. Die Berechnung der Virulenzfrequenzen erfolgte nach der Formel:

$$
\text { Virulenzfrequenz für } H t 1 \text { in der i-ten Region }\left(V_{H t 1 i}\right)=\frac{\sum i n H t 1 i}{N i}
$$

wobei $n_{H t 1 i}$ die Summe der Isolate mit einer Virulenz für $H t 1$ in der i-ten Region beschreibt. $N_{i}$ ist die Gesamtanzahl an Isolaten in der i-ten Region.

\subsubsection{Anbau und Bonitur verschiedener $\boldsymbol{H t}$-Differentialsortimente im Feld}

Um die Ergebnisse der Rassenbestimmung an Ganzpflanzen im Gewächshaus mit den bonitierten Virulenzeigenschaften von E. turcicum im Feld zu vergleichen, wurden an sechs Standorten in Europa Differentialsortimente angebaut. 
Tab. 5: Standorte, Jahre und Genotypen der im Feld angebauten Differentialsortimente mit den verwendeten Resistenzgenen.

\begin{tabular}{|c|c|c|c|}
\hline $\begin{array}{l}\text { Region } \\
\text { (Standort) }\end{array}$ & Anbaujahr & $\begin{array}{c}\text { Genotyp } \\
\text { (rekurrenter Elter) }\end{array}$ & $\begin{array}{l}\text { Differentialsortimente } \\
\text { mit verwendeten } \boldsymbol{H t} \text {-Resistenzgenen }\end{array}$ \\
\hline $\begin{array}{l}\text { Österreich/Ungarn } \\
\text { (Graz) }\end{array}$ & 2012 & B37, Pa91, W22 & $\begin{array}{l}\text { B37-Ht1, B37-Ht2, B37-Ht3, B37-HtN } \\
\text { Pa91-Ht1, W22-HtN }\end{array}$ \\
\hline $\begin{array}{l}\text { Oberrheinregion } \\
\text { (Rheinfelderhof) }\end{array}$ & 2011 & B37, A619 & $\begin{array}{l}\text { B37- } \boldsymbol{H t 1} \text {, B37- } \boldsymbol{H t 2} \text {, B37- } \boldsymbol{H t 3} \text {, B37- } \boldsymbol{H t N} \\
\text { A619-Ht1, A619-Ht2, A619-Ht3 }\end{array}$ \\
\hline $\begin{array}{l}\text { Südwestfrankreich } \\
\text { (Meilhan) }\end{array}$ & 2012 & B37 & B37-Ht1, B37-Ht2, B37-Ht3, B37- HtN \\
\hline $\begin{array}{l}\text { Süddeutschl./Österreich } \\
\text { (Pocking) }\end{array}$ & $2011 \& 2012$ & B37, H4460 & $\begin{array}{l}\mathrm{B} 37-\boldsymbol{H t 1}, \mathrm{B} 37-\boldsymbol{H t 2}, \mathrm{B} 37-\boldsymbol{H t 3}, \mathrm{B} 37-\boldsymbol{H t N} \\
\mathrm{H} 4460-\boldsymbol{H} \mathbf{1}, \mathrm{H} 4460-\boldsymbol{H} 2, \mathrm{H} 4460-\boldsymbol{H} \mathbf{3}\end{array}$ \\
\hline $\begin{array}{l}\text { Norddeutschland } \\
\text { (Borken) }\end{array}$ & 2011 & B37, A619 & $\begin{array}{l}\text { B37- } \boldsymbol{H t 1} \text {, B37-Ht2, B37-Ht3, B37- } \boldsymbol{H t N} \\
\text { A619-Ht1, A619-Ht2, A619-Ht3 }\end{array}$ \\
\hline $\begin{array}{l}\text { Niederlande/Belgien } \\
\text { (Wilbertoord) }\end{array}$ & $2011 \& 2012$ & A619, $\mathrm{H} 4460$ & $\begin{array}{l}\text { A619-Ht1, A619-Ht2, A619-Ht3 } \\
\text { H4460-Ht1, H4460-Ht2, H4460-Ht3 }\end{array}$ \\
\hline
\end{tabular}

Der Anbau, die Versuchsbetreuung und die Bonitur erfolgten vollständig durch die beteiligten Züchterfirmen der Abteilung Mais der GFPi. Nach Abschluss der Bonitur wurden die Rohdaten zur Auswertung bereitgestellt. Die Auswahl der Standorte erfolgte nach Absprache unter den Züchtern. Durch die weiträumige Ausdehnung des untersuchten Gebietes in Nord-Süd-Richtung war es erforderlich, Genotypen für die Differentialsortimente zu verwenden, deren Reifezeit an den jeweiligen Standort angepasst war. Eine vollständige Auflistung der berücksichtigten Regionen mit den genauen Standorten, dem Anbaujahr und den verwendeten Genotypen für das jeweilige Differentialsortiment ist in Tabelle 5 dargestellt. Jeder Genotyp des Differentialsortiments wurde an den jeweiligen Standorten in zweifacher Wiederholung angebaut. Eine Reihe mit ca. 20 Pflanzen und drei Metern Länge stellte eine Wiederholung dar. Im Rahmen der Bonitur wurde für jede dieser Reihen eine Note vergeben. Die Boniturskala ist in Tabelle 6 dargestellt. Zur Auswertung wurde das arithmetische Mittel der Boniturnoten für einzelnen Resistenzgene bzw. der rekurrenten Eltern ohne $\mathrm{Ht}$ Resistenzgen gebildet. Es wurden jeweils die Daten des Boniturzeitpunktes verwendet, an dem eine maximale Differenzierung zwischen den einzelnen Linien des Differentialsortiments erreicht wurde. Aufgrund der variierenden Anzahl an Genotypen je Resistenzgen und Standort und den unterschiedlichen Boniturzeitpunkten erfolgte die Ergebnisdarstellung ausschließlich als Mittelwertvergleich in Tabellenform. 
Tab. 6: Boniturskala für die phänotypische Beurteilung der Turcicum-Blattdürre an Mais im Feldversuch nach Infektion durch E. turcicum.

\begin{tabular}{|c|c|}
\hline Note & Phänotyp \\
\hline 1 & Pflanzen zeigen keine Symptome, Befallsstärke: $0 \%$ \\
\hline 2 & Wenige Pflanzen in einer Reihe zeigen kleine Läsionen $(<2 \mathrm{~cm})$, Befallsstärke: $<5 \%$ \\
\hline 3 & $\begin{array}{l}\text { Einige Läsionen auf unteren Blattetagen auf mehreren Pflanzen je Reihe sichtbar, } \\
\text { Befallsstärke: } 5-10 \%\end{array}$ \\
\hline 4 & $\begin{array}{l}\text { Eindeutige länglich ovale Turcicum-Läsionen auf mehreren Blattetagen } \\
\text { Befallsstärke: } 10-20 \%\end{array}$ \\
\hline 5 & Läsionen schmelzen zusammen, Befallsstärke: $20-40 \%$ \\
\hline 6 & Ausgedehnter Befall auf den Blättern sichtbar, Befallsstärke: $40-60 \%$ \\
\hline 7 & $\begin{array}{l}\text { Hälfte der Blattfläche ist abgestorben bzw. ausgetrocknet durch Turcicum-Befall, } \\
\text { Befallsstärke: } 60-80 \%\end{array}$ \\
\hline 8 & $\begin{array}{l}\text { Mehr als die Hälfte der Blattfläche ist abgestorben bzw. ausgetrocknet durch Turci- } \\
\text { cum-Befall, Befallsstärke: } 80-90 \%\end{array}$ \\
\hline 9 & $\begin{array}{l}\text { Nahezu die gesamte Blattfläche ist abgestorben bzw. ausgetrocknet durch Turcicum- } \\
\text { Befall, Befallsstärke: } 90-100 \%\end{array}$ \\
\hline
\end{tabular}

\subsection{Temperatureinfluss auf die Wirksamkeit der untersuchten Resistenzgene}

\subsubsection{Einfluss der Temperatur auf die Wirksamkeit von $\mathrm{Ht}$-Genen}

\subsubsection{Versuchsaufbau}

Die Anzucht der Pflanzen erfolgte bis zum Zeitpunkt der Inokulation, wie bereits unter Punkt 2.4.1 beschrieben. Jedoch wurde in diesem Versuch nur eine Pflanze je Topf pikiert. Die verwendeten Genotypen waren die nah-isogenen Inzuchtlinien des Differentialsortiments, die bereits unter Punkt 2.4.1 beschrieben wurden. Die Herstellung der Sporensuspension und die Inokulation erfolgten wie unter Punkt 2.4 .2 beschrieben. Anstatt mit 3.000 Sporen/ml wurden die Pflanzen in diesem Versuch mit 1.500 Sporen/ml inokuliert. Aufgrund der größeren Pflanzenzahl je Isolat wurden 900 ml Sporensuspension von jedem Isolat hergestellt. In Tabelle 7 sind die verwendeten Isolate mit ihrer Herkunft und ihren Virulenzeigenschaften aufgelistet. 
Tab. 7: Bezeichnung, Herkunft und Virulenzgenausstattung der verwendeten Isolate im Temperaturversuch ohne Temperaturvorbehandlung ( ${ }^{*} \mathrm{~V}=$ virulent; $\mathrm{A}=$ avirulent).

\begin{tabular}{lllcccc} 
& & \multicolumn{4}{c}{ Resistenzgene/Virulenzeigenschaften } \\
\cline { 3 - 6 } Bezeichnung & Rasse & Herkunft & $H t 1$ & $H t 2$ & $H t 3$ & $H t N$ \\
\hline $76-4$ & 0 & Frankreich, Normandie & $\mathrm{A}$ & $\mathrm{A}$ & $\mathrm{A}$ & $\mathrm{A}$ \\
$48-1$ & 123 & Österreich, Steiermark & $\mathrm{V}$ & $\mathrm{V}$ & $\mathrm{V}$ & $\mathrm{A}$ \\
$25-3$ & $3 \mathrm{~N}$ & Frankreich, Südwest & $\mathrm{A}$ & $\mathrm{A}$ & $\mathrm{V}$ & $\mathrm{V}$
\end{tabular}

Die Virulenzeigenschaften der ausgewählten Isolate ermöglichten die Untersuchung von kompatiblen und inkompatiblen Interaktionen für jedes der Resistenzgene. Die Pflanzen wurden im Alter von 36 Tagen bei vollständiger Entwicklung des fünften Blattes inokuliert. Direkt nach der Inokulation wurden die Pflanzen für 24 Stunden im Folienzelt bei einer Temperatur von $19^{\circ}$ bis $24^{\circ} \mathrm{C}$ und einer rel. Luftfeuchtigkeit von über $90 \%$ inkubiert. Nach der Inkubation wurden die Pflanzen in RUMED ${ }^{\circledR}$ Klimakammern (Fa. Rubarth Apparate GmbH, Deutschland) mit vier verschiedenen Temperaturregimen gebracht. Der Tag/Nacht-Rhythmus lag bei 12 Stunden mit einer Beleuchtungsintensität von $155 \mu \mathrm{mol} \mathrm{m}{ }^{-2} \mathrm{~s}^{-1}$. Die vier Temperaturregime mit folgenden Tag/Nacht-Temperaturen betrugen: $15 / 10^{\circ} \mathrm{C} ; 20 / 15^{\circ} \mathrm{C}$; $25 / 20^{\circ} \mathrm{C}$ und $30 / 25^{\circ} \mathrm{C}$. Die Temperaturvariante $25 / 20^{\circ} \mathrm{C}$ entsprach den Bedingungen des Rassenscreenings und diente deshalb als Kontrollvariante. Die rel. Luftfeuchtigkeit in den Klimakammern lag konstant bei 75\%. Je Klimakammer wurden 90 Pflanzen (5 Genotypen x 3 Isolate $x 6$ Wiederholungen) vollrandomisiert angeordnet. Das Experiment wurde zweimal unabhängig voneinander durchgeführt. Für den gesamten Versuch wurden 720 Pflanzen benötigt. Die Pflanzen wurden 21 Tage unter den beschriebenen Temperaturregimen bis zur Endbonitur beobachtet. Eine Übersicht des Versuchs ist in Tabelle 8 dargestellt.

Tab. 8: Genotypen, Isolate und Temperaturen im Versuch zur Allgemeinen Temperaturstabilität der Resistenzgene $H t 1, H t 2, H t 3$ und $H t N$ gegen die $E$. turcicum in Mais.

\begin{tabular}{lcl} 
Faktor & Anzahl & Beschreibung \\
\hline Genotyp & 5 & B37, B37- $\boldsymbol{H t 1}$, B37- $\boldsymbol{H t 2}$, B37- $\boldsymbol{H t 3}, \mathrm{B} 37-\boldsymbol{H t N}$ \\
Isolat & 3 & $76-4$ (Rasse 0), 48-1 (Rasse 123), 25-3 (Rasse $3 \mathrm{~N}$ ) \\
Temperatur (Tag/Nacht) & 4 & $15 / 10^{\circ} \mathrm{C}, 20 / 15^{\circ} \mathrm{C}, 25 / 20^{\circ} \mathrm{C}, 30 / 25^{\circ} \mathrm{C}$ \\
Wiederholungen & 6 & Pflanze = Wiederholung \\
Wiederholung des gesamten Versuchs & 2 &
\end{tabular}




\subsubsection{Bonitur}

Die Bonitur wurde zu sieben Zeitpunkten im Zweitagesrhythmus durchgeführt: 8, 10, 12 , 14, 16, 18 und 20 Tage nach Inokulation (dpi). Die erfassten Merkmale waren Befallsstärke in Prozent der befallenen Blattfläche, die Läsionsqualität und die Inkubationszeit. Die Grafik in Abbildung 6 diente als Hilfsmittel zur Bestimmung des Merkmals Befallsstärke auf einzelnen Blättern. Als Läsionsfläche wurden grau-grünliche Welkesymptome und nekrotische Bereiche ohne Chlorosen gewertet. Die Befallsstärke wurde lediglich für den Genotyp B37 (ohne $H t$ Resistenzgen) erfasst. An jedem Boniturzeitpunkt wurde die Befallsstärke für das vierte und fünfte Blatt einzeln erfasst. Aus diesen beiden Werten wurde ein Mittelwert gebildet, sodass für weitere Berechnungen ein Mittelwert je Pflanze bzw. Wiederholung aus zwei Einzelwerten genutzt werden konnte. Auf Basis der Werte für das Merkmal Befallsstärke wurde der AUDPC Wert berechnet. Für die Berechnung des AUDPC-Wertes wurde folgende Formel verwendet (Leath \& Pedersen, 1986):

$$
\text { AUDPC }=\frac{y_{i}+y_{i+1}}{2} *\left(t_{i+1}\right)-t_{\mathrm{i}}
$$

wobei $\gamma_{i}$ die Befallsstärke zum Zeitpunkt $\mathrm{i}$ und $\mathrm{t}_{\mathrm{i}}$ die Anzahl der Tage nach der Inokulation bezeichnet.

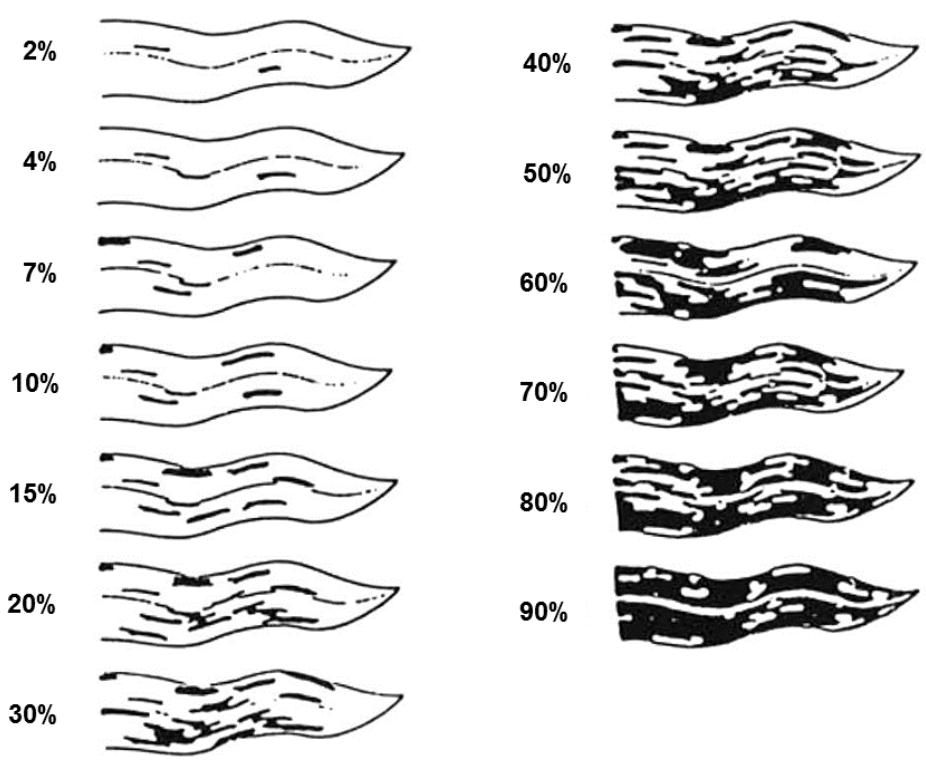

Abb. 6: Boniturskala zur Beurteilung der Befallsstärke für die Turcicum-Blattdürre an Mais auf einzelnen Blättern nach Gewächshausinokulation (Pataky, 1992). 
An allen Pflanzen wurde zu jedem Boniturzeitpunkt die Qualität der Läsionen durch die Vergabe von Boniturnoten mit Hilfe der unter Punkt 2.4.4 beschriebenen Boniturskala erfasst. Für dieses Merkmal wurde eine Note je Pflanze bzw. Wiederholung vergeben. Entsprechend der Boniturskala (Punkt 2.4.4, Tab. 3) wurden die Isolate bei Befallsreaktionen der Noten 0 bis 3 als avirulent und bei den Noten 4 bis 6 als virulent bezeichnet. Anhand des Zeitpunktes des Erstauftretens von Symptomen im Verlauf der Bonitur wurde die Inkubationszeit in Tagen als Mittelwert über die Wiederholungen berechnet. Sobald eine Pflanze eine Boniturnote von größer/gleich zwei erhalten hat, wurde dieser Tag als Inkubationszeit gewertet.

\subsubsection{Spezifischer Einfluss der Temperatur auf die Wirksamkeit von $H+2$}

\subsubsection{Versuchsaufbau}

In diesem Versuch wurden die nah-isogenen Inzuchtlinien B37 und B37-Ht2 verwendet. Die Anzucht erfolgte wie bereits unter Punkt 2.5.1.1 beschrieben. Die Pflanzen wurden zehn Tage vor dem Inokulationstermin aus dem Gewächshaus in RUMED ${ }^{\circledR}$ Klimakammern (Fa. Rubarth Apparate $\mathrm{GmbH}$, Deutschland) mit zwei unterschiedlichen Temperaturregimen gebracht. Jeweils die Hälfte der Pflanzen eines jeden Genotyps wurde für die Dauer von zehn Tagen mit Tag/Nacht-Temperaturen von $30 / 25^{\circ} \mathrm{C}$ bzw. $20 / 15^{\circ} \mathrm{C}$ inkubiert. Alle anderen Umweltbedingungen waren mit einem Tag/Nacht-Rhythmus von 14/10 Stunden, einer Lichtintensität von $155 \mu \mathrm{mol} / \mathrm{m}^{2} / \mathrm{s}$ und einer rel. Luftfeuchtigkeit von $75 \%$ für alle Pflanzen identisch. Zum Zeitpunkt der Inokulation wurden die Temperaturen für alle Pflanzen auf Tag/Nacht-Temperaturen von $25 / 20^{\circ} \mathrm{C}$ eingestellt. Dadurch war gewährleistet, dass lediglich die Maispflanzen und nicht der Pilz E. turcicum dem Einfluss der unterschiedlichen Temperaturen ausgesetzt war. Die Inokulation erfolgte bei einem Pflanzenalter von 31 Tagen, nachdem das fünfte Blatt in beiden Temperaturvarianten vollständig entwickelt war. Die Inokulation wurde, wie bereits unter Punkt 2.5.1.2 erläutert, mit einer Sporenkonzentration von 1.500 Sporen/ml, durchgeführt. Es wurde das avirulente Isolat 76-4 (Rasse 0) und das für das Resistenzgen Ht2 virulente Isolat 48-1 (Rasse 123) verwendet. Weitere Informationen zu den beiden Isolaten sind in Tabelle 7 beschrieben. Ab dem Zeitpunkt der Inokulation wurden die Pflanzen zunächst für 24 Stunden bei einer rel. Luftfeuchtigkeit von über 95\%, einem Tag/Nacht-Rhythmus von 14/10 Stunden und einer Tag/Nacht-Temperatur von $25 / 20^{\circ} \mathrm{C}$ in den Klimakammern inkubiert, wobei hier die Inkubation nach der Inokulation mit der Nachtphase begonnen wurde. Im Anschluss an die 24 Stunden andauernde Inkubationsphase wurde für den weiteren Versuchsverlauf die rel. Luftfeuchtigkeit auf $75 \%$ eingestellt. 
Tab. 9: Genotypen, Isolate und Temperaturen im Versuch zur Temperaturstabilität des Resistenzgens Ht2 gegen E. turcicum in Mais mit vorkonditionierten Pflanzen.

\begin{tabular}{lcl} 
Faktor & Anzahl & Beschreibung \\
\hline Genotypen (nah-isogone Inzuchtlinien) & 2 & B37, B37-Ht2 \\
Isolate & 2 & $76-4$ (Rasse 0, avr), 48-1 (Rasse 123, vir) \\
Temperaturen zur Vorkonditionierung (Tag/Nacht) & 2 & $30 / 25^{\circ} \mathrm{C}$ und $20 / 15^{\circ} \mathrm{C}$ \\
Kontrolle & 1 & Mock-Variante \\
Wiederholungen & 8 & Pflanze = Wiederholung \\
Wiederholungen des gesamten Versuchs & 2 &
\end{tabular}

In jedem der zwei unabhängigen Durchgänge des Versuchs wurden insgesamt 96 Pflanzen untersucht. Die Pflanzen wurden ab Inokulation 21 Tage unter den beschriebenen Bedingungen beobachtet. Eine Übersicht des Versuchs ist in Tabelle 9 dargestellt.

\subsubsection{Bonitur und Probenahme zur DNA Quantifizierung}

Die Bonitur wurde an vier Zeitpunkten im Vier-Tage-Rhythmus an folgenden Tagen nach der Inokulation vorgenommen: 9, 13, 17, 21 dpi. Es wurden die gleichen Merkmale erhoben, wie bereits unter Punkt 2.5.1.2 beschrieben, jedoch wurde in diesem Versuch ebenfalls die Befallsstärke für die Genotypen mit Resistenzgen erfasst. Als Läsionsfläche wurden sowohl grau-grünliche Welkesymptome und nekrotische Bereiche ohne Chlorosen als auch nekrotische Bereiche mit Chlorosen gewertet.

Um die erfassten phänotypischen Boniturdaten zu den Merkmalen Befallsstärke und Befallsqualität durch ein weiteres Merkmal zu ergänzen bzw. zu bestätigen, wurden die Mengen an DNA des Pilzes E. turcicum in den bonitierten Blattbereichen bestimmt. Dazu wurden im Anschluss an die letzte Bonitur zum Termin 21 dpi das vierte und fünfte Blatt je Pflanze unmittelbar am Stängel mit einer Schere abgetrennt und zunächst gemeinsam in Papiertüten tiefgefroren. Nach dem Gefriertrocknen wurden die Proben mit Hilfe einer Kugel-Schwingmühle (Model MM 400, Fa. Retsch) feinst vermahlen und homogenisiert. Bis zur folgenden DNA-Extraktion und abschließenden quantitativen Real Time PCR (qPCR) wurden die Proben trocken, bei $4^{\circ} \mathrm{C}$ und dunkel gelagert.

\subsubsection{DNA - Quantifizierung durch Real-Time-PCR}

Alle in dieser Arbeit durchgeführten DNA-Extraktionen basieren auf der CTAB-Methode nach (Brandfass \& Karlovsky, 2008). Für die Erstellung der Standardreihen wurde zunächst reine Pilz-DNA von E. turcicum gewonnen. Für die Myzelgewinnung wurden $2 \mathrm{ml}$ der tiefgefrorenen Suspensionen eines Einsporisolats in Czapek Dox Medium (200 ml) gegeben 
Tab. 10: Real-Time PCR-Programm zur Quantifizierung von E. turcicum in Maisblattgewebe

\begin{tabular}{clll} 
PCR-Schritt & Bezeichnung & Zeit & Temperatur $\left[{ }^{\circ} \mathrm{C}\right]$ \\
\hline 1 & Initiale Denaturierung & $3 \mathrm{~min}$ & 94 \\
2 & Denaturierung & $5 \mathrm{~s}$ & 94 \\
3 & Primer-Hybridisierung (Annealing) & $15 \mathrm{~s}$ & 63,5 \\
4 & Amplifikation (Elongation) & $15 \mathrm{~s}$ & 72 \\
& (Wiederholung der Schritte 2-4 40x) & & 72
\end{tabular}

und 14 Tage bei $22^{\circ} \mathrm{C}$ als Schüttelkultur (100 RPM) ohne Licht inkubiert. Nachdem ausreichend Myzel in der Flüssigkultur gewachsen war, wurde diese mittels Saugfiltration in einer Nutsche auf Filterpapier vom Pilzmyzel getrennt. Das Myzel wurde tiefgefroren, um es im Anschluss einer Gefriertrocknung zu unterziehen. Die Extraktion der Pilz-DNA von E. turcicum erfolgte aus $50 \mathrm{mg}$ in flüssigem Stickstoff fein vermahlenem Myzelpulver. Um die Konzentration der Pilz-DNA zu bestimmen, wurden Standardreihen erstellt. Dafür wurde die gewonnene Pilz-DNA mittels Agarosegel (1\%) aufgetrennt und auf Basis der Densitometrie mit bekannter DNA-Konzentration des Bakteriophagen Lambda verglichen (MBI, Fa. Fermentas, St. Leon-Rot, Deutschland). Auf diesem Weg wurden über Verdünnungsschritte Standardreihen reiner E. turcicum DNA mit den Konzentrationen 0,01 pg/ $\mu$, $0,1 \mathrm{pg} / \mu \mathrm{l}, 1 \mathrm{pg} / \mu \mathrm{l}, 10 \mathrm{pg} / \mu \mathrm{l}, 100 \mathrm{pg} / \mu \mathrm{l}$ und $1.000 \mathrm{pg} / \mu \mathrm{l}$ erstellt. Die densitometrische Bestimmung der DNA Konzentrationen erfolgte mit der Software Multi-Analyst (Bio-Rad, Hercules, USA). Für die Extraktion von Gesamt-DNA aus den Blattproben wurden $50 \mathrm{mg}$ des gefriergetrockneten und fein vermahlenen Blattpulvers verwendet. Die gewonnenen DNAProben wurden nach der Extraktion auf einem Agarosegel (1\%) mittels Elektrophorese aufgetrennt, um ihre Qualität zu beurteilen. Bis zur weiteren Verwendung wurden sie bei $-20^{\circ} \mathrm{C}$ gelagert.

Die PCR-Analyse basierte auf E. turcicum spezifischen Primern, die von ITS-Sequenzen ribosomaler DNA abgeleitet sind. Das Primerpaar JB 586 (5'-TGGCAATCAGTGCTCTGCTG-3') und JB 595 (5'-TCCGAGGTCAAAATGTGAGAG-3') amplifiziert ein E. turcicum spezifisches DNA-Fragment mit einer Größe von 485 Basenpaaren (Beck, 1998). Für die PCR-Reaktion wurde der Premix SensiFAST TM SYBR No-ROX Kit (Fa. Bioline Reagents Ltd, UK) mit allen für die Reaktion notwendigen Bestandteilen verwendet. Die beiden spezifischen Primer wurden mit einer Konzentration von 0,4 $\mu \mathrm{M}$ zugegeben. Der Ansatz wurde mit Wasser auf ein Volumen von $9 \mu$ aufgefüllt. Von der DNA-Probe wurde $1 \mu \mathrm{l}$ je Reaktion dazugegeben, sodass das Endvolumen des Reaktionsansatzes $10 \mu \mathrm{l}$ betrug. Der Ablauf des PCR-Programms ist in Tabelle 10 dargestellt. 
Die Filtereinstellungen für die Anregung und Emission des Fluoreszenzfarbstoffes SybrGreen wurden auf $490 \pm 10 \mathrm{~nm}$ und $530 \pm 15 \mathrm{~nm}$ eingestellt. Der Farbstoff SybrGreen lagert sich in doppelsträngige DNA ein und entfaltet dadurch die Absorptions- und Emsissionseigenschaften für die genannten Wellenlängenbereiche. Mit jedem Schritt der PCR steigt der Anteil doppelsträngiger DNA und dadurch auch das emittierte Fluoreszenzsignal. Als Bezugsgröße diente die erstellte Standardreihe. Für die Amplifikation und die ersten Auswertungsschritte wurde das Real-Time PCR System CFX 384 Touch $^{\text {TM }}$ C1000 Detection System (Fa. Bio-Rad, USA) verwendet. Weiterführende Auswertungen und grafische Darstellungen erfolgten mit dem Tabellenkalkulationsprogramm Microsoft Excel 2013.

\subsection{Symptomausprägung an Genotypen mit dem Resistenzgen Ht2}

Linien mit dem Resistenzgen Ht2 zeigten heterogene Befallsreaktionen gegenüber gleichen Isolaten. Zudem war auf der Linie B37-Ht2 in einigen Fällen eine klare Abgrenzung der Befallsreaktion in resistent bzw. anfällig nicht möglich. Durch Untersuchungen des Resistenzgens $H t 2$ mit verschiedenen Isolaten und mit verschiedenen genetischen Hintergründen sollte dieses Phänomen näher untersucht werden.

\subsubsection{Exserohilum turcicum Isolate}

Die Auswahl der Isolate erfolgte auf Grundlage der Virulenzeigenschaften gegenüber dem Resistenzgen Ht2 anhand der Ergebnisse des Rassenscreenings. Es wurden insgesamt sechs Isolate verwendet. Dabei handelte es sich um drei avirulente (avr) und drei virulente (vir) Isolate. Neben den Virulenzeigenschaften wurde bei der Auswahl darauf geachtet, möglichst heterogene Boniturergebnisse innerhalb der beiden Virulenzgruppen zu berücksichtigen. Dadurch sollte ein möglichst breites Spektrum in Bezug auf die Symptomausprägung und deren Beurteilung abgedeckt werden. Neben den sechs eigenen Isolaten aus dem Rassenscreening wurden zwei weitere als virulent auf $H t 2$ charakterisierte Isolate als Referenzisolate verwendet. Die Referenzisolate stammen aus den USA und wurden von Prof. Balint-Kurti von der North Carolina State University bereitgestellt. In Tabelle 11 sind die verwendeten Isolate mit Herkunft, Rasse und Informationen zu den Virulenzeigenschaften bzw. Boniturergebnissen aufgelistet. 
Tab. 11: Bezeichnung, Herkunft und Virulenzeigenschaften ausgewählter Isolate für Untersuchungen zur Befallssymptomatik auf Genotypen mit dem Resistenzgen Ht2.

\begin{tabular}{|c|c|c|c|c|c|}
\hline \multirow[b]{2}{*}{ Isolat } & \multicolumn{2}{|r|}{ Herkunft } & \multirow[b]{2}{*}{ Rasse } & \multirow{2}{*}{$\begin{array}{c}\text { Virulenzeigenschaft } \\
\text { gegenüber } H t 2\end{array}$} & \multirow{2}{*}{$\begin{array}{c}\varnothing \text { Boniturnote } \\
\text { Rassenscreening }\end{array}$} \\
\hline & Land & Region & & & \\
\hline $130-2$ & Frankreich & Südwest-Frankreich & 0 & avr & 1 \\
\hline $186-1$ & Frankreich & Zentralfrankreich & 1 & avr & 1,8 \\
\hline $161-1$ & Niederlande & Niederlande/Belgien & 0 & avr & 3 \\
\hline $122-2$ & Türkei & Türkei (Adana) & $23 \mathrm{~N}$ & vir & 4 \\
\hline $127-2$ & Frankreich & Südwest-Frankreich & $23 N$ & vir & 4,3 \\
\hline $159-4$ & Belgien & Niederlande/Belgien & $23 \mathrm{~N}$ & vir & 4 \\
\hline $28 \mathrm{~A}$ & USA & Kentucky (KY) & $23 \mathrm{~N}$ & vir & I \\
\hline $257 \mathrm{~A}$ & USA & Illinois (IL) & 23 & vir & I \\
\hline
\end{tabular}

\subsubsection{Pflanzenmaterial}

Der Versuch wurde mit den zwei nah-isogenen Inzuchtlinien B37 und B37-Ht2 des Differentialsortiments durchgeführt. Darüber hinaus wurden im zweiten Durchgang zusätzlich zum eigentlichen Experiment die Inzuchtlinien Pa91 und Pa91-Ht2 und die Linien 9V-90112 und 9V-90112-Ht2 als weitere Genotypen in den Versuch aufgenommen. Dabei handelt es sich jeweils um nah-isogene Inzuchtlinien, die sich lediglich in dem Resistenzgen Ht2 unterscheiden. Sowohl die Linie Pa91 (Ogliari et al., 2005) als auch die Linie 9V-90112 (B. Kessel, KWS, pers. Mitteilung 18.01.2012) sind als hochanfällige Linien gegenüber $E$. turcicum bekannt. Das Saatgut der Linien 9V-90112 und 9V-90112-Ht2 wurde von der KWS Saat SE aus Einbeck durch Dr. Bettina Kessel zur Verfügung gestellt. Diese beiden Linien werden im weiteren Verlauf der Arbeit zur Vereinfachung als KWS und KWS-Ht2 bezeichnet. Das Saatgut der Linien Pa91 und Pa91-Ht2 war als Lagerbestand der Abteilung Allgemeine Phytopathologie und Pflanzenschutz der Universität Göttingen aus abgeschlossenen Projekten vorhanden und wurde ursprünglich ebenfalls durch die Firma KWS Saat SE vermehrt und bereitgestellt. Die Anzucht und Behandlung der Pflanzen bis zum Zeitpunkt der Inokulation erfolgte wie bereits unter Punkt 2.2.1 beschrieben, mit dem Unterschied, dass in diesem Versuch je Topf eine Pflanze pikiert wurde und die Pflanzen zum Zeitpunkt der Inokulation das 5. und 6. Blatt voll ausgebildet hatten. Der Hauptversuch wurde in zwei voneinander unabhängigen Durchgängen wiederholt. Jeder Versuch wurde mit neun biologischen Wiederholungen durchgeführt, wobei jede Pflanze eine Wiederholung darstellte. Bei zwei Genotypen, mit sechs Isolaten und einer Kontrollvariante in neunfacher Wiederholung wurden je Durchgang 252 Pflanzen benötigt. 


\subsubsection{Inokulation und Bonitur}

Die Inokulation erfolgte mit wenigen Änderungen, wie bereits unter Punkt 2.2.2 beschrieben. Die Vermehrung der Sporen wurde mit befallenem Blattmaterial durchgeführt. Um befallenes Blattmaterial mit den entsprechenden E. turcicum Isolaten zu erhalten, wurden zunächst Pflanzen der Linie B37 inokuliert, um von innen infiziertes Blattmaterial zu gewinnen. Das trockene Blattmaterial wurde dunkel und bei $4^{\circ} \mathrm{C}$ gelagert. Eine Woche vor der Inokulation wurden Segmente des befallenen Blattmaterials ausgeschnitten, für $30 \mathrm{~s}$. in $2 \%$ $\mathrm{NaOCl}$ oberflächensterilisiert und anschließend in zwei Waschschritten für je $30 \mathrm{~s}$. in sterilem Leitungswasser gewaschen. Danach wurden die Blattsegmente in Petrischalen mit feuchtem Filterpapier bei Raumtemperatur und Tageslicht für sieben Tage inkubiert. Das Abwaschen der Sporen von der Blattoberfläche und alle weiteren Schritte erfolgten wie unter Punkt 2.4.2 beschrieben. Die Sporenkonzentration wurde in diesem Versuch auf 3.000 Sporen/ml eingestellt. Bei der Inokulation wurde darauf geachtet, dass das 5. und 6. Blatt ganzflächig und gleichmäßig mit der Sporensuspension bis kurz vor der Tropfenbildung benetzt wurden. Als Kontrolle wurde eine Mockvariante bestehend aus Wasser mit 125 ppm Silwet Gold ${ }^{\circledR}$ im Versuch verwendet. Nach erfolgter Inokulation und 24 h Inkubation im Folienzelt bei $90 \%$ rel. Luftfeuchtigkeit wurden die Pflanzen in einen Klimaraum mit einem Tag/Nacht-Rhythmus von 14/10 Stunden mit einer Temperatur von $24 / 20^{\circ} \mathrm{C}$ und einer relativen Luftfeuchtigkeit $75 \%$ gebracht.

Die Bonitur erfolgte an fünf Zeitpunkten jeweils im Abstand von zwei Tagen (8, 10, 12, 14, und $16 \mathrm{dpi}$ ). Es wurden die Merkmale Befallsstärke in Prozent befallene bzw. nekrotisierter Blattfläche und die Läsionsqualität in Form von Noten aufgenommen. Die Merkmale wurden entsprechend der Methoden, wie sie unter Punkt 2.5.2.2 beschrieben sind, aufgenommen. Bei der Bonitur wurden das 5. und 6. Blatt von jeder Pflanze berücksichtigt.

\subsubsection{Erfassung der Sporulation}

Zur Erfassung der Sporulation wurde aus jeder Variante von mehreren Pflanzen das vierte Blatt genutzt. Die Blätter wurden zunächst am 17. Tag nach der Inokulation in Papiertüten gesammelt und bei $4^{\circ} \mathrm{C}$ in einem Kühlraum dunkel und trocken gelagert. Für die weitere Verarbeitung wurden 20 Blattsegmente von ca. 1 x $3 \mathrm{~cm}$ Größe aus den nekrotisierten Bereichen der Blätter ausgeschnitten. Die Segmente wurden 1 min in $2 \% \mathrm{NaOCl}$ oberflächensterilisiert und in zwei Waschschritten je 1 min lang in sterilem Leitungswasser gewaschen. Wie in Abbildung 7 dargestellt, wurden die Blattsegmente in eine mit feuchtem Filterpapier ausgelegte Knopfschale mit der Blattoberseite nach oben platziert. Es wurden insgesamt 20 Blattsegmente ausgelegt, wobei immer zwei Segmente zusammen eine Wiederholung 
darstellten. Die Inkubation erfolgte für 72 Stunden bei Raumtemperatur und Tageslicht. Während der Inkubation wurde darauf geachtet, dass keines der Fächer austrocknete.

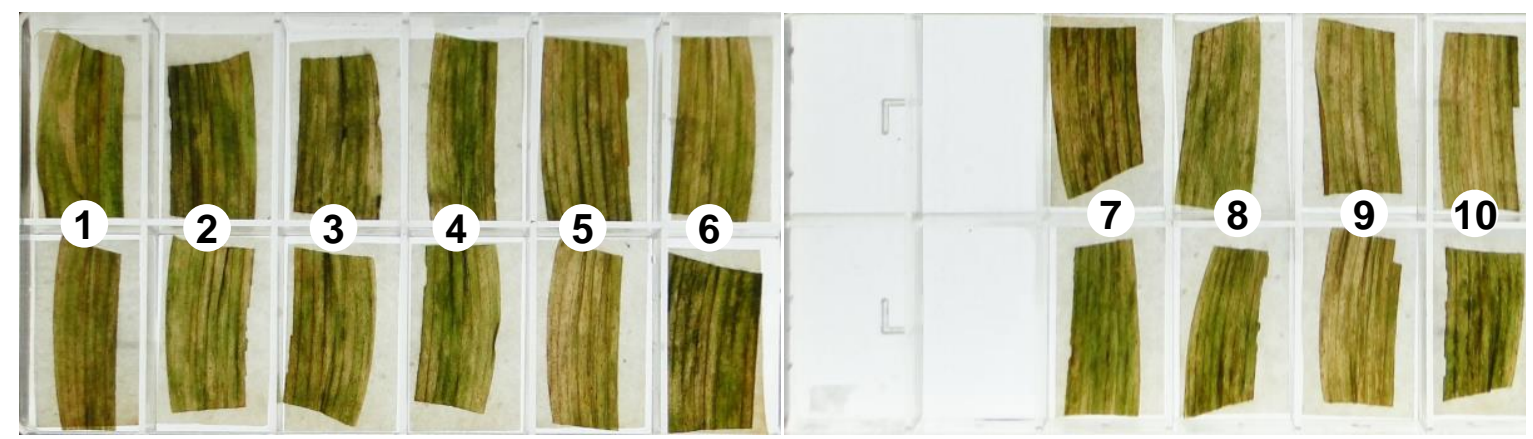

Abb. 7: Maisblattsegmente in einer Knopfschale zur Bestimmung der Sporulation von $E$. turcicum mit zehn Wiederholungen. Je zwei Blattsegmente wurden zu einer Wiederholung zusammengefasst. Dunkle Bereiche sind ein Indikator für Sporenbildung.

Gegebenenfalls wurde das entsprechende Fach mit sterilem Leitungswasser erneut befeuchtet. Im Anschluss an die 72 Stunden Inkubation wurden die Knopfschalen zunächst bei $-23^{\circ} \mathrm{C}$ tiefgefroren, um durch die niedrigen Temperaturen die Sporenbildung direkt nach Inkubationsende zu unterbinden. Für die Berechnung der Läsionsfläche wurde vor der weiteren Verarbeitung ein Digitalfoto von den Knopfschalen mit den Blattsegmenten aufgenommen. Dies erfolgte für alle Varianten mit der gleichen Kamera mit gleichen Kameraeinstellungen. Zudem wurde ein Foto unter gleichen Einstellungen von einer definierten Referenzfläche (Millimeterpapier) aufgenommen. Durch das Bild-Analyseprogramm für Pflanzenkrankheiten Assess 2.0 (Lakhdar Lamari, 2008, APS, USA) wurde anhand der unterschiedlichen Farbgebung von nekrotisierten und gesunden Blattbereichen die Läsionsfläche in Pixel bestimmt. Auf Basis der Pixelzahl der Referenzfläche wurde die Läsionsfläche je Blattsegment in die Einheit $\mathrm{cm}^{2}$ umgerechnet.

Zunächst wurde jede Kammer der Knopfschale mit $10 \mathrm{ml}$ Wasser (Leitungswasser + 125 ppm Silwet Gold ${ }^{\circledR}$ ) gefüllt. Mit Hilfe eines Gummiwischers wurden die Sporen vorsichtig durch Aufwirbeln des Wassers von der Blattoberfläche gelöst. Aus jeder Kammer wurden dann mit Hilfe einer Pipette 0,5 ml Sporensuspension entnommen und je zwei übereinander liegende Kammern zu einer Probe von einem ml zusammengeführt. Auf diese Weise wurden pro Variante zehn Suspensionen erstellt, wobei jede Suspension eine Wiederholung darstellte. Die Sporensuspensionen wurden bis zur Bestimmung der Konzentration einge- 
froren. Die Bestimmung der Sporenzahl erfolgte mit Hilfe einer Fuchs Rosenthal Zählkammer unter dem Mikroskop. Nachdem die Sporenkonzentrationen für alle Varianten bestimmt und die Flächen der dazugehörigen Läsionen berechnet waren, wurden diese ins Verhältnis gesetzt, um die Werte für das Merkmal Sporulation mit der Einheit Sporen je $\mathrm{cm}^{2}$ zu erhalten. Für die Darstellung wurden die Werte der Sporulation der einzelnen Isolate als relative Sporulation auf dem Genotypen B37-Ht2 zur Sporulation des Genotypen B37 ins Verhältnis gesetzt, wobei die Sporulation des anfälligen Genotypen B37 mit 100 gleichgesetzt wurde.

\subsubsection{DNA Quantifizierung durch Real-Time-PCR}

Die Probenahme für die DNA-Mengenbestimmung erfolgte am 17. Tag nach der Inokulation. Für jede Variante wurden drei Mischproben gewonnen. Eine Mischprobe bestand aus dem Material von sechs Blättern, jeweils das fünfte und sechste Blatt von drei Pflanzen (=Wiederholung). Das Blattmaterial wurde direkt nach der Probenahme bei $-20^{\circ} \mathrm{C}$ tiefgefroren. Die weiteren Schritte der Probenaufbereitung, der DNA-Extraktion und der Durchführung der Real-Time-PCR erfolgten wie bereits unter Punkt 2.5.2.3 beschrieben.

\subsection{Histologische Untersuchungen zur Pathogenese von E. turcicum}

\subsubsection{E. turcicum Isolate und Pflanzenmaterial}

In diesem Versuch wurde die Pathogenese von E. turcicum in Mais vor dem Hintergrund verschiedener monogener Resistenzen untersucht. Dazu wurden drei Isolate ausgewählt, deren Virulenzeigenschaften gegenüber den Resistenzgenen $\mathrm{Ht} 1, \mathrm{Ht} 2, \mathrm{Ht} 3$ und $\mathrm{HtN}$ so beschaffen sind, dass sich für jedes der Resistenzgene je eine kompatible und eine inkompatible Interaktion ergibt. Die verwendeten Isolate und ihre Virulenzeigenschaften sowie die Herkunftsangabe sind in Tabelle 12 gelistet. Es wurden dieselben Genotypen des Differentialsortiments verwendet, wie bereits unter Punkt 2.4.1 in den Versuchen zum Rassenscreening beschrieben. Die Anzucht der Pflanzen bis zum Zeitpunkt der Inokulation erfolgte ebenfalls entsprechend den Ausführungen unter Punkt 2.4.1. Die Sporengewinnung und die Inokulation wurden in diesem Versuch nach den gleichen Vorgaben durchgeführt, wie unter Punkt 2.6.3 dargelegt. Für die Inokulation wurde eine Sporenkonzentration von 5.000 Sporen/ml verwendet. Die Wachstumsbedingungen nach der Inkubation (24 h) im Folienzelt waren $14 / 10$ Stunden und $24 / 20^{\circ} \mathrm{C}$ Tag/Nacht mit einer rel. Luftfeuchtigkeit von $80 \%$. 
Tab.12: Bezeichnung, Herkunft und Virulenzeigenschaften der verwendeten Isolate im Rahmen der histologischen Untersuchung zur Interaktion von $E$. turcicum und Mais. $\left(^{*} V=\right.$ virulent; $\mathrm{A}$ = avirulent)

\begin{tabular}{|c|c|c|c|c|c|c|c|}
\hline \multirow[b]{2}{*}{ Bezeichnung } & \multirow[b]{2}{*}{ Rasse } & \multicolumn{2}{|c|}{ Herkunft } & \multicolumn{4}{|c|}{ Resistenzgene/Virulenzeigenschaften } \\
\hline & & Land & Region & Ht1 & Ht2 & Ht3 & HtN \\
\hline $172-4$ & 0 & Niederlande & Niederlande/Belgien & A & $\mathrm{A}$ & $\bar{A}$ & $\mathrm{~A}$ \\
\hline $138-1$ & 1 & Frankreich & Oberrheinregion & V & $A$ & A & $A$ \\
\hline $123-3$ & $23 N$ & Türkei & Türkei (Adana) & $A$ & V & $\mathrm{V}$ & $\mathrm{V}$ \\
\hline
\end{tabular}

\subsubsection{Versuchsaufbau und Probenahme}

Eine Einstufung der Befallsreaktionen erfolgte zu den Zeitpunkten 12 und 18 dpi an jeweils drei gleichen Genotypen jeder Variante nach der in Tabelle 3 beschriebenen Notenskala. Die Einstufung der Virulenzeigenschaften wurde auf Basis der Rassennomenklatur aus Tabelle 4 vorgenommen. Anhand dieser Sichtbonitur sollten die Virulenzeigenschaften der ausgewählten Isolate im Rahmen dieses Versuchs überprüft werden.

Die Pflanzen wurden in Gruppen entsprechend ihrer Variante (Genotyp x Isolat) im Klimaraum angeordnet, um die Probenahme im Verlauf des Versuchs möglichst unkompliziert zu gestalten. Die Hauptschritte der Probenahme sind in Abbildung 8 dargestellt. Die Probenahme erfolgte zu sechs Zeitpunkten: 1, 3, 6, 12 und 18 dpi. An jedem Probenahmezeitpunkt wurden von je zwei Pflanzen jeder Variante das vierte und fünfte Blatt verwendet. Die Blätter wurden zunächst nah am Stängel abgeschnitten. Im weiteren Schritt wurde mittels Skalpell die Mittelrippe des Blattes entfernt. Die verbleibenden Blattspreiten wurden mit Hilfe einer Schere in kleine Segmente einer Größe von ca. 2 bis $3 \mathrm{~cm}^{2}$ geschnitten. Je Variante wurden 20 Blattsegmente zur Fixierung direkt in ein mit AFE Fixierungslösung gefülltes $50 \mathrm{ml}$ Reaktionsgefäß gegeben. In dieser Fixierungslösung konnten die Blattsegmente für einen langen Zeitraum bei Raumtemperatur bis zum Zeitpunkt weiterer Schritte für die Mikroskopie aufbewahrt werden. 

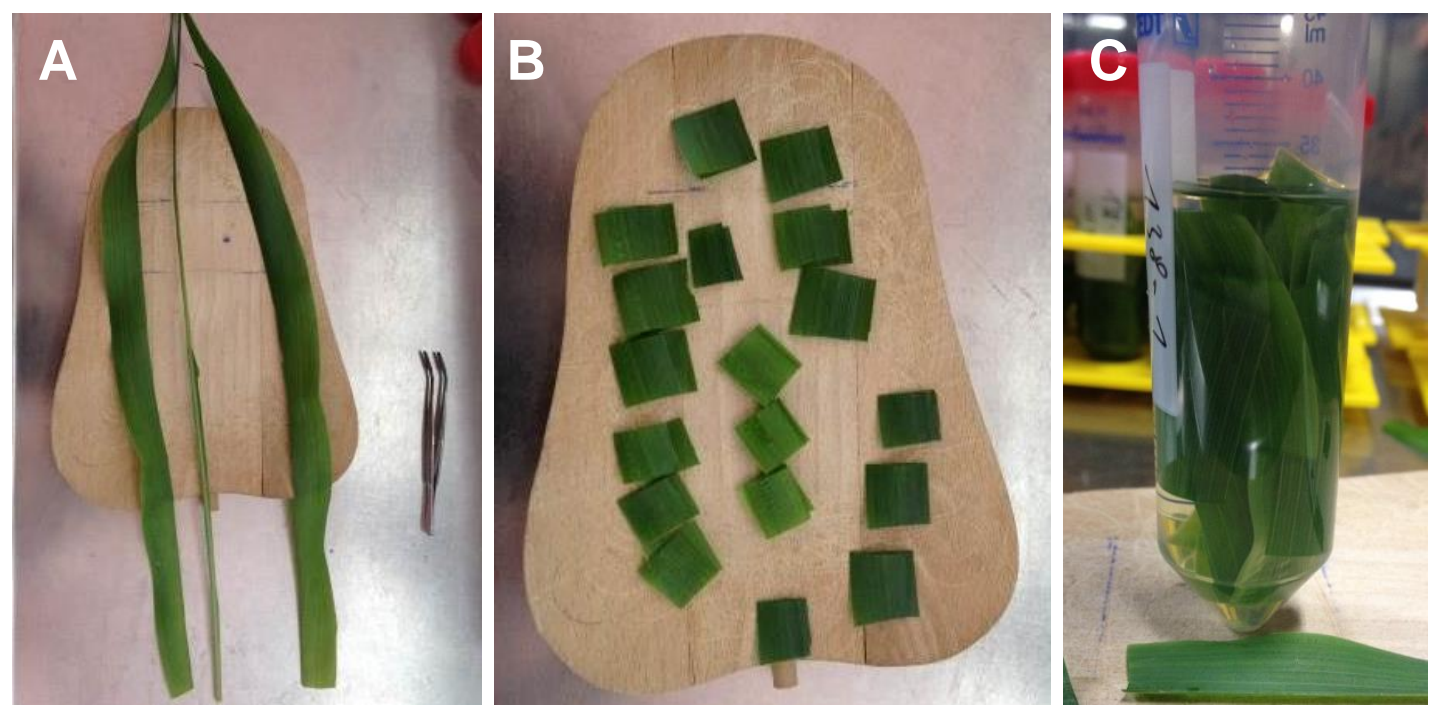

Abb. 8: A: Von der Mittelrippe abgetrennte Blattspreiten, B: 2 bis $3 \mathrm{~cm}^{2}$ große Blattsegmente, C: Blattsegmente in AFE Fixierungslösung.

\subsubsection{Färbung mit Chlorazol Black E (CBE)}

Für die mikroskopischen Untersuchungen wurden die Pilzstrukturen von E. turicucm im Blattgewebe mit Hilfe des Farbstoffs CBE nach vorheriger Behandlung mit Kaliumhydroxid $(\mathrm{KOH})$ gefärbt. Durch die schwarze Färbung der Pilzstrukturen kontrastieren diese vor dem helleren Hintergrund des Pflanzengewebes. Für die Verarbeitung im Färbeprozess wurden die Blattsegmente einzeln behandelt. Die Färbung erfolgte nach einem Färbeprotokoll verändert nach (Wilcox \& Marsh, 2009). Die Veränderung bestand in der deutlich verringerten Inkubationsdauer der Blattsegmente in $\mathrm{KOH}$.

Alle im Folgenden beschriebenen Schritte erfolgten in Reaktionsgefäßen ( $5 \mathrm{ml}$, Fa. Eppendorf, Deutschland) mit je einem Blattsegment. Zunächst wurden die in AFE fixierten Blattsegmente für zwei Stunden in Ethanol eingelegt. Danach folgte ein Waschschritt in Leitungswasser. Im Anschluss wurde das Reaktionsgefäß mit dem Blattsegment mit $2 \mathrm{M} \mathrm{KOH}$ gefüllt und in geschlossenem Zustand für zweieinhalb Stunden bei $90^{\circ} \mathrm{C}$ im Wasserbad erhitzt. Mit diesem Schritt wurde eine vollständige Entfärbung des Blattsegments erreicht. Nach der Entfärbung war es unbedingt erforderlich, äußerst vorsichtig mit dem Blattsegment im Reaktionsgefäß umzugehen, damit die Blattstrukturen für die abschließende Mikroskopie erhalten blieben. Nach zweieinhalb Stunden Inkubation wurde die Kalilauge dekantiert und die Probe zwecks Waschens mit Leitungswasser versetzt. Beim Entleeren des 
Reaktionsgefäßes war es sinnvoll, darauf zu achten, dass das Blattsegment an der Innenwand des Gefäßes anliegt, sodass ein Entleeren des Gefäßes möglich wurde, ohne das Blattsegment zu beschädigen. Danach wurde das Reaktionsgefäß mit der CBE-Färbelösung gefüllt und über Nacht bei $60^{\circ} \mathrm{C}$ im Wasserbad inkubiert. In diesem Schritt wurden sowohl die Blatt- als auch die Pilzstrukturen schwarz gefärbt. Am nächsten Tag wurde die gebrauchte CBE-Färbelösung mit einer Pipette entnommen und zur Wiederverwendung aufbewahrt. Die nun schwarz erscheinenden Blattsegmente wurden mindestens 48 Stunden in 50\% Glycerin entfärbt und darin bis zur Mikroskopie aufbewahrt. Durch einen längeren Entfärbungsprozess wurden die Blattstrukturen deutlich stärker entfärbt als die Pilzstrukturen. Dadurch wurde der Kontrast zwischen Blattzellen und Pilz verstärkt.

\subsubsection{Mikroskopische Untersuchungen}

Für die Mikroskopie wurden die Blattsegmente zunächst auf Objektträger übertragen. Dazu wurde das Glycerin abgegossen und mögliche abgesetzte CBE Rückstände am Boden des Reaktionsgefäßes durch Zugabe von Wasser mit Hilfe einer Pipette entnommen. Durch Zugabe von Wasser und leichten Bewegungen des Reaktionsgefäßes wurde das Blattsegment vorsichtig von der Innenwand des Gefäßes gelöst, um es dann mit dem Wasser vorsichtig auf den Objektträger zu überführen. Das überflüssige Wasser wurde mit Hilfe einer Pipette oder durch Aufsaugen mit Papiertüchern vom Objektträger entfernt. Die mikroskopischen Untersuchungen erfolgten mit einem Durchlichtmikroskop (Leitz DMRBE, Fa. Leica).

Bei den mikroskopischen Untersuchungen zur Pathogenese wurden ausschließlich die Postpenetrationsabläufe im Pflanzengewebe berücksichtigt. Es wurden systematisch drei Parameter erfasst. Die „Xylem-Penetrations-Effizienz“ beschreibt den Anteil der Penetrationsstellen der Epidermis, denen ein Eindringen in das Xylem folgte. Es ist ein qualitativer Parameter, da nicht bewertet wurde, wie stark das jeweilige Xylemgefäß besiedelt war. Als Penetrationsstellen wurden die Bereiche definiert, an denen eine erfolgreiche Penetration der Epidermiszellen unter dem gebildeten Appressorium erfolgt ist. In Abbildung 9 ist eine Penetrationsstelle als Draufsicht in zwei Fokusebenen dargestellt: Zunächst links die Fokusebene $(A)$ der Blattoberfläche mit einer gekeimten Konidiospore und rechts die darunter liegende Fokusebene (B) der Epidermiszellen, in denen nach erfolgreicher Penetration Pilzhyphen zu sehen sind. 

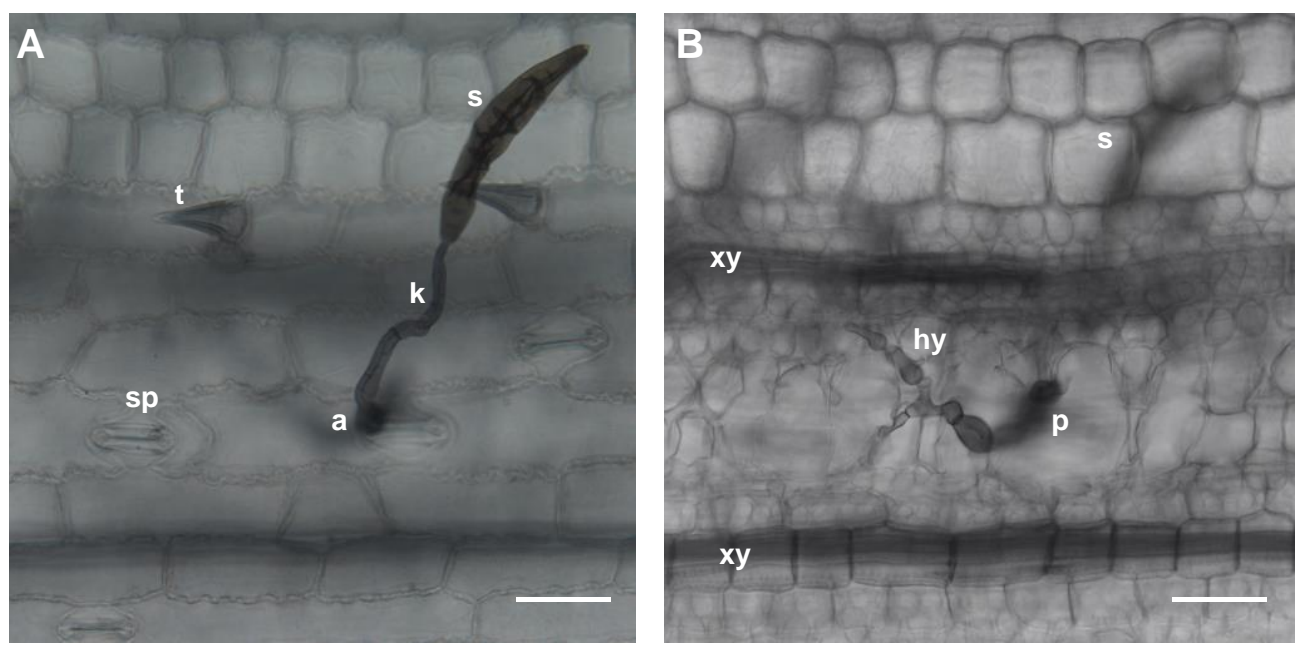

Abb. 9: Lichtmikroskopische Aufnahme einer E. turcicum Penetrationsstelle an Mais (3 dpi) auf zwei Fokusebenen nach CBE-Färbung. A: Konidiospore (s) mit Keimschlauch (k) und Appressorium (a) auf der Blattoberfläche mit Spaltöffnungen (sp) und Trichomen (t) (40x); $B$ : Penetrationsstelle ( $p$ ) mit septierten Hyphenstrukturen (hy) in den Epidermiszellen zwischen zwei Xylemgefäßen (xy), (s) = durscheinende Konidiospore auf der Blattoberfläche, Maßstab $=\mathbf{5 0} \mu \mathrm{m}$.

Parameter 1: Xylem-Penetrations-Effizienz (Abbildung 10)

$$
\begin{aligned}
& 0=\text { keine Hyphen im Xylem sichtbar } \\
& 1=\text { ein Xylemgefäß besiedelt }
\end{aligned}
$$

In diesem Fall bedeutet besiedelt, dass Hyphen im Xylem sichtbar sind.
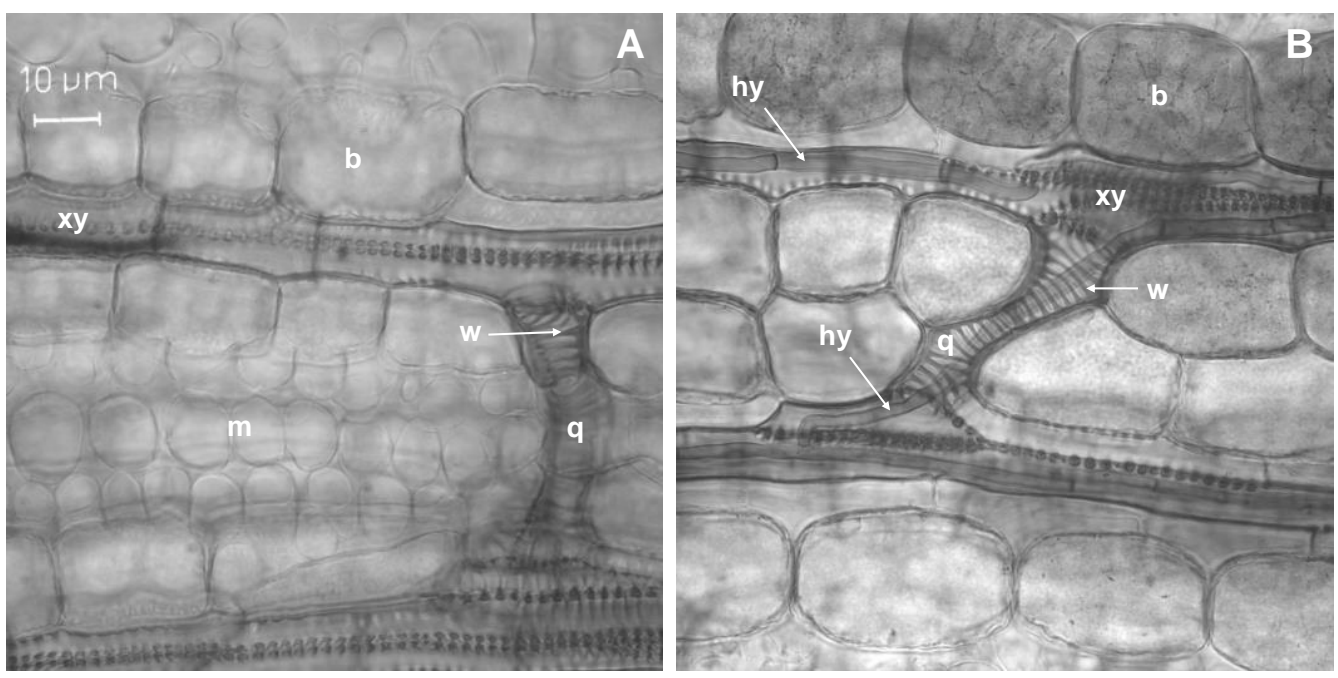

Abb. 10: Lichtmikroskopische Aufnahmen eines Maisblattes auf der Fokusebene der Xylem Leitgefäße nach CBE Färbung (6 dpi), A: Parallel verlaufende Xylemgefäße (xy) mit einer Querverbindung $(q)$ ohne Hyphenbesiedlung umgeben von Bündelscheidenzellen (b) und Mesophyllzellen (m) (100x); B: Parallel verlaufende Xylemgefäße (xy) mit Besiedlung durch E. turcicum mit einer oder mehreren Hyphen (hy)mit einer Querverbindung (q) (100x); Zellwände der Xylemgefäße sind durch spiralförmige Wandverstärkungen (w) charakterisiert. 
Mit einem weiteren Parameter wurde die Besiedlung der Xylemgefäße quantitativ bewertet. Dabei wurde die jeweilige Note vergeben sobald ein Xylemgefäß je Penetrationstelle die Anforderungen erfüllte.

Parameter 2: Xylem-Besiedlungs-Effizienz

1 = maximal eine Hyphe im Xylem sichtbar

2 = zwei oder mehr Hyphen im Xylem sichtbar

Als dritter Parameter wurde die Besiedlung des Mesophylls durch Pilzhyphen qualitativ bewertet.

Parameter 3: Mesophyll-Besiedlungs-Effizienz

$0=$ keine Hyphen außerhalb des Xylems sichtbar

1 = Hyphen im Mesophyll sichtbar

Für die Veranschaulichung der erhobenen Parameter zur Xylem-Besiedlungs-Effizienz bzw. der Mesophyll-Besiedlungs-Effizienz sind in Abbildung 11 jeweils eine starke Xylem Besiedlung und eine starke Kolonisation des Mesophylls dargestellt.
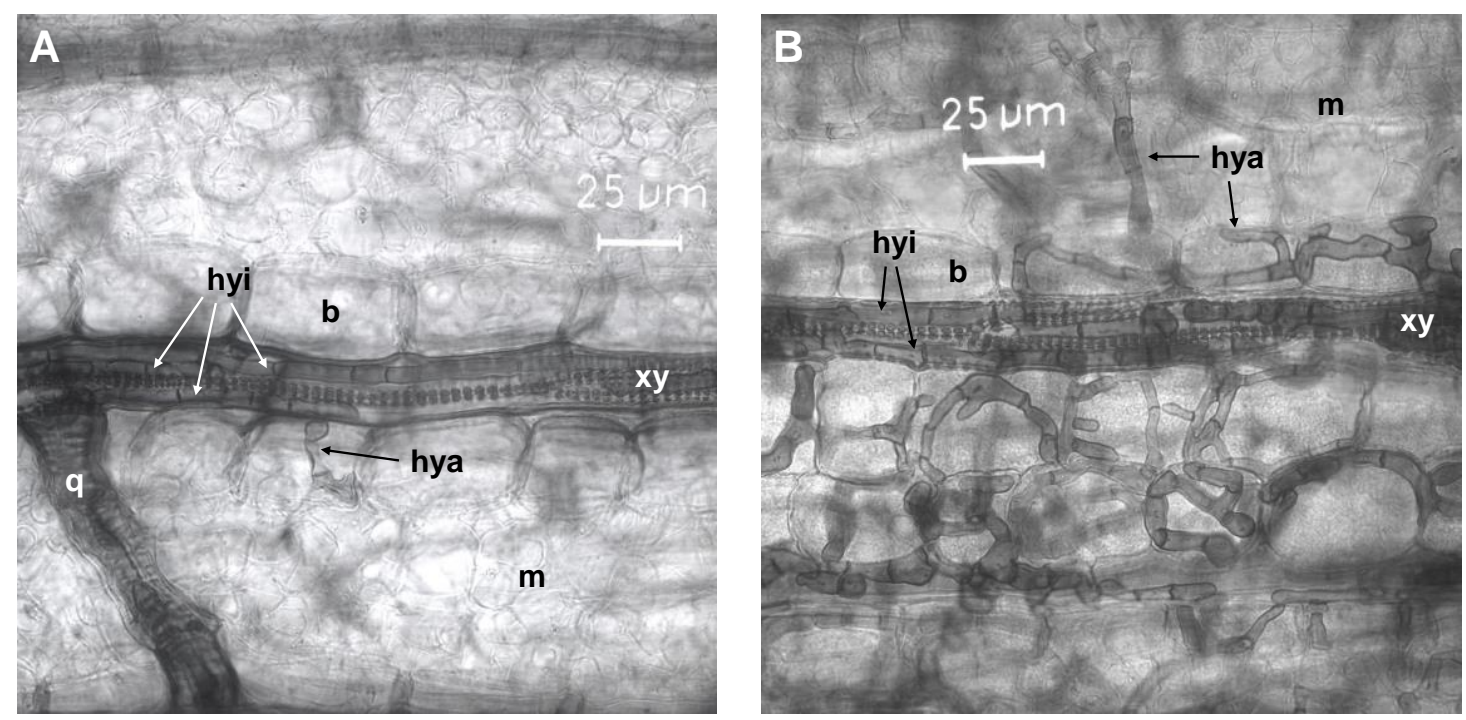

Abb. 11: Lichtmikroskopische Aufnahmen eines Maisblattes auf der Fokusebene der Xylem Leitgefäße nach CBE-Färbung (12 dpi), A: Xylemgefäß (xy) mit mehreren Pilzhyphen innerhalb des Xylems (hyi) und außerhalb (hya) in den Bündelscheidenzellen (b) mit einer Querverbindung (q) (40x); B: Xylemgefäß mit starker Hyphenkolonisation innerhalb (hyi) und deutlichem Hyphenwachstum außerhalb (hya) im Mesophyll (m) und den Bündelscheidenzellen (b). 
Auf Basis dieser Parameter wurden 40 Penetrationsstellen je Variante untersucht und ausgewertet. Eine Variante entspricht die Bewertung der Parameter an einem Genotyp mit entsprechender Resistenzgenausstattung mit einer bestimmten Interaktion zu einem bestimmten Zeitpunkt. Es wurden 48 verschiedene Varianten für die Genotypen untersucht: Vier Genotypen mit unterschiedlicher Resistenzgenaustattung an fünf Zeitpunkten mit zwei möglichen Interaktionen (kompatibel und inkompatibel). Zudem wurden für die anfällige Linie B37 zehn Varianten untersucht, d. h. zwei Isolate zu fünf Zeitpunkten. Insgesamt wurden 58 Varianten mit je 40 Penetrationsstellen ausgewertet.

\subsection{Statistische Auswertung}

Die statistische Auswertung aller Versuche wurde mit der Software Statistica (Version 9, Fa. StatSoft, Tulsa, USA) durchgeführt. Die varianzanalytischen Verrechnungen der intervallskalierten Daten wurden auf Basis multipler Mittelwertvergleiche unter der Annahme einer Normalverteilung vorgenommen. Signifikante Mittelwert-Unterschiede zwischen den Varianten wurden mit Hilfe des Post-hoc Tukey-Tests mit einer Irrtumswahrscheinlichkeit von $5 \%(p \leq 0,05)$ überprüft. Ordinalskalierte Daten wurden mit dem Kruskal-Wallis-Test (Median-Test) auf signifikante Unterschiede überprüft. Signifikante Unterschiede sind in den grafischen Darstellungen durch unterschiedliche Buchstaben gekennzeichnet.

Korrelationsanalysen erfolgen nach dem Pearson-Korrelationskoeffizienten. In der tabellarischen Darstellung der Korrelationskoeffizienten wurden signifikante Unterschiede mit unterschiedlicher Anzahl an Sternchen wie folgt gekennzeichnet: ${ }^{*}=p \leq 0,05 ;{ }^{* *}=p \leq 0,01$; ${ }^{* * *}=p \leq 0,001$. Nicht gekennzeichnete Koeffizienten wiesen keine signifikanten Korrelationen auf.

Die statistische Auswertung der mikroskopischen Untersuchungen erfolgte mit Hilfe des Chi-Quadrat-Homogenitätstests mit dem Programm Microsoft Excel 2013. Es wurden die Häufigkeitsverteilungen für jedes Merkmal und Resistenzgen auf Basis von $n=40$ Penetrationsstellen jeweils mit der anfälligen Linie B37 verglichen. Signifikante Unterschiede sind mit unterschiedlicher Anzahl an Sternchen wie folgt gekennzeichnet: * $=p \leq 0,05$; ${ }^{* *}=p \leq 0,01 ;{ }^{* * *}=p \leq 0,001$ 


\section{Ergebnisse}

\subsection{Kultur- und Lagereigenschaften von E. turcicum}

Die optimale Temperatur für das in vitro Wachstum von E. turcicum auf V8-Nährmedium liegt bei $24^{\circ} \mathrm{C}$ (Abb. 12). Mit 8,3 mm Zuwachs des Koloniedurchmessers je Tag unterscheidet sich die $24^{\circ} \mathrm{C}$ Variante signifikant sowohl von der höheren $\left(28^{\circ} \mathrm{C}\right)$ als auch von der niedrigeren $\left(20^{\circ} \mathrm{C}\right)$ Temperaturvariante mit Werten von 6,4 bzw. 7,0 mm Zuwachs. Darüber hinaus weist $E$. turcicum ein signifikant schnelleres Wachstum bei $16^{\circ} \mathrm{C}$ mit $4,4 \mathrm{~mm}$ im Vergleich zur $32^{\circ} \mathrm{C}$ Variante mit $2,7 \mathrm{~mm}$ auf. Ausgehend von $24^{\circ} \mathrm{C}$ reagiert E. turcicum stärker mit reduzierten Wachstumsraten auf höhere als auf niedrigere Temperaturen. Der optimale Temperaturbereich für die Anzucht und Kultur von E. turcicum unter in vitro Bedingungen im Labor wurde für den Bereich 20 bis $24^{\circ} \mathrm{C}$ definiert.

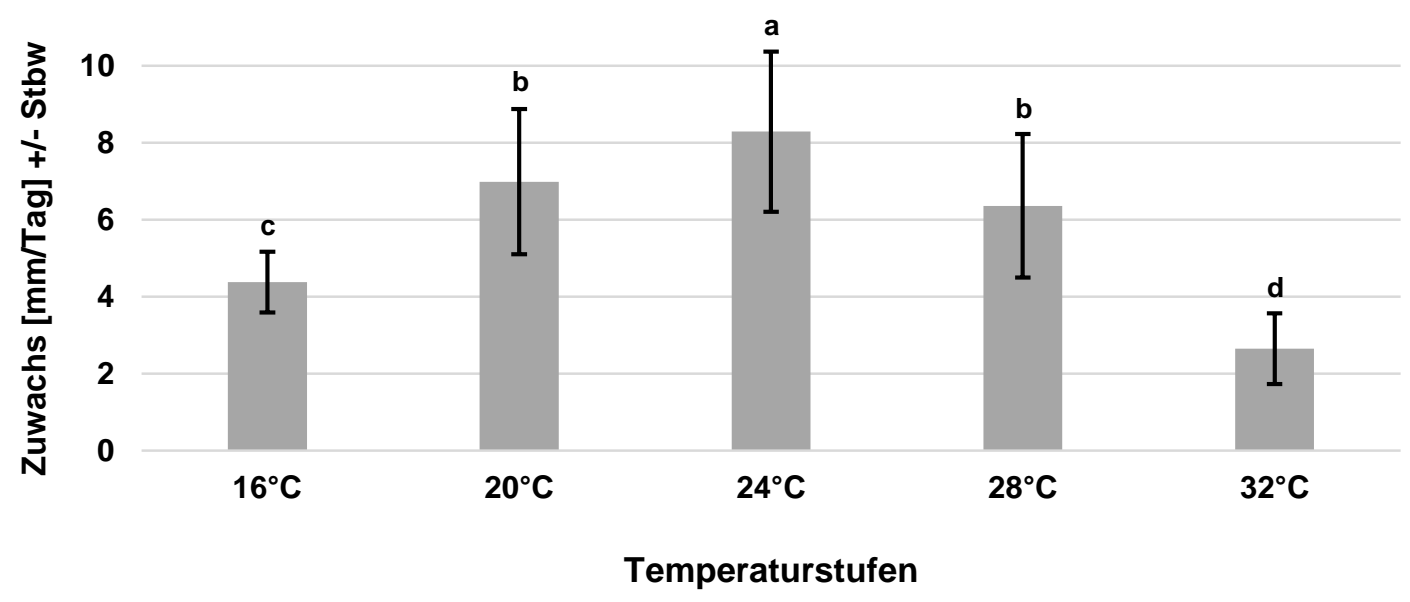

Abb. 12: Einfluss verschiedener Temperaturen auf den Zuwachs des Koloniedurchmessers von E. turcicum auf V8 Nährmedium in $\mathrm{mm}$ je Tag, unterschiedliche Buchstaben kennzeichnen signifikante Unterschiede (Tukey Test $p \leq 0,05$ ), $n=40$

Die Lagerfähigkeit der Konidiosporen von E. turcicum wurde anhand des Anteils keimfähiger Sporen nach Lagerung bei $-23^{\circ} \mathrm{C}$ in $25 \%$ Glycerin bestimmt. In Abbildung 13 sind die Anteile gekeimter Sporen der sechs untersuchten Isolate in Abhängigkeit von der Lagerdauer dargestellt. Die Keimfähigkeit betrug im Mittel der sechs untersuchten Isolate unmittelbar nach dem Erstellen der Sporensuspension ohne Einfluss von Frost 63,9\%. Bereits vor dem Einfrieren der Sporensuspensionen waren demnach 36,1\% der Sporen nicht in der Lage, unter den in vitro Versuchsbedingungen zu keimen. Die höchste Keimfähigkeit weist das Isolat Niederlande/Belgien mit 78,3\% auf. 


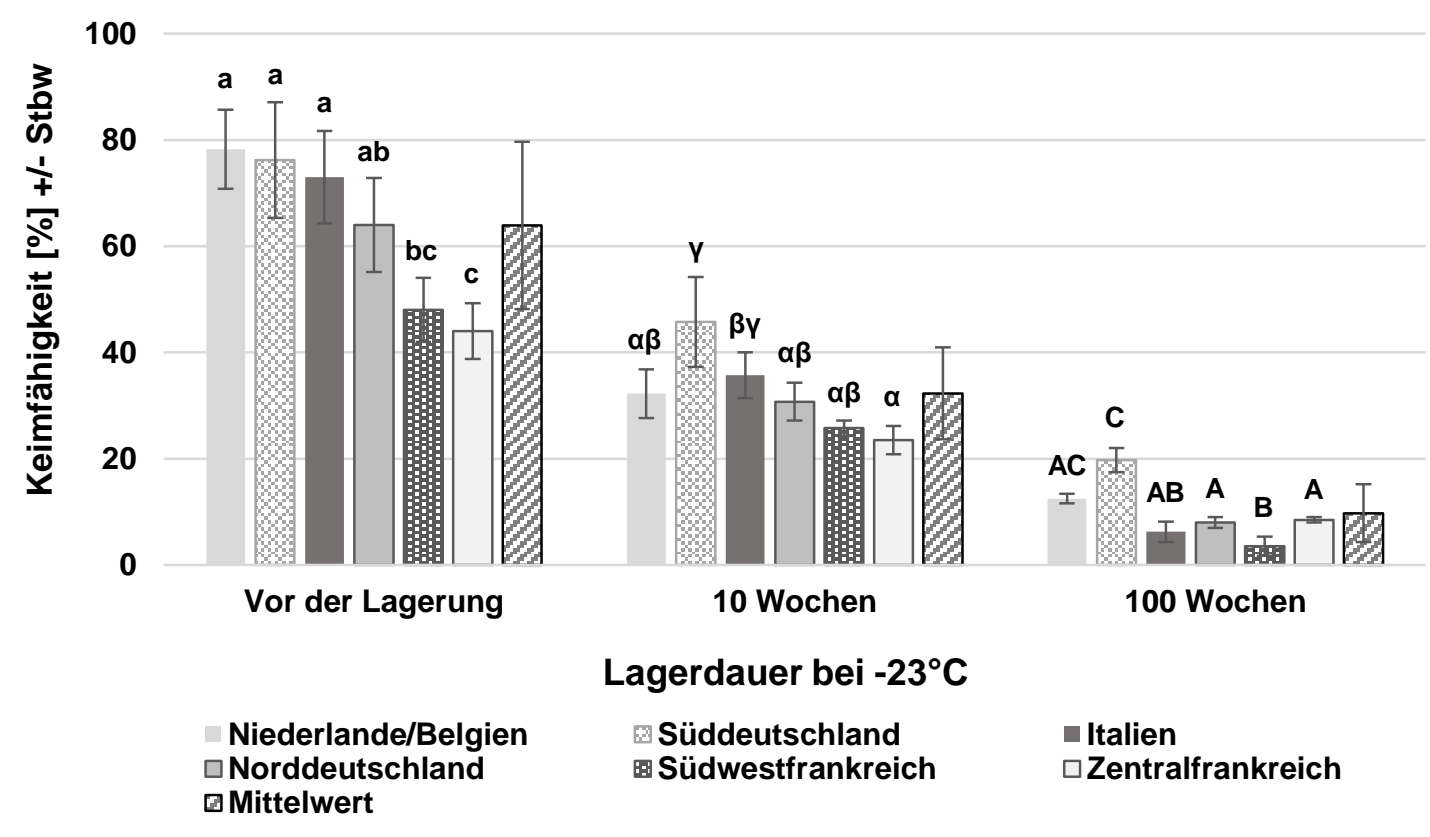

Abb. 13: Keimfähigkeit von E. turcicum Sporen verschiedener Isolatherkünfte vor und nach der Lagerung in $25 \%$ Glycerin bei $-23^{\circ} \mathrm{C}$, unterschiedliche Buchstaben kennzeichnen signifikante Unterschiede innerhalb der drei dargestellten Varianten, (Tukey Test $p \leq 0,05$, nach Log Transformation), $\mathrm{n}=4$.

Den niedrigsten Wert mit 44,0\% zeigte das Isolat aus Zentralfrankreich. Diese beiden Werte verdeutlichen die enorme Variation innerhalb der untersuchten Isolate ohne Frosteinfluss. Nach einer Woche Lagerung bei $-23^{\circ} \mathrm{C}$ lag die Keimfähigkeit mit $42,1 \%$ signifikant unter dem Ausgangswert. Die Werte vor der Lagerung zeigen signifikante Unterschiede zwischen den Isolaten unmittelbar nach der Erstellung der Sporensuspensionen. Diese Unterschiede verringern sich nach zehn Wochen Lagerung bei $-23^{\circ} \mathrm{C}$. Zu diesem Zeitpunkt unterscheidet sich lediglich das Isolat aus Süddeutschland durch eine hohe Keimfähigkeit signifikant von den anderen Isolaten. Nach 100 Wochen Lagerdauer grenzt sich wiederum das Isolat aus Süddeutschland mit der höchsten Keimfähigkeit $(19,8 \%)$ von den anderen Isolaten ab. Zudem weist das Isolat aus der Region Niederlande/Belgien im Vergleich eine signifikant höhere Keimfähigkeit auf. Das Isolat aus Südwestfrankreich ist als einziges durch eine sehr geringe Keimfähigkeit (3,5\%) signifikant von den anderen Isolaten verschieden. Diese Werte verdeutlichen, dass eine Lagerung von E. turcicum Sporen in $25 \%$ Glycerin bei $-23^{\circ} \mathrm{C}$ über einen Zeitraum von 100 Wochen möglich ist, aber mit einem deutlichen Verlust an keimfähigen Sporen verbunden ist. 


\subsection{Rassencharakterisierung europäischer E. turcicum Isolate}

\subsubsection{Isolatsammlung von E. turcicum der Jahre 2011 und 2012}

Von den eingesandten Blattproben aus den Jahren 2011 und 2012 wurde eine Isolatsammlung mit insgesamt 559 E. turcicum Isolaten von 168 verschiedenen Standorten erstellt. Tabelle 13 gibt einen Überblick über die gewonnenen Isolate hinsichtlich Herkunftsregion und Jahr. Aus dem Jahr 2011 stammen 54\% der Isolate ( $N=302)$ und aus 2012 46\% ( $N=$ 257). Die vier Regionen Niederlande/Belgien, Süddeutschland/Österreich, Oberrheinregion und Südwestfrankreich mit der höchsten Anzahl an Isolaten decken zusammen 63\% ( $N=$ 352) aller Isolate ab. Die Regionen Österreich/Ungarn, Norditalien und Tschechien/Polen sind mit einem geringen Anteil von jeweils unter $5 \%$ gekennzeichnet. Der kumulierte Anteil dieser drei Regionen liegt bei 11,3\%. Insbesondere in den Regionen mit geringem Gesamtanteil an Isolaten sind die Anteile der beiden Jahre zum Teil sehr unterschiedlich. Für die Region Tschechien/Polen ( $N=19)$ stammen 84\% der Isolate aus 2012. Die Isolate der Regionen Norditalien ( $\mathrm{N}=20)$ bzw. Bretagne/Normandie $(\mathrm{N}=34)$ stammen zu 80 bzw. $85 \%$ aus dem Jahr 2011. Die Anzahl der gewonnenen Isolate je Standort (N/S) variiert von 2,9 bis 4,0 und liegt im Durchschnitt bei 3,3 Isolaten je Standort. Für die Regionen Türkei (Adana) und Spanien (Galicien) konnten jeweils nur aus einem Jahr Isolate gewonnen werden. Darüber hinaus ist die Anzahl der Isolate für diese Regionen aufgrund der geringen Anzahl eingegangener Proben mit $\mathrm{N}=11$ für die Türkeibzw. N = 6 für Spanien sehr gering.

Tab. 13: Anzahl (N) und Anteil (\%) der untersuchten E. turcicum Isolate aus den Jahren 2011 und 2012 nach Regionen; Anzahl Standorte (S) je Region und Anzahl untersuchter Isolate je Standort (N/S), absteigend sortiert nach Gesamtanzahl untersuchter Isolate.

\begin{tabular}{|c|c|c|c|c|c|c|c|c|}
\hline \multirow[b]{2}{*}{ Region } & \multicolumn{2}{|c|}{2011} & \multicolumn{2}{|c|}{2012} & \multicolumn{4}{|c|}{ Gesamt } \\
\hline & $\mathrm{N}$ & $\%$ & $\mathrm{~N}$ & $\%$ & $\mathrm{~N}$ & $\%$ & $\mathrm{~s}$ & $\mathrm{~N} / \mathrm{S}$ \\
\hline Niederlande/Belgien & 45 & 14,9 & 62 & 24,1 & 107 & 19,1 & 30 & 3,6 \\
\hline Süddeutschland/Österreich (Inntal) & 56 & 18,5 & 36 & 14,0 & 92 & 16,5 & 29 & 3,2 \\
\hline Oberrheinregion & 33 & 10,9 & 44 & 17,1 & 77 & 13,8 & 23 & 3,3 \\
\hline Südwestfrankreich & 53 & 17,5 & 23 & 8,9 & 76 & 13,6 & 23 & 3,3 \\
\hline Norddeutschland & 16 & 5,3 & 31 & 12,1 & 47 & 8,4 & 14 & 3,4 \\
\hline Zentralfrankreich & 29 & 9,6 & 17 & 6,6 & 46 & 8,2 & 14 & 3,2 \\
\hline Bretagne/Normandie & 29 & 9,6 & 5 & 1,9 & 34 & 6,1 & 11 & 3,1 \\
\hline Österreich (Steiermark)/Ungarn & 16 & 5,3 & 8 & 3,1 & 24 & 4,3 & 6 & 4,0 \\
\hline Norditalien & 16 & 5,3 & 4 & 1,6 & 20 & 3,6 & 7 & 2,9 \\
\hline Tschechien/Polen & 3 & 1,0 & 16 & 6,2 & 19 & 3,4 & 6 & 3,2 \\
\hline Türkei (Adana) & - & - & 11 & 4,3 & 11 & 2,0 & 3 & 3,7 \\
\hline Spanien (Galicien) & 6 & 2,0 & - & - & 6 & 1,1 & 2 & 3,0 \\
\hline Summe & 302 & 100 & 257 & 100 & 559 & 100 & 168 & $\varnothing 3,3$ \\
\hline
\end{tabular}




\subsubsection{Regionale Rassenspektren der Jahre 2011 und 2012}

Es wurden insgesamt 559 Isolate aus den Jahren 2011 und 2012 auf ihre Virulenzeigenschaften untersucht. In Abbildung 14 ist das zusammengefasste Rassenspektrum der beiden Untersuchungsjahre dargestellt. Mit einem kumulierten Anteil der Rassen 0, 1, 3 und $3 \mathrm{~N}$ decken diese vier Rassen in den Jahren 2011 und 2012 mit 95\% und 98\% nahezu das gesamte Rassenspektrum von E. turcicum in Europa ab. Die Anteile der dominierenden Rassen haben sich zwischen den Jahren leicht verändert. Am deutlichsten sichtbar wird dies am Beispiel der Rassen 3N und 3. Beide Rassen haben ihren Anteil in 2012 im Vergleich zu 2011 in etwa verdoppelt. Gleichzeitig ist der Anteil der Rasse 1 von gut einem Viertel (26\%) auf 17\% gesunken. Der Anteil der Rasse 0 ist ebenfalls um neun Prozentpunkte auf 40\% im Jahr 2011 zurückgegangen.

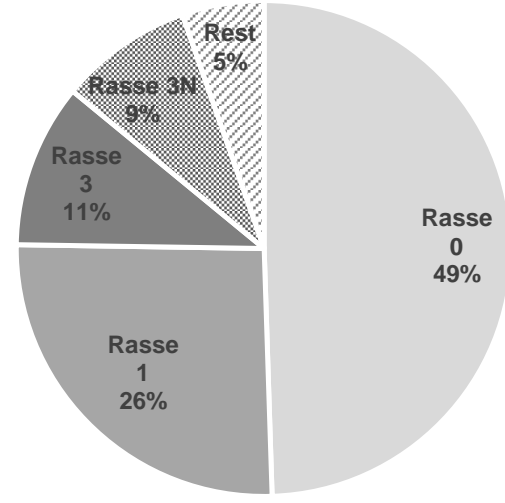

$2011 \mathrm{~N}=296$

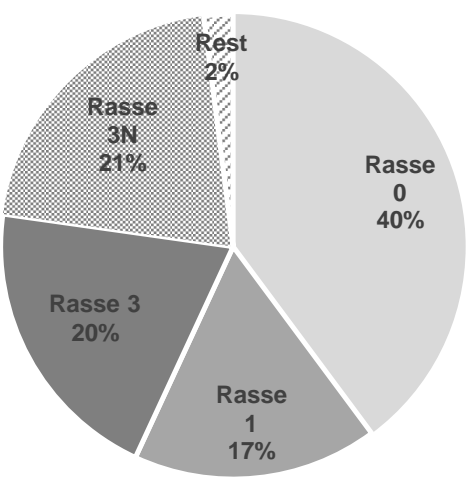

$2012 \mathrm{~N}=246$

Abb. 14: Anteile der häufigsten Rassen innerhalb der gesamten untersuchten europäischen E. turcicum Isolate der Jahre 2011 und 2012; unter „Rest“" sind die weniger bedeutenden Rassen zusammengefasst, 2011: 13, 23, 123, 2 und 12; 2012: 2, 13, 13N und 1N (ohne Türkei und Spanien).

Aus der Region Spanien (Galicien) sind lediglich sechs Isolate aus dem Jahr 2011 in die Untersuchungen eingeflossen. Alle Isolate dieser Region waren avirulent gegenüber den getesteten Resistenzgenen und wurden demnach als Rasse 0 beschrieben. Aus der Region Türkei (Adana) wurden insgesamt 11 Isolate aus dem Jahr 2012 untersucht. In dieser Region dominierten die Rasse 3N mit 73\% und die Rasse 23N mit 18\% das Rassenspektrum. Ein Isolat (9\%) wurde als Rasse 0 eingestuft. Diese beiden Regionen werden aufgrund der geringen Anzahl an Isolaten und der geographischen Abgrenzung zu den anderen Regionen in der folgenden Ergebnisbesprechung nicht weiter berücksichtigt. 
Tab.14: Gesamtes Rassenspektrum der Jahre 2011 und 2012 nach Regionen, absteigend sortiert nach Anzahl Isolaten.

\begin{tabular}{|c|c|c|c|c|c|c|c|c|c|c|c|c|}
\hline \multirow[b]{2}{*}{ Region } & \multicolumn{11}{|c|}{ Rassenspektrum } & \multirow{2}{*}{$\begin{array}{l}\text { Anzahl } \\
\text { Isolate }\end{array}$} \\
\hline & 0 & 1 & 3 & $3 N$ & 13 & 23 & 123 & 2 & 12 & $13 \mathrm{~N}$ & $1 \mathrm{~N}$ & \\
\hline Niederlande/Belgien & 81 & & 9 & 13 & & 1 & & 3 & & & & 107 \\
\hline Süddeutschland/Österreich & 38 & 14 & 25 & 10 & 2 & 2 & 1 & & & & & 92 \\
\hline Oberrheinregion & 21 & 36 & 9 & 10 & & & & & & 1 & & 77 \\
\hline Südwestfrankreich & 24 & 18 & 5 & 29 & & & & & & & & 76 \\
\hline Norddeutschland & 17 & 6 & 16 & 6 & 2 & & & & & & & 47 \\
\hline Zentralfrankreich & 12 & 23 & 6 & 3 & & & & 1 & 1 & & & 46 \\
\hline Bretagne/Normandie & 30 & & 2 & 2 & & & & & & & & 34 \\
\hline Österreich/Ungarn & 3 & 15 & 1 & & 2 & & 2 & & & & 1 & 24 \\
\hline Norditalien & 8 & & 9 & 1 & 1 & 1 & & & & & & 20 \\
\hline Tschechien/Polen & 9 & 7 & & 3 & & & & & & & & 19 \\
\hline Summe & 243 & 119 & 82 & 77 & 7 & 4 & 3 & 4 & 1 & 1 & 1 & 542 \\
\hline
\end{tabular}

Das gesamte Rassenspektrum in den untersuchten Regionen über beide Jahre ist in Tabelle 14 in absoluten Zahlen zusammengefasst und in Tabelle 15 als relative Anteile der verschiedenen Rassen dargestellt. Die beiden Regionen Niederlande/Belgien und Bretagne/Normandie grenzen sich durch ihre sehr hohen Anteile avirulenter Isolate der Rasse 0 von allen anderen Regionen ab. Der Anteil der Rasse 0 liegt in der Region Niederlande/Belgien bei 75,7\% ( $\mathrm{N}=81$ ) und in der Region Bretagne/Normandie bei 88,2\% ( $\mathrm{N}=30$ ). Die Rasse $3 \mathrm{~N}$ hat mit 12,1\% (N=13) in der Region Niederlande/Belgien die zweithöchste Bedeutung. Die verbleibenden Rassen sind in diesen beiden Regionen von untergeordneter Bedeutung. In der Region Süddeutschland/Österreich dominieren die vier Rassen 0 (41,3\%), 3 (27,2\%), 1 (15,2\%) und 3N (10,9\%) mit zusammen 94,6\%. Die Rassen 13, 23 und 123 haben mit maximal 2,2\% in dieser Region eine sehr geringe Bedeutung. Ein Merkmal der Oberrheinregion ist der hohe Anteil der Rasse 1 (46,8\%), gefolgt von der Rasse 0 mit 27,3\%. Zwei weitere Rassen von Bedeutung in dieser Region sind die Rassen 3N (13\%) und die Rasse 3 mit 11,7\%. Die Rasse 13N wurde ausschließlich in dieser Region beschrieben, hat allerdings mit einem Isolat $(1,3 \%)$ kaum Bedeutung. Das Alleinstellungsmerkmal der Region Südwestfrankreich ist der höchste Anteil der Rasse 3N (38,2\%). Zwei weitere bedeutende Rassen dieser Region sind die Rassen 0 (31,6\%) und 1 (23,7\%). Das Gebiet Norddeutschland wird vor allem durch die zwei Rassen $0(36,2 \%)$ und $3(34,0 \%)$ dominiert. Die zwei weiteren Rassen 1 und 3N haben jeweils einen Anteil von 12,8\%. Die fünfte vorkommende Rasse in Norddeutschland (Rasse 13) ist mit einem Anteil von 4,3\% weniger bedeutend. In der Region Zentralfrankeich dominiert die Rasse 1 mit einem Anteil von 50\% deutlich das Rassenspektrum. Daneben sind die Rassen 0 (26,1\%) und 3 (13\%) von Bedeutung. Zudem konnten für diese Region die Rassen 3N mit 6,5\% und die Rassen 2 und 12 mit jeweils 2,2\% nachgewiesen werden. 
Tab.15: Anteile der Rassen von E. turcicum in Prozent in den untersuchten Regionen der Jahre 2011 und 2012.

\begin{tabular}{lcccccccccccc} 
& \multicolumn{10}{c}{ Rassenanteile in \% } & Anzahl \\
\cline { 2 - 9 } Region & $\mathbf{0}$ & $\mathbf{1}$ & $\mathbf{3}$ & $\mathbf{3 N}$ & $\mathbf{1 3}$ & $\mathbf{2 3}$ & $\mathbf{1 2 3}$ & $\mathbf{2}$ & $\mathbf{1 2}$ & $\mathbf{1 3 N}$ & $\mathbf{1 N}$ & Isolate \\
\hline Niederlande/Belgien & 75,7 & - & 8,4 & 12,1 & - & 0,9 & - & 2,8 & - & - & - & 107 \\
Süddeutschland/Österreich & 41,3 & 15,2 & 27,2 & 10,9 & 2,2 & 2,2 & 1,1 & - & - & - & - & 92 \\
Oberrheinregion & 27,3 & 46,8 & 11,7 & 13,0 & - & - & - & - & - & 1,3 & - & 77 \\
Südwestfrankreich & 31,6 & 23,7 & 6,6 & 38,2 & - & - & - & - & - & - & - & 76 \\
Norddeutschland & 36,2 & 12,8 & 34,0 & 12,8 & 4,3 & - & - & - & - & - & - & 47 \\
Zentralfrankreich & 26,1 & 50,0 & 13,0 & 6,5 & - & - & - & 2,2 & 2,2 & - & - & 46 \\
Bretagne/Normandie & 88,2 & - & 5,9 & 5,9 & - & - & - & - & - & - & - & 34 \\
Österreich/Ungarn & 12,5 & 62,5 & 4,2 & - & 8,3 & - & 8,3 & - & - & - & 4,2 & 24 \\
Norditalien & 40,0 & - & 45,0 & 5,0 & 5,0 & 5,0 & - & - & - & - & - & 20 \\
Tschechien/Polen & 47,4 & 36,8 & 0,0 & 15,8 & - & - & - & - & - & - & - & 19 \\
\hline Alle Regionen & 44,8 & $\mathbf{2 2 , 0}$ & $\mathbf{1 5 , 1}$ & $\mathbf{1 4 , 2}$ & $\mathbf{1 , 3}$ & $\mathbf{0 , 7}$ & $\mathbf{0 , 6}$ & $\mathbf{0 , 7}$ & $\mathbf{0 , 2}$ & $\mathbf{0 , 2}$ & $\mathbf{0 , 2}$ & $\mathbf{5 4 2}$
\end{tabular}

Die Region mit dem höchsten Anteil der Rasse 1 mit 62,5\% ist Österreich/Ungarn. Neben der Rasse 1 hat noch die Rasse 0 mit 12,5\% eine nennenswerte Bedeutung. Weitere Rassen der Region sind die Rassen 13 und 123 mit je 8,3\% und 3 bzw. $1 \mathrm{~N}$ mit je 4,2\%. Ähnlich wie in Norddeutschland dominieren auch in Norditalien die Rassen 3 (45\%) und 0 (40\%) das Rassenspektrum deutlich. Weitere Rassen mit je 5\% Anteil sind die Rassen 3N, 13 und 23. In Tschechien/Polen dominiert die Rasse 0 mit 47,4\% das Rassenspektrum, gefolgt von Rasse 1 mit 36,8\% und Rasse 3N mit einem Anteil von 15,8\%. Die Summe der untersuchten Isolate ist für die Regionen Norditalien $(\mathrm{N}=20)$ und Tschechien/Polen $(\mathrm{N}=19)$ am geringsten.

\subsubsection{Regionale Diversität und Komplexität der Rassen}

\section{Rassendiversität}

In Tabelle 16 sind Parameter zur Beschreibung der Diversität der Rassenzusammensetzung zwischen den Regionen und innerhalb der Regionen dargestellt. Der erste Parameter beschreibt den Umfang der Isolatsammlung für jede Region. Anhand dieses Parameters wird deutlich, dass die Größen der Isolat-Sammlungen zwischen den Regionen stark variieren. Die Region mit der größten Anzahl an Isolaten ist die Region Niederlande/Belgien $(\mathrm{N}=107)$ und die mit der geringsten Anzahl ist Tschechien/Polen $(\mathrm{N}=19)$. 
Tab.16: Anzahl Isolate und Rassen von E. turcicum nach Regionen mit Parametern` zur Beschreibung der Rassenverteilung und Diversität in den untersuchten Regionen, Datengrundlage der Jahre 2011 und 2012

\begin{tabular}{lrrrrrrrrrr} 
Region & Isolate & Rassen & $\mathrm{V}_{\mathrm{i}}$ & $\mathrm{V}_{\mathrm{v}}$ & $\mathrm{R}_{1}$ & $\mathrm{R}_{2}$ & $\mathrm{H}_{\mathrm{G}}$ & $\mathrm{H}_{\mathrm{GR}}$ & $\mathrm{H}_{\mathrm{S}}$ & $\mathrm{H}_{\mathrm{SR}}$ \\
\hline Niederlande/Belgien & $\mathbf{1 0 7}$ & 5 & 0,37 & 1,54 & 0,77 & 0,88 & 0,86 & $\underline{0,04}$ & 0,82 & 0,18 \\
Süddeutschland/Österreich & 92 & $\mathbf{7}$ & 0,76 & 1,30 & 0,41 & 0,68 & 1,33 & 0,07 & $\mathbf{1 , 4 6}$ & 0,32 \\
Oberrheinregion & 77 & 4 & 0,88 & 1,21 & 0,47 & 0,74 & 0,69 & 0,04 & 1,28 & 0,30 \\
Südwestfrankreich & 76 & 4 & 1,07 & $\mathbf{1 , 5 6}$ & 0,37 & $\underline{0,68}$ & 0,69 & 0,04 & 1,25 & 0,29 \\
Norddeutschland & 47 & 5 & 0,81 & 1,27 & $\underline{0,36}$ & 0,70 & 1,04 & 0,09 & 1,39 & 0,36 \\
Zentralfrankreich & 46 & 6 & 0,83 & $\underline{1,12}$ & 0,50 & 0,76 & 1,31 & 0,11 & 1,31 & 0,34 \\
Bretagne/Normandie & 34 & $\underline{3}$ & $\underline{0,18}$ & 1,50 & $\mathbf{0 , 8 8}$ & $\mathbf{0 , 9 4}$ & $\underline{0,57}$ & 0,06 & $\underline{0,44}$ & $\underline{0,13}$ \\
Österreich/Ungarn & 24 & 6 & $\mathbf{1 , 1 7}$ & 1,33 & 0,63 & 0,75 & $\mathbf{1 , 5 7}$ & $\mathbf{0 , 2 2}$ & $\mathbf{1 , 2 3}$ & 0,39 \\
Norditalien & 20 & 5 & 0,75 & 1,25 & 0,45 & 0,85 & 1,34 & 0,21 & 1,18 & $\mathbf{0 , 3 9}$ \\
Tschechien/Polen & $\underline{19}$ & $\underline{3}$ & 0,68 & 1,30 & 0,47 & 0,84 & 0,68 & 0,11 & 1,01 & 0,34 \\
\hline Alle Regionen & 542 & 11 & 0,73 & 1,33 & 0,45 & 0,67 & 1,59 & 0,02 & 1,44 & 0,23
\end{tabular}

${ }^{*} \mathrm{~V}_{\mathrm{i}}=$ Mittel der Virulenzkomplexität aller Isolate; $\mathrm{V}_{\mathrm{v}}=$ Mittel der Virulenzkomplexität bezogen auf virulente Isolate (ohne Rasse 0); $\mathrm{R}_{1}=$ Anteil der häufigsten Rasse; $\mathrm{R}_{2}=$ Kumulierter Anteil der zwei häufigsten Rassen; $H_{G}=$ Gleason Index; $H_{G R}=$ relativer Gleason Index; $H_{S}=$ Shannon Index; $H_{S R}=$ relativer Shannon Index

Der Parameter „Rassen“ beschreibt die Anzahl verschiedener Rassen innerhalb der Regionen. Die höchste Anzahl unterschiedlicher Rassen ist für die Region Süddeutschland/Österreich mit sieben beschrieben. Jeweils sechs verschiedene Rassen treten in den Regionen Zentralfrankreich und Österreich/Ungarn auf. Für die Regionen Tschechien/Polen und Bretagne/Normandie sind die geringsten Anzahlen verschiedener Rassen beschrieben worden. Die Virulenzkomplexität aller Isolate $\left(\mathrm{V}_{\mathrm{i}}\right)$ ist am geringsten in der Region Bretagne/Normandie $(0,18)$ und Niederlande/Belgien $(0,37)$ und am höchsten in Österreich/Ungarn $(1,17)$ bzw. in Südwestfrankreich $(1,07)$. Dieses Ergebnis verschiebt sich bei der Berechnung der Virulenzkomplexität bezogen auf virulente Isolate $\left(\mathrm{V}_{\mathrm{v}}\right)$. Hier weisen die Regionen Südwestfrankreich $(1,56)$ und Niederlande/Belgien $(1,54)$ die höchsten Werte auf. Die Regionen Zentralfrankreich $(1,12)$ und die Oberrheinregion $(1,21)$ weisen in diesem Merkmal die geringsten Werte auf. Die Werte der Anteile der häufigsten Rasse $\left(R_{1}\right)$ reichen von $88 \%$ in der Region Bretagne/Normandie bis zu 36\% in Norddeutschland. Der kumulierte Anteil der zwei häufigsten Rassen $\left(\mathrm{R}_{2}\right)$ liegt im Durchschnitt aller untersuchten Regionen bei $67 \%$. Die höchsten Werte liegen bei $94 \%$ bzw. $88 \%$ für die Regionen Bretagne/Normandie bzw. Niederlande/Belgien. Die Regionen mit den geringsten kumulierten Anteilen sind Südwestfrankreich und Süddeutschland/Österreich mit je 68\%.

Der Gleason-Index $\left(\mathrm{H}_{\mathrm{G}}\right)$ ist relativ anfällig gegenüber der Anzahl verschiedener Rassen, ohne deren Anteile zu berücksichtigen. Dementsprechend entfallen die niedrigsten Index- 
Werte auf die Regionen Bretagne/Normandie $(0,57)$ bzw. Tschechien/Polen $(0,68)$, die jeweils lediglich drei verschiedene Rassen aufweisen. Die höchsten Werte des Gleason-Index entfallen auf die Regionen Österreich/Ungarn $(1,57)$ und Norditalien $(1,34)$ mit hohen Anzahlen an verschiedenen Rassen. Die zwei höchsten Werte für den relativen GleasonIndex $\left(\mathrm{H}_{\mathrm{GR}}\right)$ entfallen ebenfalls auf die Regionen Österreich/Ungarn $(0,22)$ und Norditalien $(0,21)$. Die niedrigsten Werte entfallen auf die Oberrheinregion, Niederlande/Belgien und Südwestfrankreich mit je 0,04. Gegenüber dem Gleason-Index berücksichtigt der ShannonIndex neben der Anzahl der verschiedenen Rassen auch deren Anteil in der untersuchten Population. Die geringsten Werte des Shannon-Index entfallen auf die Regionen Bretagne/Normandie $(0,44)$ und Niederlande/Belgien $(0,82)$. Die Regionen Süddeutschland/Österreich $(1,46)$ und Norddeutschland $(1,39)$ erreichen die höchsten Werte. Für den relativen Shannon-Index entfallen die niedrigsten Werte ebenfalls auf die beiden Regionen Bretagne/Normandie $(0,13)$ und Niederlande/Belgien $(0,18)$. Die höchsten Werte entfallen, anders als beim Shannon-Index, auf die Regionen Norditalien $(0,39)$ und Österreich/Ungarn $(0,39)$.

Lineare Korrelationskoeffizienten zu den beschriebenen Diversitätsparametern sind in Tabelle 17 aufgelistet. Der Parameter "Isolate“ zeigte eine signifikante negative Korrelation mit den relativen Gleason Index $\left(\mathrm{H}_{\mathrm{GR}}\right)$. Das Merkmal „Rassen“ korrelierte signifikant mit beiden Diversitätsindizes. Aufgrund der Berechnung des Gleason-Index war die deutlich höhere Korrelation in diesem Fall zu erwarten. Die Virulenzkomplexität aller Isolate korrelierte signifikant mit den Anteilen der häufigsten Rassen. Darüber hinaus wies das Merkmal

Tab.17: Korrelationskoeffizienten der Parameter ${ }^{\mathrm{a}}$ zur Beschreibung der Rassenverteilung und Diversität von E. turcicum, $\mathbf{N}=542$ Isolate aus 10 Regionen

\begin{tabular}{|c|c|c|c|c|c|c|c|c|c|}
\hline & Isolate & Rassen & $v_{i}$ & $\mathbf{V}_{\mathrm{v}}$ & $\mathbf{R}_{\mathbf{1}}$ & $\mathbf{R}_{\mathbf{2}}$ & $\mathrm{H}_{\mathrm{G}}$ & $\mathrm{H}_{\mathrm{s}}$ & $\mathrm{H}_{\mathrm{GR}}$ \\
\hline Rassen & 0,275 & & & & & & & & \\
\hline$V_{i}$ & $-0,110$ & 0,386 & & & & & & & \\
\hline $\mathbf{V}_{\mathbf{v}}$ & 0,346 & $-0,375$ & $-0,351$ & & & & & & \\
\hline $\mathbf{R}_{1}$ & $-0,014$ & $-0,260$ & $-0,698^{*}$ & 0,474 & & & & & \\
\hline $\mathbf{R}_{\mathbf{2}}$ & $-0,299$ & $-0,515$ & $-0,801^{* *}$ & 0,298 & $0,796^{* *}$ & & & & \\
\hline $\mathrm{HG}_{\mathrm{G}}$ & $-0,202$ & $0,869^{\star \star}$ & 0,481 & $-0,492$ & $-0,226$ & $-0,336$ & & & \\
\hline $\mathrm{Hs}_{\mathrm{s}}$ & 0,140 & $0,632^{*}$ & $0,807^{* *}$ & $-0,586$ & $-0,879^{\star \star *}$ & $-0,905^{\star \star *}$ & 0,551 & & \\
\hline $\mathrm{H}_{\mathrm{GR}}$ & $-0,743^{*}$ & 0,295 & 0,379 & $-0,400$ & $-0,072$ & 0,087 & $0,627^{*}$ & 0,179 & \\
\hline$H_{S R}$ & $-0,423$ & 0,439 & 0,786 & $-0,682^{*}$ & $-0,759^{*}$ & $-0,572$ & $0,663^{*}$ & $0,804^{* *}$ & $0,668^{*}$ \\
\hline
\end{tabular}

${ }^{\text {a }}$ Beschreibung der Parameter: Isolate = Anzahl Isolate je Region, Rassen = Anzahl verschiedener Rassen je Region, $V_{i}=$ Mittel der Virulenzkomplexität aller Isolate, $V_{v}=$ Mittel der Virulenzkomplexität bezogen auf virulente Isolate (ohne Rasse 0 ), $\mathbf{R}_{\mathbf{1}}=$ Anteil der häufigsten Rasse, $\mathbf{R}_{\mathbf{2}}=$ Kumulierter Anteil der zwei häufigsten Rassen, $\mathrm{H}_{\mathrm{G}}=$ Gleason Index; HS = Shannon Index, $\mathrm{H}_{\mathrm{GR}}=$ relativer Gleason Index, $H_{s R}=$ relativer Shannon Index; Signifikante Koeffizienten sind gekennzeichnet mit * $=p \leq 0,05,{ }^{* *}=p \leq 0,01$, $* * *=0,001$ 
Virulenzkomplexität einen starken Zusammenhang ( $p \leq 0,01)$ zum Shannon-Diversitätsindex auf. Die Virulenzkomplexität der virulenten Isolate korrelierte mit dem relativen Shannon-Index $\left(\mathrm{H}_{\mathrm{SR}}\right)$. Das Merkmal $\mathrm{R}_{1}$ weist sehr starke negative Korrelationen zu den Parametern $R_{2}$, und $H_{s}$ auf. Darüber hinaus weist $R_{1}$ einen negativen Zusammenhang zum Merkmal $\mathrm{H}_{\mathrm{SR}}$ auf. Der Zusammenhang zwischen dem kumulierten Anteil der zwei häufigsten Rassen $\left(R_{2}\right)$ und dem Shannon-Diversitäts-Index ist mit -0,905 der höchste Korrelationskoeffizient unter den untersuchten Merkmalen. Er ist signifikant bei $p \leq 0,001$. Der lineare Zusammenhang dieser beiden Merkmale ist grafisch in Abbildung 15 dargestellt. Sowohl der Gleason $\left(\mathrm{H}_{\mathrm{G}}\right)$ als auch der Shannon-Diversität-Index $\left(\mathrm{H}_{\mathrm{S}}\right)$ weisen erwartungsgemäß hohe und signifikante Korrelationen mit ihren jeweils auf relativer Basis umgerechneten Indizes $\mathrm{H}_{\mathrm{GR}}$ und $\mathrm{H}_{\mathrm{SR}}$ auf. Zwischen den beiden relativen Indizes besteht ebenfalls ein signifikanter $(p \leq 0,05)$ Zusammenhang. Es besteht hingegen kein Zusammenhang zwischen den beiden normalen Gleason $\left(\mathrm{H}_{\mathrm{G}}\right)$ und Shannon Diversitäts-Indizes $\left(\mathrm{H}_{\mathrm{S}}\right)$.

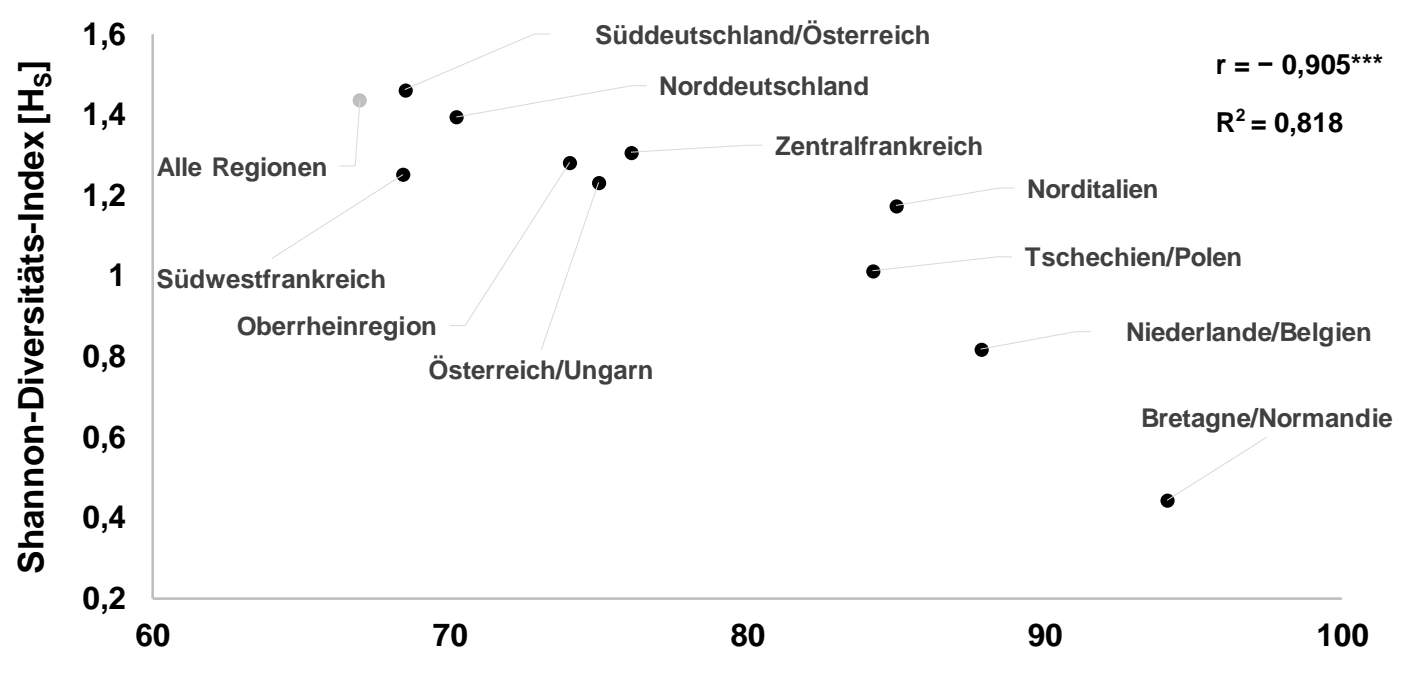

Kumulierter Anteil der zwei häufigsten Rassen $\mathbf{R}_{\mathbf{2}}[\%]$

Abb. 15: Korrelation des Shannon-Diversitäts-Index $\left[\mathrm{H}_{\mathrm{s}}\right]$ mit dem kumulierten Anteil der zwei häufigsten Rassen [ $R_{2}$ ], N = 542 Isolate aus den Jahren 2011 und 2012, ${ }^{\star \star \star}=$ Korrelationskoeffizient signifikant bei $p \leq 0,001$.

\section{Virulenzkomplexität}

Die Virulenzkomplexität (Vk) beschreibt die Anzahl an Virulenzen je Isolat. In Abbildung 16 sind die Anteile der unterschiedlichen Vk in den untersuchten Regionen dargestellt. In den beiden Regionen Bretagne/Normandie und Niederlande/Belgien dominieren avirulente Iso- 


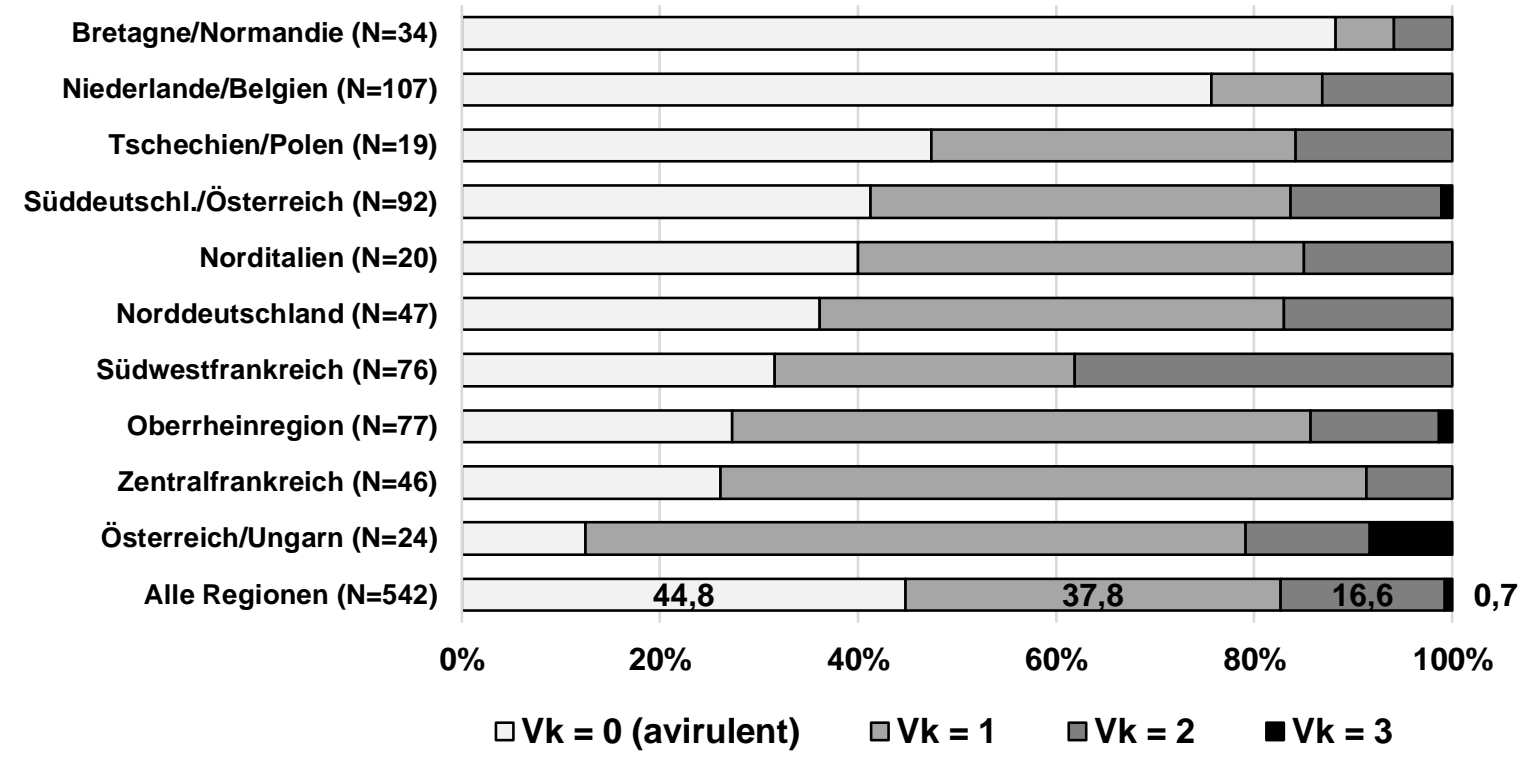

Abb. 16: Anteil verschiedener Virulenzkomlexitäten (Vk) von E. turcicum Isolaten nach Regionen, Daten aus den Jahren 2011 und 2012, absteigend sortiert nach dem Anteil an Isolaten mit der Virulenzkomplexität $\mathbf{V k}=\mathbf{0}$.

late mit einer Vk = 0. Die folgenden vier Regionen (Tschechien/Polen, Süddeutschland/Österreich, Norditalien, Norddeutschland) weisen alle sehr ähnliche Anteile der Vk auf. In dieser Gruppe reichen die Anteile der Isolate mit einer $\mathrm{Vk}=1$ von 37 bis $47 \%$ und die Anteile der Isolate mit einer Vk = 2 von 15 bis 17\%. Einzig die Region Süddeutschland/Österreich weist zudem etwa $1 \%$ Isolate auf mit einer $\mathrm{Vk}=3$. Die Region Südwestfrankreich hat mit $38,2 \%$ den höchsten Anteil an Isolaten, die zwei Virulenzen in sich tragen. Die Gruppe der letzten drei Regionen (Oberrheinregion, Zentralfrankreich, Österreich/Ungarn) haben die Gemeinsamkeit, dass dort sehr hohe Anteile von Isolaten mit einer einzigen Virulenz (Vk = 1) zu finden sind. Den höchsten Anteil dieser Kategorie weist die Region Österreich/Ungarn mit einem Anteil von 66,7\% auf. Zudem tragen in dieser Region 8,3\% der Isolate 3 Virulenzen. Auch dieser Wert ist der höchste unter allen untersuchten Regionen. Lediglich 12,5\% der Isolate in der Region Österreich/Ungarn sind nicht in der Lage, eines der getesteten Resistenzgene zu überwinden.

\subsubsection{Regionale Wirksamkeit der Resistenzgene}

Die Virulenzfrequenz beschreibt die Häufigkeit, mit der ein Resistenzgen in einer geographisch definierten Region von einem Isolat überwunden wird. Mit Hilfe dieses Merkmals können konkrete Aussagen über die regionale Wirksamkeit eines Resistenzgens getätigt werden. Die Virulenzfrequenzen für die Resistenzgene $\mathrm{Ht} 1, \mathrm{Ht} 2, \mathrm{Ht} 3$ und $\mathrm{HtN}$ in den untersuchten Regionen sind in Tabelle 18 dargestellt. 
Tab. 18: Virulenzfrequenzen (\%) von E. turcicum Isolaten nach Regionen für die Resistenzgene Ht1, Ht2, Ht3 und HtN, Mittelwerte der Jahre 2011 und 2012, absteigend sortiert nach Ht1.

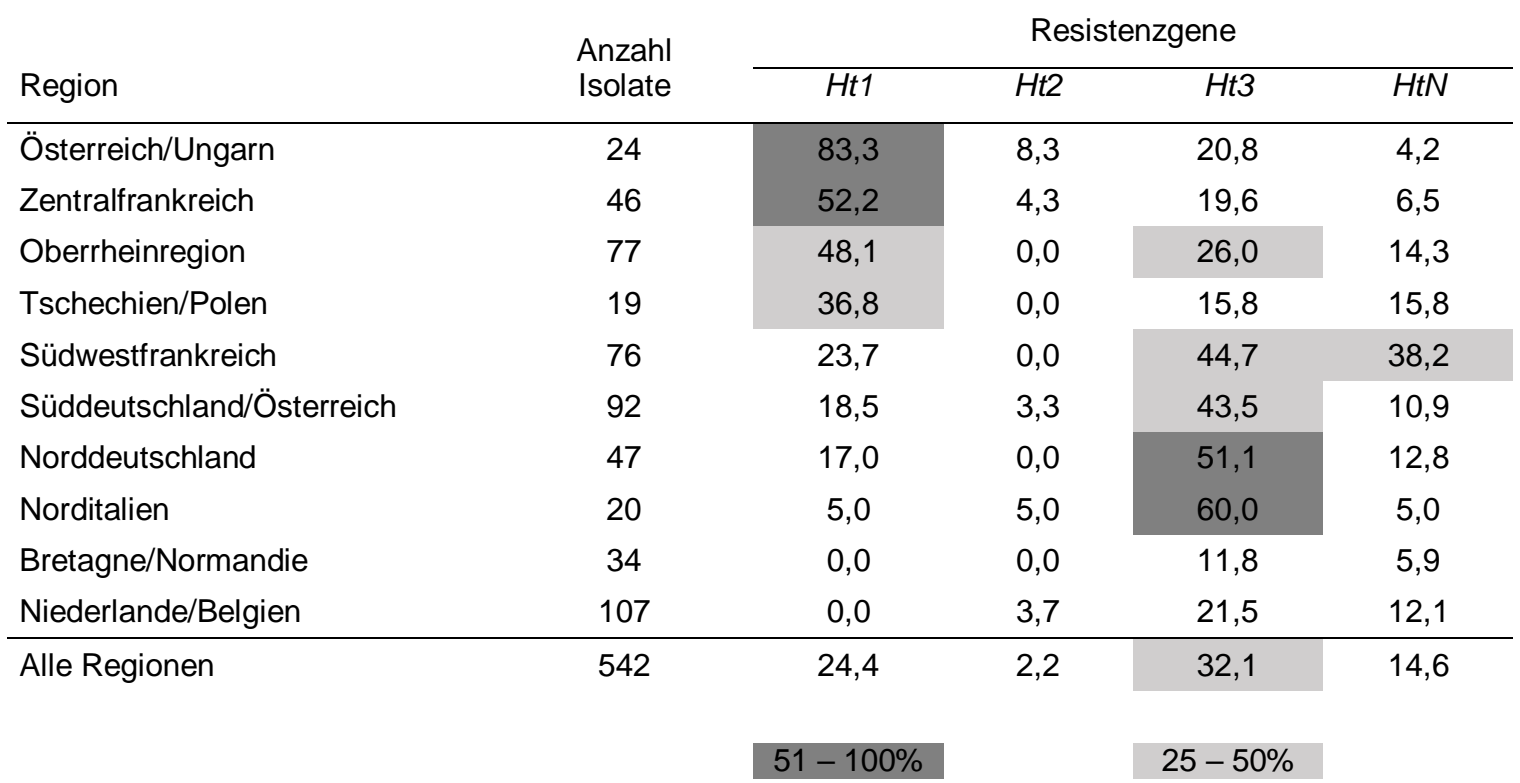

Alle Werte über 50\% sind dunkelgrau und alle Werte zwischen $25 \%$ und $50 \%$ sind hellgrau hervorgehoben. Für das Resistenzgen $\mathrm{Ht} 1$ konnten die höchsten Wirksamkeitsverluste in den Regionen Österreich/Ungarn (83,3\%) und Zentralfrankreich mit 52,2\% nachgewiesen werden. Darüber hinaus zeigen die Oberrheinregion mit 48,1\% und Tschechien/Polen mit $36,8 \%$ hohe Virulenzfrequenzen für das Resistenzgen $H t 1$. In allen anderen Regionen zeigte das Resistenzgen Ht1 in den Jahren 2011 und 2012 eine Wirksamkeit gegenüber wenigstens $75 \%$ der untersuchten Isolate. In den nördlichen Küstenregionen Bretagne/Normandie und Niederlande/Belgien erwies sich das Resistenzgen Ht1 als wirksam gegenüber $100 \%$ der untersuchten Isolate. Das Resistenzgen Ht2 zeigt mit einer Virulenzfrequenz von 2,2\% als Mittelwert über alle Regionen und beide Jahre die höchste Wirksamkeit unter den getesteten Resistenzgenen. Die höchste Virulenzfrequenz für Ht2 wurde für die Region Österreich/Ungarn mit 8,3\% beschrieben. In allen anderen Regionen war Ht2 gegenüber mindestens 95\% der Isolate wirksam. Das Resistenzgen Ht3 weist im Durchschnitt mit 32,1\% die höchste Virulenzfrequenz auf. Insbesondere für die Regionen Norditalien (60\%) und Norddeutschland $(51,1 \%)$ wird für Ht3 ein deutlicher Wirksamkeitsverlust festgestellt. Die Regionen Südwestfrankreich (44,7\%), Süddeutschland/Österreich $(43,5 \%)$ und die Oberrheinregion (26\%) sind ebenfalls durch erhöhte Virulenzfrequenzen gegenüber Ht3 gekennzeichnet. Die höchste Wirksamkeit von Ht3 wurde für die Region Bretagne/Normandie mit lediglich $11,8 \%$ virulenten Isolaten festgestellt. Für das Resistenzgen $H t N$ wurden genau wie für Ht3 in allen Regionen virulente Isolate nachgewiesen. Die höchste Virulenzfrequenz 
für $\mathrm{HtN}$ erreicht mit Abstand die Region Südwestfrankreich mit 38,2\%. Alle anderen Regionen weisen Werte von unter $16 \%$ für $\mathrm{HtN}$ auf. Die höchste Wirksamkeit zeigt $\mathrm{HtN}$ in der Region Österreich/Ungarn mit einer Virulenzfrequenz von 4,2\%.

\subsubsection{Feldbonitur verschiedener Ht-Differentialsortimente}

Durch Anbau und Bonitur von Differentialsortimenten im Feld ist es möglich, die gewonnenen Ergebnisse aus dem Gewächshausscreening auf ihre Übertragbarkeit für das Feld zu beurteilen. In Tabelle 19 sind die Ergebnisse von Feldbonituren verschiedener Differentialsortimente aus sechs verschiedenen Regionen dargestellt. Je dunkler die Zellen schattiert sind, desto höher lag die Befallsstärke in der Region für die jeweilige Differentiallinie. Die Werte über alle Regionen weisen für die Linien mit den Resistenzgenen $\mathrm{Ht} 1$ und $\mathrm{Ht3}$ mit Noten von 4,0 und 3,8 den höchsten Befall auf. Diese Werte variieren zwischen den Regionen deutlich. So weisen die Regionen Österreich/Ungarn und die Oberrheinregion jeweils den höchsten Befall auf Linien mit den Resistenzgenen Ht1 und Ht3 auf. Den höchsten Befallswert auf einer Linie mit $\mathrm{Ht}$-Gen für alle Regionen erreicht die Region Österreich/Ungarn mit der Note 6,0 für das Resistenzgen Ht1. In dieser Region wurde ebenfalls auf den Linien ohne Resistenzgen der höchste Befall bonitiert. Einen ebenfalls hohen Befall für Ht1 wies die Oberrheinregion mit 4,9 auf. In Südwestfrankreich zeigten alle Linien sowohl mit als auch ohne Resistenzgen einen wenig differenzierenden Befall zwischen 3,5 und 5,0. Der höchste Befall wurde in dieser Region für die Linien mit dem Resistenzgen Ht3 festgestellt. Die südwestfranzösische Region ist durch die höchsten Werte für die Resistenzgene $H t 3$ und $H t N$ mit 5,0 und 4,0 gekennzeichnet. Für die Grenzregion zwischen Deutschland

Tab. 19: Boniturergebnisse des regionalen Anbaus der Differentiallinien mit den $\mathrm{Ht}$-Resistenzgenen $H t 1, H t 2, H t 3$ und $H t N$ und der rekurrenten Eltern ohne $H t$-Gen, nach Regionen, \pm Standardabweichung, Boniturskala $1-9$, dunklere Schattierungen kennzeichnen höheren Befall.

Resistenzgene der Differentiallinien

\begin{tabular}{lccccc}
\cline { 2 - 6 } Region & ohne Ht-Gen & $H t 1$ & $H t 2$ & $H t 3$ & $H t N$ \\
\hline Österreich/Ungarn & $7,3 \pm 1,2$ & $6,0 \pm 0,7$ & $2,0 \pm 0,0$ & $3,8 \pm 0,4$ & $1,5 \pm 0,8$ \\
Oberrheinregion & $4,7 \pm 0,8$ & $4,9 \pm 0,7$ & $3,3 \pm 1,1$ & $4,3 \pm 0,6$ & $1,0 \pm 0,0$ \\
Südwestfrankreich & $4,0 \pm 0,0$ & $3,5 \pm 0,5$ & $3,5 \pm 0,5$ & $5,0 \pm 0,0$ & $4,0 \pm 0,0$ \\
Süddeutschl./Österreich & $5,6 \pm 1,4$ & $4,0 \pm 1,0$ & $2,3 \pm 0,9$ & $3,6 \pm 1,0$ & $2,3 \pm 0,7$ \\
Norddeutschland & $3,3 \pm 2,3$ & $2,5 \pm 1,1$ & $4,0 \pm 2,3$ & $2,8 \pm 1,1$ & $2,5 \pm 1,5$ \\
Niederlande/Belgien & $2,7 \pm 0,9$ & $3,2 \pm 1,3$ & $3,2 \pm 1,1$ & $3,7 \pm 0,9$ & - \\
\hline Alle Regionen & $4,6 \pm 2,1$ & $4,0 \pm 1,4$ & $3,0 \pm 1,4$ & $3,8 \pm 1,0$ & $2,3 \pm 1,1$ \\
\multicolumn{1}{c}{ Kategorien Befallsstärke: } & $1-3,4$ & $3,5-4,4$ & $4,5-5,4$ & $5,5-9$
\end{tabular}


und Österreich im Inntal wurde erhöhter Befall für die Linien mit den Resistenzgenen Ht1 und Ht3 festgestellt. Die beiden nördlichen Regionen Norddeutschland und Niederlande/Belgien fallen durch vergleichsweise geringen Befall auf den Linien ohne Resistenzgen auf. Dennoch wurde in der Region Norddeutschland der höchste Befall auf den Linien mit dem Resistenzgen Ht2 festgestellt. Die Region Niederlande/Belgien weist einen leicht erhöhten Befall für das Resistenzgen $\mathrm{Ht3}$ auf. 


\subsection{Temperatureinfluss auf die Wirksamkeit der Resistenzgene gegen E. turcicum}

\subsubsection{Temperatureinfluss auf die Wirksamkeit der Gene Ht1, Ht2, Ht3 und HtN}

In Klimakammerversuchen wurde der Einfluss verschiedener Temperaturen auf die Wirksamkeit der Resistenzgene $\mathrm{Ht1}, \mathrm{Ht} 2, \mathrm{Ht} 3$ und $\mathrm{HtN}$ im genetischen Hintergrund der Maislinie B37 an Ganzpflanzen untersucht. Der untersuchte Temperaturbereich reichte in $5^{\circ} \mathrm{C}$-Schritten von $15^{\circ} \mathrm{C}$ bis $30^{\circ} \mathrm{C}$. Die Ergebnisse der qualitativen Virulenzeinstufungen der untersuchten Isolate sind in Tabelle 20 zusammengefasst. In der rechten Spalte sind die Ergebnisse des Rassenscreenings der Isolate dargestellt. In den Spalten links davon sind die Virulenzeinstufungen für jede Temperatur dargestellt. Grau hinterlegte Felder signalisieren Abweichungen zwischen der Einstufung im Rassenscreening und den untersuchten Temperaturvarianten. Für die Resistenzgene $H t 1$ und $H t N$ wurde eine sehr stabile Wirkung ohne Abweichungen über den gesamten Temperaturbereich für alle Isolate festgestellt. Für das Resistenzgen $H t 3$ wurde im niedrigen Temperaturbereich von $15 / 10^{\circ} \mathrm{C}$ ein heterogener Wirksamkeitsverlust festgestellt. In diesem Fall wurde das eigentlich avirulente Isolat 76-4 auf sieben der 12 Wiederholungen als virulent eingestuft. Demgegenüber wurde das virulente Isolat $48-1$ in der hohen Temperaturvariante $30 / 25^{\circ} \mathrm{C}$ in allen 12 Wiederholungen als avirulent eingestuft. Bei $H t 3$ führten in diesem Versuch sehr niedrige Temperaturen zu einem

Tab. 20: Einstufung der Virulenzeigenschaften verschiedener Isolate auf dem Differentialsortiment bei unterschiedlichen Temperaturen; $A=$ avirulent, $V=$ virulent, $A / V=$ heterogene Symptomausprägung zwischen den Wiederholungen $(n=12)$.

\begin{tabular}{|c|c|c|c|c|c|c|}
\hline \multirow[b]{2}{*}{ Isolat } & \multirow[b]{2}{*}{ Linie } & \multicolumn{4}{|c|}{ Temperatur in ${ }^{\circ} \mathrm{C}$ (Tag/Nacht) $12 \mathrm{~h}$} & \multirow{2}{*}{$\begin{array}{c}\text { Ergebnis } \\
\text { Rassenscreening } \\
24 / 20^{\circ} \mathrm{C}\end{array}$} \\
\hline & & $30 / 25$ & $25 / 20$ & $20 / 15$ & $15 / 10$ & \\
\hline \multirow{4}{*}{$\begin{array}{c}\text { 76-4 } \\
\text { Rasse } 0 \\
\text { avirulent }\end{array}$} & B37 Ht1 & A & A & A & A & A \\
\hline & B37 Ht2 & A & A & V & V & A \\
\hline & B37 Ht3 & A & A & A & $\mathrm{A} / \mathrm{V}$ & A \\
\hline & B37 HtN & A & A & A & A & A \\
\hline \multirow{4}{*}{$\begin{array}{c}48-1 \\
\text { Rasse } 123\end{array}$} & B37 Ht1 & $\mathrm{V}$ & V & V & V & V \\
\hline & B37 Ht2 & A & $\mathrm{A} / \mathrm{V}$ & V & V & V \\
\hline & B37 Ht3 & A & V & $\mathrm{V}$ & $\mathrm{v}$ & $\mathrm{v}$ \\
\hline & $\mathrm{B} 37 \mathrm{HtN}$ & A & A & A & A & A \\
\hline \multirow{4}{*}{$\begin{array}{c}25-3 \\
\text { Rasse 3N }\end{array}$} & B37 Ht1 & A & A & $A$ & A & A \\
\hline & B37 Ht2 & A & A & $\mathrm{A} / \mathrm{V}$ & V & A \\
\hline & B37 Ht3 & v & V & V & V & V \\
\hline & B37 HtN & V & V & $\mathrm{V}$ & V & V \\
\hline
\end{tabular}

$=$ Abweichung von Virulenzeigenschaften unter Standardbedingungen $24 / 20^{\circ} \mathrm{C}$ 
geringfügigen Wirksamkeitsverlust und hohe Temperaturen zu einer Steigerung der Wirksamkeit. Ein Verlust der Virulenz wurde auch für das virulente Isolat 48-1 gegenüber dem Resistenzgen $H t 2$ bei hohen $\left(25 / 20^{\circ} \mathrm{C}\right)$ und sehr hohen $\left(30 / 25^{\circ} \mathrm{C}\right)$ Temperaturen festgestellt. In der $25 / 20^{\circ} \mathrm{C}$ Variante wurde das Isolat $48-1$ in sieben der zwölf Wiederholungen auf $\mathrm{Ht} 2$ als avirulent eingestuft. In der höchsten Temperaturvariante wurden einheitlich alle zwölf Wiederholungen als avirulent bewertet. Diese Ergebnisse belegen einen Verlust der Virulenz gegenüber $H t 2$ bei Temperaturen über $25^{\circ} \mathrm{C}$. Die Ergebnisse zeigen, dass $H t 2$ insbesondere in den niedrigen Temperaturvarianten durch Wirksamkeitsverluste gekennzeichnet ist. Das avirulente Isolat 76-4 wurde in den beiden niedrigen Temperaturvarianten $20 / 15^{\circ} \mathrm{C}$ und $15 / 10^{\circ} \mathrm{C}$ auf $\mathrm{Ht} 2$ einheitlich als virulent beurteilt. Ähnliche Ergebnisse zeigt auch das avirulente Isolat 25-3 für $\mathrm{Ht2}$, das in der niedrigsten Temperaturvariante einheitlich als virulent und in der Variante $20 / 15^{\circ} \mathrm{C}$ in acht von zwölf Wiederholungen als virulent bewertet wurde. Diese Ergebnisse weisen auf einen deutlichen Wirksamkeitsverlust des Resistenzgens $\mathrm{Ht} 2$ bei Temperaturen unter $20^{\circ} \mathrm{C}$ hin.

Durch die Bewertung der Befallsstärke von E. turcicum auf der anfälligen Maislinie B37 wurde in diesem Klimakammerversuch ebenfalls die Wirkung der Temperatur auf den quantitativen Befall bestimmt. Die Boniturergebnisse dazu sind in Abbildung 17 als Befallsstärke und als Befallsverlauf über den Versuchszeitraum mit Hilfe von AUDPC Werten dargestellt. Die Befallsstärke lag 16 Tage nach Inokulation in der $15 / 10^{\circ} \mathrm{C}$ Variante bei $12,5 \%$ und in allen wärmeren Varianten ohne signifikante Unterschiede zwischen 57\% und 47\%. Bereits vier Tage später zum Zeitpunkt 20dpi lag die Befallsstärke in der niedrigsten Temperaturvariante bereits bei $42 \%$. Die Werte für die zwei Temperaturvarianten $20 / 15$ und $25 / 20^{\circ} \mathrm{C}$

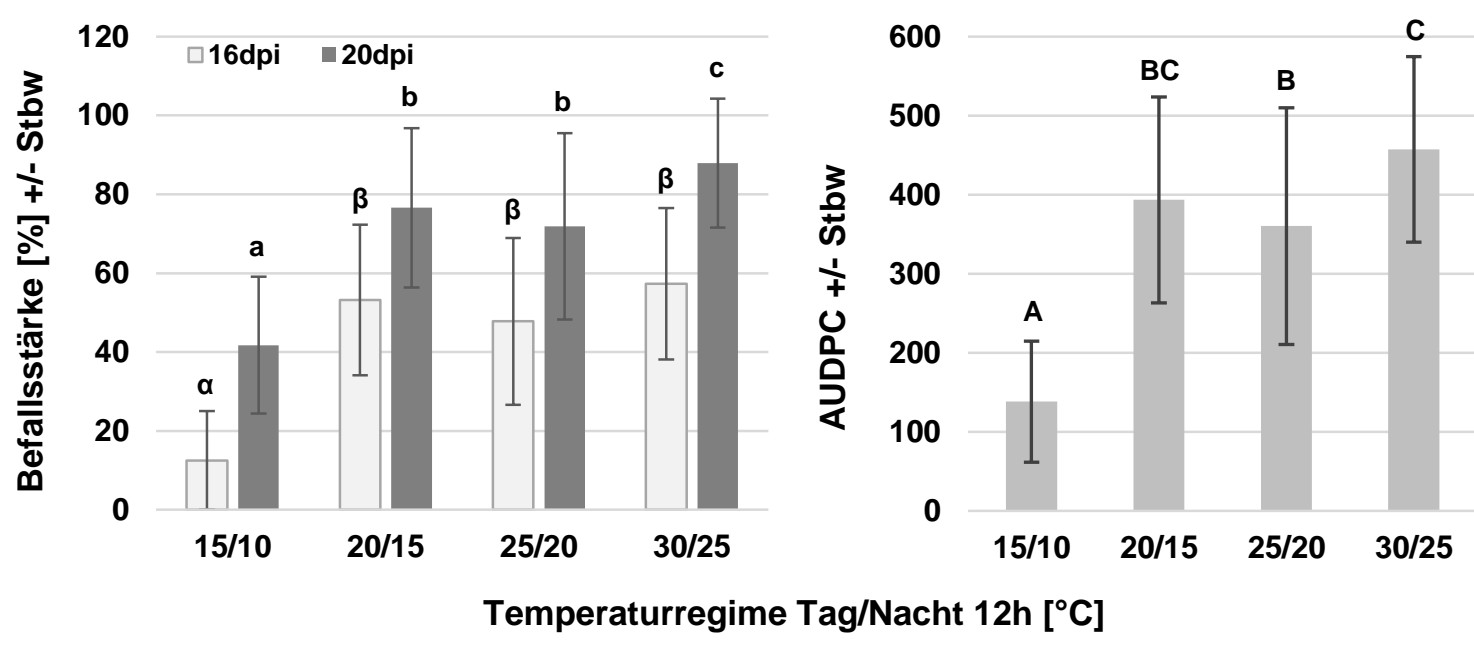

Abb. 17: Temperatureinfluss auf die Aggressivität von E. turcicum am Genotyp B37, Mittelwert aus drei Isolaten, links: Befallsstärke in Prozent an den Zeitpunkten 16 und 20 dpi; rechts: AUDPC Werte nach $20 \mathrm{dpi}$; unterschiedliche Buchstaben kennzeichnen signifikante Unterschiede zwischen den Temperaturen (Tukey-Test, $p \leq 0,05$ ), $n=36$. 
lagen bei $77 \%$ und $72 \%$ und unterschieden sich nicht signifikant voneinander. In der Variante mit der höchsten Temperatur $\left(30 / 25^{\circ} \mathrm{C}\right)$ reagierte E. turcicum zum Zeitpunkt 20 dpi mit signifikant höheren Befallswerten (88\%) verglichen mit den geringeren Temperaturen. Der gesamte Befallsverlauf bis zum Zeitpunkt 20 dpi als AUDPC Werte zeigt ein ähnliches Bild. Die Werte der $15 / 10^{\circ} \mathrm{C}$ Variante unterscheiden sich signifikant von allen anderen Temperaturen. Die höchste Temperaturvariante zeigt auch den höchsten AUDPC-Wert, aber grenzt sich lediglich von der Variante $25 / 20^{\circ} \mathrm{C}$ signifikant ab. Die AUDPC-Werte in den Varianten $30 / 25^{\circ} \mathrm{C}$ und $20 / 15^{\circ} \mathrm{C}$ unterscheiden sich nicht signifikant voneinander. In Abbildung 12 wurde die optimale in vitro Wachstumstemperatur von E. turcicum für den Bereich $20^{\circ}$ bis $24^{\circ} \mathrm{C}$ definiert. Die optimale in planta Besiedlungstemperatur von E. turcicum lässt sich auf Basis dieses Versuchs lediglich für den Bereich über $20^{\circ} \mathrm{C}$ festlegen, wobei tendenziell höhere Temperaturen über $25^{\circ} \mathrm{C}$ förderlich für den Befallsverlauf sind. Eine Eingrenzung auf einen schmalen optimalen Temperaturbereich ist auf Basis dieser Ergebnisse nicht eindeutig möglich.

\subsubsection{Spezifischer Temperatureinfluss auf das Resistenzgen Ht2}

In einem weiteren Klimakammerversuch wurden nur die Pflanzen vor der Inokulation für eine Dauer von zehn Tagen den unterschiedlichen Temperaturen ausgesetzt. Ab dem Zeitpunkt der Inokulation herrschten einheitlich für den gesamten Versuch und die gesamte Versuchsdauer $25 / 20^{\circ} \mathrm{C}$ Tag/Nacht in einem $12 \mathrm{~h}$ Rhythmus. Die Ergebnisse der qualitativen Virulenzeinstufung und der nekrotisierten Blattfläche (Befallsstärke) auf dem Genotyp B37-Ht2 sind in Tabelle 21 dargestellt. Das avirulente Isolat 76-4 wurde an beiden Boniturterminen 17 und $21 \mathrm{dpi}$ in der hohen Temperaturvariante $30 / 25^{\circ} \mathrm{C}$ als avirulent eingestuft. In der niedrigen Variante $20 / 15^{\circ} \mathrm{C}$ zum Zeitpunkt 17 dpi wurde das Isolat ebenfalls einheitlich als avirulent eingestuft. Nach weiteren vier Tagen zum Zeitpunkt $21 \mathrm{dpi}$ wurde das Isolat aufgrund der Befallsreaktion in elf von 16 Wiederholungen als virulent eingestuft.

Tab. 21: Virulenzeigenschaften von zwei E. turcicum Isolaten auf der Maislinie B37-Ht2, Behandlung der Maispflanzen für 10 Tage vor der Inokulation mit hohen $\left(30 / 25^{\circ} \mathrm{C}\right)$ und niedrigen $\left(20 / 15^{\circ} \mathrm{C}\right)$ Temperaturen (Tag/Nacht, $\left.12 \mathrm{~h}\right), \mathrm{n}=16$.

\begin{tabular}{|c|c|c|c|c|c|}
\hline \multirow[b]{2}{*}{ Isolat } & \multirow[b]{2}{*}{ Temperatur } & \multicolumn{2}{|c|}{ Virulenzeinstufung* } & \multicolumn{2}{|c|}{ Befallsstärke \% } \\
\hline & & $17 \mathrm{dpi}$ & $21 \mathrm{dpi}$ & $17 \mathrm{dpi}$ & $21 \mathrm{dpi}$ \\
\hline \multirow{2}{*}{$\begin{array}{l}\text { Isolat 76-4 } \\
\text { (avr) }\end{array}$} & $20 / 15^{\circ} \mathrm{C}$ & avr & avr/vir & 1,3 & 3,3 \\
\hline & $30 / 25^{\circ} \mathrm{C}$ & avr & avr & 0,0 & 0,0 \\
\hline \multirow{2}{*}{$\begin{array}{l}\text { Isolat } 48-1 \\
\text { (vir) }\end{array}$} & $20 / 15^{\circ} \mathrm{C}$ & vir & vir & 7,9 & 16,0 \\
\hline & $30 / 25^{\circ} \mathrm{C}$ & avr & avr/vir & 0,4 & 4,4 \\
\hline
\end{tabular}


Die qualitative Bewertung der Befallsreaktionen für das Isolat 76-4 bei niedrigen Temperaturen war demnach in diesem Versuch weniger eindeutig als im vorherigen Klimakammerversuch (siehe Tabelle 20), in dem sowohl die Pflanze als auch der Pilz den unterschiedlichen Temperaturen ausgesetzt waren. Die Werte der Befallsstärke mit 3,3\% zum Zeitpunkt 21dpi verdeutlichen den sehr geringen Befall durch das Isolat 76-4 selbst in der niedrigen Temperaturvariante, in der das Resistenzgen $H t 2$ an Wirksamkeit verloren hat. Die Virulenzeinstufungen für das virulente Isolat 48-1 wurden in der niedrigen Temperaturvariante an beiden Zeitpunkten als virulent bestätigt. In der wärmeren $30 / 25^{\circ} \mathrm{C}$ Variante hingegen wurde das Isolat zum Zeitpunkt $17 \mathrm{dpi}$ einheitlich als avirulent eingestuft. Zum Zeitpunkt 21 dpi hingegen fiel diese Einstufung nicht einheitlich aus. In diesem Fall wurde das Isolat 48-1 in zehn der 16 Wiederholungen als avirulent eingestuft. Die Befallsstärke wurde für das virulente Isolat 48-1 zum Zeitpunkt 21 dpi durch die erhöhte Temperatur von $16 \%$ auf $4,4 \%$ reduziert. Der Wirksamkeitsverlust bei niedrigen Temperaturen bzw. die Steigerung der Wirksamkeit bei höheren Temperaturen konnte in diesem Versuch bestätigt werden, wenngleich der Wirksamkeitsverlust bei niedrigen Temperaturen in diesem Fall weniger deutlich ausfällt, verglichen mit den Versuchsergebnissen des vorherigen Versuchs (siehe Tabelle 20).

In Abbildung 18 sind die Ergebnisse der quantitativen Befallserfassung als Befallsstärke in Prozent nekrotisierter Blattfläche zum Zeitpunkt 21 dpi dargestellt. Sowohl für das virulente

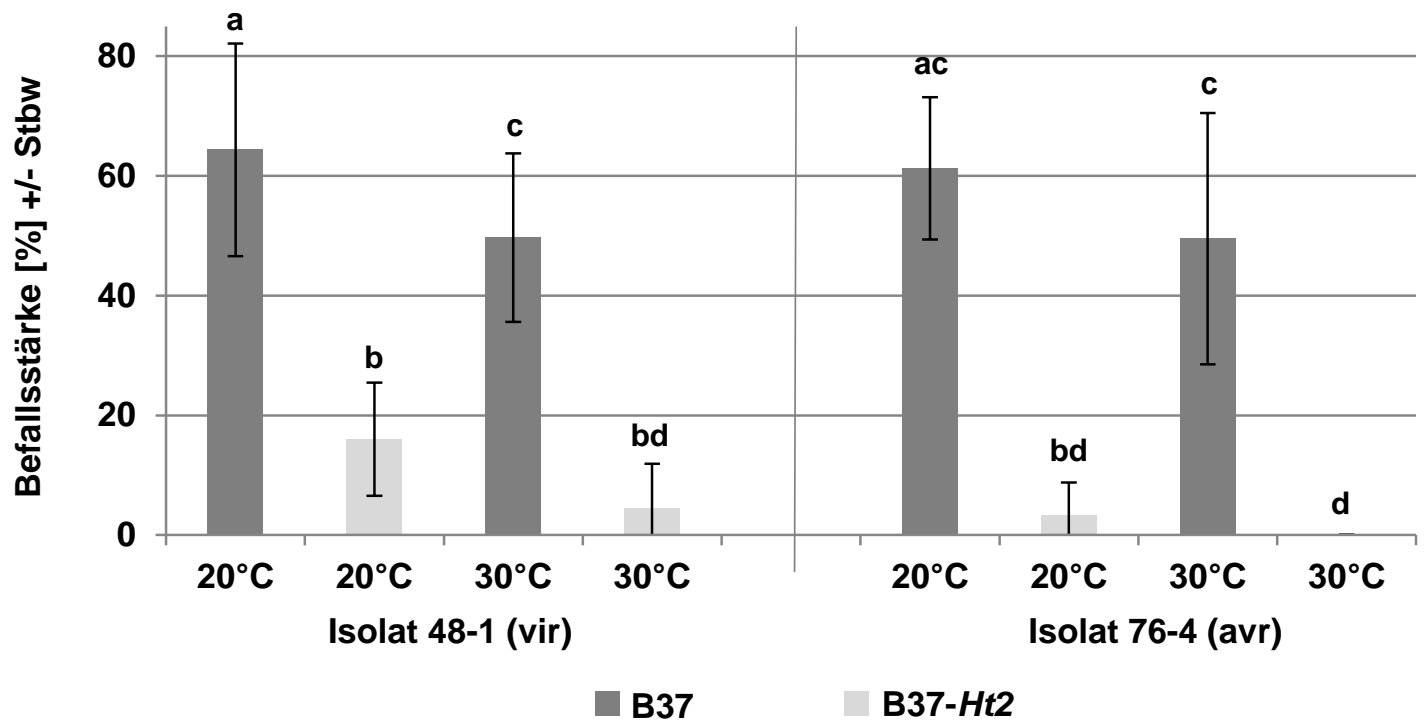

Abb. 18: Befallsstärke von E. turcicum an Mais nach Behandlung von nah-isogenenen Maislinien für 10 Tage vor der Inokulation mit hohen $\left(30^{\circ} \mathrm{C}\right)$ und niedrigen $\left(20^{\circ} \mathrm{C}\right)$ Tagestemperaturen, Bonitur $21 \mathrm{dpi}$, unterschiedliche Buchstaben kennzeichnen signifikante Unterschiede (Tukey-Test $p \leq 0,05$ ), $n=16$. 
Isolat 48-1 als auch für das avirulente Isolat 76-4 hat das Resistenzgen Ht2 in beiden Temperaturvarianten zu einer signifikanten $(p<0,05)$ Reduktion der Befallsstärke gegenüber der anfälligen nah-isogenen Maislinie B37 geführt. In der $20^{\circ} \mathrm{C}$ Variante ist der Befall durch das virulente Isolat um 75\% gegenüber der Linie B37 auf 16\% auf der Linie B37-Ht2 verringert worden. In der wärmeren $30^{\circ} \mathrm{C}$ Variante ist der Befall durch $\mathrm{Ht2}$ verhältnismäßig stärker um $91 \%$ auf $4,4 \%$ reduziert worden. Für das avirulente Isolat wurde lediglich in der $20^{\circ} \mathrm{C}$ Variante ein Befall von 3,3\% auf der Linie B37-Ht2 festgestellt, was einer Reduktion von 95\% entspricht. In diesem Versuch ist der quantitative Befall nach Vorbehandlung der Pflanzen mit hohen und niedrigen Temperaturen in der höheren $\left(30^{\circ} \mathrm{C}\right)$ Temperaturvariante für das Isolat 48-1 signifikant geringer, verglichen mit der niedrigeren $\left(20^{\circ} \mathrm{C}\right)$ Variante. Dieser Trend trifft auch für das Isolat 76-4 zu, ist aber für keines der beiden Isolate statistisch signifikant.

Um die Ausbreitung des Pilzes im Blattgewebe genauer beurteilen zu können, wurde mit Hilfe der quantitativen PCR die DNA-Menge von E. turcicum im Blattmaterial bestimmt. Die Ergebnisse in Abbildung 19 zeigen einen signifikanten Unterschied zwischen dem virulenten und avirulenten Isolat auf dem Genotyp B37-Ht2. Ebenso ist der Abbildung zu entnehmen, dass das Resistenzgen $H t 2$ für beide Isolate in beiden Temperaturvarianten eine signifikante Reduktion der Besiedlung des Pilzes bewirkte. Im Gegensatz zu den Boniturergebnissen der Befallsstärke in Abbildung 18 zeigt sich im Pilz-DNA-Gehalt ein signifikanter Unterschied zwischen den beiden Isolaten auf der anfälligen Linie B37, wobei es zwischen den Temperaturvarianten innerhalb der Isolate keine signifikanten Unterschiede gibt.

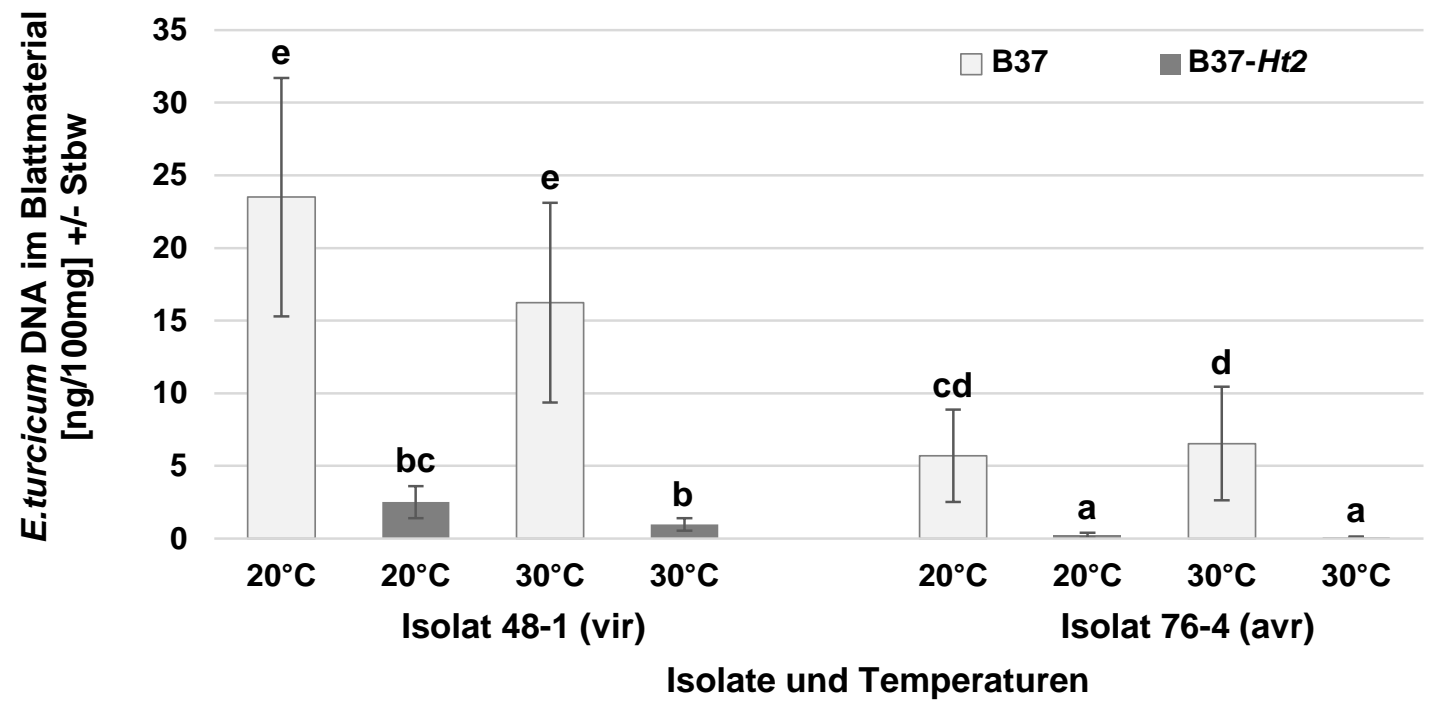

Abb. 19: DNA-Menge von E. turcicum in Maisblattmaterial $(\mathrm{ng} / 100 \mathrm{mg})$ nach Behandlung von nah-isogenenen Maislinien für 10 Tage vor der Inokulation mit hohen $\left(30^{\circ} \mathrm{C}\right)$ und niedrigen $\left(20^{\circ} \mathrm{C}\right)$ Tagestemperaturen, Bonitur $21 \mathrm{dpi}$, unterschiedliche Buchstaben kennzeichnen signifikante Unterschiede, Tukey-Test, $p \leq 0,05$ nach Log Transformation, $n=8$. 
In Abbildung 20 sind die Merkmale Befallsstärke und Pilz-DNA-Gehalt gesondert für den Genotyp B37 (links) und B37-Ht2 (rechts) miteinander korreliert. Die Ergebnisse zeigen, dass in diesem Experiment für die anfällige Linie B37 kein Zusammenhang ( $r=0,199)$ zwischen dem bonitierten Befall an der Ganzpflanze (Befallsstärke) und dem gemessenen DNA-Gehalt von E. turcicum im Blattmaterial besteht. Für den Genotyp B37-Ht2 konnte ein signifikanter $(p<0,001)$ Zusammenhang zwischen dem DNA-Gehalt im Blatt und der erhobenen Befallsstärke an der Ganzpflanze mit einem Korrelationskoeffizienten von $r=0,82$ nachgewiesen werden. Sowohl auf der anfälligen Linie B37 als auch auf der Linie B37-Ht2 erreicht das als virulent für Ht2 eingestufte Isolat 48-1 höhere Pilz-DNA-Konzentrationen im Blatt, verglichen mit dem avirulenten Isolat 76-4 (siehe Abbildung 19).

Um den Effekt des Resistenzgens Ht2 vor dem Hintergrund der beiden Temperaturvarianten zu verdeutlichen, sind in Abbildung 21 die relativen Befallswerte und die relativen E. turcicum DNA-Mengen der Linie B37-Ht2 im Verhältnis zur anfälligen Linie B37 $(=100)$ dargestellt. In der $20^{\circ} \mathrm{C}$ Variante zeigt B37- $\mathrm{Ht} 2$ die sichtbaren Krankheitssymptome von $E$. turcicum auf $25 \%$ für das Isolat $48-1$, auf $5 \%$ für das Isolat 76-4 reduziert. Die erhöhte Temperatur hat für das Isolat 48-1 zu einer weiteren signifikanten Reduktion der Befallssymptome um $64 \%$ auf letztlich $9 \%$ geführt. Ausgehend von einem sehr geringen Befallsniveau in der $20^{\circ} \mathrm{C}$ Variante, trat in der höheren Temperaturvariante für das Isolat $76-4$ kein Befall auf. Mit Hilfe der bestimmten E. turcicum DNA Mengen ist es möglich, die Ausbreitung des Pilzes im Pflanzengewebe zu bewerten.
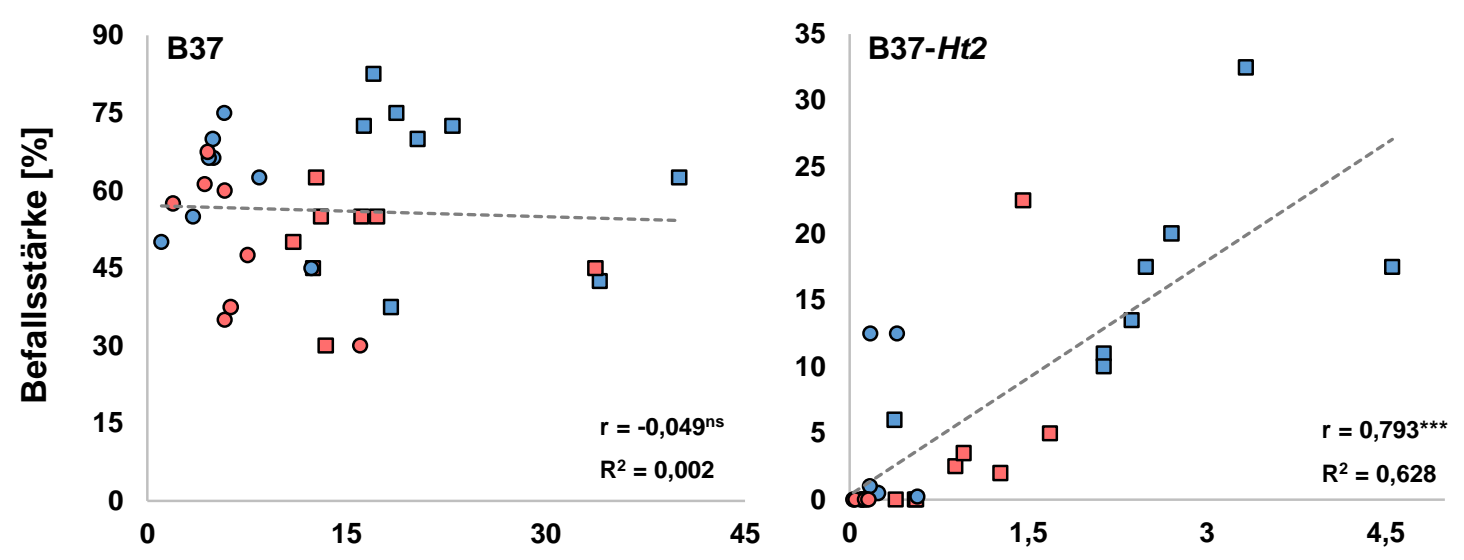

E. turcicum DNA im Blattmaterial [ng/100mg]

O 76-4 avirulent $\square 48-1$ virulent $\square 20^{\circ} \mathrm{C} \bigcirc 30^{\circ} \mathrm{C}$

Abb. 20: Korrelation der Befallsstärke [\%] und DNA-Gehalt [ng/100 mg] von E. turcicum an Mais nach Behandlung der Maislinien B37 \& B37-Ht2 mit hohen $\left(30 / 25^{\circ} \mathrm{C}\right)$ und niedrigen $\left(20 / 15^{\circ} \mathrm{C}\right)$ Temperaturen für 10 Tage (Tag/Nacht, $\left.12 \mathrm{~h}\right)$ vor der Inokulation mit zwei Isolaten: 76-4 avirulent und 48-1 virulent für $H t 2$, Bonitur und Probenahmezeitpunkt: 21 dpi, Korrelationskoeffizienten: $n s=$ nicht signifikant; ${ }^{* \star *}=$ signifikant bei $\mathrm{p} \leq 0,001$ (t-Test), $\mathrm{N}=32$. 
Die relativen Pilz-DNA-Gehalte zeigen in der $20^{\circ} \mathrm{C}$ Variante eine Reduktion der Besiedlung auf der Linie B37-Ht2 auf $11 \%$ für das Isolat $48-1$, auf $4 \%$ für das Isolat $76-4$, verglichen mit den Werten auf der Linie B37. Durch die erhöhte Temperatur wurde die DNA-Menge für das Isolat $48-1$ um weitere $44 \%$ auf $6 \%$ reduziert. Für das Isolat $76-4$ führte die erhöhte Temperatur zu einer Reduktion der DNA-Menge um 63\% auf 1,5\% im Vergleich zur Linie B37.

Die Ergebnisse in den Abbildungen 20 und 21 zeigen eine tendenziell höhere Besiedlung (DNA-Gehalt) der Maispflanzen in der $20^{\circ} \mathrm{C}$ Variante im Vergleich zur $30^{\circ} \mathrm{C}$ Variante. Diese Tendenz ist unabhängig vom Isolat zu beobachten, aber in keinem der Fälle statistisch signifikant.
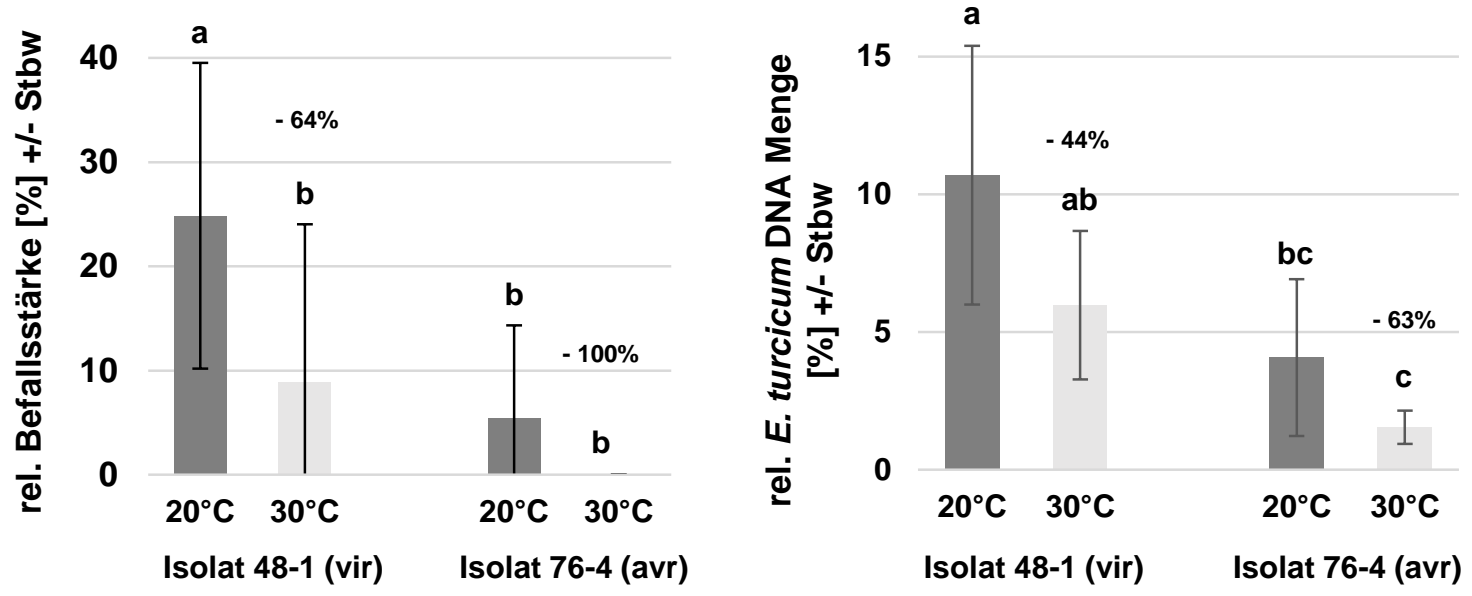

Temperaturen und Isolate

Abb. 21: Relativwerte der Befallsstärke (links) und der DNA-Menge im Blattmaterial (rechts) von E. turcicum im Blatt der Maislinie B37-Ht2 gegenüber B37 (B37 $=100)$ nach Behandlung der Maispflanzen für 10 Tage bis zur Inokulation mit hohen $\left(30 / 25^{\circ} \mathrm{C}\right)$ und niedrigen $\left(20 / 15^{\circ} \mathrm{C}\right)$ Temperaturen (Tag/Nacht, 12h), Zeitpunkt: $21 \mathrm{dpi}$, unterschiedliche Buchstaben kennzeichnen signifikante Unterschiede (Tukey-Test, $p \leq 0,05$ ), Befallsstärke $n=16$, DNAMenge $\mathrm{n}=8$. 


\subsection{Symptomausprägung von E. turcicum an Genotypen mit dem Resistenzgen Ht2}

\subsubsection{Symptomausprägungen verschiedener E. turcicum Isolate auf den nah-isoge- nen Inzuchtlinien B37 und B37-Ht2}

In Gewächshausversuchen wurden unter kontrollierten klimatischen Bedingungen sechs verschiedene E. turcicum-Isolate gegenüber dem Resistenzgen $\mathrm{Ht2}$ an den nah-isogenen Maisinzuchtlinien B37 und B37-Ht2 untersucht. Auf Basis der Virulenzeinstufungen des Rassenscreenings wurden drei virulente (vir) und drei avirulente (avr) Isolate untersucht. Wie in Abbildung 22 dargestellt, traten auf der anfälligen Linie B37 bereits nach 8,1 Tagen erste Symptome durch das Isolat 122-2 auf. Die längste Inkubationszeit auf der Linie B37 wurde für das Isolat 159-4 mit 9,4 Tagen beobachtet. Die Inkubationszeiten wiesen auf B37 keine signifikanten Unterschiede auf. Die ersten Symptome traten auf B37 im Durchschnitt bereits nach 8,9 Tagen auf. Die Inkubationszeit war mit 13 Tagen für die Linie B37-Ht2 um 4,1 Tage länger. Für jedes der Isolate führte das Resistenzgen Ht2 zu einer signifikanten Verzögerung des Erstauftretens von Symptomen. Die längste Verzögerung wurde für das Isolat 130-2 mit 5,6 Tagen beobachtet. In diesem Fall traten die ersten Symptome auf B37$H t 2$ nach 14,7 Tagen auf. Die geringste Verzögerung des ersten Symptomauftretens wurde für das Isolat 122-2 mit 3,4 Tagen beschrieben. Für die sechs untersuchten Isolate besteht kein Zusammenhang zwischen den Virulenzeigenschaften und der Inkubationszeit. So wiesen die beiden avirulenten Isolate 186-1 und 161-1 signifikant niedrigere Werte im Vergleich

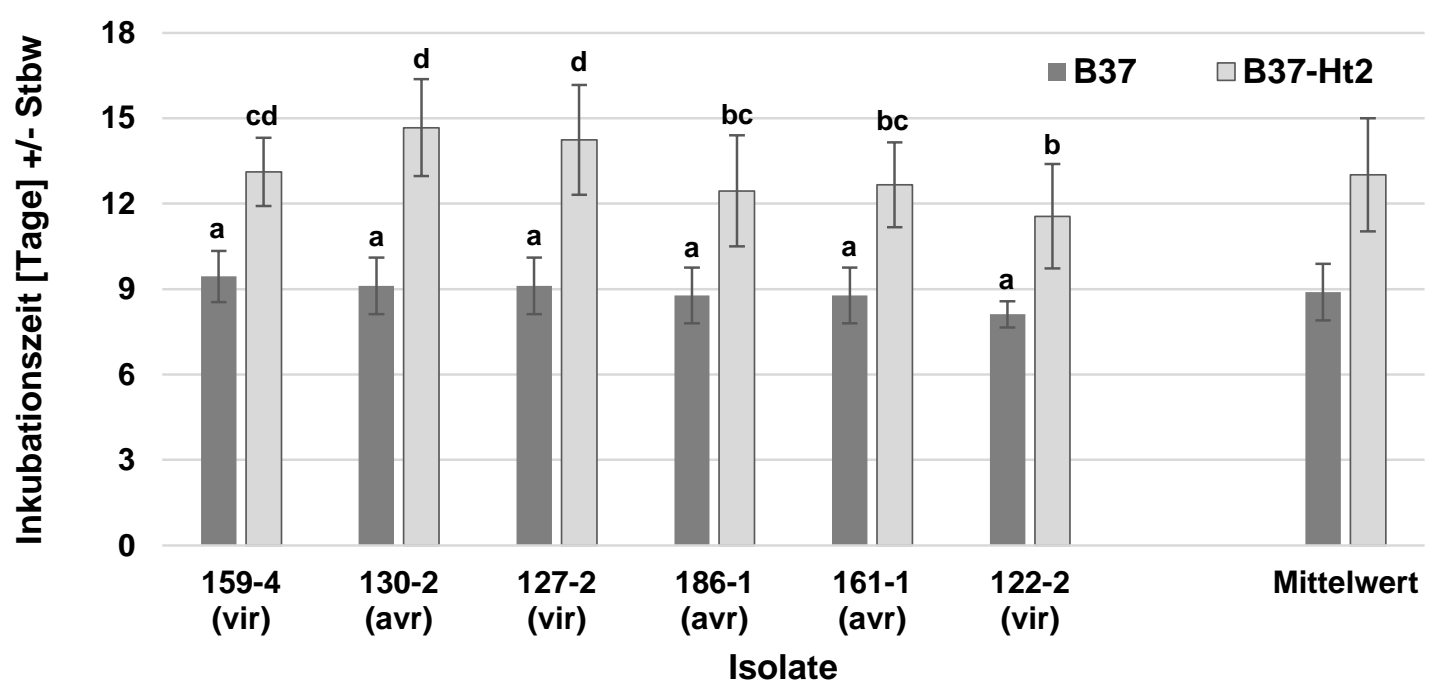

Abb. 22: Inkubationszeit von E. turcicum Isolaten mit unterschiedlichen Virulenzeigenschaften gegenüber $\boldsymbol{H t 2}$ auf nah-isogenen Mais-Inzuchtlinien (B37 und B37-Ht2), unterschiedliche Buchstaben kennzeichnen signifikante Unterschiede (Tukey Test, $p \leq 0,05$ ), $\mathrm{n}=18$. 
zum virulenten Isolat 127-2 auf. Im umgekehrten Fall wurden für das avirulente Isolat 130 2 signifikant höhere Werte im Vergleich zum virulenten Isolat $122-2$ beobachtet.

Neben der quantitativen Befallserhebung erfolgte auch eine qualitative Beurteilung der Symptomausprägungen auf Basis der Boniturskala in Tabelle 3 unter Punkt 2.2.4. Die als anfällig bzw. resistent eingestuften Befallsreaktionen der Pflanzen entsprechen den jeweiligen Isolaten zugeordneten Virulenzeinstufungen virulent bzw. avirulent. Die Virulenzeinstufung „intermediär" beschreibt eine Befallsreaktion der Pflanze, die nicht eindeutig als anfällig bzw. resistent angesprochen werden konnte und somit keine eindeutige Virulenzeinstufung für das jeweilige Isolat zuließ. Wie in Tabelle 22 dargestellt, wurden die Isolate 130-2 und 186-1 entsprechend der Einstufung aus dem Rassenscreening eindeutig als avirulent beurteilt. Das Isolat 161-1 wurde lediglich in 61\% der Wiederholungen eindeutig als avirulent eingestuft. In 17\% der Fälle fand eine Einstufung als virulent statt, und bei $22 \%$ war eine eindeutige Zuordnung nicht möglich. Das als virulent eingestufte Isolat 122-2 wurde in 50\% der Fälle auch als solches eingestuft. Allerdings fand in 39\% der Wiederholungen eine Beurteilung als avirulent statt und $11 \%$ konnten nicht eindeutig zugeordnet werden. Das Isolat 122-2 weist mit 38,2\% die höchste Befallsstärke vor dem Isolat 161-1 mit 19,6\% auf. Die beiden als virulent eingestuften Isolate 127-2 und 159-4 wurden im Rahmen dieses Versuchs nicht eindeutig als solche identifiziert. In 61\% (127-2) bzw. 50\% (159-4) der Fälle wurden die Isolate als avirulent eingestuft. Eine Einstufung als virulent erfolgte in $28 \%$ bzw. 22\% der Fälle. Die höchste Einstufung als intermediär erreichte das Isolat 159-4 mit $28 \%$. Für das als virulent bekannte Isolat $28 \mathrm{~A}$ aus den USA erfolgte eine Einstufung in

Tab. 22: Virulenzeinstufungen von $E$. turcicum Isolaten gegenüber dem Resistenzgen $\mathrm{Ht2}$ auf der Linie B37-Ht2, Befallsstärke als nekrotisierte Blattfläche in \% zum Zeitpunkt 16 dpi, Anzahl berücksichtigter Pflanzen (N), "Virulenzeinstufung aus dem Rassenscreening, Isolat 28A (Rasse 23N) diente als Referenzisolat aus den USA (Condon et al., 2013).

\begin{tabular}{|c|c|c|c|c|c|c|c|}
\hline \multirow[b]{2}{*}{ Isolat } & \multirow[b]{2}{*}{ Rasse } & \multirow{2}{*}{$\begin{array}{l}\text { Virulenz- } \\
\text { einstufung* } \\
\text { auf } H t 2\end{array}$} & \multicolumn{3}{|c|}{ Virulenzeinstufung (Anteile in \%) } & \multirow{2}{*}{$\begin{array}{l}\text { Befallsstärke } \\
16 \text { dpi [\%] }\end{array}$} & \multirow[b]{2}{*}{$\mathrm{N}$} \\
\hline & & & virulent & avirulent & intermediär & & \\
\hline $130-2$ & 0 & avirulent & - & 100 & - & 4,0 & 18 \\
\hline $186-1$ & 1 & avirulent & - & 100 & - & 12,2 & 18 \\
\hline $161-1$ & 0 & avirulent & 17 & 61 & 22 & 19,6 & 18 \\
\hline $122-2$ & $23 N$ & virulent & 50 & 39 & 11 & 38,2 & 18 \\
\hline $127-2$ & $23 N$ & virulent & 28 & 61 & 11 & 11,3 & 18 \\
\hline $159-4$ & $23 N$ & virulent & 22 & 50 & 28 & 10,8 & 18 \\
\hline $28 \mathrm{~A}$ & $23 N$ & virulent & 33 & 11 & 56 & 11,2 & 9 \\
\hline
\end{tabular}




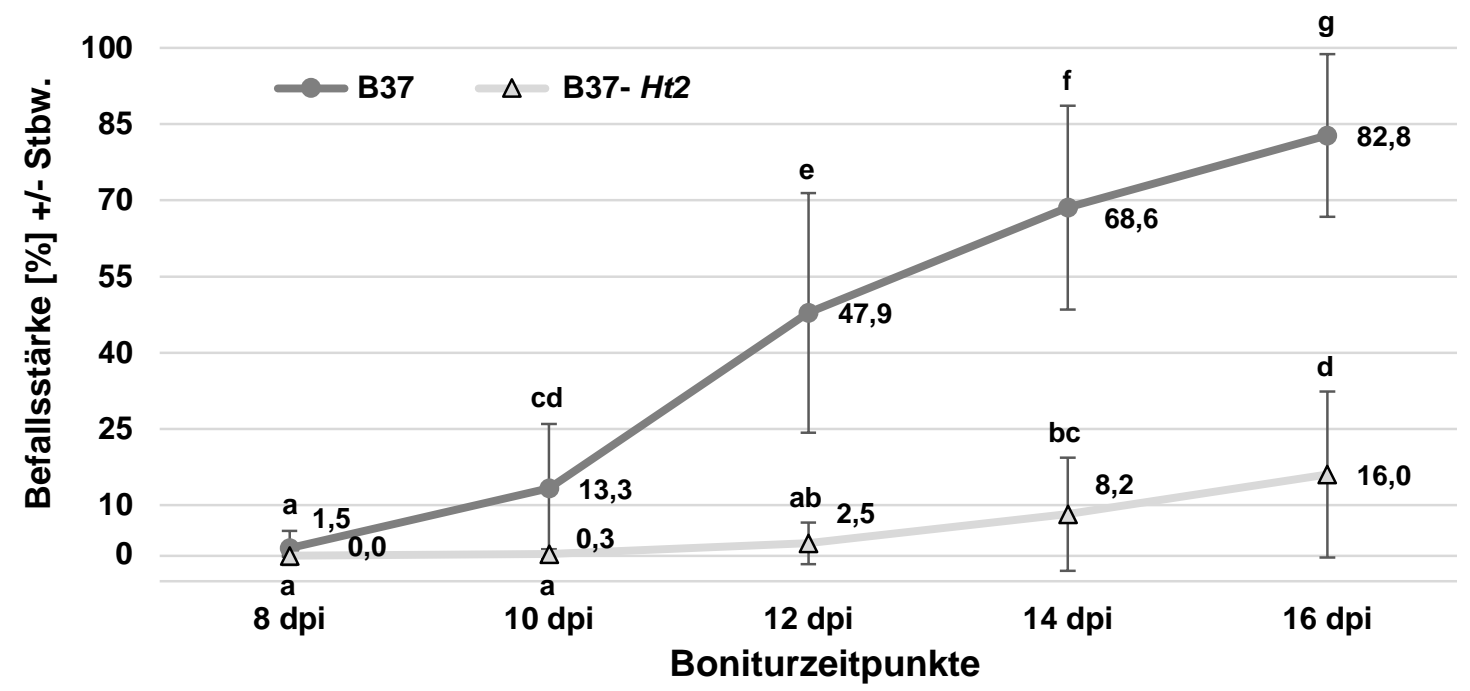

Abb. 23: Entwicklung der Befallsstärke von E. turcicum auf zwei Maisinzuchtlinien (B37 \& B37-Ht2) zu den Boniturzeitpunkten 8, 10, 12, 14 und 16 Tagen nach Inokulation (dpi), Mittelwerte von sechs Isolaten, unterschiedliche Buchstaben kennzeichnen signifikante Unterschiede (Turkey-Test $p \leq 0,05$ ), $n=108$

die entsprechende Kategorie virulent bei lediglich einem Drittel der Fälle. Der überwiegende Teil (56\%) konnte nicht eindeutig zugeordnet werden und erhielt demnach die Einstufung intermediär.

Die quantitative Befallserhebung im Zeitverlauf ist in Abbildung 23 von 8 bis 16 dpi als Befallsstärke dargestellt. Bereits zum Zeitpunkt 10 dpi besteht ein signifikanter Unterschied zwischen der Linie B37 und B37-Ht2. Mit einem durchschnittlichen täglichen Zuwachs in der Befallsstärke von über 10 Prozentpunkten ab dem achten Tag nach Inokulation erreicht der Wert zum Zeitpunkt 16 dpi 82,8\%. Der Wert der Linie B37-Ht2 liegt zum Zeitpunkt 16 dpi mit 16,0\% signifikant niedriger. Der durchschnittliche tägliche Zuwachs für die Linie B37Ht2 liegt bei zwei Prozentpunkten ab dem achten Tag nach Inokulation. In Abbildung 24 sind die Befallsstärken für alle untersuchten Isolate zum Zeitpunkt 16 dpi für die Linien B37 und B37-Ht2 dargestellt. Auf dem Genotyp B37 setzt sich lediglich das Isolat 122-2 mit einem Wert von 96,4\% signifikant von den beiden Isolaten $130-2(75,9 \%)$ und $159-4$ $(71,6 \%)$ ab. Zwischen allen anderen Isolaten waren keine signifikanten Unterschiede zu beobachten. Auf der Linie B37-Ht2 setzt sich das Isolat 122-2 als einziges Isolat mit einer Befallsstärke von 38,2\% signifikant von allen anderen Isolaten ab. Zudem ist das Isolat 1611 mit einem Wert von 19,6\% signifikant von dem Isolat 130-2 mit dem geringsten Wert von $4 \%$ verschieden. Die Befallsstärken der anderen Isolate liegen im Bereich zwischen 4 und $12,2 \%$ und unterschieden sich nicht signifikant voneinander. 


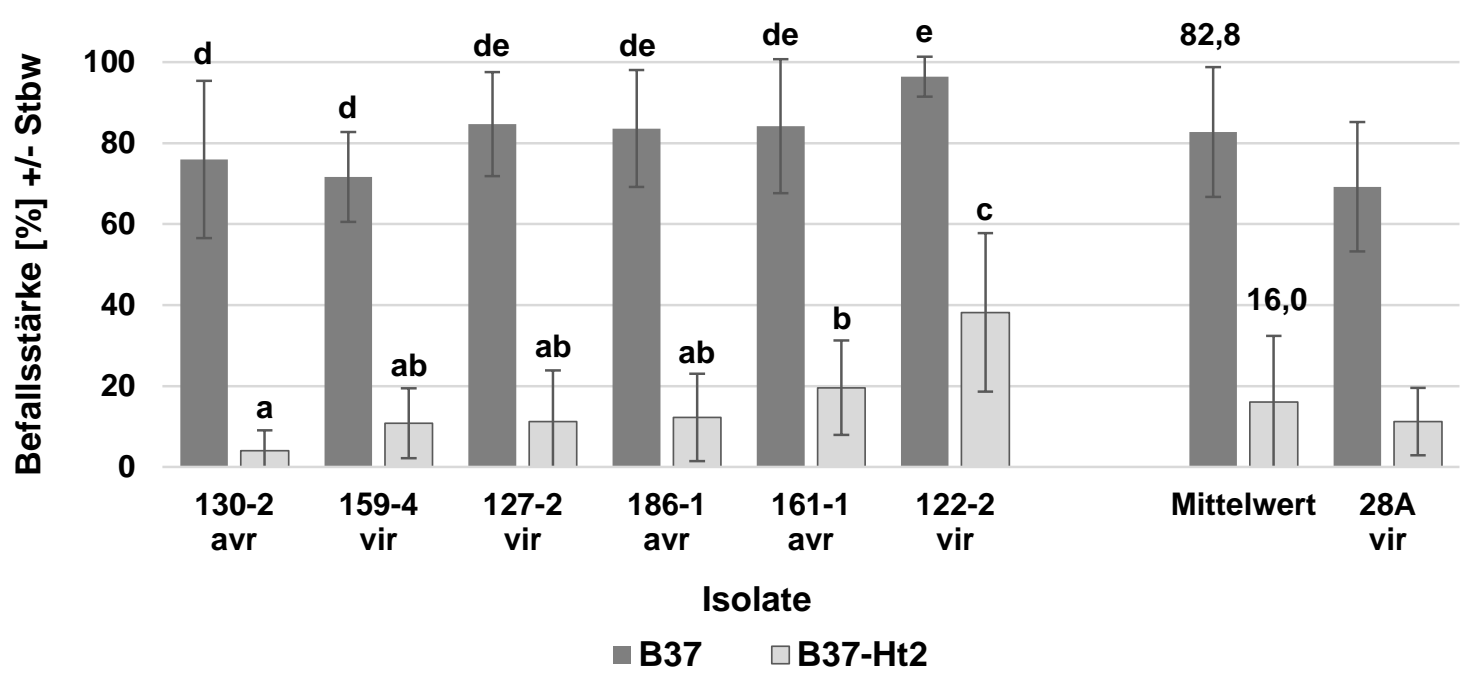

Abb. 24: Befallsstärke von sechs E. turcicum Isolaten auf den Maisinzuchtlinien B37 \& B37Ht2 zum Boniturzeitpunkt 16 Tage nach Inokulation (dpi), Virulenzeinstufungen gegenüber $\mathrm{Ht} 2$ vorläufig aus eigenen Versuchen; als Referenz diente das virulente Isolat 28A (Condon et al., 2013); Mittelwerte aus 9 Wiederholungen und zwei Durchgängen, unterschiedliche Buchstaben kennzeichnen signifikante Unterschiede (Turkey-Test $p \leq 0,05$ ), $n=18$.

Das virulente Referenzisolat 28A weist mit $11,2 \%$ einen vergleichsweise geringen Wert auf. Da das Isolat 28A lediglich mit neun Wiederholungen im Versuch berücksichtigt wurde, war keine statistische Verrechnung für dieses Isolat für das Merkmal Befallsstärke möglich. Die Mock inokulierte Kontrollvariante war in beiden Durchgängen frei von Symptomen.

Neben der Befallsstärke wurde der DNA-Gehalt von E. turcicum in den Maisblättern der verschiedenen Varianten bestimmt. In Abbildung 25 ist zu erkennen, dass deutliche Unterschiede zwischen den Isolaten auf der anfälligen Linie B37 gemessen wurden. Das Isolat 186-1 hebt sich durch einen sehr geringen DNA-Gehalt signifikant von den drei Isolaten mit den höchsten Gehalten ab. Zwischen allen anderen Isolaten sind die Unterschiede im DNAGehalt in der Abbildung 25 deutlich sichtbar, aber aufgrund der hohen Variation in keinem Fall statistisch signifikant. Die Mittelwerte der Gehalte für die Maisgenotypen B37 und B37$\mathrm{Ht} 2$ unterscheiden sich mit 7,56 ng/mg TM und 0,31 ng/mg TM deutlich. Übereinstimmend mit den Werten der Befallsstärke heben sich die beiden Isolate 122-2 und 161-1 durch vergleichsweise hohe DNA-Gehalte auf der Linie B37-Ht2 von den Isolaten 186-1, 130-2 und 159-4 signifikant ab. Das virulente Referenzisolat $28 \mathrm{~A}$ ist ebenfalls durch einen deutlichen Unterschied im DNA-Gehalt zwischen den beiden Maisgenotypen gekennzeichnet. Die Werte liegen für den Genotyp B37 bei 13,08 ng/mg TM und für den Genotyp B37-Ht2 bei 0,54 ng/mg TM. 


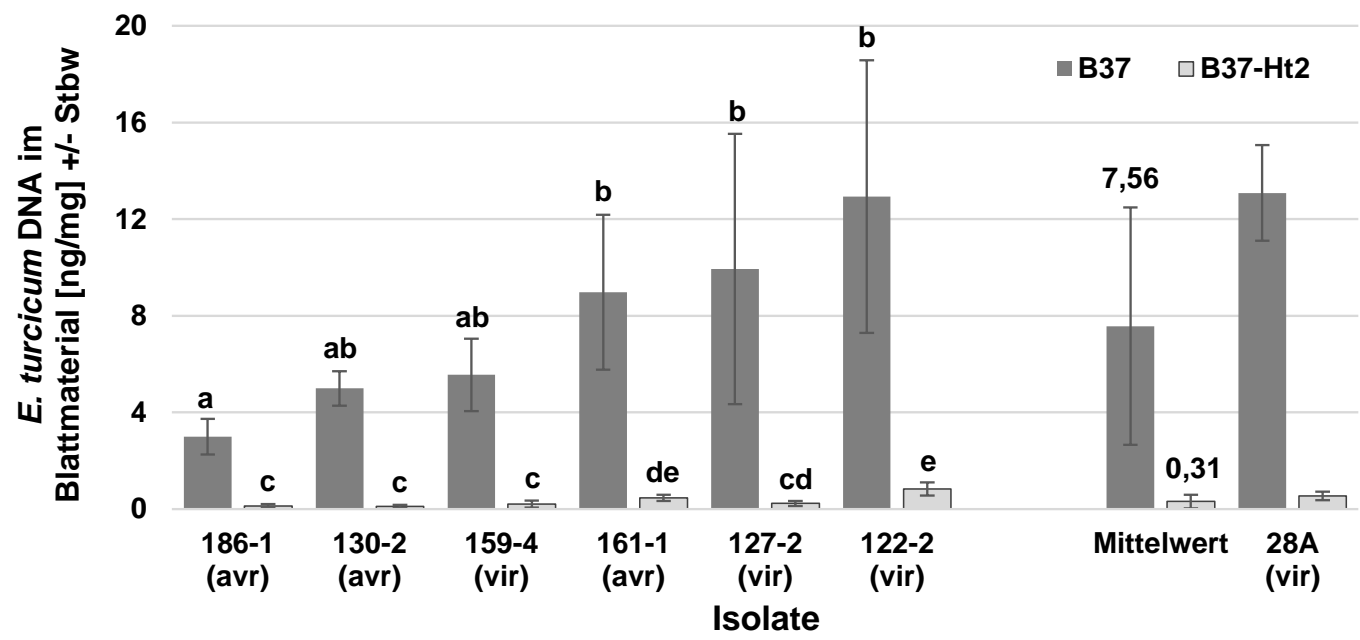

Abb. 25: DNA Menge [ng/mg TM] von sechs europäischen $E$. turcicum Isolaten in befallenem Blattmaterial der nah-isogenen Maisinzuchtlinien B37 und B37-Ht2, Virulenzeinstufungen gegenüber Ht2 vorläufig aus eigenen Versuchen; als Referenz diente das virulente Isolat 28A (Condon et al., 2013); Probenahme 16 Tage nach Inokulation, unterschiedliche Buchstaben kennzeichnen signifikante Unterschiede, (Tukey Test, $p \leq 0,05$ ) nach LogTransformation, $\mathrm{n}=6$.

Der DNA-Gehalt des Isolates 28A liegt damit zwischen den beiden Werten der Isolate $122-$ 2 und 161-1 mit 0,83 und 0,46 ng/mg TM. In den Kontrollvarianten wurden sehr geringe Mengen an DNA von E. turcicum nachgewiesen. Die Größenordnung der DNA-Mengen in den Kontrollvarianten lag um den Faktor 13 unterhalb der Menge, die für das Isolat 186-1 auf der Linie B37-Ht2 ermittelt wurde. Neben den Merkmalen zur Charakterisierung der Infektion und Besiedlung des Blattgewebes durch E. turcicum wurde das Potential der Vermehrung durch Sporulation der sechs Isolate auf den beiden Maislinien untersucht. Abbildung 26 zeigt die Sporulation in [Sporen/ $\mathrm{cm}^{2}$ ] auf befallenem Blattmaterial der Linien B37 und B37-Ht2. Die durchschnittliche Sporulation war auf der Linie B37 mit 16.300 Sporen/cm² um den Faktor 7 höher als auf der Linie B37-Ht2 mit 2.300 Sporen/cm². Auf der Linie B37 war die Sporulation des Isolates 130-2 mit 10.300 Sporen/ $/ \mathrm{cm}^{2}$ signifikant geringer im Vergleich zu den Isolaten 186-1, 159-4 und 122-2 mit einer Sporulation von 18.900 bis 20.500 Sporen $/ \mathrm{cm}^{2}$. Abgesehen vom Isolat 130-2 zeigten alle anderen Isolate keine signifikanten Unterschiede auf der Linie B37. Die drei Isolate 159-4, 122-2 und 161-1 setzen sich auf der Linie B37-Ht2 durch eine relativ hohe Anzahl gebildeter Sporen von 3.200 bis 4.500 Sporen/ $\mathrm{cm}^{2}$ signifikant von dem Isolat 130-2 mit der geringsten Sporenmenge von 300 Sporen $/ \mathrm{cm}^{2} \mathrm{ab}$. Das Isolat 161-1 ist durch die höchste Sporulation gekennzeichnet, die sich signifikant von den beiden Isolaten 130-2 und 127-2 absetzt. Das virulente Referenzisolat verzeichnet die höchste Sporenmenge mit 5.100 Sporen je $\mathrm{cm}^{2}$ auf der Linie B37$\mathrm{Ht} 2$. 


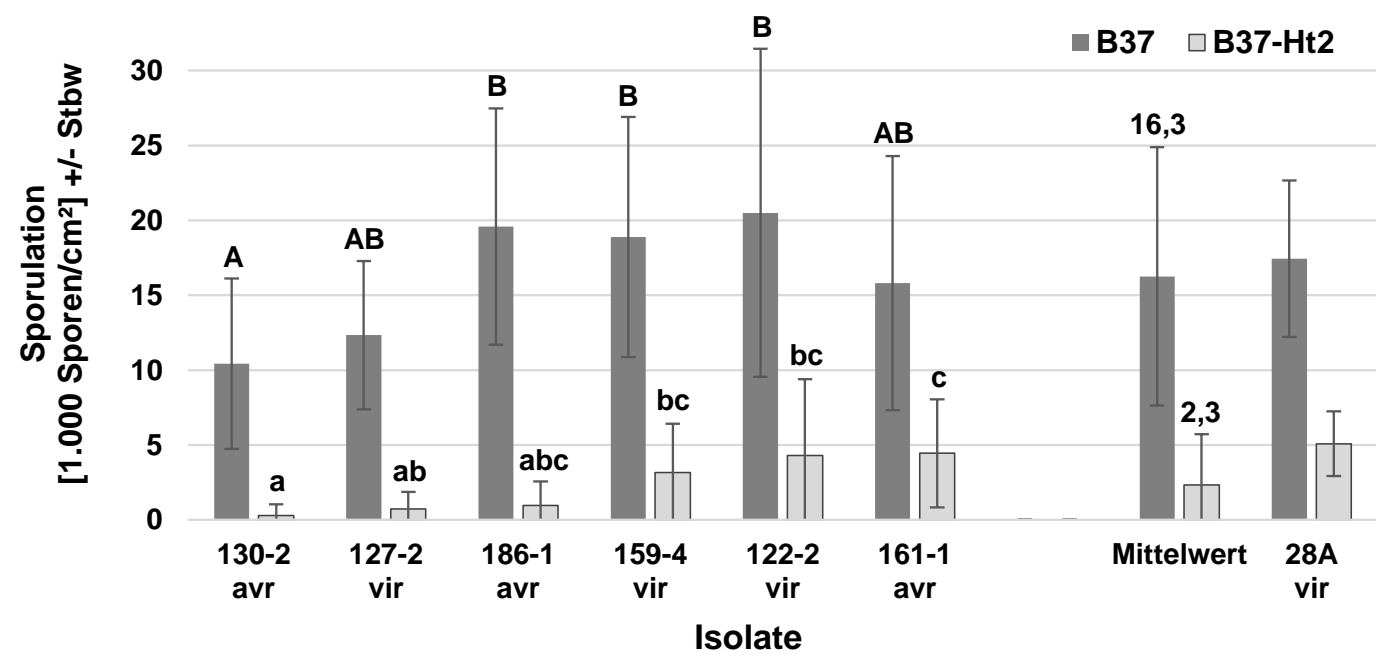

Abb. 26: Anzahl gebildeter Sporen je $\mathrm{cm}^{2}$ Läsionsfläche von E. turcicum an Mais bezogen auf sechs europäische Isolate auf zwei nah-isogenen Maisinzuchtlinien (B37 und B37-Ht2). Virulenzeinstufungen gegenüber $H t 2$ vorläufig aus eigenen Versuchen; als Referenz diente das virulente Isolat 28A (Condon et al., 2013), unterschiedliche Buchstaben kennzeichnen signifikante Unterschiede (Kruskal-Wallis-Test, $p \leq 0,05$ ), $n=20$.

\subsubsection{Epidemiepotential als Grundlage der Symptombeurteilung von E. turcicum am Genotyp B37-Ht2}

Um die Isolate anhand der Merkmale Befallsstärke [\%] und Sporulation [Sporen/cm²] vergleichen zu können, wurden die relativen Werte dieser beiden Merkmale berechnet. Dazu wurde der jeweilige Wert auf der Linie B37 gleich 100 gesetzt und der Wert der Linie B37$H t 2$ relativ dazu berechnet. Die Relativwerte zu den Merkmalen Befallsstärke und Sporulation sind in Abbildung 27 dargestellt. Die Mittelwerte für die Befallsstärke bzw. Sporulation liegen bei 18,7\% bzw. 11,7\%. Demnach hat das Resistenzgen Ht2 für die sechs untersuchten Isolate den Befall im Durchschnitt um 81,3\% und die Sporulation um 88,3\% reduziert. Das virulente Referenzisolat 28A weist für die Sporulation mit 29,2\% den höchsten ermittelten Wert auf. Der Relativwert für die Befallsstärke liegt mit 16,2\% für das Isolat 28A im Bereich der sechs untersuchten Isolate. Von den sechs europäischen Isolaten hebt sich das Isolat 122-2 mit 39,1\% relativer Befallsstärke am deutlichsten von den anderen Isolaten ab. Es weist einen signifikant höheren Wert auf im Vergleich zu den Isolaten 130-2, 127-2, 186-2 und 159-4. Den zweithöchsten Wert für die relative Befallsstärke verzeichnet mit $23,5 \%$ das Isolat 161-1, das sich statistisch signifikant lediglich vom Isolat 130-2 mit dem geringsten Wert von 5,8\% unterscheidet. Die höchste relative Sporulation, unter den europäischen Isolaten, weist das Isolat 161-1 mit 27,4\% auf. Mit diesem Wert grenzt es sich signifikant zu den drei Isolaten 130-2, 127-2 und 186-1 mit den geringsten Werten ab. 


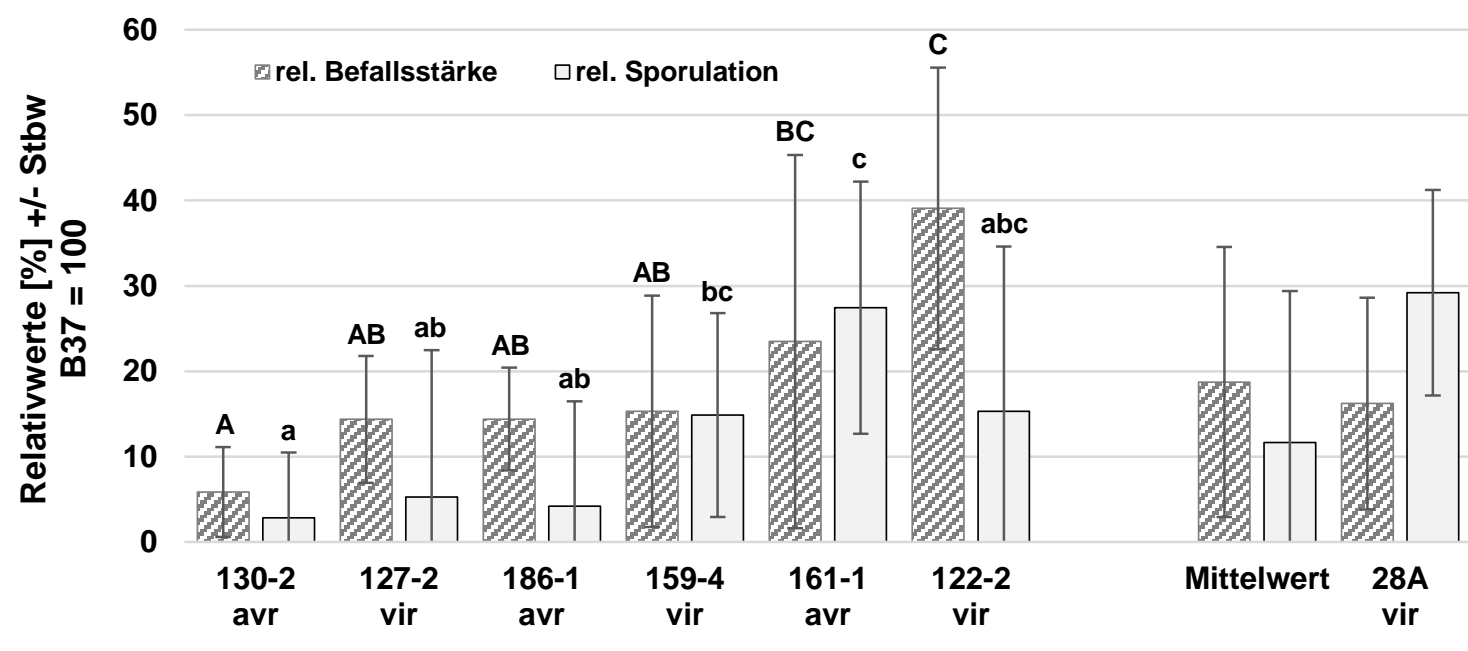

Isolate

Abb. 27: Relative Befallsstärke und Sporulationsintensität sechs europäischer E. turcicum Isolate auf Maisblättern der Inzuchtlinie B37-Ht2 in Relation zu B37 = 100. Virulenzeinstufungen gegenüber $H t 2$ vorläufig aus eigenen Versuchen; als Referenz diente das virulente Isolate 28A (Condon et al., 2013), unterschiedliche Buchstaben kennzeichnen signifikante Unterschiede (Kruskal-Wallis-Test, $p \leq 0,05$ ), Befallsstärke $n=18$, Sporulation $n=20$.

Nach dem Isolat 161-1 stehen die Isolate 122-2 und 159-4 mit Werten von 15,3 und 14,9\% an zweiter und dritter Stelle der relativen Sporulationsintensität. Ein signifikanter Unterschied besteht lediglich zum Isolat 130-2.

In Abbildung 28 ist das Merkmal Epidemiepotential zu den sechs europäischen Isolaten und dem virulenten Referenzisolat aus den USA dargestellt. Dieses Merkmal beschreibt das relative Potential des jeweiligen Isolates, sich auf der Linie B37-Ht2 im Vergleich zur Linie B37 auszubreiten und zu vermehren. Im Mittel liegt dieser Wert für alle europäischen Isolate bei 2,9\%. Das bedeutet, dass das Resistenzgen $\mathrm{Ht2}$ für die sechs untersuchten Isolate im genetischen Hintergrund der Linie B37 eine Reduktion des Epidemiepotentials um $97,1 \%$ bewirkt hat. Das Epidemiepotential für das virulente Referenzisolat liegt mit 4,7\% an dritter Stelle im Vergleich zu den europäischen Isolaten. Eine statistische Verrechnung war aufgrund unterschiedlicher Wiederholungszahlen für dieses Isolat nicht möglich. Am deutlichsten heben sich die beiden Isolate $122-2$ und $161-1$ mit $7,8 \%$ und $6,4 \%$ von den anderen Isolaten ab. Sie zeigen signifikante Unterschiede zu den Isolaten 130-2, 127-2 und 186-1, die durch sehr geringe Epidemiepotentiale zwischen 0,2 und 0,5\% gekennzeichnet sind. Das Isolat 159-4 liegt mit 2,5\% im Mittelfeld der sechs Isolate und weist einen signifikanten Unterschied lediglich zum Isolat $130-2$ mit $0,2 \%$ auf. 


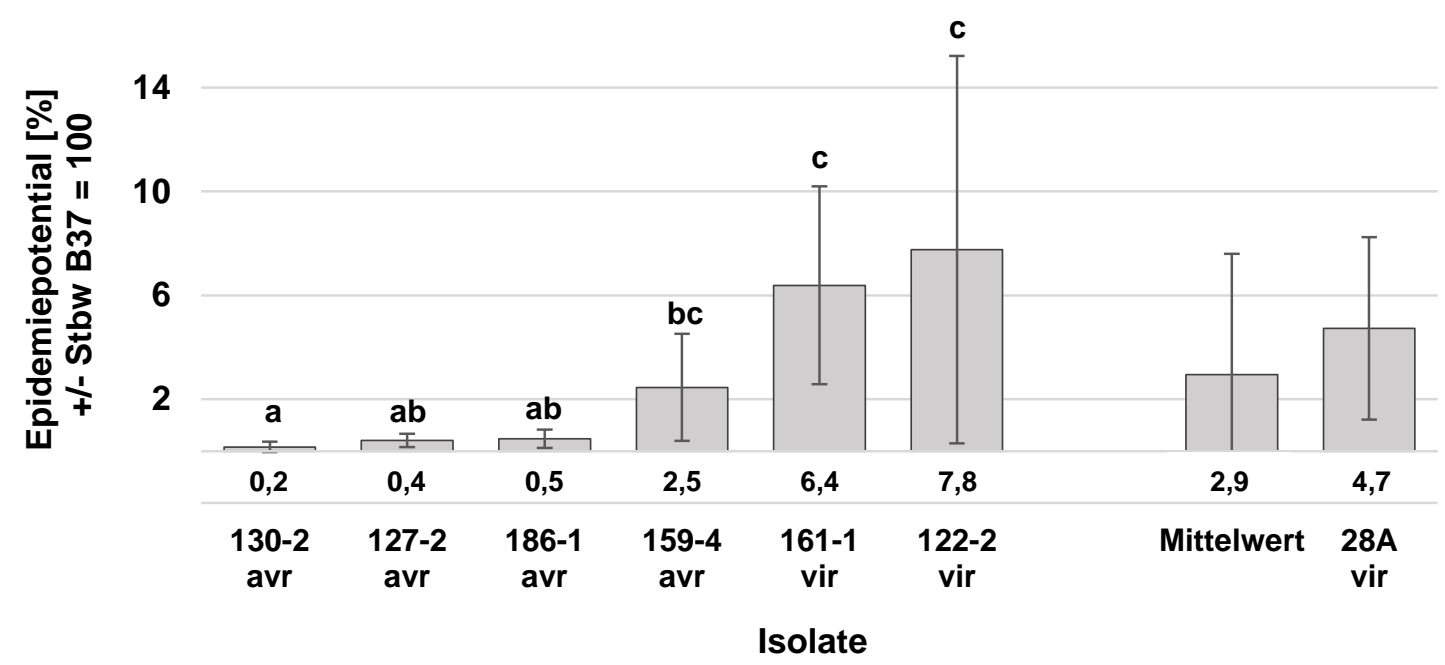

Abb. 28: Epidemiepotential von E. turcicum Isolaten auf der Maisinzuchtlinie B37-Ht2 relativ zur nah-isogenen Linie B37, Virulenzeinstufungen gegenüber $H t 2$ auf Basis des Epidemiepotentials; als Referenz diente das virulente Isolat 28A (Condon et al., 2013), unterschiedliche Buchstaben kennzeichnen signifikante Unterschiede (Kruskal-Wallis-Test, $p \leq$ $0,05), n=18$.

\subsubsection{Korrelation der Merkmale zur Ht2-Symptomatik am Genotyp B37}

Für ein besseres Verständnis der Zusammenhänge zwischen den erhobenen und berechneten Parametern wurden Korrelationsanalysen zwischen allen Parametern vorgenommen. Eine Übersicht über die Korrelationskoeffizienten zwischen allen Parametern ist in Tabelle 23 dargestellt. Das Merkmal Befallsstärke der Linie B37 (\% B37) wies lediglich mit dem Merkmal E. turcicum-DNA-Gehalt (DNA in B37) eine positiv signifikante $(p \leq 0,05)$ Korrelation $(r=0,689)$ auf. Mit keinem der anderen Parameter konnte ein signifikanter Zusammenhang zum Merkmal Befallsstärke der Linie B37 nachgewiesen werden. Für das Merkmal Befallsstärke der Linie B37-Ht2 konnten hoch signifikante Zusammenhänge zu drei anderen Merkmalen nachgewiesen werden. Die engen positiven Zusammenhänge zu den beiden Merkmalen relative Befallsstärke der Linie B37-Ht2 (rel. \% B37-Ht2) und Epidemiepotential ist durch die gemeinsame Berechnungsgrundlage zu erklären. Der enge positive Zusammenhang des Merkmals Befallsstärke auf B37-Ht2 (\% B37-Ht2) zum E. turcicum-DNAGehalt in der Linie B37-Ht2 (DNA in B37-Ht2) von $r=0,853$ ist signifikant bei $p \leq 0,001$. Das Sporulationsvermögen der Isolate auf der Linie B37 (Sporen B37) wies einen engen positiven Zusammenhang $(0,783)$ zur Sporulationsintensität auf der Linie B37-Ht2 (Sporen B37$H t 2)$ auf $(p \leq 0,01)$. Die ebenfalls positive signifikante $(p \leq 0,05)$ Korrelation zum Merkmal 
relative Sporulation auf B37-Ht2 ist durch den bereits beschriebenen engen Zusammenhang zur Sporulationsintensität auf der Linie B37-Ht2 zu erklären. Die sehr engen Zusammenhänge des Merkmals Sporulation auf B37-Ht2 mit den beiden Merkmalen relative Sporulation auf B37-Ht2 und dem Epidemiepotential ist durch die gemeinsame Berechnungsgrundlage zu erklären. Der DNA-Gehalt von E. turcicum in der Linie B37-Ht2 korreliert sehr eng $(r=0,833 ; p \leq 0,001)$ mit dem Merkmal relative Befallsstärke auf der Linie B37$H t 2$. Eine ebenfalls signifikante $(p \leq 0,05)$, aber weniger enge Korrelation $(r=0,684)$ besteht ebenfalls zum Merkmal Epidemiepotential. Der Zusammenhang der beiden Merkmale relative Befallsstärke auf B37- Ht2 (rel. \% B37-Ht2) und der relativen Sporulation auf B37$H t 2$ (Sporen \% B37-Ht2) mit dem Epidemiepotential ist durch die gemeinsame Berechnungsgrundlage zu erklären.

Tab. 23: Korrelationskoeffizienten der Parameter ${ }^{\mathrm{a}}$ zur Untersuchung der Symptomausprägung von E. turcicum auf den nah-isogenen Maisinzuchtlinien B37 und B37-Ht2, Daten von Inokulationsversuchen mit sechs Isolaten.

\begin{tabular}{|c|c|c|c|c|c|c|c|c|}
\hline & $\%$ B37 & $\%$ B37-Ht2 & $\begin{array}{l}\text { Sporen } \\
\text { B37 }\end{array}$ & $\begin{array}{l}\text { Sporen } \\
\text { B37-Ht2 }\end{array}$ & $\begin{array}{l}\text { DNA } \\
\text { in B37 }\end{array}$ & $\begin{array}{l}\text { DNA in } \\
\text { B37- Ht2 }\end{array}$ & $\begin{array}{l}\text { rel. } \% \\
\text { B37- } H t 2\end{array}$ & $\begin{array}{l}\text { Sporen \% } \\
\text { B37-Ht2 }\end{array}$ \\
\hline$\%$ B37- Ht2 & 0,282 & & & & & & & \\
\hline Sporen B37 & 0,337 & 0,313 & & & & & & \\
\hline Sporen B37-Ht2 & 0,277 & 0,356 & $0,783^{\star *}$ & & & & & \\
\hline DNA in B37 & $0,689^{\star}$ & 0,423 & 0,259 & 0,458 & & & & \\
\hline DNA in B37-Ht2 & 0,435 & $0,853^{* * *}$ & 0,136 & 0,342 & 0,707 & & & \\
\hline rel. \% B37-Ht2 & 0,346 & $0,930^{* * *}$ & 0,393 & 0,403 & 0,532 & $0,833^{* * *}$ & & \\
\hline Sporen \% B37-Ht2 & 0,177 & 0,347 & $0,591^{*}$ & $0,962^{* \star *}$ & 0,481 & 0,395 & 0,386 & \\
\hline Epidemiepotential & 0,178 & $0,738^{* *}$ & 0,556 & $0,850^{\star \star \star}$ & 0,502 & $0,684^{*}$ & $0,726^{* *}$ & $0,883^{* \star *}$ \\
\hline
\end{tabular}


In Abbildung 29 sind die Daten des Merkmals Befallsstärke auf B37 (Abszisse) gegenüber den Merkmalen E. turcicum DNA-Menge in B37 (linke Ordinate) und der Sporulationsintensität auf B37 (rechte Ordinate) zum Zeitpunkt 16 dpi in Form eines Streudiagramms dargestellt. Für das Merkmal DNA-Menge im Blattmaterial ist für den Genotyp B37 in der Grafik zu erkennen, dass bis zu einer Befallsstärke von $80 \%$ der DNA-Gehalt den Wert von $7 \mathrm{ng} / \mathrm{mg}$ TM nicht wesentlich überschreitet. Ab einer Befallsstärke von 90\% nimmt der DNAGehalt von E. turcicum deutlich zu und erreicht Werte von bis zu $16 \mathrm{ng} / \mathrm{mg}$ TM. Die Korrelation der beiden Merkmale $(r=0,689)$ ist signifikant bei $p \leq 0,05$. Das Bestimmtheitsmaß $\left(R^{2}=0,664\right)$ bestätigt auf Basis einer polynomischen Regression einen engen Zusammenhang zwischen der Befallsstärke und dem DNA-Gehalt von E. turcicum auf der Linie B37. Im Gegensatz zum Merkmal DNA-Gehalt besteht zwischen dem Merkmal Befallsstärke und Sporulation auf dem Genotyp B37 kein signifikanter Zusammenhang.

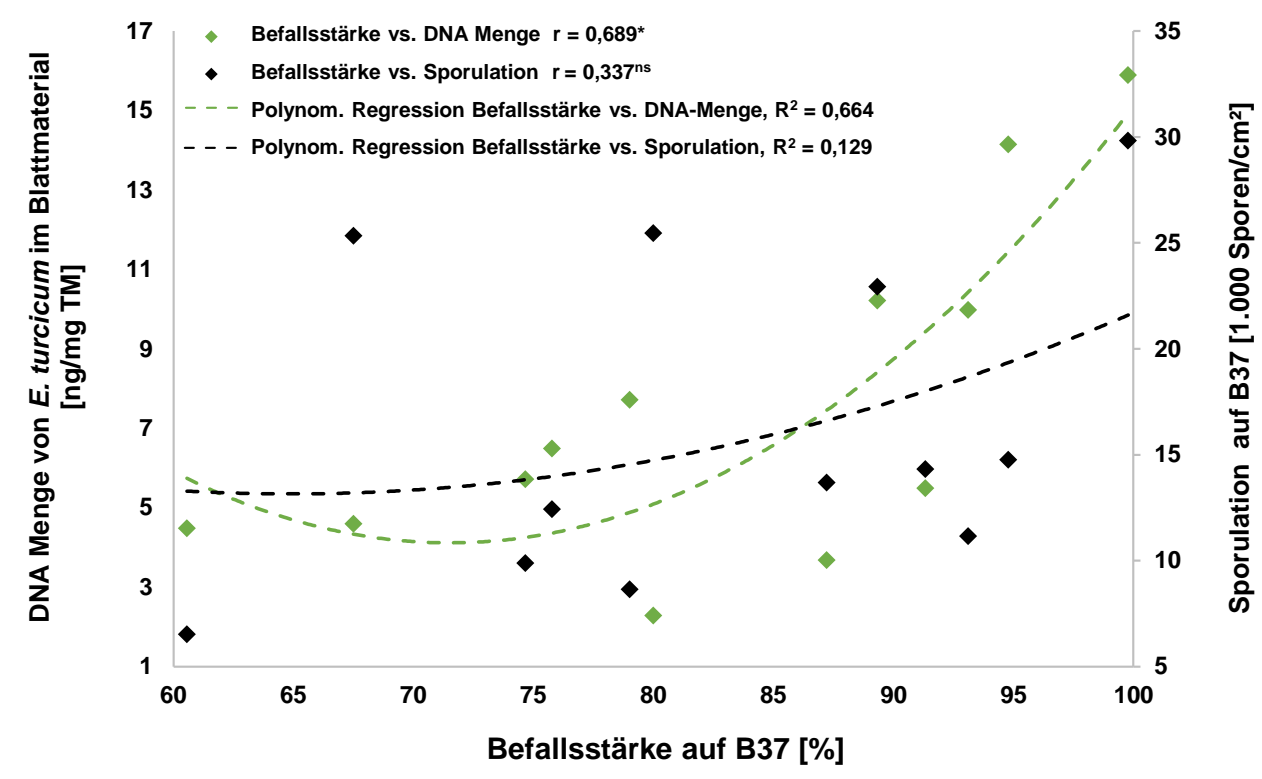

Abb. 29: Korrelation der DNA-Menge von E. turcicum im Blattmaterial (DNA in B37) und der Sporulation auf der Maislinie B37 (Sporen B37) mit der Befallsstärke auf B37 (\% B37); Korrelationskoeffizienten nach Pearson $(r){ }^{*}=$ signifikant, $^{n s}=$ nicht signifikant $(p \leq 0,05), n=12$. 
Ein Streudiagramm derselben Art zur Darstellung der Daten für das Merkmal Befallsstärke auf B37-Ht2 gegenüber den Merkmalen E. turcicum DNA-Menge in B37-Ht2 und der Sporulation auf B37-Ht2 ist in Abbildung 30 gezeigt. In diesem Fall besteht ein enger, statistisch signifikanter $(p \leq 0,001)$ Zusammenhang $(r=0,853)$ zwischen der Befallsstärke und dem DNA-Gehalt. Das Bestimmtheitsmaß der linearen Regression liegt bei $R^{2}=0,728$. Insgesamt liegen die Werte der Befallsstärke und des DNA-Gehaltes mit Höchstwerten von 55\% und 1,0 ng/mg TM deutlich unter den Höchstwerten für die Maislinie B37. Der Zusammenhang zwischen der Befallsstärke und der Sporulation ist mit $r=0,356$ als positiv beschrieben, aber nicht statistisch abgesichert. Dies wird deutlich durch die gleichzeitig sehr hohen (6.700 Sporen $\left./ \mathrm{cm}^{2}\right)$ und sehr niedrigen $\left(100\right.$ Sporen $\left./ \mathrm{cm}^{2}\right)$ Sporulationsintensitäten für verschiedene Isolate, für Befallsstärken im Bereich um 20\%.

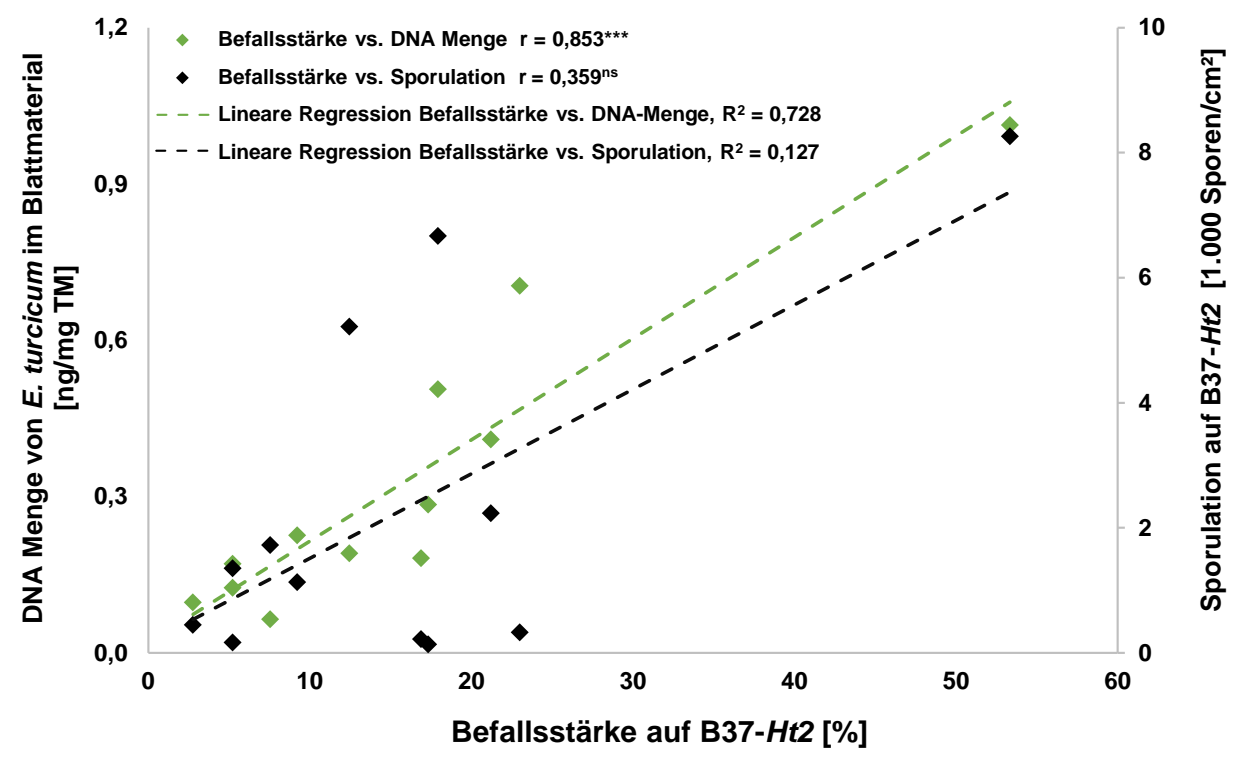

Abb. 30: Korrelation der DNA-Menge von E. turcicum im Blattmaterial (DNA in B37-Ht2) und der Sporulation auf der Maislinie B37-Ht2 (Sporen B37-Ht2) mit der Befallsstärke auf B37$H t 2$ (\% B37-Ht2), Korrelationskoeffizienten nach Pearson (r): * ${ }^{*}$ signifikant, ${ }^{\text {ns }}=$ nicht signifikant $(p \leq 0,05), n=12$. 


\subsubsection{Symptome von E. turcicum auf den nah-isogenen Inzuchtlinien Pa91 und Pa91-Ht2 bzW. KWS und KWS-Ht2}

Neben den sechs europäischen Isolaten und den zwei nah-isogenen Linien B37 und B37$H t 2$ wurden zwei als virulent für $H t 2$ beschriebene Referenzisolate und zwei der europäischen Isolate auf weiteren Paaren nah-isogener Maislinien untersucht. Bei den nah-isogenen Linien handelt es sich um die Paare Pa91 mit Pa91-Ht2 und KWS mit KWS-Ht2. Die Symptome auf den jeweils nah-isogenen Linien ohne Resistenzgen konnten alle als klassische grau-grüne bis braune Welkesymptome ohne chlorotische Resistenzreaktionen der Pflanze angesprochen werden. Zum Zeitpunkt 16 dpi lagen die Befallsstärken auf den Linien ohne Ht2 Resistenzgen für alle untersuchten Isolate im sehr hohen Bereich zwischen 70\% und 100\%. In Tabelle 24 sind die Ergebnisse der qualitativen Virulenzeinstufung und der quantitativen Befallserhebung der vier Isolate auf den Maislinien B37-Ht2, Pa91-Ht2 und KWS-Ht2 dargestellt. Auf dem Genotyp B37-Ht2 wurde das Isolat 130-2 einheitlich als avirulent bestätigt. Auch die geringe Befallsstärke von 5,2\% unterstützt diese Einstufung. Das virulente Isolat 122-2 wurde auf B37-Ht2 in 77\% der Fälle als avirulent bewertet und in 23\% der Fälle intermediär eingestuft. Dennoch war die Befallsstärke mit 23\% für dieses Isolat relativ hoch. Das Isolat 28A wurde von Prof. Balint-Kurti von der North Carolina State University (USA) als Rasse $23 \mathrm{~N}$ bereitgestellt. Darüber hinaus ist dieses Isolat auch von anderen Autoren als virulent auf $H t 2$ beschrieben (Condon et al., 2013). Das Isolat 28A zeigte im Rahmen der eigenen Virulenzeinstufungen auf B37-Ht2 allerdings heterogene Ergebnisse. Ein Drittel wurde als virulent eingestuft, $11 \%$ als avirulent und mit $56 \%$ der größte Teil als intermediär. Die Befallsstärke lag mit 11,2\% für das Isolat 28A zwischen den Werten der anderen Isolate auf dem Genotyp B37-Ht2. Auf dem Genotyp KWS-Ht2 wurde das avirulente Isolat $130-2$ mit $78 \%$ als avirulent beschrieben. Ein Unterschied zum Genotyp B37-Ht2 liegt in der deutlich höher ausfallenden Befallsstärke mit 32,9\%. Für das Isolat 122-2 war in zwei Drittel der Fälle keine eindeutige Virulenzeinstufung möglich, der Rest wurde als avirulent bewertet. Die Befallsstärke fällt für das Isolat 122-2 mit 50,6\% auf dem Genotyp KWS-Ht2 doppelt so hoch aus verglichen mit dem Genotyp B37-Ht2. Die Virulenzeinstufungen des Isolates 28A sind wie auf dem Genotyp B37-Ht2 auch auf dem Genotyp KWS-Ht2 mit 56\% virulent und 44\% intermediär sehr heterogen. Im Vergleich zum Genotyp B37-Ht2 hat sich die Befallsstärke auf dem Genotyp KWS-Ht2 mit 51,7\% signifikant ( $p \leq$ $0,05)$ erhöht. Das als virulent beschriebene Isolat 257A wurde auf dem Genotyp KWS-Ht2 in allen Fällen als avirulent eingestuft. Dennoch erreicht es mit 50,6\% Befallsstärke zusammen mit dem Isolat 122-2 den zweithöchsten Wert. Das avirulente Isolat 130-2 wurde auch auf dem Genotyp Pa91-Ht2 trotz einer Befallsstärke von 42,5\% in allen Fällen als avirulent 
Tab. 24: Virulenzeinstufungen von E. turcicum Isolaten gegenüber dem Resistenzgen Ht2 in verschiedenen genetischen Hintergründen, Befallsstärke als nekrotisierte Blattfläche in \% zum Zeitpunkt $16 \mathrm{dpi}$, Anzahl berücksichtigter Pflanzen (N), *Virulenzeinstufungen aus dem Rassenscreening bzw. nach, Isolat 28A, Rasse 23N (Condon et al., 2013) und 257A, Rasse 23 (Balint-Kurti P, pers. Mitteilung 04.04.2014) dienten als Referenzisolate aus den USA, unterschiedliche Buchstaben kennzeichnen signifikante Unterschiede (Kruskal-Wallis-Test, $p$ $\leq 0,05)$.

\begin{tabular}{|c|c|c|c|c|c|c|c|}
\hline \multirow[b]{2}{*}{ Isolat } & \multirow{2}{*}{$\begin{array}{l}\text { Virulenz- } \\
\text { einstufung* } \\
\text { auf } H t 2\end{array}$} & \multirow[b]{2}{*}{ Genotyp } & \multicolumn{3}{|c|}{ Virulenzeinstufung (Anteile in \%) } & \multirow{2}{*}{$\begin{array}{l}\text { Befallsstärke } \\
16 \text { dpi [\%] }\end{array}$} & \multirow{2}{*}{$\mathrm{N}$} \\
\hline & & & virulent & avirulent & intermediär & & \\
\hline $130-2$ & avirulent & $\mathrm{B} 37-\mathrm{Ht} 2$ & - & 100 & - & $5,2 \mathrm{a}$ & 9 \\
\hline $122-2$ & virulent & $\mathrm{B} 37-\mathrm{Ht} 2$ & - & 77 & 23 & $23,0 \mathrm{ab}$ & 9 \\
\hline $28 \mathrm{~A}$ & virulent & $\mathrm{B} 37-\mathrm{Ht} 2$ & 33 & 11 & 56 & 11,2 a & 9 \\
\hline $130-2$ & avirulent & KWS-Ht2 & - & 78 & 22 & $32,9 a b$ & 9 \\
\hline $122-2$ & virulent & KWS-Ht2 & - & 33 & 67 & $50,6 \mathrm{~b}$ & 9 \\
\hline $28 \mathrm{~A}$ & virulent & KWS-Ht2 & 56 & - & 44 & $51,7 \mathrm{~b}$ & 9 \\
\hline $257 \mathrm{~A}$ & virulent & KWS-Ht2 & & 100 & - & $50,6 \mathrm{~b}$ & 9 \\
\hline $130-2$ & avirulent & Pa91-Ht2 & - & 100 & - & 42,5 & 2 \\
\hline $122-2$ & virulent & Pa91-Ht2 & - & 100 & - & 64,0 & 2 \\
\hline $28 \mathrm{~A}$ & virulent & Pa91-Ht2 & 100 & - & - & 90,5 & 2 \\
\hline $257 \mathrm{~A}$ & virulent & Pa91-Ht2 & - & 100 & - & 60,0 & 2 \\
\hline \multicolumn{3}{|c|}{ Anteile der Virulenzeinstufungen: } & $=40-60 \%$ & & $=61-100 \%$ & & \\
\hline
\end{tabular}

eingestuft. Eine einheitliche Einstufung als avirulent erhielten auch die als virulent beschriebenen Isolate 122-2 und 257A. Dennoch lag für diese beiden Isolate die Befallsstärke mit $64 \%$ und $60 \%$ sehr hoch. Das virulente Isolat $28 \mathrm{~A}$ wurde auf der Linie Pa91-Ht2 einheitlich als virulent beschrieben und verzeichnete auf diesem Genotyp mit 90,5\% den höchsten Befallswert auf einem Genotyp mit dem Ht2 Resistenzgen.

In Abbildung 31 sind die Ergebnisse zur Bestimmung der Sporulation der verschiedenen Isolate auf den unterschiedlichen nah-isogenen Maisinzuchtlinien jeweils mit und ohne Resistenzgen $H t 2$ dargestellt. Für die Linie KWS ohne $H t 2$ war nicht ausreichend Saatgut vorhanden. Grundsätzlich zeigen die Daten, dass die Sporulation auf den Linien ohne Resistenzgen Ht2 zumindest für die Genotypen B37 und KWS deutlich höher ausfallen im Vergleich zu den Linien mit $H t 2$. Für den Genotyp Pa91 ist dieser Unterschied nicht eindeutig zu erkennen. Auf den Linien mit Ht2 Resistenzgen hebt sich vor allem das virulente Isolat 28A mit zum Teil sehr hohen Sporulationsraten von den anderen Isolaten ab. Auf dem Genotyp B37-Ht2 ist die Sporulation signifikant $(p \leq 0,05)$ höher im Vergleich zu den Isolaten 130-2 und 122-2. 


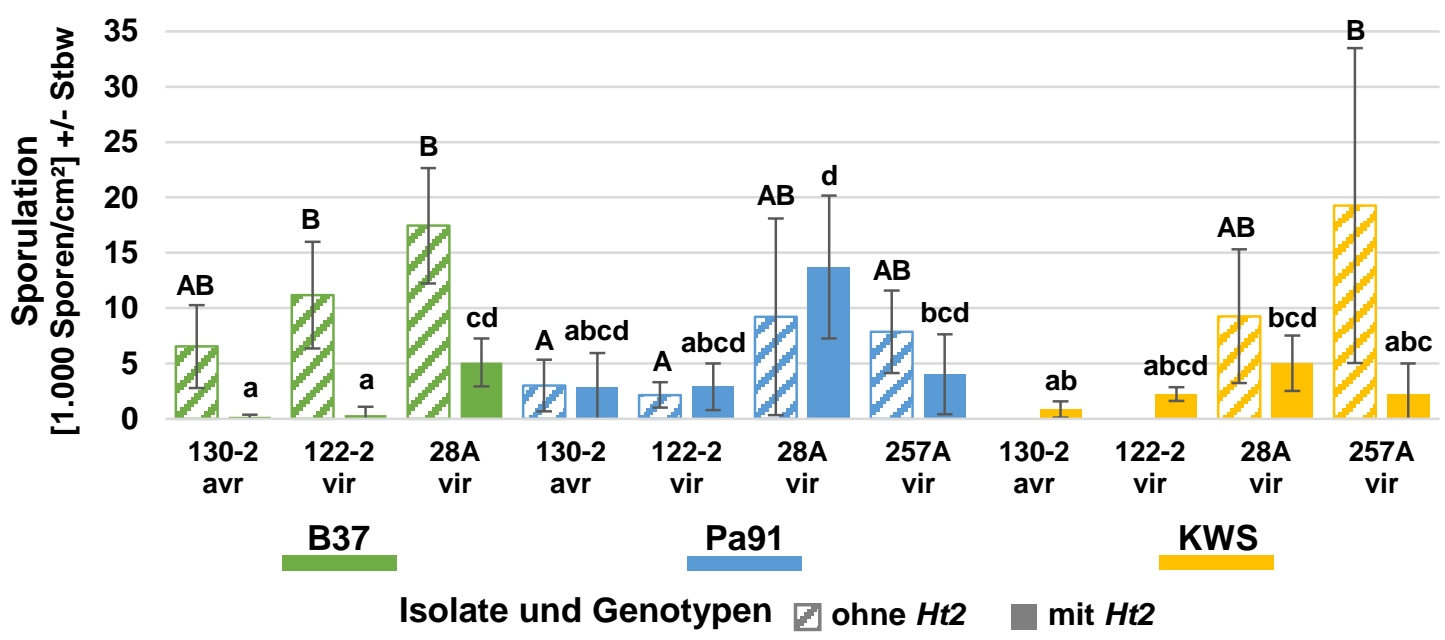

Abb. 31: Sporulation von E. turcicum Isolaten mit unterschiedlichen Virulenzeigenschaften für $H t 2$ auf verschiedenen nah-isogenen Maisinzuchtlinien jeweils mit und ohne Resistenzgen Ht2. Isolate 28A und 257A dienten als virulente Referenzisolate, unterschiedliche Buchstaben kennzeichnen signifikante Unterschiede (Kruskal-Wallis-Test, $p \leq 0,05), n=10$.

Für die beiden Genotypen Pa91-Ht2 und KWS-Ht2 weist das Isolat 28A ebenfalls die höchsten Sporulationsraten auf, allerdings ohne signifikanten Unterschied zu den anderen Isolaten auf der jeweiligen Linie. Auf dem Genotyp Pa91 liegt die Sprorulationsintensität des Isolates 28A auf der Linie mit Resistenzgen höher als auf der nah-isogenen Linie ohne Ht2. Die beiden europäischen Isolate weisen auf allen drei Maislinien mit Ht2 Resistenzgen die geringsten Sporualtionsraten im Vergleich zu den virulenten Isolaten aus den USA auf.

Für eine bessere Vergleichbarkeit der Isolate untereinander wurden die absoluten Werte der Merkmale Befallsstärke und Sporulation auf den Maislinien mit Ht2 Resistenzgen jeweils in Relation zu den Werten auf der entsprechenden nah-isogenen Linie ohne Resistenzgen gesetzt, wobei die Werte auf den Linien ohne Resistenzgen gleich 100 gesetzt wurden. In Abbildung 32 sind die Relativwerte für die Befallsstärke und die Sporulation abgebildet. Die Relativwerte beschreiben die Wirksamkeit des Resistenzgens Ht2 in Bezug auf die beiden Merkmale für jedes der Isolate. Je höher der Wert liegt, desto geringer ist die Wirkung von $\mathrm{Ht2}$ für das entsprechende Isolat. Bei einem Wert von 100 zeigte das Resistenzgen keine Wirkung. Für Befallsstärke war auf der Linie B37-Ht2 am niedrigsten. Den höchsten Wert auf B37-Ht2 verzeichnete das Isolat 122-2 mit 24,7\%, dieser lag auf der Linie Pa91-Ht2 bei 73,7\%. Den insgesamt geringsten Relativwert für das Merkmal Befallsstärke verzeichnete das Isolat 130-2 mit 5,6\% auf B37-Ht2. Auf der Linie Pa-91-Ht2 lag der Wert hingegen mit 55,6\%. zehnfach höher. 


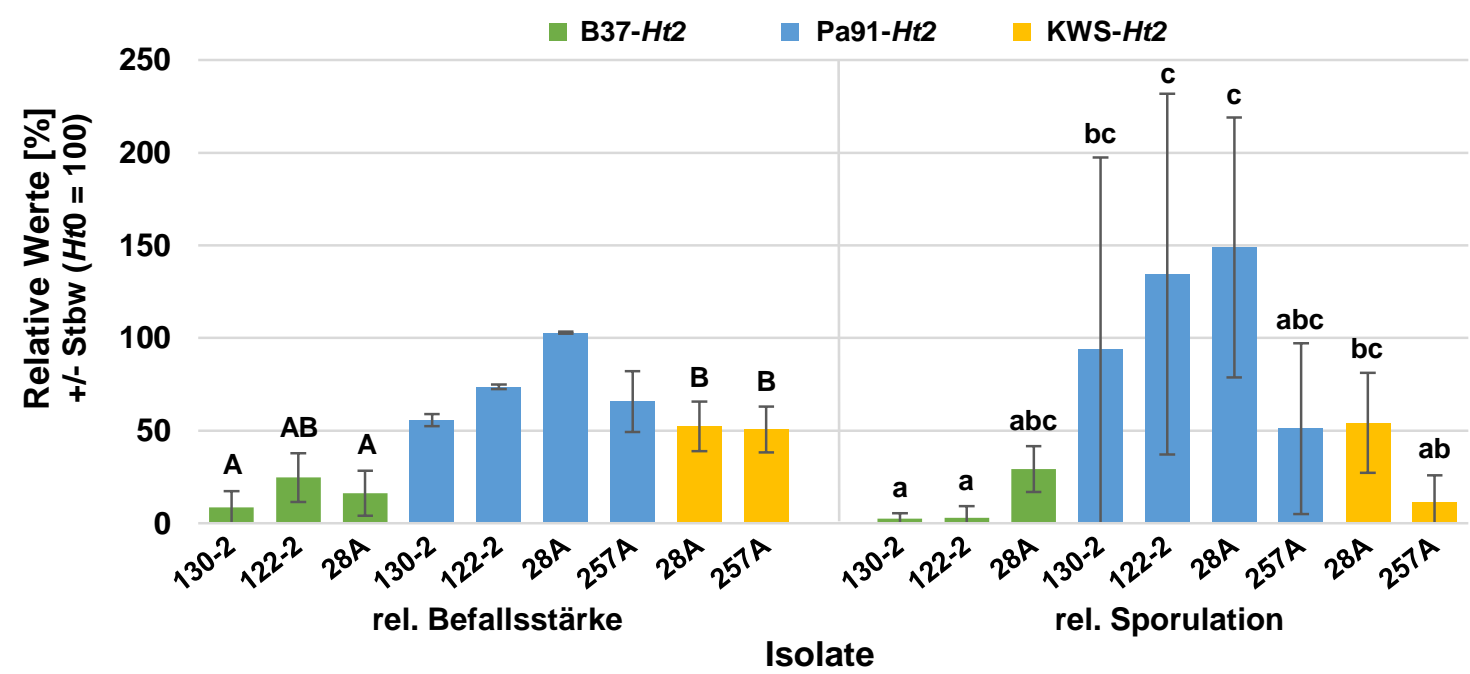

Abb. 32: Relative Befallsstärke und relative Sporulation von E. turcicum Isolaten auf Maisinzuchtlinien mit dem Resistenzgen $\mathrm{Ht2}$, Werte berechnet relativ zum Befall bzw. zur Sporulation auf der nah-isogenen Inzuchtlinie ohne $H t$ Resistenzgen $(H t O=100)$, Isolate 28A und 257A dienten als virulente Referenzisolate, Boniturzeitpunkt: $16 \mathrm{dpi}$; unterschiedliche Buchstaben kennzeichnen signifikante Unterschiede (Kruskal-Wallis-Test, $p \leq 0,05$ ), Befallsstärke: $n=9$, Sporulation: $n=10$.

Für das Isolat 28A lag der Wert auf der Linie B37-Ht2 mit 16,2\% ebenfalls deutlich unter dem Wert auf der Linie Pa91-Ht2 mit 102,8\% und unterschied sich zudem signifikant ( $p \leq$ $0,05)$ von dem Wert auf der Linie KWS-Ht2 mit 52,3\%. Die Tendenz zu höheren Befallswerten auf der Linie Pa91-Ht2 wird auch durch das virulente Isolat 257A bestätigt. Für dieses Isolat lag der Wert auf der Linie Pa91-Ht2 mit 65,5\% um ca. 15 Prozentpunkte höher im Vergleich zur Linie KWS-Ht2.

Insgesamt beschreiben die Relativwerte der Befallsstärke in Abbildung 32 für das Resistenzgen Ht2 eine abnehmende Wirkung in den genetischen Hintergründen in folgender Reigenfolge: B37 < KWS < Pa91. Für das Merkmal Sporulation konnten sehr ähnliche Effekte beobachtet werden. Für dieses Merkmal wies der Genotyp B37-Ht2 ebenfalls die geringsten Werte im Vergleich zu den Genotypen Pa91-Ht2 und KWS-Ht2 auf. Bei Werten von 2,5 und 2,9\% für die Isolate 130-2 und 122-2 bewirkte das Resistenzgen $\mathrm{Ht2}$ im genetischen Hintergrund der Linie B37 eine fast vollständige Reduktion der Sporulation. Die Werte für die entsprechenden Isolate lagen auf der Linie Pa91-Ht2 signifikant höher bei 94 und 134,5\%. Auf dieser Linie zeigte das Resistenzgen $H t 2$ gegenüber diesen beiden Isolaten für das Merkmal Sporulation keine Wirkung. Gegenüber dem Isolat 28A zeigte $\mathrm{Ht2}$ in der Linie B37 mit 29,2\% eine vergleichsweise deutliche Wirkung. Diese verringerte sich in der 


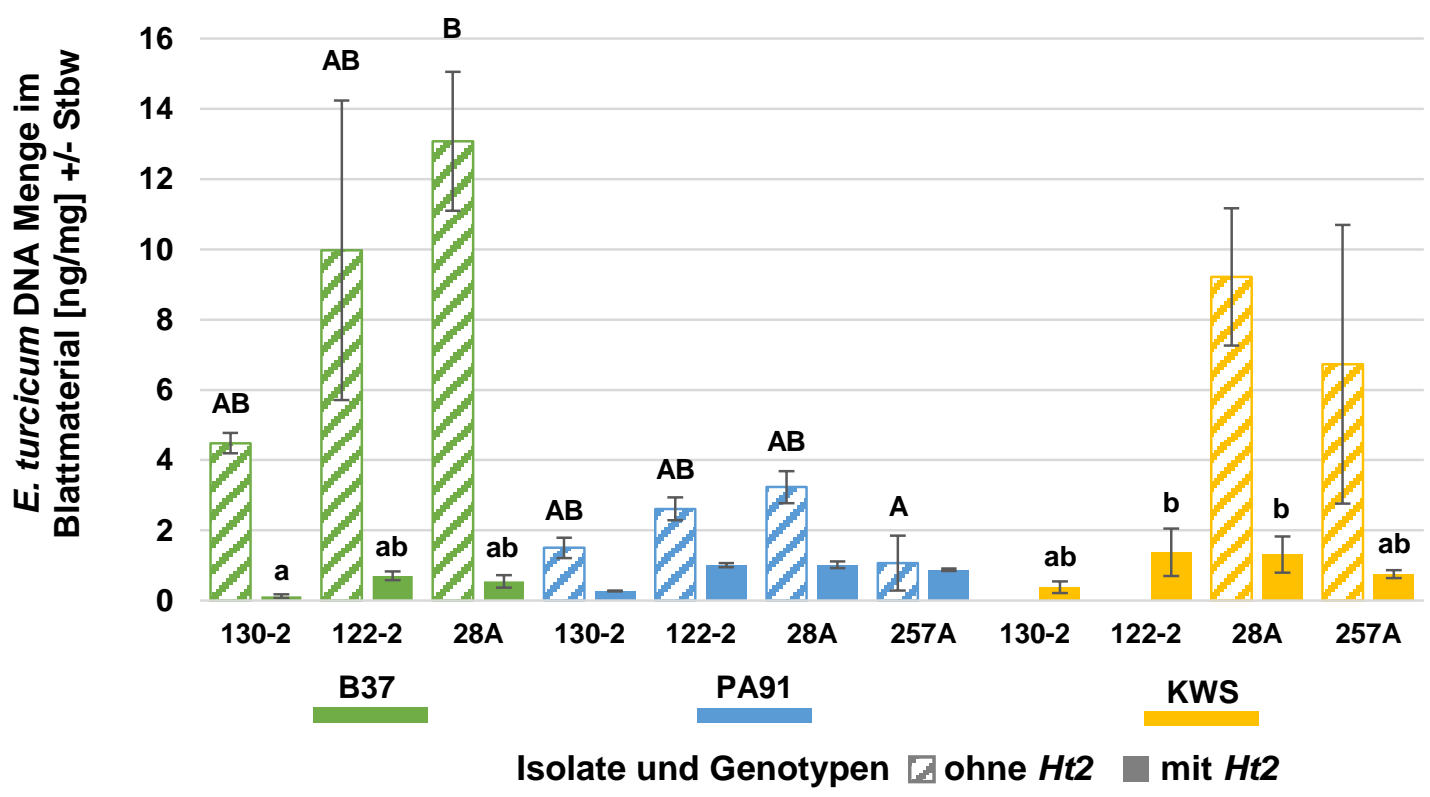

Abb. 33: DNA Menge von E. turcicum Isolaten mit unterschiedlichen Virulenzeigenschaften gegenüber $H t 2$ in befallenem Blattmaterial nah-isogener Maisinzuchtlinien. Isolate 122-2 (virulent) und 130-2 (avirulent) stammen aus Europa und die Isolate 28A und 257A (beide virulent auf $H$ t2) aus den USA, Probenahmezeitpunkt $16 \mathrm{dpi}$.

Linie KWS-Ht2 mit einem Wert von 54,2 noch einmal deutlich. Im Genotyp Pa91 war in Bezug auf die Sporulation mit einem relativen Wert von 148,9\% für das Isolat 28A keine Wirkung des Resistenzgens $H t 2$ zu beobachten. Für das Isolat 257A ist für die Linie Pa91 ebenfalls eine deutlich geringere Wirkung durch das Resistenzgen Ht2 in Bezug auf die Sporulation zu beobachten. Auf Basis der Versuchsergebnisse zu den Merkmalen Befallsstärke und Sporulation wurden signifikante Unterschiede in der Wirksamkeit des Resistenzgens $\mathrm{Ht2}$ in den verwendeten Maisinzuchtlinien festgestellt. Die höchste Wirksamkeit wurde für die Linie B37 beschrieben. In der Linie Pa91 wies $\mathrm{Ht} 2$ für alle getesteten Isolate und beide erhobenen Merkmale die geringste Wirksamkeit auf.

Das Blattmaterial aller Versuchsvarianten wurde auf den Gehalt an pilzlicher DNA von E. turcicum untersucht. Die Ergebnisse sind in Abbildung 33 dargestellt. Alle Maislinien ohne $H t 2$ Resistenzgen wiesen für die jeweiligen Isolate einen meist deutlich höheren PilzDNA-Gehalt auf im Vergleich zu ihren nah-isogenen Inzuchtlinien mit dem Resistenzgen Ht2. Für die Linie KWS ohne Ht2 war nicht ausreichend Saatgut vorhanden. Der Gehalt an E. turcicum-DNA lag für den Genotyp Pa91 ohne Ht2 im Vergleich zu den Genotypen B37 und KWS jeweils ohne $H t 2$ auf einem vergleichsweise niedrigen Niveau. Allen Maislinien mit Ht2-Resistenzgen waren durch die geringsten DNA-Gehalte des Isolates 130-2 gekennzeichnet. Den insgesamt geringsten Gehalt für das Isolat 130-2 verzeichnete die Linie B37- 
Ht2 mit 0,1 ng/mg TM. Die Gehalte an E. turcicum-DNA der anderen Isolate über alle Genotypen mit $H t 2$ lagen im Bereich zwischen 0,5 und 1,4 $\mathrm{ng} / \mathrm{mg}$ TM. Tendenziell lagen die Werte der Linien Pa91-Ht2 und KWS-Ht2 höher als die Werte auf der Linie B37-Ht2. Diese Unterschiede waren aber zu gering, um einen statistisch signifikanten Unterschied belegen zu können. 


\subsection{Histologische Untersuchungen zur Pathogenese von E. turcicum an Mais}

Für den Versuch zu den histologischen Untersuchungen wurden getrennt vom Versuch zum Rassenscreening Pflanzen neu angezogen und inokuliert. Um die Virulenzeigenschaften der verwendeten Isolate für diesen Versuch zu bestätigen, wurde eine Bonitur der Befallssymptome zu den Zeitpunkten 12 und 18 Tage nach Inokulation vorgenommen. In Tabelle 25 sind die Ergebnisse dieser beiden Boniturtermine neben den Ergebnissen aus dem Rassenscreening dargestellt. Die bonitierten Virulenzeigenschaften stimmten zum Zeitpunkt 18 dpi vollkommen mit den Ergebnissen aus dem Rassenscreening überein. Dadurch konnte für jedes der Resistenzgene mindestens eine kompatible und eine inkompatible Interaktion in den histologischen Untersuchungen abgebildet werden. Zum Zeitpunkt 12 dpi gab es für das Isolat 123-3 eine Abweichung für das Resistenzgen Ht2. In diesem Fall wurde das Isolat im Rassenscreening als virulent eingestuft und im aktuellen Versuch als avirulent. Nach weiteren vier Tagen (18 dpi) wurde das gleiche Isolat auf der Linie Ht2 als virulent eingestuft.

Tab. 25: Boniturergebnisse der Virulenzeigenschaften der für die histologischen Untersuchungen verwendeten Isolate auf dem Differentialsortiment der Linie B37 mit den Resistenz-genen $H t 1, H t 2, H t 3$ und $H t N$, Ergebnisse aus dem Rassenscreening und Ergebnisse der Isolate im Versuch zu den histologischen Untersuchungen (12 \& $18 \mathrm{dpi})$, *: A = avirulent, $\mathrm{V}=$ virulent (grau hervorgehoben).

\begin{tabular}{|c|c|c|c|c|c|c|c|c|c|c|c|c|c|}
\hline \multirow[b]{3}{*}{ Isolat } & \multirow[b]{3}{*}{ Rasse } & \multicolumn{12}{|c|}{ Virulenzeigenschaften* } \\
\hline & & \multicolumn{4}{|c|}{ Rassenscreening } & \multicolumn{4}{|c|}{$12 \mathrm{dpi}$} & \multicolumn{4}{|c|}{$18 \mathrm{dpi}$} \\
\hline & & $H t 1$ & $\mathrm{Ht} 2$ & $H+3$ & $H t N$ & $H+1$ & $\mathrm{Ht} 2$ & $H+3$ & $H t N$ & $H t 1$ & $\mathrm{Ht} 2$ & $H+3$ & $H t N$ \\
\hline $172-4$ & 0 & A & A & A & A & A & A & A & A & A & A & A & A \\
\hline $138-1$ & 1 & $\mathrm{~V}$ & A & A & A & $\mathrm{V}$ & A & A & A & $\mathrm{V}$ & A & A & A \\
\hline $123-3$ & $23 \mathrm{~N}$ & A & $\mathrm{V}$ & V & $\mathrm{V}$ & A & A & $\mathrm{V}$ & V & A & V & $\mathrm{V}$ & V \\
\hline
\end{tabular}

\subsubsection{Infektionsprozess von E. turcicum an Mais}

Für die histologischen Studien zur Interaktion von E. turcicum und Mais in tieferen Blattschichten wurde als Färbesubstanz Chlorazol Black E (CBE) verwendet. Lediglich für die initialen Schritte des Infektionsprozesses, wie die Sporenkeimung und Appressorienbildung auf der Blattoberfläche wurden weitere Färbesubstanzen verwendet. In Abbildung 34 sind die initialen Schritte des Infektionsprozesses in Form von lichtmikroskopischen Aufnahmen dargestellt. In Bild A ist eine bipolar gekeimte dunkel-braun erscheinende Konidiospore auf der Blattoberfläche zu erkennen. 

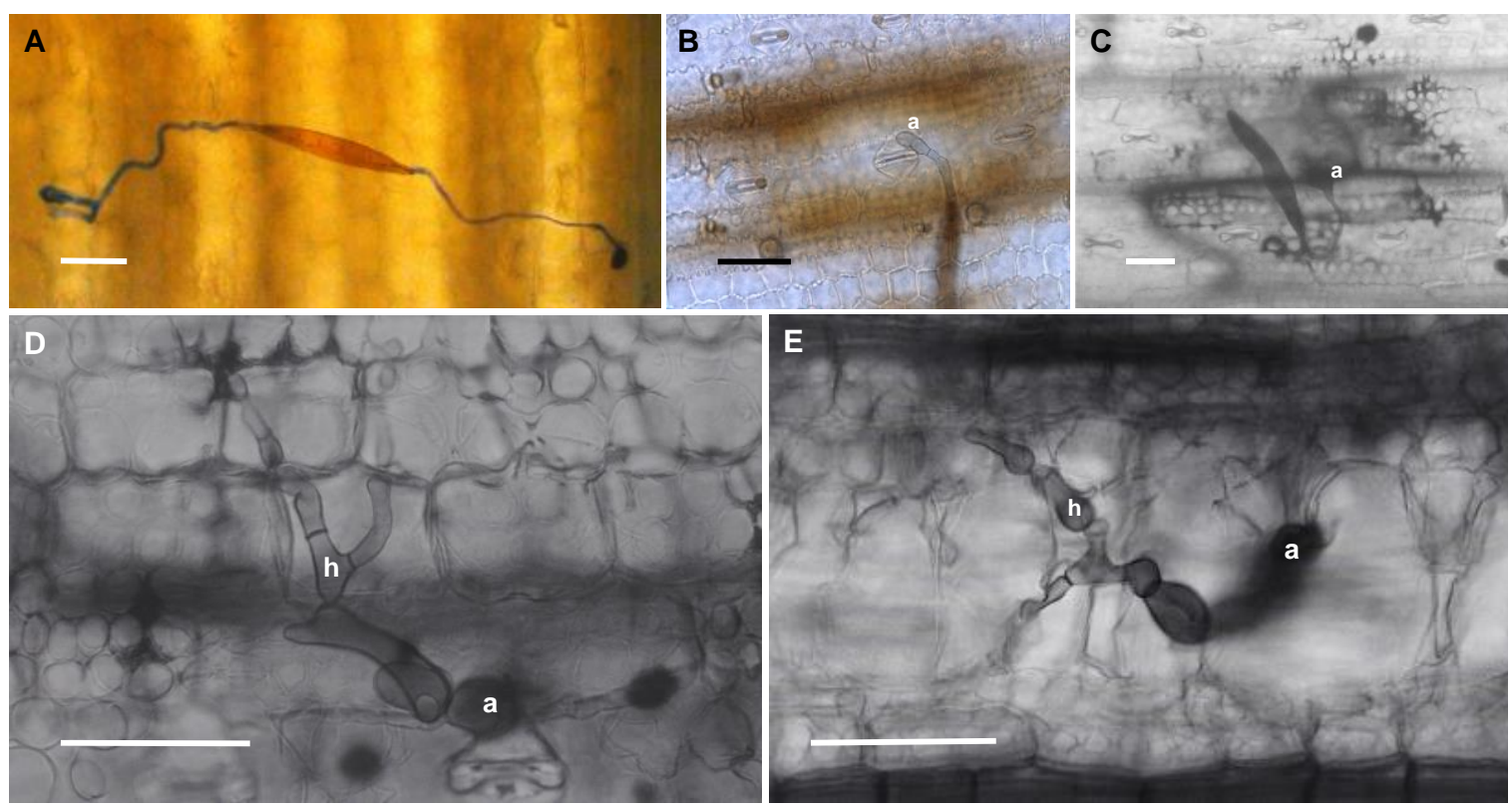

Abb. 34: Lichtmikroskopische Aufnahmen der Anfangsstadien der Pathogenese von E. turcicum an Mais einen Tag nach Inokulation; (A) Bipolar gekeimte Konidiospore mit Keimschläuchen und Appressorien nach Trypan-Blau Färbung in der Blattaufsicht; (B) Konidiospore mit Keimschlauch und Appressorium 3 dpi (a) mit bräunlich erscheinenden Bereichen entlang der Leitbündelgefäße nahe der Penetrationsstelle nach Entfärbung durch Ethanol in der Blattaufsicht; (C) dunkel erscheinender Bereich unter der Penetrationsstelle mit Konidiospore, Keimschlauch und Appressorium (a) nach Chlorazol Black E Färbung in der Blattaufsicht; (D und E) Intrazelluläres Hyphenwachstum (h) in den Epidermiszellen ausgehend vom Appressorium (a); verwendete Genotypen: A bis D: B37, E: B37-Ht2 inkompatibel; Maßstab: $50 \mu \mathrm{m}$.

An beiden Polen der Spore entspringt ein bläulich eingefärbter Keimschlauch, an dessen Enden jeweils ein Appressorium in Form einer dunkelblauen kreisförmigen Struktur zu erkennen ist. Die Färbung erfolgte in diesem Fall mit Trypan-Blau. Im Bild B ist eine gekeimte Konidiospore mit transparentem mehrfach septiertem Keimschlauch zu erkennen. Am Ende des Keimschlauches ist ein rundliches Appressorium (a) unmittelbar neben einer Spaltöffnung platziert. Entlang der Leitbündelgefäße erscheint eine bräunliche Verfärbung unter der Penetrationsstelle. Die Färbung der in den Bildern C bis E dargestellten Strukturen erfolgte mit CBE. Dieser Farbstoff lässt die Zellwände von Pilzen unter dem Lichtmikroskop schwarz erscheinen. Bild C zeigt eine gekeimte Spore mit Keimschlauch und Appressorium (a) auf der Blattoberfläche. Der Bereich der dunkel gefärbten Zellstrukturen mit den sich abgrenzenden schwarz/grau gefärbten Leitbahnen unterhalb des Appressoriums wird im Folgenden als Penetrationsstelle bezeichnet. Bild $D$ ist fokussiert auf die in der epidermalen Zellschicht intrazellulär wachsenden Hyphen, ausgehend vom Appressorium (a) auf der anfälligen Linie B37 einen Tag nach der Inokulation. Zu erkennen ist ein verzweigtes 
Wachstum septierter Hyphen mit rundlichen aufgetriebenen Hyphen an den Stellen, an denen eine Zellwandpenetration stattfindet. Im Bild E sind ebenfalls die ersten Schritte der Besiedlung der Epidermiszellen durch E. turcicum zu sehen. In diesem Fall handelt es sich um ein avirulentes Isolat auf dem Genotyp B37-Ht2 einen Tag nach Inokulation. Hier ist ähnlich wie auf dem anfälligen Genotyp B37 (Bild D) zu erkennen, wie die septierten Hyphen ( $h$ ) intrazellulär die Epidermiszellen des Maisblattes vom Appressorium (a) ausgehend besiedeln. Auch in diesem Fall sind rundlich aufgetriebene Hyphen an den Stellen der Zellwandpenetrationen zu beobachten, die sich zum Penetrationsort hin verjüngen, um nach der Passage durch die Zellwand wieder aufzutreiben. Grundsätzlich bleibt festzuhalten, dass in den ersten Stunden des Infektionsprozesses in Bezug auf die Faktoren Sporenkeimung, Appressorienbildung, Penetration und Besiedlung der Epidermiszellen keine Unterschiede zwischen den Maislinien mit den verschiedenen Resistenzgenen und den Isolaten mit unterschiedlichen Virulenzeigenschaften festgestellt werden konnten.

In Abbildung 35 sind die Stadien des Infektionsprozesses nach der Epidermispenetration dargestellt. Diese Stadien sind durch die Xylem-Besiedlung bis hin zu einer intensiven Kolonisation des Mesophylls charakterisiert. Bild A zeigt eine Penetrationsstelle (ps) mit einem darunter verlaufenden Xylemgefäß. In diesem Xylemgefäß verläuft eine septierte Hyphe (hy) in beide Richtungen. Ausgehend von der Penetrationsstelle hat eine erfolgreiche Penetration der Xylemwand und folgendem Hyphenwachstum im Xylem stattgefunden. Bild $B$ zeigt intrazelluläres Hyphenwachstum (hy), ausgehend vom Appressorium (a) in einer kompatiblen Interaktion auf der Linie B37-Ht3 einen Tag nach der Inokulation. Darüber hinaus ist die Stelle der Penetration der Xylemwand (xp) mit den typischen rundlichen Strukturen an beiden Seiten der Penetrationsstelle zu erkennen. Im Xylemgefäß ist ein Wachstum septierter Hyphen in beide Richtungen sichtbar. 


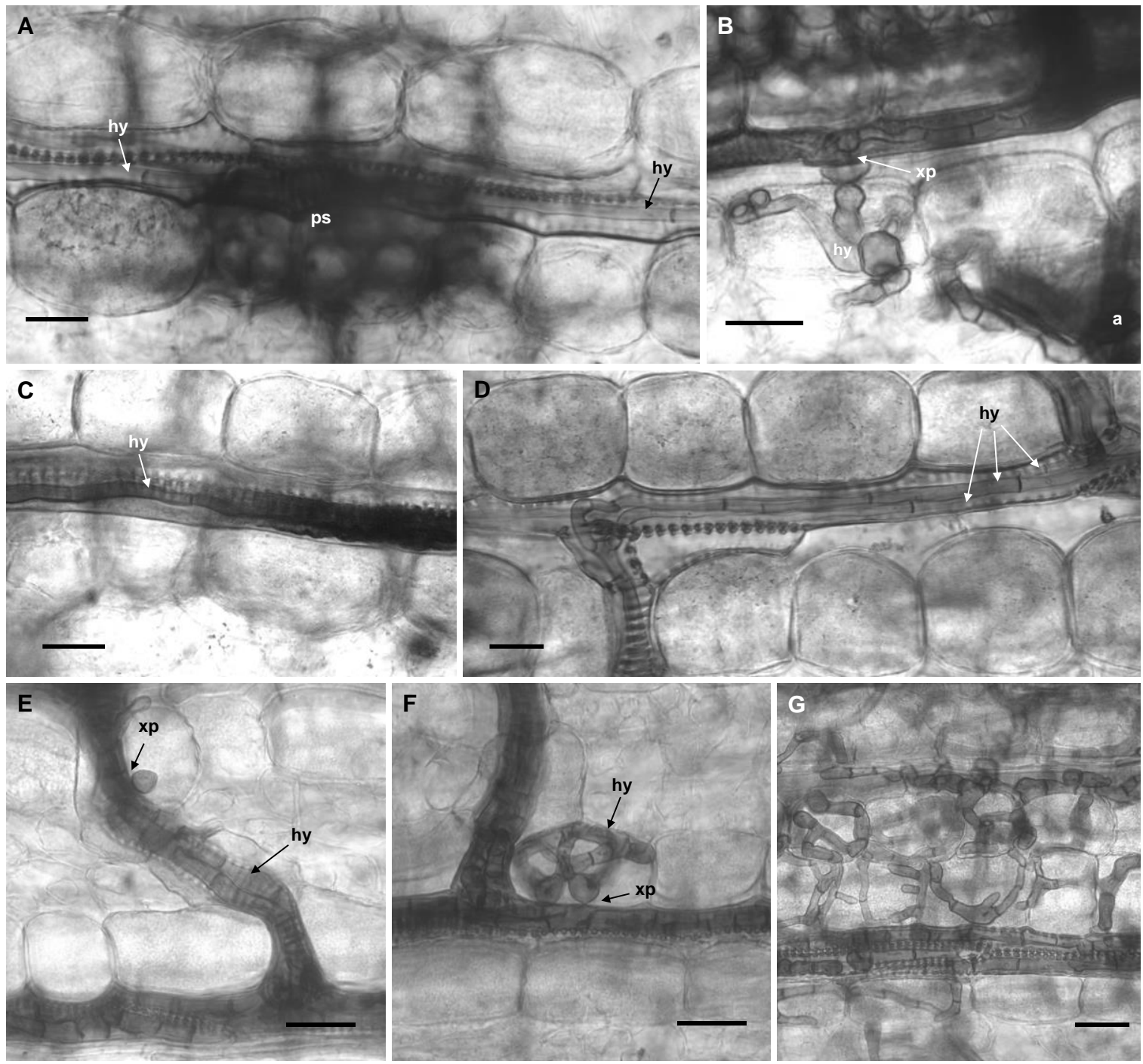

Abb. 35: Lichmikroskopische Aufnahmen verschiedener Stadien der Pathogenese von E. turcicum an Mais; (A) Erfolgreich penetriertes und durch Hyphen (hy) besiedeltes Xylemgefäß unterhalb einer Penetrationsstelle (ps), (B) Hyphenwachstum (hy) im Mesophyll ausgehend vom Appressorium (a) in Richtung Xylem, Xylempenetrationsstelle (xp) als rundliche Pilzstrukturen außen und innen an der Xylemwand; (C) Hyphenwachstum (hy) im Xylem gestoppt durch Abwehrreaktion (ar) im Xylem; (D) Starkes Hyphenwachstum mehrerer Einzelhyphen (hy) im quervernetzem Xylem; (E) Vollständig durch Hyphen (hy) gefülltes Xylem mit rundlicher Pilzstruktur als Austrittsstelle an der äußeren Xylemwand, Xylempenetrationsstelle (xp); (F) Austritt von Pilzhyphen in das Mesophyll an der Xylempenetrationsstelle (xp) mit rundlicher Pilzstruktur an der äußeren Xylemwand; (G) Intensive Kolonisation der Bündelscheidenzellen und des Mesophylls durch Pilzhyphen ausgehend vom stark besiedelten Xylem; Genotyp, Zeitpunkt, Interaktion: A: B37 6dpi, B: B37-Ht3 1dpi kompatibel, C: B37-Ht1 6dpi inkompatibel, D: B37 6dpi, E bis G: B37 12dpi, Längenmaßstab: $50 \mu \mathrm{m}$.

In Bild $C$ ist ein horizontal verlaufendes Xylemgefäß mit einer von links nach rechts gewachsenen Hyphe (hy) zu sehen. Es handelt sich in diesem Fall um eine inkompatible Interaktion auf der Maislinie B37-Ht1 sechs Tage nach Inokulation. Im rechten Teil des Xylems ist deutlich ein dunkel erscheinender Bereich zu sehen. Das Hyphenwachstum ist innerhalb 
dieses dunklen Bereiches stark reduziert bzw. unterbunden. Der dunkel erscheinende Teil des Xylems könnte auf Substanzen zurückgehen, die als Abwehrreaktion (ar) der Pflanze auf die Xylem-Besiedlung gebildet wurden. In Bild D ist ein horizontal verlaufendes Xylemgefäß mit Querverbindungen der Linie B37 sechs Tage nach Inokulation zu sehen. Im Xylemgefäß sind mehrere septierte Hyphen (hy) nebeneinander und übereinander verlaufend sichtbar. Zudem ist deutlich zu erkennen, wie sich die Hyphen über die Querverbindungen in alle Richtungen in den Xylemgefäßen ausbreiten. Die Aufnahmen E bis G stammen von der Linie B37 12 Tage nach Inokulation. Zu diesem Zeitpunkt traten bereits sichtbare welkeähnliche Symptome an der Pflanze auf. Eine vollständig mit Pilzhyphen (hy) besiedelte Xylem Querverbindung ist in Bild E zu sehen. Im Xylem sind einzelne Hyphen anhand ihrer Septierungen zu erkennen. Im oberen Bereich der Querverbindung ist eine rundliche abgeschnürte pilzliche Struktur an der Außenwand des Xylems sichtbar. An dieser Stelle (xp) hat der Pilz die Xylemwand penetriert und ist in die anliegenden Bündelscheidenzellen eingedrungen. Im Bild F ist ebenfalls ein sehr stark durch Pilzhyphen kolonisiertes Xylemgefäß mit einer Querverbindung zu sehen. Wie in Bild E ist es dem Pilz an einer Stelle gelungen, die Xylemwand zu penetrieren (xp). Nach der Xylempenetration ( $x p)$ ist ausgehend von der rundlichen abgeschnürten Struktur deutliches Hyphenwachstum (hy) innerhalb der penetrierten Bündelscheidenzelle sichtbar. In der Aufnahme G ist ein stark mit Hyphen besiedeltes horizontal verlaufendes Xylemgefäß zu sehen. Darüber hinaus ist die Besiedlung durch die Pilzhyphen bis weit in die Mesophyllzellen fortgeschritten. Deutlich zu erkennen sind die septierten Hyphen, die sich zunächst in der nächsten penetrierten Zelle ausbreiten, um dann direkt eine weitere benachbarte Zelle zu penetrieren und zu besiedeln. Zu diesem Zeitpunkt ist das pflanzliche Gewebe bereits vollständig kollabiert und abgestorben. Die Symptome auf den Blättern erscheinen zunächst wie grau-grünliche Welkesymptome nach Wassermangel. Das Unterbinden des Wassertransports durch die mit Pilzhyphen verstopften Xylemgefäße führt zum Austrocknen der befallenen Blattbereiche und letztlich zum Absterben des besiedelten Gewebes.

\subsubsection{Vergleichende Auswertung der mikroskopischen Untersuchungen}

In Gewächshausversuchen wurden die nah-isogenen Maislinien B37, B37-Ht1, B37-Ht2, $\mathrm{B} 37-\mathrm{Ht3}$ und B37-HtN jeweils mit virulenten bzw. avirulenten Isolaten inokuliert. Dadurch war es möglich, die Pathogenese von E. turcicum in einer inkompatiblen und kompatiblen Interaktion für jedes der Resistenzgene zu untersuchen. Nach der Probenahme zu den Zeitpunkten 1, 3, 6, 12 und 18 dpi wurden für jede Variante 40 Penetrationsstellen mikroskopisch nach Chlorazol Black E Färbung ausgewertet. Mit Hilfe des Merkmals „Xylem- 
Penetrations-Effizienz" ist es möglich, eine qualitative Aussage über die Effizienz der Xylempenetration zu treffen. Ein Wert von 20\% bedeutet für dieses Merkmal, dass ausgehend von 40 Sporen, die erfolgreich die Epidermis penetriert haben (= Penetrationsstelle), $20 \%$ erfolgreich das Xylem penetriert haben. Dies ist eine rein qualitative Bewertung, da dieser Wert noch keine Aussage darüber trifft, wie intensiv die Xylem-Besiedlung stattgefunden hat.

In Abbildung 36 sind die Ergebnisse zum Merkmal Xylem-Penetrations-Effizienz für alle untersuchten Resistenzgene zu allen erhobenen Zeitpunkten jeweils in der inkompatiblen (A) und kompatiblen (B) Interaktion dargestellt. Die gekennzeichneten signifikanten Unterschiede beziehen sich immer auf einen Zeitpunkt und auf die Linie B37 ohne Ht Resistenzgen. Einen Tag nach Inokulation zeigten alle Linien in der inkompatiblen Interaktion sehr geringe Werte zwischen 2,5 und 5\% ohne signifikante Unterschiede zu B37. Bereits zwei Tage später (3 dpi) erreichten die Linien B37 und B37-Ht2 den Wert 20\%.

Den geringsten und signifikant reduzierten Wert verzeichnete die Linie B37- HtN mit 5\%. Alle anderen Linien zeigten zu diesem Zeitpunkt keinen signifikanten Unterschied zur Linie B37. Bereits sechs Tage nach Inokulation war E. turcicum an $50 \%$ der Penetrationsstellen der Linie B37 erfolgreich in das Xylem eingedrungen. Den höchsten Wert unter den Linien mit Resistenzgen erreichte B37-Ht2 mit 35\% und unterschied sich als einzige Linie zu diesem Zeitpunkt nicht signifikant von B37. Alle anderen Resistenzgene zeigten mit Werten zwischen 25 und 17,5\% zu diesem Zeitpunkt eine signifikante Reduktion in der Penetrationsrate des Xylems. Weitere sechs Tage später (12 dpi) ging mit einem Wert von 98,8\% auf der Linie B37 von fast jeder Penetrationsstelle eine erfolgreiche Besiedlung des Xylems aus. Alle Resistenzgene bewirkten zu diesem Zeitpunkt eine deutliche und signifikante ( $p \leq$ 0,001) Reduktion der Xylem Penetration. Die stärkste Reduktion erreichte HtN mit einem Wert von 7,5\%. Die geringste Reduktion verzeichnete $H t 3$ mit 35\%. Zum Zeitpunkt 18 dpi erreichten alle Resistenzgene mit Werten zwischen 37,5 und $20 \%$ ebenfalls eine signifikante ( $p \leq 0,001)$ Reduktion der Xylem-Besiedlung gegenüber der Linie B37 mit einem Wert von $97,5 \%$. Trotz der inkompatiblen Interaktion lagen die Werte sechs Tage nach Inokulation für die Resistenzgene $H t 1, H t 2$ und $H t 3$ bereits bei $20 \%$ oder höher. Spätestens zum Zeitpunkt 18 dpi verzeichneten alle avirulenten Isolate Werte von über $20 \%$. Der Wert für Ht1 lag am letzten Zeitpunkt bei 37,5\%.

Im unteren Teil der Abbildung 36 sind die Ergebnisse der Xylem-Penetrations-Effizienz der kompatiblen Interaktionen dargestellt. Im Vergleich zu den inkompatiblen Interaktionen traten hier bereits am ersten Tag nach der Inokulation signifikante Unterschiede zur Linie B37 auf. Die Linien B37-Ht1 und B37-HtN wiesen zum Zeitpunkt 1dpi mit 22,5\% und $20 \%$ als einzige Linien signifikant $(p \leq 0,01)$ höhere Werte im Vergleich zur Linie B37 mit 5\% auf. 

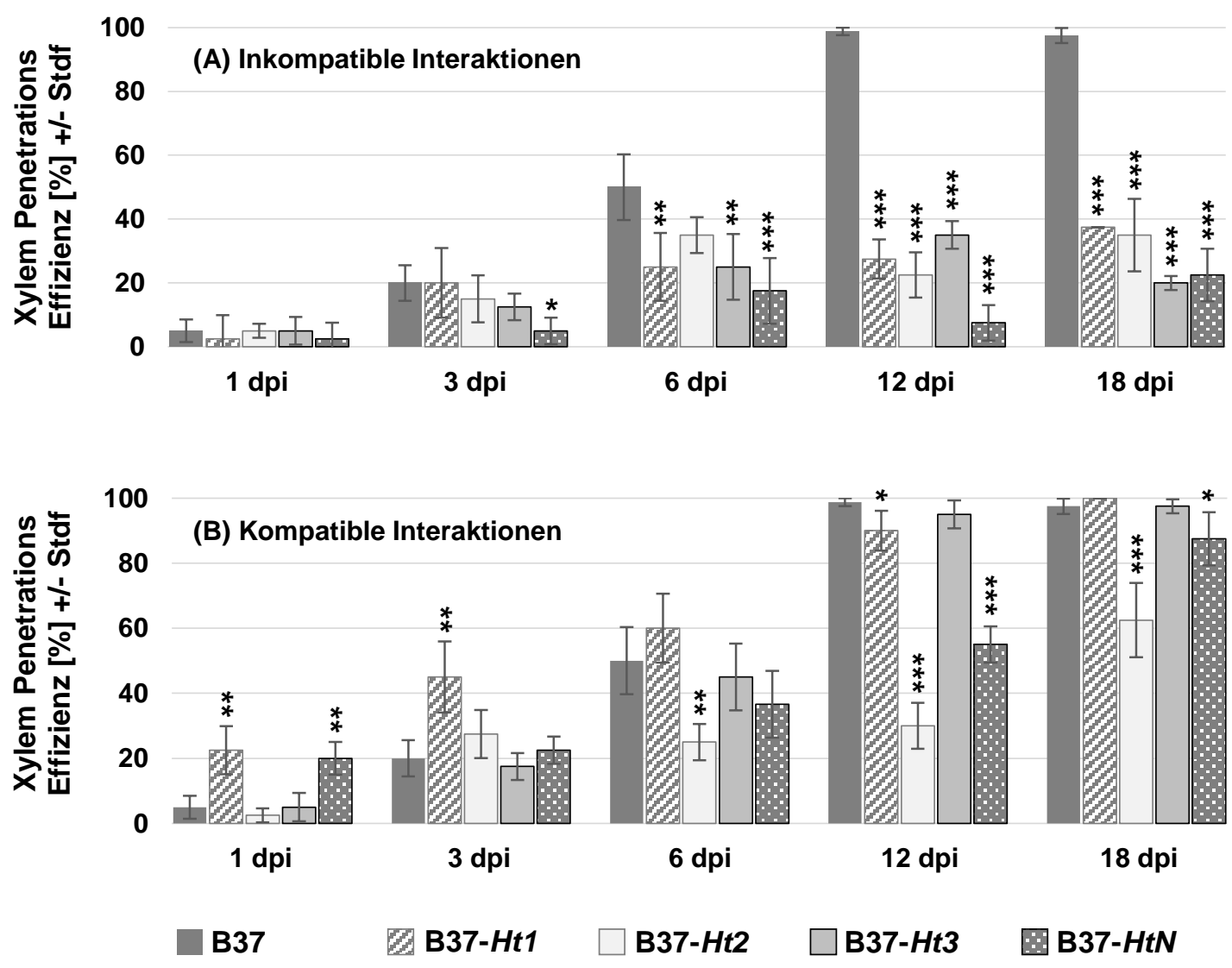

Abb. 36: Effekte der Resistenzgene $H t 1, H t 2, H t 3$, und $H t N$ in der Maislinie B37 auf die Xylem-Penetrations-Effizienz von E. turcicum an sechs verschiedenen Zeitpunkten des Krankheitsverlaufs jeweils in inkompatiblen und kompatiblen Interaktionen, $d$. $h$. je einem avirulenten und virulenten Isolat. Ausgehend von $\mathbf{4 0}$ Penetrationsstellen der Epidermis beschreibt jeder Wert den Anteil der Stellen, denen eine erfolgreiche Penetration des Xylems (= Hyphen im Xylem sichtbar) folgte, signifikante Unterschiede gegenüber der nah-isogenen Linie B37 sind wie folgt gekennzeichnet: ${ }^{*} p \leq 0,05 ;{ }^{* *} p \leq 0,01 ;{ }^{* \star *} p \leq 0,001$; Chi-Quadrat Test, Standardfehler ist aus dem Mittelwert von vier Wiederholungen berechnet: 4 Blattsegmente $\times 10$ Penetrationsstellen, $n=40$.

Zwei Tage später (3dpi) erreichte die Linie B37-Ht1 den höchsten Wert von 45\% und zeigte damit als einzige Linie einen signifikant verschiedenen Wert von der Linie B37 mit 20\%. Die Werte der anderen drei Linien B37-Ht2, B37-Ht3 und B37-HtN lagen im Bereich zwischen 17,5 und 27,5\% ohne signifikante Abweichung vom Wert der Linie B37. Sechs Tage nach Inokulation wiesen 60\% der untersuchten Penetrationsstellen auf der Linie B37-Ht1 eine erfolgreiche Besiedlung des Xylems auf. Dieser Wert stellte gefolgt von der Linie B37 mit $50 \%$ den höchsten Wert zu dem Zeitpunkt dar. Die Werte der Linien B37-Ht3 und B37-HtN lagen mit $45 \%$ und $36,7 \%$ unter $50 \%$, aber nicht statistisch signifikant niedriger zur Linie B37. Als einzige Linie wies B37-Ht2 mit einem Wert von $25 \%$ einen statistisch signifikant ( $p$ $\leq 0,01)$ geringeren Wert auf. Bei den inkompatiblen Interaktionen wiesen alle Linien bis auf B37-Ht2 zum Zeitpunkt 6 dpi eine signifikante Reduktion der Xylem-Penetrations-Effizienz 
auf. In der kompatiblen Interaktion ist dies genau umgekehrt lediglich für die Linie B37-Ht2 zu beobachten. Alle anderen Linien mit Resistenzgen weisen Werte auf, die sich nicht signifikant von der Linie B37 unterscheiden. Sechs Tage später (12dpi) erreichen die Linien B37, B37-Ht1 und B37-Ht3 sehr hohe Werte von 90\% oder höher. Einzig die Linie B37-Ht1 unterscheidet sich trotz des sehr hohen Wertes von $90 \%$ signifikant $(p \leq 0,05)$ von der Linie B37. Die Linie B37- $H t N$ weist mit $55 \%$ einen relativ hohen, aber dennoch genau wie die Linie B37-Ht2 mit 30\% einen signifikant geringeren Wert im Vergleich zur Linie B37 auf. Am letzten Boniturtermin 18 dpi lagen die Werte für die Linien B37, B37-Ht1 und B37-Ht3 ohne signifikante Unterschiede bei nahezu 100\%. Der Wert der Linie B37-HtN lag mit 87,5\% sehr hoch, dennoch unterschied er sich signifikant $(p \leq 0,05)$ von der Linie B37 $(97,5 \%)$. Mit $62,5 \%$ wies die Linie B37-Ht2 den geringsten Wert für eine kompatible Interaktion zum Zeitpunkt 18 dpi auf.

Zusammenfassend konnte für die inkompatiblen Interaktionen für alle Resistenzgene eine deutliche und signifikante, wenn auch nicht vollständige, Reduktion der Xylem Penetration ab dem Zeitpunkt 12 dpi nachgewiesen werden. Für die kompatiblen Interaktionen konnte für die Resistenzgene $H t 1$ und $H t 3$ ein nahezu vollständiger Wirksamkeitsverlust über den gesamten Boniturzeitraum nachgewiesen werden. Für die Resistenzgene Ht2 und HtN lagen die Werte für die Xylem-Penetration in der kompatiblen Interaktion zwar deutlich höher als in der inkompatiblen Interaktion, aber dennoch spätestens ab dem Zeitpunkt 12 dpi signifikant unter dem der nah-isogenen Linie B37.

Anhand des Merkmals Xylem-Penetration-Effizienz wurde eine Einstufung vorgenommen, um die Xylem-Penetration in der inkompatiblen und kompatiblen Interaktion zwischen den resistenzgentragenden isogenen Linien auf eine qualitative Weise zu vergleichen. Um darüber hinaus die Wirksamkeit der Resistenzgene auf die quantitative Besiedlung des Pflanzengewebes durch E. turcicum beschreiben zu können, wurden die Merkmale Xylem-Besiedlungs-Effizienz und Mesophyll-Besiedlungs-Effizienz verwendet. Das Merkmal XylemBesiedlungs-Effizienz beschreibt den Anteil der Penetrationstellen, von denen eine Besiedlung des Xylems mit zwei oder mehr Hyphen je Xylem Gefäß ausging. Durch das Merkmal Mesophyll-Besiedlungs-Effizienz wurde der Anteil der Penetrationstellen beschrieben, von denen eine erfolgreiche Besiedlung des Mesophylls ausging. Die erfolgreiche Besiedlung des Mesophylls setzte in diesem Fall einen Austritt der Pilzhyphen aus dem Xylem durch Penetration der Xylemwand von innen nach außen voraus. In Abbildung 37 sind die Ergebnisse der Merkmale Xylem- und Mesophyll-Besiedlungs-Effizienz zu verschiedenen Zeitpunkten jeweils für inkompatible (A) und kompatible (B) Interaktionen dargestellt. 
(A) Inkompatible Interaktionen
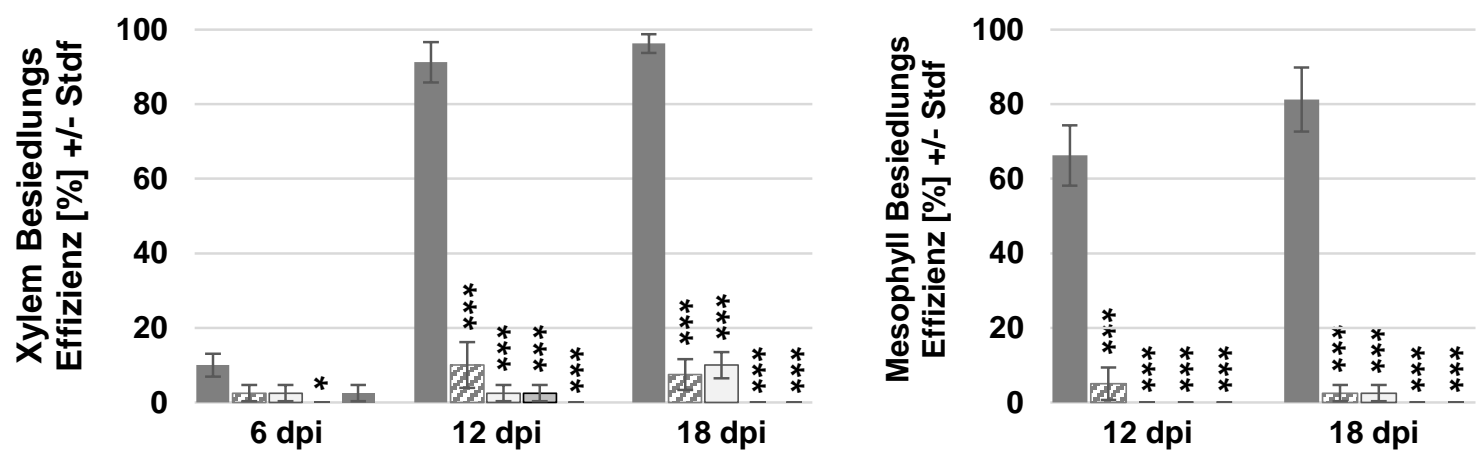

(B) Kompatible Interaktionen

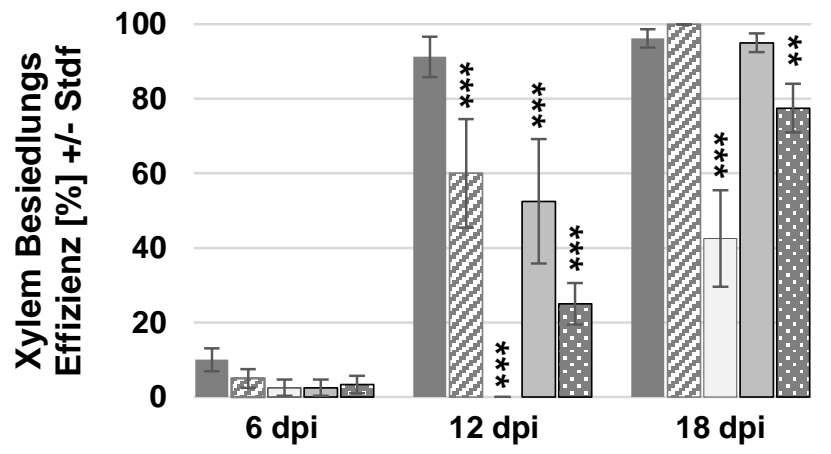

B37
ஜB37-Ht1 $\square$ B37-Ht2
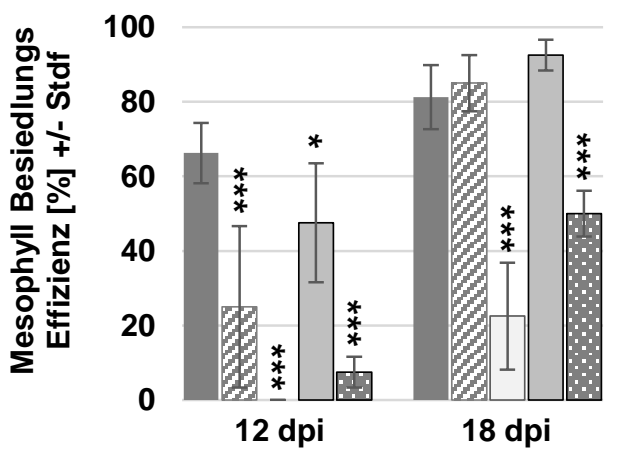

B37-Ht3

B37-HtN

Abb. 37: Effekte der Resistenzgene $H t 1, H t 2, H t 3$, und $H t N$ im genetischen Hintergrund der Maislinie auf die Effizienz der Xylem- und Mesophyll-Besiedlung durch E. turcicum an drei bzw. zwei verschiedenen Zeitpunkten des Krankheitsverlaufs in inkompatiblen und kompatiblen Interaktionen, d. h. je einem avirulenten und virulenten Isolat. Ausgehend von $40 \mathrm{Pe}-$ netrationsstellen der Epidermis beschreibt jeder Wert den Anteil der Stellen, denen eine erfolgreiche Besiedlung des Xylems (= mehr als 2 Hyphen im Xylem sichtbar) bzw. des Mesophylls folgte, signifikante Unterschiede gegenüber der nah-isogenen Linie B37 sind wie folgt gekennzeichnet: ${ }^{*} p \leq 0,05 ;{ }^{\star \star} p \leq 0,01$; ${ }^{* \star \star} p \leq 0,001$; Chi-Quadrat Test, Standardfehler ist aus dem Mittelwert von vier Wiederholungen berechnet: 4 Blattsegmente $x 10$ Penetrationsstellen, $n=40$.

Zunächst soll nun näher auf das Merkmal Xylem-Besiedlungs-Effizienz eingegangen werden. Bei diesem Merkmal zeigten sich bis einschließlich sechs Tage nach Inokulation sowohl in der inkompatiblen als auch in der kompatiblen Interaktion kaum signifikante Unterschiede zu B37. Den höchsten Wert verzeichnete zu diesem Zeitpunkt die Linie B37 mit 10\%. Alle anderen Linien mit Resistenzgen lagen unterhalb von 5\%. Bereits sechs Tage später (12 dpi) lag der Wert für B37 bei 91,3\%. In den inkompatiblen Interaktionen waren alle resistenzgentragenden Linien in der Lage, die Xylem-Besiedlung deutlich und signifikant $(p \leq 0,001)$ zu reduzieren. Den höchsten Wert verzeichnete B37-Ht1 mit 10\%. Alle anderen Werte lagen bei 2,5\% oder niedriger. Im Gegensatz dazu wiesen die Linien mit 
Resistenzgen in der kompatiblen Interaktion sehr heterogene und zudem deutlich höhere Werte auf. Den höchsten Wert verzeichnete B37-Ht1 mit 60\% gefolgt von B37-Ht3 und B37$H t N$ mit 52,5\% und 25\%. Auf der Linie B37-Ht2 wurde zum Zeitpunkt 12 dpi kein Xylemgefäß beobachtet, das durch mehr als eine Pilzhyphe besiedelt worden war.

Alle Werte der Linien mit Resistenzgen lagen signifikant $(p \leq 0,001)$ unter dem Wert der Linie B37 mit 91,3\%. Weitere sechs Tage später zum Boniturzeitpunkt 18 dpi betrug der Wert für B37 96,3\%. In den inkompatiblen Interaktionen zeigten auch an diesem Zeitpunkt die Linien mit Resistenzgen signifikant ( $p \leq 0,001)$ reduzierte Werte. Den höchsten, aber dennoch relativ niedrigen, Wert verzeichnete B37-Ht2 mit 10\%. In den kompatiblen Interaktionen lagen die Werte der Linien B37-Ht1 und B37-Ht3 zum Zeitpunkt 18 dpi mit 100\% und 95\% auf sehr hohem Niveau ohne signifikanten Unterschied zu B37 mit 96,3\%. Die Linie B37- $H t N$ wies mit $77,5 \%$ einen ebenfalls hohen Wert auf. Dieser lag aber signifikant unter dem der Linie B37. Den geringsten Wert verzeichnete die Linie B37-Ht2 mit einem signifikant niedrigeren Wert von $42,5 \%$.

Zusammenfassend bleibt festzuhalten, dass für die Besiedlung des Xylems erst ab 12 Tage nach der Inokulation ein deutlicher Anstieg in der Xylem-Besiedlung beobachtet werden konnte. In den inkompatiblen Interaktionen waren alle Resistenzgene in der Lage, die Xylem-Besiedlung durch zwei oder mehr Hyphen je Xylem-Gefäß auf maximal 10\% zu begrenzen. In den kompatiblen Interaktionen konnte für die Resistenzgene $\mathrm{Ht2}$ und $\mathrm{HtN}$ zum Zeitpunkt $18 \mathrm{dpi}$ noch eine Wirkung nachgewiesen werden. Diese Reduktion lag für Ht2 mit knapp 60\% relativ hoch. Die Resistenzgene $H t 1$ und $H t 3$ waren zu diesem Zeitpunkt wirkungslos.

In Abbildung 37 ist auf der rechten Seite das Merkmal Mesophyll-Besiedlungs-Effizienz abgebildet. Für dieses Merkmal waren generell erst ab dem zwölften Tag nach Inokulation Effekte zu beobachten. Die Werte für die Linie B37 lagen zwölf Tage nach Inokulation bei $66,3 \%$ und weitere sechs Tage später bei $81,3 \%$. In den inkompatiblen Interaktionen waren alle Resistenzgene sehr effektiv in der Lage, die Besiedlung des Mesophylls durch E. turcicum zu verhindern. Den höchsten Wert an den Zeitpunkten 12 und 18 dpi verzeichnete B37- $\mathrm{H} 1$ mit einem sehr geringen Wert von 5\%. Die Resistenzgene $\mathrm{Ht3}$ und $\mathrm{HtN}$ konnten eine Mesophyll-Besiedlung in den inkompatiblen Interaktionen vollständig verhindern. Bei den kompatiblen Interaktionen zeigten die unterschiedlichen Resistenzgene sehr heterogene Ergebnisse in Bezug auf die Mesophyll-Besiedlung. Das Resistenzgen Ht2 verhinderte zum Zeitpunkt 12 dpi die Mesophyll-Besiedlung noch vollständig. Für die Linien mit den Resistenzgene $H t 1$ und $H t N$ wurden Werte in Höhe von $25 \%$ und $7,5 \%$ festgestellt. Diese Werte stellen nach wie vor eine signifikante Reduktion gegenüber der Linie B37 dar. Die geringste Wirksamkeit zeigte das Resistenzgen $H t 3$ mit einem Wert von 47,5\%. Dieser 
Wert lag dennoch signifikant $(p \leq 0,05)$ unter dem der Linie B37. Am letzten Boniturtermin 18 Tage nach der Inokulation zeigten die beiden Resistenzgene Ht1 und Ht3 in der kompatiblen Interaktion keine Wirkung gegen die Besiedlung des Mesophylls durch E. turcicum. Ihre Werte lagen mit 85\% und 92,5\% sogar leicht über dem Wert der Linie B37 mit 81,3\%. Die beiden Linien mit den Resistenzgenen $H t 2$ und $H t N$ waren in der Lage, die Besiedlung des Mesophylls gegenüber der Linie B37 signifikant $(p \leq 0,001)$ zu reduzieren. Mit 22,5\% war die Wirksamkeit des Resistenzgens Ht2 gegen die Mesophyll-Besiedlung am höchsten. Der Wert für $H t N$ lag zum Zeitpunkt 18 dpi in der kompatiblen Interaktion bei $50 \%$. 


\section{Diskussion}

In der folgenden Diskussion sollen zunächst die verwendeten Methoden zur Handhabung umfangreicher Isolatmengen von E. turcicum im Labor behandelt werden (4.1). Im Kapitel 4.2 folgt die ausführliche Ergebnisbesprechung zum Rassenaufkommen und der Verteilung regionaler Virulenzfrequenzen von E. turcicum. Im Rahmen der Besprechung der Ergebnisse zum Einfluss der Temperatur auf die Wirksamkeit der Resistenzgene in Kapitel 4.3 wird die besondere Stellung des Resistenzgens $H t 2$ herausgearbeitet. Eine tiefergehende Diskussion zur Wirksamkeit und Symptomatik des Resistenzgens Ht2 folgt in Kapitel 4.4. Zum Abschluss der Diskussion werden in Kapitel 4.5 die Erkenntnisse der mikroskopischen Untersuchungen zur Interaktion von E. turcicum mit Mais beleuchtet. Anhand der gewonnenen Erkenntnisse soll möglichst für jedes Resistenzgen der Ort beschrieben werden, an dem durch Abwehrmechanismen in der inkompatiblen Interaktion die Ausbreitung des Pilzes im Blattgewebe effektiv unterbunden wird.

\subsection{Kultur- und Lagereigenschaften von E. turcicum}

Die Grundlage der in dieser Arbeit durchgeführten Untersuchungen zum europäischen Rassenspektrum von E. turcicum bildeten 559 Einsporisolate (Tab. 13). Um einen reibungslosen und vor allem zügigen Ablauf des gesamten Prozesses von der Isolatgewinnung über die Einlagerung bis hin zur Inokulumherstellung zu gewährleisten, waren Kenntnisse über grundlegende Kultur- und Lageranforderungen von E. turcicum erforderlich. Dazu zählten insbesondere die Ansprüche an ein optimales Wachstum bzw. eine hohe in vitro Sporulationsrate. Aufgrund der großen Anzahl zu bearbeitender Isolate war es erforderlich, die Einsporisolate für den Zeitraum zwischen der Isolatgewinnung und Inokulumherstellung für mehrere Wochen einzulagern. Um diesen Schritt möglichst einfach zu gestalten, wurde die Einlagerung der Isolate als Sporensuspension in $25 \%$ Glycerin bei $-23^{\circ} \mathrm{C}$ gewählt. Das Glycerin diente dazu, die für die Sporen schädigende Kristallbildung während des Gefrierens zu reduzieren.

Durch in vitro Versuche auf V8-Nährmedium wurde eine optimale Wachstumstemperatur von $22^{\circ}$ bis $24^{\circ} \mathrm{C}$ ermittelt (Abb.12). Alle notwendigen Inkubations- und Subkultivierungsschritte im Rahmen der Isolatgewinnung und Inokulumherstellung wurden bei einer im Optimalbereich liegenden Raumtemperatur von $22^{\circ} \mathrm{C} \pm 2^{\circ} \mathrm{C}$ durchgeführt. Die Sporenbildung durch Inkubation von E. turcicum auf V8 Nährmedium bei Tageslicht im Labor hat sich im Rahmen dieser Arbeit als schnelle und zuverlässige Methode der Sporengewinnung erwiesen. Die Dauer vom Ausplattieren der eingelagerten Sporensuspension auf V8-Nährmedium bis zur Herstellung des Inokulums mit bis zu 5.000 Sporen/ml betrug mit dieser Methode ca. zehn Tage. 
Um die Vitalität der gewonnenen Einsporisolate nach Lagerung bei $-23^{\circ} \mathrm{C}$ zu gewährleisten, wurde die Keimfähigkeit der Konidiosporen nach unterschiedlicher Lagerdauer untersucht. In diesem Versuch ging es nicht darum, die optimalen Lagerbedingungen für Konidiosporen von E. turcicum zu bestimmen. Es sollte vielmehr geklärt werden, ob mit der genannten Lagermethode eine mittelfristige Lagerung über mehrere Wochen möglich ist. Unter den getesteten in vitro Bedingungen lag die Keimfähigkeit vor der Lagerung direkt im Anschluss an die Sporengewinnung bei $63,9 \%$. Dieser Wert erscheint zunächst relativ gering, denn Levy \& Cohen (1983) haben gezeigt, dass bei optimalen Bedingungen und einer Temperatur von $20^{\circ}$ bis $25^{\circ} \mathrm{C}$ nahezu $100 \%$ der Sporen nach Inokulation auf der Blattoberfläche keimen. Zwei grundsätzliche Unterschiede in der Versuchsdurchführung könnten für diese Differenz verantwortlich sein. Levy und Cohen haben in ihren Versuchen die Sporen direkt vom Blattmaterial gewonnen. Die in dieser Arbeit vorangegangenen Subkultivierungsschritte und die fehlende Pflanzenpassage können zu einem Fitnessverlust geführt haben und somit ein Grund für die geringere Keimfähigkeit sein. Darüber hinaus wurde die Keimfähigkeit in dieser Arbeit in vitro auf V8-Nährmedium bestimmt. Levy und Cohen haben die Werte hingegen unter natürlicheren Bedingungen auf der Oberfläche von Maisblattsegmenten untersucht. Diese artifiziellen Keimbedingungen könnten ein weiterer Grund für die geringere Keimfähigkeit der Konidiosporen in den durchgeführten Versuchen sein. Nach einer Lagerdauer von zehn Wochen bei $-23^{\circ} \mathrm{C}$ in $25 \%$ Glycerin lag die Keimfähigkeit bei $32,3 \%$ und nach 100 Wochen noch bei 9,8\% (Abb.13). Stichprobenartige Bestimmungen der gewonnenen und zur Einlagerung vorbereiteten Einsporisolate ergaben Sporenkonzentrationen im Bereich von 7 bis $10 \times 10^{4}$ Sporen $/ \mathrm{ml}$. Obwohl eines der untersuchten Isolate nach 100 Wochen Lagerung lediglich 3,5\% keimfähige Sporen aufwies, waren aufgrund der hohen Sporenkonzentration genügend keimfähige Sporen für weitere Schritte in der Suspension vorhanden. Im normalen Ablauf des Rassenscreening war eine Lagerung für maximal 50 Wochen notwendig. Somit war die gewählte Methode eine einfache und praktikable Lösung, um eine größere Anzahl an Isolaten mittelfristig bis zur weiteren Verarbeitung zu lagern.

\subsection{Rassencharakterisierung europäischer E. turcicum Isolate}

Untersuchungen zum Auftreten von Virulenzen in rassenbildenden Erregerpopulationen stellen die Grundlage für eine effiziente und erfolgreiche Nutzung monogener Resistenzen dar. Mit der vorliegenden Arbeit erfolgte erstmals eine umfangreiche Virulenzanalyse für die europäische E. turcicum Population in den intensiven Maisanbaugebieten. Diese Ergebnisse schaffen zwei konkrete Voraussetzungen für die Nutzung monogener Resistenzen gegen die Turcicum-Blattdürre. Einerseits ermöglichen sie direkte Schlussfolgerungen 
über die Wirksamkeit der getesteten Resistenzgene, wodurch die Züchtung in der Lage ist, gezielt auf Veränderungen im Virulenzspektrum reagieren zu können. Andererseits ist es möglich, auf Basis dieser Erkenntnisse regionale Sortenempfehlungen für den praktischen Anbau in Bezug auf die Resistenzeigenschaften gegenüber E. turcicum geben zu können.

Die Voraussetzung für die Durchführung von Virulenzanalysen ist die Probenahme im Feld. In der vorliegenden Arbeit erfolgte die Probenahme durch Mitarbeiter der kooperierenden Züchtungsfirmen. Als Schwerpunktregionen der Beprobung kristallisierten sich schnell die intensiven Maisanbaugebiete in Europa heraus (Abb.3). Mit einem Anteil von 62,6\% entfällt der überwiegende Teil der beprobten Standorte auf die vier Regionen Niederlande/Belgien, Süddeutschland/Österreich, Südwestfrankreich und die Oberrheinregion. Insbesondere die Regionen Südwestfrankreich und die Oberrheinregion sind durch traditionellen langjährigen Maisanbau gekennzeichnet (Borchardt et al., 1998b; Eder et al., 2015). Darüber hinaus sind die Regionen Österreich (Steiermark)/Ungarn und Norditalien ebenfalls nach jahrzehntelangem Maisanbau als intensive Maisanbauregionen bekannt (Eder et al., 2015). Dennoch entfallen insgesamt lediglich 7,8\% der Standorte auf diese Regionen. Die Ursache für diese Verschiebung der Standortanteile ist durch die unterschiedlich intensiven Aktivitäten der beteiligten Züchter in den jeweiligen Regionen zu erklären.

Neben der Anzahl der Standorte in den Regionen stellen die Genotypen der Fangpflanzen eine ebenso wichtige Voraussetzung für die Erstellung einer repräsentativen Isolat-Sammlung dar. Um eine Vorselektion auf bestimmte Virulenzen auszuschließen, sollte es vermieden werden, Isolate von Maisgenotypen mit $\mathrm{Ht}$-Resistenzgenen zu sammeln. Dieser $\mathrm{Zu}$ sammenhang wurde im Vorfeld der Probenahme mit den Projektbeteiligten diskutiert. Auf Basis von Informationen zum Genotyp der Fangpflanze im Rahmen des Probenversands kann für den überwiegenden Teil der Fangpflanzen eine selektive Eigenschaft ausgeschlossen werden. Dennoch wurden in der vorliegenden Arbeit Proben berücksichtigt, die von Blattmaterial kommerzieller Sorten gewonnen wurden. Über die Ausstattung dieser Maissorten mit $\mathrm{Ht}$-Resistenzgenen stehen allerdings keine Informationen zur Verfügung. Deshalb kann es nicht endgültig ausgeschlossen werden, dass es in wenigen Einzelfällen zu einer Vorselektion von Virulenzen gekommen ist. Um für zukünftige Virulenzanalysen eine gleichmäßigere Anzahl der Probenahmestandorte zwischen und eine möglichst einheitliche Verteilung innerhalb der Regionen zu erreichen, wäre ein systematisch räumlich geplanter Anbau anfälliger Genotypen sinnvoll. Durch den Anbau nicht selektiv wirkender anfälliger Fang-Genotypen könnte eine unerwünschte Vorselektion vollständig ausgeschlossen werden.

Von den insgesamt 559 untersuchten E. turcicum Isolaten stammte jeweils rund die Hälfte aus den Jahren 2011 bzw. 2012. Für Regionen mit einer insgesamt geringeren Zahl an 
Isolaten war dieses Verhältnis deutlich verschoben. Die untersuchten Isolate aus der Region Bretagne/Normandie stammten zu 85\% aus 2011 und zu 15\% aus 2012. Für die Region Tschechien/Polen hingegen ist das Verhältnis mit 16\% aus 2011 und $84 \%$ aus 2012 nahezu umgekehrt. Eine naheliegende Erklärung dieser Verhältnisverschiebung zwischen den Jahren kann in dem deutlich ausgeprägteren Turcicum-Befall in 2011 gegenüber 2012 gesehen werden (B. Kessel, KWS, pers. Mitteilung, 25.10.2013). Demnach war das Auffinden von befallenen Maispflanzen 2012 in einigen Regionen deutlich erschwert. Eine weitere Erklärung für die Unterschiede können neu aufgenommene Zuchtstandorte der Kooperationspartner in den entsprechenden Regionen sein. Dadurch könnte die räumliche Veränderung des Einzugsgebiets der Probenahme zwischen den Jahren erklärt werden.

Grundsätzlich ist $E$. turcicum in der Lage, sich unter tropischen Bedingungen durch sexuelle Rekombination und hohe asexuelle Vermehrungsraten schnell anzupassen und bei entsprechend hohem Selektionsdruck innerhalb weniger Jahre Virulenzen gegenüber monogenen Resistenzen auszubilden (Bergquist \& Masias, 1974; Borchardt et al., 1998a). Molekulargenetische Diversitätsuntersuchungen haben allerdings gezeigt, dass E. turcicum unter dem gemäßigten Klima in Mitteleuropa bisher vermutlich keinen sexuellen Vermehrungszyklus vollzieht und im Vergleich zu tropischen Bedingungen geringere Vermehrungsraten und damit auch geringere Mutationsraten aufweist (Borchardt et al., 1998b). Diese Faktoren sprechen prinzipiell für ein geringeres Anpassungspotential von E. turcicum in Mitteleuropa verglichen mit tropischen Regionen. Somit ist das Anpassungspotential von E. turcicum unter europäischen Bedingungen im Vergleich zu anderen rassenbildenden Erregern als deutlich geringer einzuschätzen. Die in Europa verbreiteten Getreidepathogene Gelbrost im Weizen (Puccinia striiformis f. sp. tritici) und Mehltau in der Gerste (Erysiphe graminis f. sp. hordel) sind beispielsweise in der Lage, bei entsprechendem Selektionsdruck bereits nach zwei bis drei Jahren monogene Resistenzen vollständig zu überwinden (Vallavieille-Pope et al., 2012; Wolfe \& McDermott, 1994; Hovmøller et al., 2015). Anpassungspotentiale in diesen kurzen Zeiträumen in klimatisch gemäßigten Breiten sind für das Pathosystem Mais - E. turcicum bisher nicht belegt.

Vor diesem Hintergrund und den genannten Unterschieden in der Anzahl der Isolate zwischen den Jahren einzelner Regionen erscheint es wenig sinnvoll, im Verlauf der Diskussion Jahreseffekte innerhalb des Erhebungszeitraums von zwei Jahren zu diskutieren. Deshalb wurde in der vorliegenden Arbeit darauf verzichtet, die Ergebnisse zum Rassenaufkommen und zu den Virulenzfrequenzen für die beiden Jahre einzeln darzustellen. Für die Darstellung dynamischer Prozesse in der Entstehung virulenter Rassen von E. turcicum in Europa wäre ein längerer Erhebungszeitraum notwendig. 
Die Bezeichnung der Rassen von E. turcicum erfolgt seit 1989 als Auflistung der Resistenzgene, gegenüber denen das jeweilige Isolat virulent ist. Die Rasse $3 \mathrm{~N}$ ist beispielsweise virulent gegen $H t 3$ und $H t N$. Isolate mit der Rassenbezeichnung 0 sind avirulent gegenüber den getesteten Resistenzgenen. Mit dieser systematischen Rassenbenennung haben Leonard et al. (1989) eine einfache und international einheitliche Nomenklatur etabliert. In der vorliegenden Arbeit wurden vier Resistenzgene untersucht, demnach besteht theoretisch die Möglichkeit, $2^{4}=16$ verschiedene Rassen bzw. Pathotypen zu beschreiben.

Für die Jahre 2011 und 2012 wurden insgesamt zwölf verschiedene Rassen in der europäischen E. turcicum Population beschrieben. Diese Zahl deutet zunächst auf eine hohe Diversität in der Population hin. Auffällig ist allerdings, dass im Mittel der beiden Jahre 96\% der Isolate in lediglich vier Rassen eingeteilt werden können, wobei der Gesamtanteil der avirulenten Isolate (Rasse 0 ) bei $45 \%$ lag.

Die mit Abstand höchsten Anteile der Rasse 0 wurden in den nordwestlichen Küstenregionen Bretagne/Normandie und Niederlande/Belgien mit $88 \%$ und $76 \%$ nachgewiesen. Diese beiden Küstenregionen haben sich seit Anfang der 1970er Jahre zu aktuell sehr intensiven Maisanbauregionen entwickelt (AGPM, 2016; Baufeld, 2004). Eine plausible Erklärung für die hohen Anteile avirulenter Isolate in diesen Regionen könnte ein fehlender Selektionsdruck durch den Anbau von Sorten ohne die untersuchten $\mathrm{Ht}$-Resistenzgene sein. Rasse 1 wurde in diesen Regionen bisher nicht nachgewiesen. Das Vorkommen der Rassen 3 und $3 \mathrm{~N}$ in den beiden Regionen, wenn auch in geringen Anteilen, spricht hingegen grundsätzlich dafür, dass Sorten mit den Resistenzgenen $H t 3$ und $H t N$ eine gewisse Bedeutung im Anbau haben. Ein Grund für den geringen Anteil der Rassen 3 und 3N könnte auch darin begründet sein, dass der Anbau von Sorten mit den entsprechenden Resistenzgenen erst seit einem kurzen Zeitraum oder in sehr geringem Umfang in diesen Regionen stattfindet. Darüber hinaus sind diese Regionen durch maritimes Seeklima gekennzeichnet, das sich durch milde bis kühle Frühsommermonate auszeichnet (Schuhmann, 1986). Diese klimatischen Bedingungen tragen vermutlich, im Vergleich zu den wärmeren südlicheren Regionen des Untersuchungsgebietes, bei vorhandenem Selektionsdruck zu einem verringerten Anpassungspotential von E. turcicum bei.

Untersuchungen mit Isolaten aus den Jahren 1991 und 1992 aus den Regionen Südwestfrankreich, Österreich (Steiermark) und der Schweiz ergaben einen Anteil der Rasse 0 von 95\% (Welz \& Geiger, 1995). Legt man den Untersuchungen von Welz \& Geiger (1995) vergleichend die entsprechenden Regionen Südwestfrankreich, Österreich (Steiermark)/Ungarn und die Oberrheinregion der vorliegenden Arbeit zu Grunde, so ist der Anteil der Rasse 0 in diesem 20-jährigen Zeitraum von 95\% auf 24\% zurückgegangen. In den USA wurde ein ähnlicher Rückgang des Anteils der Rasse 0 von $83 \%$ auf $49 \%$ über einen 
20-jährigen Zeitraum von 1974 bis 1994 beobachtet. Im gleichen Zeitraum stieg dort der Anteil der Rasse 1 von 2\% auf 36\% an (Ferguson \& Carson, 2007). Im Norden Chinas dominierten in den Jahren 2000 bis 2002 ebenfalls die Rasse 0 und Rasse 1 mit Anteilen von $41 \%$ und $18 \%$ (Dong et al., 2008). In Israel (Abadi et al., 1989) und Uganda (Bigirwa et al., 1993) wurde ausschließlich Rasse 0 beschrieben. In Kenia stellte die Rasse 0 ebenfalls den größten Anteil mit 29\%, gefolgt von Rasse 2 mit 20\% (Muiru et al., 2010).

Sowohl in den USA als auch in China wird der Rückgang der Rasse 0 mit einem einhergehenden Anstieg der Rasse 1 durch die Nutzung des Resistenzgens Ht1 in kommerziellen Sorten und dem dadurch gestiegenen Selektionsdruck erklärt (Ferguson \& Carson, 2007; Dong et al., 2008). Nachdem Welz \& Geiger (1995) für die oben genannten europäischen Regionen fast ausschließlich Rasse 0 beschrieben hatten, gaben sie Mitte der 1990er Jahre zu Recht die Empfehlung, dass die Verwendung von Ht1 in europäischen Maissorten zumindest kurzfristigen Schutz vor der Turcicum-Blattdürre bieten würde. Die seit Anfang der 1990er Jahre deutlich angestiegenen Anteile der Rasse 1, von 0\% auf aktuell 44\%, deuten stark darauf hin, dass europäische Maiszüchter dieser Empfehlung gefolgt sind. Über die tatsächliche Ausstattung aktueller europäischer Maissorten mit $\mathrm{Ht}$-Resistenzgenen sind allerdings keine Informationen öffentlich verfügbar.

Hohe Anteile der Rasse 1 wurden vor allem in den wärmeren, südlicher gelegenen Regionen beschrieben. Hier sind insbesondere die Regionen Österreich (Steiermark)/Ungarn mit 63\%, Zentralfrankreich mit 50\% und die Oberrheinregion mit einem Anteil von $47 \%$ der Rasse 1 zu nennen. Von diesen Regionen sind die Steiermark und die Oberrheinregion durch traditionell intensiven Maisanbau mit aktuell regionalen Maisanteilen von über $50 \%$ der Ackerfläche geprägt (Eder et al., 2015; WIFO, 2015). Die hohen Anteile der Rasse 1 sprechen sehr für eine bereits langjährige Nutzung von Sorten mit dem Resistenzgen Ht1. Da die jährlichen Wärmesummen aufgrund der klimatischen Gegebenheiten in den drei Regionen zum Teil den Ansprüchen der in den USA angebauten Sorten entsprechen (Schmidt, 2003), liegt die Vermutung nahe, dass nordamerikanisches Sortenmaterial für die Einkreuzung von $H t 1$ in europäische Sorten genutzt wurde. Diese Vorgehensweise ist ebenfalls für klimatisch ähnliche Regionen, wie Nordchina (Welz \& Geiger, 2000) und Serbien (Levic et al., 2007) beschrieben. Erwartungsgemäß ist in diesen Regionen daraufhin der Anteil der Rasse 1 durch den erzeugten Selektionsdruck deutlich angestiegen.

In der vorliegenden Arbeit wurde in Europa erstmals die Rasse 3 nachgewiesen. Die höchsten Anteile dieses Pathotyps verzeichnen die Regionen Norditalien mit $45 \%$ und Norddeutschland mit 34\%. Diese Anteile liegen im weltweiten Vergleich auffallend hoch. In Kenia wurde ein Anteil von 10\% beschrieben (Muiru et al., 2010), wohingegen die Anteile in Nord- 
China mit 3,9\% (Dong et al., 2008) deutlich geringer ausfielen. Im Rahmen von Virulenzuntersuchungen an Isolaten, die Mitte der 1990er Jahre gesammelt wurden, konnte die Rasse 3 weder in Kenia, China noch Europa nachgewiesen werden (Welz, 1998). Ferguson \& Carson (2007) konnten in ihren Untersuchungen für die USA in einer Sammlung von 242 Isolaten lediglich ein Isolat der Rasse 3 zuordnen. Unter den virulenten Isolaten in Norditalien wiesen alle mindestens eine Virulenz für $H$ t3 auf. Die Rasse 1 wurde in dieser Region nicht nachgewiesen. Die Situation in Norditalien deutet also stark darauf hin, dass dort seit mehreren Jahren flächendeckend Sorten angebaut wurden, die neben Ht3 keine der weiteren der untersuchten $\mathrm{Ht}$-Resistenzgene trugen oder nur in sehr geringem Umfang. Für diese Schlussfolgerung sprechen der geringe Anteil weiterer virulenter Rassen und darüber hinaus der sehr geringe Anteil komplexer Rassen. Komplexe Rassen erreichen vor allem dann hohe Anteile in einer Pathogenpopulation, wenn über einen längeren Zeitraum gleichzeitig ein Selektionsdruck durch mehrere Resistenzgene besteht, insbesondere dann, wenn diese Resistenzgene in flächenmäßig stark angebauten Genotypen pyramidisiert genutzt wurden. Aufgrund der Dominanz von Isolaten mit der alleinigen Virulenz für $H t 3$ scheint dies für die Region Norditalien nicht der Fall zu sein. Ähnliche Schlussfolgerungen können auch für das Resistenzgen $\mathrm{Ht1}$ in der Region Österreich (Steiermark)/Ungarn getroffen werden. Dort wurden neben der Rasse 1 mit einem Anteil von 63\% auch weitere komplexere Rassen beschrieben. Der Anteil der komplexeren Rassen fiel allerdings vergleichsweise gering aus und lässt dadurch ebenfalls den Schluss zu, dass in dieser Region kein langjähriger flächendeckender Selektionsdruck auf die E. turcicum Population durch die parallele Verwendung mehrerer $\mathrm{Ht}$-Resistenzgene bestand.

Die Rasse 3N wurde in dieser Arbeit ebenfalls erstmals und zugleich flächendeckend mit Ausnahme der Region Österreich/Ungarn in Europa nachgewiesen. Den höchsten Anteil erreicht die Rasse 3N in Südwestfrankreich mit 38\% und stellt damit in der Region vor der Rasse 0 die dominierende Rasse dar. Südwestfrankreich ist durch hohe Temperaturen und langjährigen, intensiven mit zum Teil unter Beregnung stattfindendem Maisanbau gekennzeichnet (Meissle et al., 2010). Der hohe Anteil der Rasse 3N legt die Vermutung nahe, dass in dieser Region seit mehreren Jahren ein relativ hoher Selektionsdruck durch die Verwendung der Resistenzgene $H t 3$ und $H t N$ in den dort angebauten Sorten besteht. Aufgrund des relativ geringen Anteils der Rasse 3 von $7 \%$ liegt es darüber hinaus nahe, dass die angebauten Maisgenotypen häufig beide Resistenzgene gleichzeitig tragen. Nur in diesem Fall bewirkt eine kombinierte Virulenz gegenüber $H t 3$ und $H t N$ einen Fitnessvorteil für Isolate der Rasse 3N und lässt dessen Frequenz in der Population signifikant ansteigen. Aufgrund der gleichmäßigen Verteilung der Rasse $3 \mathrm{~N}$ in den Regionen Norddeutschland, 
Niederlande/Belgien, Süddeutschland/Österreich, Tschechien/Polen und der Oberrheinregion mit Anteilen zwischen $10 \%$ und $16 \%$ ist es wahrscheinlich, dass auch in diesen Regionen zumindest zu einem gewissen Anteil die angebauten Sorten mit den Resistenzgenen $H t \mathrm{~N}$ und/oder $H t^{3}$ ausgestattet sind.

Die Kombination der Virulenzen für $H t 3$ und $H t N$, als Rasse $3 \mathrm{~N}$, stellt in der vorliegenden Arbeit keine Besonderheit dar. Insgesamt treten 95\% der Virulenzen für $H \mathbb{t N}$ in Kombination mit $H t 3$ auf. Lediglich in der Region Österreich/Ungarn konnte eine Virulenz gegenüber $H \mathbb{N} N$ unabhängig von $H t 3$ in einem Isolat der Rasse $1 \mathrm{~N}$ nachgewiesen werden. Diese Beobachtungen lassen zunächst eine enge Kopplung der Virulenzen für $H t \mathrm{~N}$ und $H t 3$ vermuten. In Kreuzungsversuchen zwischen E. turcicum Isolaten der Rassen 0 und $23 \mathrm{~N}$ mit anschlieBender Bestimmung der Aufspaltungsverhältnisse der Virulenzen konnten Welz \& Geiger (1995) zeigen, dass die Virulenzen für $H+\mathrm{N}$ und $H t 3$ unabhängig voneinander vererbt werden. Für eine unabhängige Vererbung sprechen ebenfalls Ergebnisse zu Untersuchungen des Rassenspektrums aus China und Kenia, in denen lediglich $28 \%$ und $38 \%$ der $\mathrm{HtN}$ Virulenzen in Kombination mit einer Virulenz für Ht3 auftraten (Dong et al., 2008; Welz \& Geiger, 1995). Im Rahmen von Untersuchungen zum Rassenauftreten aus den USA wurden Virulenzen gegen $H t \mathbb{N}$ hingegen ausschließlich in Kombination mit $H t 3$ nachgewiesen (Ferguson \& Carson, 2007).

Der insgesamt hohe und in den nordwestlichen Küstenregionen sehr hohe Anteil der Rasse 0 deutet darauf hin, dass nach wie vor ein großer Anteil der im Anbau befindlichen Sorten keines der untersuchten $\mathrm{Ht}$-Resistenzgene trägt. Über die Hintergründe der Entstehung der komplexeren Rassen 123 und 13N bzw. der Rassen mit sehr geringen Anteilen, wie 2, 23, 12 und $1 \mathrm{~N}$ kann aufgrund der fehlenden Informationen zur Resistenzgenausstattung der angebauten Sorten nur spekuliert werden. Grundsätzlich sind nennenswerte Anteile von virulenten Isolaten in Pathogenpopulation erst nach entsprechendem Selektionsdruck und darauf folgenden koevolutionären Anpassungen in der Pathogenpopulation zu erwarten (Wolfe \& McDermott, 1994). Dennoch ist es möglich, dass bereits vor dem Aufbau eines Selektionsdrucks durch die Verwendung von Resistenzgenen, virulente Pathotypen gegen eben diese Resistenzgene in sehr geringer Frequenz in der Population vorhanden sind. So wurden zum Beispiel die Rassen 23 und $23 \mathrm{~N}$ in den USA erstmals für Isolate beschrieben, die 1957 gesammelt wurden. Darüber hinaus erreichte die Rasse $23 \mathrm{~N}$ in den Jahren 1974 bis 1977 in den USA einen Anteil von 14\% (Ferguson \& Carson, 2007). Dies ist bemerkenswert, denn die Resistenzgene Ht2 (Hooker, 1977), Ht3 (Hooker, 1981) und $H+N$ (Gevers, 1975) wurden alle erst Ende der 1970er Jahre entdeckt und systematisch beschrieben. Bis Ende der 1980er Jahre beschränkte sich die Nutzung der drei Resistenz- 
gene in den USA auf Experimentalhybriden auf sehr begrenzter Fläche in Zuchtgärten (Leonard et al., 1989). Diese Beispiele verdeutlichen, dass es nicht nur möglich ist, sondern dass man grundsätzlich davon ausgehen muss, Virulenzen für die untersuchten $\mathrm{Ht}$-Resistenzgene auch ohne vorhandenen Selektionsdruck in der E. turcicum Population zu finden. Die Ergebnisse der vorliegenden Arbeit zeigen, dass vor allem Virulenzen für $H t 2$ und $H \mathbb{N}$ in Rassen vorkommen, die vielfach einen sehr geringen Anteil in der Population abbilden. Dazu zählen sowohl hochkomplexe Rassen, wie 123 und 13N, aber auch weniger komplexe Rassen, wie 2, 23, 12 oder 1N. Aufgrund der bereits vorhandenen Virulenzen in der E. turcicum Population würde die flächendeckende Nutzung der Resistenzgene Ht2 und HtN in den untersuchten Regionen wahrscheinlich zu einem schnellen Anstieg der entsprechenden Virulenzen führen.

Ein weiterer Grund für die geringen Anteile von Pathotypen mit kombinierten Virulenzen kann in dem bekannten Phänomen des Fitnessverlustes durch das Tragen mehrerer kombinierter Virulenzen begründet liegen (Agrios, 2008). Die Anteile der genannten Rassen fallen trotz offensichtlich vorhandenem Selektionsdruck für wenigstens eine der Virulenzen in den jeweiligen Pathotypen sehr gering aus. In der vorliegenden Arbeit trifft dies auf die Rassen 123 und $1 \mathrm{~N}$ in der Region Österreich/Ungarn und auf die Rasse $13 \mathrm{~N}$ in der Oberrheinregion zu. Anhand von Aggressivitätsbestimmungen an hochanfälligen Maisinzuchtlinien gegenüber E. turcicum konnte Brandt (2014) eine negative Korrelation zwischen Virulenz und Aggressivität aufzeigen. Als Teil der Fitness eines Isolates lag die Fähigkeit, Blattgewebe zu besiedeln, bei avirulenten Isolaten höher als bei virulenten. Diese Ergebnisse könnten eine Erklärung für den sehr geringen Anteil der Rasse $13 \mathrm{~N}$ in der Oberrheinregion sein. Aufgrund der hohen Anteile der Rassen 1, 3 und 3N ist ein vorhandener Selektionsdruck vor allem durch die Resistenzgene $H t 1$ und $H t 3$ sehr wahrscheinlich. Dennoch liegt der Anteil der Isolate, die alle Virulenzen kombiniert tragen, bei gerade einmal 1,3\%. Die kombinierte Virulenz gegen drei $\mathrm{Ht}$-Gene in der Rasse $13 \mathrm{~N}$ bewirkt in diesem Fall möglicherweise einen Fitnessverlust, wodurch der Anteil der Rasse in der Region auf einem geringen Niveau verbleibt. Ein weiterer Erklärungsansatz für die geringen Anteile der komplexen Rassen kann darin gesehen werden, dass die Virulenzen bzw. Virulenzkombinationen erst seit einem kurzen Zeitraum in den jeweiligen Regionen auftreten und sich aufgrund des Zeitfaktors noch keine höheren Anteile etablieren konnten. Als grundsätzliche Voraussetzung für das Auftreten hochkomplexer Rassen mit hohen Anteilen ist der flächendeckende Anbau von Maissorten mit einer möglichst breiten Ausstattung an Resistenzgenen in einem Genotyp zu sehen. Aufgrund der Ergebnisse der vorliegenden Arbeit ist diese Bedingung in den untersuchten Regionen mit sehr großer Wahrscheinlichkeit nicht erfüllt. 
Im Folgenden sollen weniger einzelne Rassen als vielmehr die Rassendiversität innerhalb und zwischen den untersuchten Regionen im Mittelpunkt stehen. Die Vorgehensweise der Probensammlung und die daraus resultierende Sammlung an E. turcicum Isolaten als Grundlage der vorliegenden Arbeit wurden bereits diskutiert. Insbesondere die stark variierende Anzahl an Isolaten zwischen den Regionen stellt einen Nachteil für die vergleichende Bewertung der regionalen Diversitäten dar. Aufgrund der hohen Anzahl an Isolaten ermöglichen die vorliegenden Daten dennoch eine solide vergleichende Aussage zu den regionalen Rassendiversitäten von E. turcicum. Die Entwicklung der genetischen Diversität von Pathogenpopulationen wird durch mehrere Faktoren beeinflusst und stellt in jedem Fall einen Blick in die Vergangenheit der jeweiligen Population dar. Der bedeutendste Faktor, der zur Veränderung der Diversität beiträgt, ist die Selektion. Der Anteil einer in der Pathogenpopulation vorkommenden Virulenz wird sich nur dann erhöhen, wenn das korrespondierende Resistenzgen in den angebauten Sorten verwendet wird. Der Selektionsdruck wirkt umso stärker, je größer die Fläche und je länger der Zeitraum ist, in dem das Resistenzgen verwendet wird. In Folge dessen kommt es zu einem Anstieg der Virulenz in der Population und das Resistenzgen wird unwirksam (McDonald \& Linde, 2002). Die drei wichtigsten Faktoren, die auf der Pathogenseite für ein Auftreten von Virulenzen sorgen, sind Mutation, Rekombination und Migration. Es wurde bereits erläutert, dass Rekombination bei E. turcicum unter mitteleuropäischen Bedingungen als sehr unwahrscheinlich zu erachten ist (Borchardt et al., 1998b). Darüber hinaus sprechen die sehr geringen Anteile von hochkomplexen Rassen grundsätzlich ebenfalls gegen das Vorkommen von sexueller Rekombination von E. turcicum in Europa. Durch Rekombination wird die Wahrscheinlichkeit, dass Virulenzen in einem Pathotyp kombiniert bzw. pyramidisiert vorkommen, deutlich erhöht. (Andrivon \& Vallavieille-Pope, 1995; Miedaner, 2011). In vorwiegend klonalen Erregerpopulationen, wie die in der vorliegenden Arbeit untersuchte E. turcicum Population, dominieren hingegen wenige Pathotypen mit einer geringen Virulenzkomplexität. Vergleicht man die Rassespektren aller zehn Regionen miteinander, so fällt auf, dass mit Ausnahme der Regionen Österreich/Ungarn und Norditalien die Unterschiede fast ausschließlich auf der unterschiedlichen Verteilung der vier dominierenden Rassen 0, 1, 3 und 3N beruhen. Dieser Sachverhalt spricht wiederum für eine klonale Vermehrung innerhalb der regionalen Populationen und darüber hinaus für eine stattfindende Migration von Pathotypen zwischen den Regionen. Eine Migration von E. turcicum Pathotypen in Form von Sporenflug über größere Distanzen wurde bereits in den USA nachgewiesen (Ferguson \& Carson, 2004)). Für Europa konnten Borchardt et al. (1998b) die Alpen als natürliche Barriere für die Migration von E. turcicum in Nord-Süd Richtung beschreiben. Für die zwei Regionen Norditalien und Österreich/Ungarn, die durch die Alpen nach Norden von allen anderen Regionen abgegrenzt sind, zeigen sich im Vergleich zu den Regionen nördlich der Alpen deutliche Unterschiede 
im Rassenspektrum. Die Region Österreich/Ungarn grenzt sich vor allem durch den höchsten Anteil der Rasse 1 und gleichzeitig einen sehr geringen Anteil der Rasse 3 bzw. der nicht vorhandenen Rasse 3N von den Regionen nördlich der Alpen ab. In Norditalien konnte zum Beispiel die Rasse 1 gar nicht, dafür aber die Rasse 3 mit dem höchsten Anteil aller Regionen nachgewiesen werden. Die durch Borchardt et al. (1998b) aufgestellte Hypothese der Trennung der europäischen E. turcicum Populationen durch die Alpen wird demnach durch die Ergebnisse der vorliegenden Arbeit unterstützt. Offensichtlich stellen nicht nur die Alpen eine Migrationsbarriere für E. turcicum dar, denn auch die nordwestlichen Küstenregionen Bretagne/Normandie und Niederlande/Belgien grenzen sich durch ihr Rassenmuster relativ klar von den südlicheren Regionen ab. Beide Regionen weisen die mit Abstand höchsten Anteile für die Rasse 0 auf und darüber hinaus wurde in keiner der Regionen die Rasse 1 identifiziert. Dieses Rassenmuster stellt ein Alleinstellungsmerkmal dieser beiden Regionen dar. Als Barriere für die Migration ist in diesem Fall die große räumliche Distanz zu den südlicheren Regionen zu sehen. Eine weitere Erklärung dafür, dass Isolate der Rasse 1 in den beiden Regionen nicht gefunden wurden, kann ebenfalls ein fehlender Selektionsdruck durch $H t 1$ in den dort angebauten frühreifen Sortentypen sein. Vor dem Hintergrund des fehlenden Auftretens der Rasse 1 bei einem Umfang von 141 untersuchten Isolaten in den beiden Regionen erscheint eine Migration über Sporenflug beispielsweise aus der Oberrheinregion in diese Regionen als sehr unwahrscheinlich.

Eine bedeutende Quelle für Variation innerhalb einer Pathogenpopulation stellt die Mutation dar. Kommt es in einem Avirulenzgen zu einer Defektmutation, so ist die Synthese des mit dem Resistenzgen korrespondierenden Effektors unterbunden und das betreffende Isolat wird virulent. Die Wirtspflanze ist dann nicht mehr in der Lage, den Erreger zu erkennen und abzuwehren. Mutationen in Pathogenpopulationen treten allerdings sehr selten auf. Je größer eine Population ist, desto höher ist die Wahrscheinlicht des Auftretens einer Mutation (Wolfe \& McDermott, 1994). Bezogen auf die E. turcicum Populationen sind hohe Vermehrungsraten mit folglich extrem hohen Anzahlen vitaler Sporen mit steigenden absoluten Anzahlen an Mutationen verbunden. Hohe Vermehrungsraten bei E. turcicum treten vor allem bei starkem Befall in den wärmeren südlicheren Maisanbaugebieten auf, da diese Regionen durch optimale Bedingungen für E. turcicum gekennzeichnet sind. In Europa treffen diese Bedingungen insbesondere für die Regionen Südwestfrankreich, Oberrheinregion, Süddeutschland/Österreich, Österreich/Ungarn und Norditalien zu (Meissle et al., 2010) Im Folgenden werden die genannten Regionen deshalb als Regionen mit hohem TurcicumRisiko bezeichnet. Optimale klimatische Bedingungen in Kombination mit anfälligen Wirtspflanzen führen generell zu einer erhöhten Diversität in der jeweiligen Pathogenpopulation. 
Ein Selektionsdruck, hervorgerufen durch Resistenzgene hingegen, hat generell eine Reduktion der Rassendiversität zur Folge (Miedaner, 2011). Vor diesem Hintergrund wird in den Regionen mit hohem Turcicum-Risiko tendenziell eine höhere Diversität an virulenten Rassen erwartet. Unter Betrachtung des rel. Gleason Index $\left(\mathrm{H}_{\mathrm{GR}}\right)$ und des rel. Shannon Index $\left(\mathrm{H}_{\mathrm{SR}}\right)$ als Maß für die Rassendiversität weisen die Regionen Norditalien und Österreich/Ungarn für beide Indizes die höchsten Werte $\left(\mathrm{H}_{\mathrm{GR}}>0,21 ; \mathrm{H}_{\mathrm{SR}}>0,39\right)$ auf, während die beiden nördlichen Küstenregionen Bretagne/Normandie und Niederlande/Belgien für beide Indizes sehr geringe Werte zeigen. Dieser Sachverhalt kann lediglich ein Hinweis darauf sein, dass in den Regionen Norditalien und Österreich/Ungarn häufiger Mutationen auftreten als in den anderen Regionen. Die geringe Rassendiversität in den nördlichen Regionen ist vermutlich nicht das Ergebnis einer angepassten Population an einen vorhandenen Selektionsdruck. Dies zeigt sich anhand der kumulierten Anteile der zwei häufigsten Rassen. Die Regionen Tschechien/Polen, Bretagne/Normandie und Niederlande/Belgien weisen für diesen Parameter Werte von $84 \%$ bis $94 \%$ auf. Der weitaus größte Teil dieses kumulierten Wertes wird durch die Rasse 0, also durch avirulente Isolate, abgedeckt. Der hohe Anteil der Rasse 0 kann kein Ergebnis einer Anpassung an einen Selektionsdruck sein. Ganz im Gegenteil müssen diese hohen Anteile der Rasse 0 als Hinweis auf einen fehlenden Selektionsdruck und darüber hinaus für eine klonale Vermehrung innerhalb der Population gedeutet werden.

Unter den fünf Regionen mit den geringsten Anteilen der zwei häufigsten Rassen befinden sich vier Regionen mit hohem Turcicum-Risiko. Darüber hinaus weist der Shannon-Diversitäts-Index für diese Regionen die höchsten Werte auf (Abb. 15). Es konnte generell eine signifikant $(p \leq 0,001)$ negative Korrelation für den Shannon-Index und dem kumulierten Anteil der zwei häufigsten Rassen festgestellt werden. Der gemeinsame Anteil der zwei häufigsten Rassen in einer Region kann demnach als einfacher Indikator zur Einschätzung der regionalen Rassendiversität herangezogen werden. Die höheren Werte der Rassendiversität in den Turcicum-Risikoregionen waren zu erwarten. Denn in diesen Regionen ist E. turcicum schon seit Mitte der 1990er Jahre etabliert (Borchardt et al., 1998b) und war in den folgenden Jahren bei einer ausgedehnt vorhandenen Wirtspopulation in Form von intensivem Maisanbau unter optimalen Wachstumsbedingungen keinem Selektionsdruck ausgesetzt. Ein nennenswerter Selektionsdruck durch die Verwendung von $\mathrm{Ht}$-Resistenzgenen in europäischen Maiszuchtprogrammen setzte vermutlich frühestens in den 2000er Jahren ein, nachdem Welz \& Geiger (1995) die Verwendung von Ht-Resistenzgenen für die Bekämpfung der Turcicum-Blattdürre empfahlen. Bis zum Einsetzen des Selektionsdrucks als reduzierender Faktor für die Rassendiversität konnten sich die Populationen also durch 
unbeeinflusste Mutationen und Migration vorwiegend durch klonale Vermehrung frei entwickeln. Wenn sich eine E. turcicum Population über mehrere Jahre auf anfälligen Genotypen unter günstigen klimatischen Bedingungen entwickeln kann, besteht auch bei überwiegend klonaler Vermehrung die Möglichkeit die Diversität innerhalb der Population signifikant zu erhöhen (Borchardt et al., 1998b); (Ferguson \& Carson, 2004; Borchardt et al., 1998b). Diese Gegebenheiten sind für die südeuropäischen Maisanbauregionen zutreffend. Die Bedeutung des genetischen Austausches zwischen den Regionen durch Migration als Beitrag zur Steigerung der Diversität ist zwischen den Regionen nördlich der Alpen sehr wahrscheinlich. Dies legen Untersuchungen zur genetischen Verwandtschaft europäischer E. turcicum Isolate durch Borchardt et al. (1998b) nahe. Darüber hinaus wird diese Aussage durch die sehr ähnlichen Rassenspektren zwischen den Regionen nördlich der Alpen untermauert.

Die Virulenzkomplexität beschreibt die Anzahl der Virulenzen, die in einem Isolat vereint sind. Um Isolate mit mehreren Virulenzen hervorzubringen, ist entweder der eher unwahrscheinliche Fall einer Defektmutation mehrerer Avirulenzgene in ein und demselben Isolat notwendig oder die Virulenzgene müssen über Rekombination zwischen den Isolaten ausgetauscht und so kombiniert werden (Andrivon \& Vallavieille-Pope, 1993). In der vorliegenden Arbeit konnten Isolate mit bis zu drei kombinierten Virulenzen beschrieben werden. Allerdings liegt der Anteil der Isolate mit drei Virulenzen insgesamt bei lediglich 0,7\%. Im weltweiten Vergleich fallen die Anteile hochkomplexer Rassen in der europäischen E. turcicum Population vergleichsweise gering aus. Für die Regionen China und Mexiko lagen die Anteile von Isolaten mit drei kombinierten Virulenzen in den 1990er Jahren bei $22 \%$ und 36\%. In Kenia hingegen lediglich bei 4\% (Welz, 1998). Umfangreiche Untersuchungen an Isolaten, die über zwei Jahrzehnte insbesondere im Osten der USA ab 1975 gesammelt wurden, weisen im Mittel einen Anteil von 12\% hochkomplexer Rassen auf. Für einzelne Regionen erreichen die Werte bis zu 31\% (Ferguson \& Carson, 2004). Aktuellere Untersuchungen aus China mit Isolaten aus den Jahren 2000 bis 2002 ergaben Werte von $8 \%$ hochkomplexer Rassen, wobei hier ebenfalls die Rasse $123 \mathrm{~N}$ mit vier Virulenzen enthalten ist (Dong et al., 2008). In Europa weist die Region Österreich/Ungarn mit 8,3\% den höchsten Anteil einer hochkomplexen Rasse mit drei Virulenzen auf. In den Regionen Süddeutschland/Österreich und der Oberrheinregion konnten ebenfalls Isolate mit Kombinationen von drei Virulenzen nachgewiesen werden, wobei es sich bei den Funden jeweils um ein einziges Isolat handelt. Die Rasse 123 wurde lediglich in Süddeutschland und in der Region Österreich/Ungarn nachgewiesen. Eine Möglichkeit für die Kombination von Virulenzen in einem Isolat kann der Austausch durch sexuelle Rekombination sein. Diese ist für E. turcicum bisher lediglich unter günstigen tropischen Bedingungen nachgewiesen 
(Borchardt et al., 1998a; Bunkoed et al., 2014). Da die klimatischen Bedingungen in der Region Österreich/Ungarn für E. turcicum als sehr gut beschrieben werden können, kann die Entstehung der Rasse 123 durchaus in dieser Region vermutet werden. Da in beiden Regionen Zuchtstandorte von Maiszuchtfirmen angesiedelt sind, liegt die Vermutung nahe, dass Mitarbeiter insbesondere in der Befallsphase von E. turcicum zwischen diesen Regionen pendeln. Dies könnte als ein möglicher Migrationsweg der Rasse 123 aus der Region Österreich/Ungarn über die Alpen-Barriere in die Süddeutsche Region in Betracht gezogen werden.

In der vorliegenden Arbeit wiesen 16,6\% der untersuchten Isolate eine Kombination von zwei Virulenzen auf. Dieser Anteil wird fast ausschließlich durch die Rasse 3N abgedeckt. Das flächendeckende Auftreten dieser Rasse in allen Regionen, abgesehen von der Region Österreich/Ungarn, lässt die Kombination der Resistenzgene $H t 3$ und $H t \mathrm{~N}$ als wenig aussichtsreich zur Bekämpfung der Turcicum-Blattdürre erscheinen.

Es bestand ein signifikanter ( $p \leq 0,01$ ) Zusammenhang zwischen den Merkmalen Virulenzkomplexität und dem Shannon-Diversitätsindex $(r=0,807)$. Da die Werte für diese beiden Indizes zwischen den Regionen sehr stark schwanken, müssen die Ursachen für diese Schwankungen in den unterschiedlichen regionalen Bedingungen für $E$. turcicum vermutet werden. Den höchsten Shannon-Indexwert weist die Region Österreich/Ungarn auf. Darüber hinaus wies die Region mit 8,3\% den höchsten Anteil hochkomplexer Rassen auf. Neben der Region Österreich/Ungarn wurden lediglich in Süddeutschland/Österreich und der Oberrheinregion hochkomplexe Rassen mit drei Virulenzen gefunden. Diese drei Regionen sind anders als die nördlicheren Regionen durch ein hohes Turcicum-Risiko gekennzeichnet (Meissle et al., 2010). Die beiden nördlichen Küstenregionen sind durch die geringsten Werte der Virulenzkomplexität und der Rassendiversität charakterisiert. Eine Erklärung für diesen Zusammenhang kann in der möglicherweise stattfindenden Rekombination von E. turcicum in den klimatisch günstigen Regionen vermutet werden. Die vorliegenden Daten zeigen mit wenigen Ausnahmen den Trend, dass je südlicher die untersuchte Region in Europa liegt, desto höher die Rassendiversität und Komplexität ist. Die sexuelle Rekombination stellt grundsätzlich einen wichtigen Faktor im Austausch von Virulenzen zwischen Pathotypen dar. Für E. turcicum sind bisher lediglich für China anhand zwei voneinander unabhängigen Funden Isolate bekannt, die gleichzeitig vier Virulenzen in einem Pathotyp als Rasse 123N vereinen (Welz, 1998; Dong et al., 2008). Genetische Populationsanalysen für die Region im Süden Chinas haben ergeben, dass sexuelle Rekombination in der E. turcicum Population dort sehr wahrscheinlich ist (Borchardt et al., 1998a; Fan et al., 2007). Im Jahr 2014 wurden zudem in einer nahe gelegenen und klimatisch ähnlichen Region in Thailand erstmalig Pseudothezien von Setosphaeria turcica, der teleomorphen 
Form von E. turcicum, unter natürlichen Feldbedingungen nachgewiesen (Bunkoed et al., 2014).

Der hier aufgezeigte Zusammenhang zwischen der Rassendiversität und Komplexität kann anhand anderer Pathosysteme mit rassenbildenden Erregern insbesondere im Getreide nicht bestätigt werden (Andrivon \& Vallavieille-Pope, 1995). Eine Erklärung dafür kann in der verschiedenen Biologie der Erreger vermutet werden. Beispielsweise sind im Vergleich zum Pathosystem Mehltau in der Gerste (Erysiphe graminis f. sp. hordei) die Vermehrungsraten bei $E$. turcicum deutlich geringer. Die Sporen legen über Windverbreitung geringere Distanzen zurück und es findet fast ausschließlich asexuelle Vermehrung im Feld statt (McDonald \& Linde, 2002; Borchardt et al., 1998b). Darüber hinaus ist eine deutlich geringere Anzahl an monogenen Resistenzen im Mais gegen E. turcicum bekannt. All diese Faktoren führen dazu, dass das Potential, hochkomplexe Rassen auszubilden und diese schnell über große Distanzen zu verbreiten, im Vergleich zu den dominierenden rassenbildenden Erregern im Getreide, wie beispielsweise Roste und Mehltau, geringer einzuschätzen ist. Die Kenntnis über das Vorhandensein hochkomplexer Rassen ist vor allem für die Frage wichtig, ob ein Pyramidisieren von Resistenzgenen in Maissorten sinnvoll ist. Aufgrund der Biologie von E. turcicum in den untersuchten europäischen Regionen und dem damit einhergehenden geringen Risiko zur Ausbildung hochkomplexer Rassen erscheint ein Pyramidisieren der Resistenzgene in den Sorten empfehlenswert.

Bisher waren die regionalen Rassenspektren und die möglichen Hintergründe zur Entstehung und Verbreitung bestimmter Rassen innerhalb und zwischen den Regionen Gegenstand der Diskussion. Diese Zusammenhänge sind vor allem für das Verständnis der Populations- und Virulenzentwicklung von Bedeutung. Um hingegen eine konkrete Aussage über die Wirksamkeit eines Resistenzgens in einer definierten Region machen zu können, ist weniger die Rassenzusammensetzung oder Komplexität von Bedeutung, sondern viel mehr die Information darüber, welche Virulenz in welcher Häufigkeit in der jeweiligen Region vorkommt. Die Virulenzfrequenz gibt also Auskunft über die Wirksamkeit des jeweiligen Resistenzgens in einer bestimmten Region.

Im Rahmen der vorliegenden Arbeit wurden für die Virulenzfrequenzen deutliche Unterschiede sowohl zwischen den Regionen als auch zwischen den Resistenzgenen festgestellt. Insgesamt stellte sich $H t 2$ als das wirksamste der vier untersuchten Resistenzgene heraus. Über alle Regionen gesehen waren lediglich 2,2\% der Isolate virulent gegen $H t 2$. Die höchsten Anteile von Ht2-Virulenzen verzeichneten die beiden Regionen südlich der Alpen mit maximal 8,3\% in der Region Österreich/Ungarn. Untersuchungen Mitte der 1990er Jahre ergaben Werte von 12\% für Ht2 in den südlichen Maisanbauregionen Europas (Welz, 1998). Aufgrund der aktuell geringen Werte ist es sehr unwahrscheinlich, dass 
Ht2 bis zum Jahr 2012 in europäischen Maissorten enthalten war. Wie bereits durch Welz et al. (1997) und Ferguson \& Carson (2007) für die USA beschrieben, ist es möglich, dass die in sehr geringem Umfang in einzelnen Regionen vorkommenden Virulenzfrequenzen für $H$ t2 auch ohne vorhandenen Selektionsdruck als natürlich auftretende Anteile in den Populationen zu erklären sind. In anderen Maisanbauregionen der Welt wurden hingegen deutlich höhere Virulenzfrequenzen für $H t 2$ beschrieben. So lagen die Werte nach Welz (1998) Mitte der 1990er Jahre in Kenia bei 18\%, im nördlichen China bei 35\% und in Mexiko bei 55\%. Für Anfang der 2000er Jahre lagen die Werte in China bei 19\% (Dong et al., 2008). Die hier genannten Regionen sind im Gegensatz zu Europa durch tropisches Klima gekennzeichnet und bieten somit optimale Entwicklungsvoraussetzungen für Virulenzen (Borchardt et al., 1998a; Fan et al., 2007). Vor dem Hintergrund der sehr geringen Virulenzfrequenzen stellt das Resistenzgen $\mathrm{Ht2}$ unter den vier $\mathrm{Ht}$-Resistenzgenen das größte Potential zur Bekämpfung der Turcicum-Blattdürre in europäischen Sorten dar.

Die im Mittel über alle Regionen höchste Virulenzfrequenz wurde für das Resistenzgen $H$ t3 mit 32\% gefolgt von $\mathrm{Ht1}$ mit 24\% nachgewiesen. Die regionalen Werte dieser beiden Resistenzgene zeigen im Vergleich zu Ht2 deutliche Unterschiede. In der Region Österreich/Ungarn ist das Resistenzgen $H t 1$ beispielsweise gegen $83 \%$ der Isolate unwirksam. In diesem Fall ist $H t 1$ in der Region zur Bekämpfung der Turcicum-Blattdürre wertlos. In den Regionen Zentralfrankreich und der Oberrheinregion ist jedes zweite Isolat virulent gegenüber $H t 1$. Die hohen Werte für diese drei Regionen sind ein deutlicher Hinweis darauf, dass dort über einen längeren Zeitraum relativ stark Sorten mit dem Resistenzgen $H t^{1}$ angebaut wurden. Mitte der 1990er Jahre konnten für $H t 1$ noch keine Virulenzen in Europa nachgewiesen werden (Welz, 1998). Seitdem ist die Virulenzfrequenz für $H t 1$ innerhalb von ca. 20 Jahren in der Region Österreich/Ungarn von 0\% auf über $80 \%$ und in den Regionen Zentralfrankreich und der Oberrheinregion von $0 \%$ auf rund $50 \%$ angestiegen. Mitte der 1990er Jahre wurden für $H t 1$ in Europa, Kenia und Mexiko keine Virulenzen gefunden. Im Norden Chinas und in Teilen der USA hingegen lagen die Virulenzfrequenzen für $\mathrm{Ht} 1 \mathrm{zu}$ der Zeit bereits bei $80 \%$ bis $85 \%$ (Moghaddam \& Pataky, 1994; Welz, 1998). In den USA wurden seit Ende der 1960er Jahre vermehrt Sorten mit dem Resistenzgen $H t 1$ angebaut. Erste Virulenzen traten in den USA 1972 auf und hatten sich bereits 1980 in allen Maisanbaugebieten der USA ausgebreitet (Jordan et al., 1983; Pedersen et al., 1986). Aufgrund der ähnlichen klimatischen Bedingungen wurden Sorten mit dem Resistenzgen $\mathrm{Ht} 1$ aus den USA ebenfalls flächendeckend in China angebaut (Dong et al., 2008). Diese beiden Beispiele zeigen, dass eine intensive flächendeckende Nutzung von $\mathrm{Ht1}$ den Anstieg von Virulenzfrequenzen für $H t 1$ innerhalb eines Zeitraums von zehn Jahren auf über $80 \%$ zur 
Folge haben kann. Offensichtlich wurde $H t 1$ bisher weniger intensiv in frühreifen Sortentypen eingesetzt, die vor allem in den nördlichen Maisanbaugebieten von Bedeutung sind. Denn die Regionen Bretagne/Normandie und Niederlande/Belgien weisen keine Virulenzen für $H t 1$ auf. Die Region Norddeutschland weist mit $17 \%$ einen ebenfalls vergleichsweise geringen Wert auf. In diesem Fall besteht bei flächendeckender Nutzung von $H t 1$ das Risiko, dass durch den Selektionsdruck die Virulenzfrequenzen schnell ansteigen und $H t^{1}$ somit auch hier deutlich an Wirkung verliert. Neben den nördlichen Regionen ist interessanterweise auch die südlich der Alpen gelegene Region Norditalien durch eine sehr geringe Virulenzfrequenz für $H t 1$ gekennzeichnet. Norditalien grenzt sich in diesem Punkt stark von der ebenfalls südlich der Alpen gelegenen Region Österreich/Ungarn ab. Aufgrund der Überschneidung der klimatischen Bedingungen in Norditalien mit Teilen der USA (Schmidt, 2003) wäre gerade in dieser Region eine intensive züchterische Nutzung des amerikanischen Sortenmaterials mit $H t 1$ zu erwarten gewesen. Vor dem Hintergrund der vorliegenden Ergebnisse war dies offensichtlich nicht der Fall und somit kann die Verwendung von $H t 1$ in dieser Region aktuell als effektive Maßnahme gegen die Turcicum-Blattdürre empfohlen werden. Jedoch besteht insbesondere für Norditalien aufgrund der klimatischen Bedingungen eine größere Gefahr des schnellen Anstiegs der Virulenzfrequenzen als in der kühleren Region Norddeutschland.

Im Gegensatz zu $H t 1$ ist die Virulenzfrequenz für $H t 3$ in Norditalien mit $60 \%$ am höchsten, gefolgt von Norddeutschland mit 51\%. Die Regionen Bretagne/Normandie (12\%) und Tschechien/Polen (16\%) weisen die geringsten Werte für $H$ t3 auf. Abgesehen von diesen beiden Regionen liegt die Virulenzfrequenz für $H t 3$ in allen anderen Regionen bei 20\% oder höher. Diese Werte unterstützen die Hypothese, dass in Europa der Anbau von Sorten mit dem Resistenzgen Ht3 stattfindet, wenn auch nicht flächendeckend. Ein flächendeckender Anbau von Sorten mit $H+3$ ist vor allem für die Regionen Norditalien sehr wahrscheinlich. In dieser Region zeigt $H t 3$ deutliche Wirksamkeitsverluste. Mitte der 1990er Jahre lag die Virulenzfrequenz für $H t 3$ in den südlich gelegenen Anbaugebieten Europas bereits bei $11 \%$ (Welz, 1998). Da es nicht dokumentiert ist, ob $H t 3$ zu dieser Zeit bereits flächendeckend im europäischen Sortenmaterial vorhanden war, kann der Wert von 11\% als natürlich vorkommender Anteil der Virulenz in der Population zu bewerten sein. Über die Frage, ob diese durch Mutation oder Migration entstanden ist, kann aktuell lediglich spekuliert werden. Anteile von $11 \%$ einer Virulenz in einer Population ohne korrespondieren Selektionsdruck setzen voraus, dass die Virulenz nicht mit einem Fitnessverlust des jeweiligen Isolates verbunden ist, denn in dem Fall würden die Anteile der Isolate mit geringerer Fitness schnell und deutlich sinken (Agrios, 2008). In den USA wurde erstmals 1979 eine Virulenz für Ht3 nachgewiesen (Smith \& Kinsey, 1980), obgleich in den USA zu diesem Zeitpunkt laut Welz et 
al. (1997) noch keine Sorten mit $H t 3$ angebaut wurden. Anfang der 1990er Jahre betrug der Anteil virulenter Isolate für $H+3$ 15\% (Ferguson \& Carson, 2007). Es wird für die USA vermutet, dass die Virulenz für Ht3 aus Mexiko in die USA migriert ist (Welz et al., 1997). Die Virulenzfrequenz für $H$ t3 lag Mitte der 1990er Jahre in Mexiko bei 47\% (Welz, 1998). Aufgrund des in den europäischen Maisanbauregionen flächendeckenden Auftretens von Virulenzen für $H$ t3 erscheint die züchterische Nutzung dieses Resistenzgens für die untersuchten Regionen als wenig erfolgversprechend.

Für $H t N$ wurden wie für $H t 3$ in jeder der untersuchten Regionen Virulenzen gefunden, wobei die Werte auch zwischen den Regionen deutliche Unterschiede aufweisen. Insgesamt lag die Virulenzfrequenz im Mittel über alle Regionen für $H+\mathbb{N}$ bei $14,6 \%$. Würde man die Region Südwestfrankreich mit dem höchsten Wert von 38,2\% aus der Betrachtung herausnehmen, läge der Mittelwert der restlichen Regionen bei 9,7\% und damit auf einem relativ geringen Niveau. Der hohe Wert für Südwestfrankreich ist ein Alleinstellungsmerkmal unter den europäischen Regionen und kann als Beleg für eine langjährige und flächendeckende Nutzung von $H \mathbb{N}$ in den dort angebauten Sorten gesehen werden. Untersuchungen Anfang der 1990er Jahre konnten keine Virulenz für $H \mathbb{N}$ in Europa feststellen (Welz, 1998). Ebenso wie für das Resistenzgen $H t 1$ beschrieben, muss es im Zeitraum zwischen 1990 und 2010 zu einer verbreiteten Nutzung von $H t \mathbb{N}$ in europäischen Sorten gekommen sein. Die Ergebnisse der vorliegenden Arbeit deuten auf einen Schwerpunkt dieser Nutzung in Südwestfrankreich hin. In anderen Maisanbauregionen der Welt lagen die Virulenzfrequenzen für $H \mathbb{N}$ bereits in den 1990er Jahren ähnlich hoch oder zum Teil noch deutlich höher als in Südwestfrankreich. Dazu zählen zum Beispiel Regionen wie Nord-China mit 41,7\%, Mexiko mit 55,5\% und Kenia mit 28,2\%. In den USA hingegen wurden Anfang der 1990er Jahre Virulenzfrequenzen für $H \mathbb{N}$ von $12 \%$ festgestellt (Welz, 1998; Ferguson \& Carson, 2007). Abgesehen von den sehr hohen Werten aus den eher tropischen Regionen liegt der Wert in den USA aus den 1990er Jahren auf demselben Niveau wie der aktuell festgestellte Wert für die europäischen Regionen. Der älteste Nachweis einer Virulenz für $H \mathbb{N N}$ in den USA erfolgte an einem Isolat aus dem Jahr 1957. Im Rahmen von Virulenzuntersuchungen wurde an Isolaten Anfang der 1970er Jahre bereits eine Virulenzfrequenz von 14\% für HtN beschrieben (Ferguson \& Carson, 2007). Da zu der Zeit das Resistenzgen HtN noch nicht beschrieben war (Gevers, 1975), müssen andere Faktoren als ein vorhandener Selektionsdruck zu diesen relativ hohen Anteilen geführt haben. Ebenso wie für $H t 3$ liegt hier die Vermutung nahe, dass Virulenzen für $H \mathbb{N}$ aus Mexiko in die USA migriert sind und ohne Fitnessverlust über einen langen Zeitraum in der Population bestehen konnten. Vor dem Hintergrund des Anstiegs der Virulenzfrequenz für $H \mathbb{t N}$ in Europa von 0\% auf aktuell 14,6\% innerhalb eines Zeitraums von 20 Jahren bleibt die Herkunft bzw. Entstehung der Virulenz 
ungeklärt. Dieser Frage könnte mit Hilfe von molekulargenetischen Verwandtschaftsanalysen der europäischen E. turcicum Population nachgegangen werden. Abgesehen von der Region Südwestfrankreich kann $H \mathbb{N}$ in Regionen mit geringen Virulenzfrequenzen unter $10 \%$ mittelfristig durchaus einen Schutz vor der Turcicum-Blattdürre bieten. Dennoch muss auch hier aufgrund der flächendeckend vorhandenen Virulenzen mit einem schnellen Anstieg der Virulenzfrequenzen bei entsprechendem Selektionsdruck gerechnet werden.

Die in dieser Arbeit in Gewächshausversuchen gewonnenen Ergebnisse zur Virulenzverteilung gegenüber $\mathrm{Ht}$-Resistenzgenen innerhalb Europas wurden durch den regionalen Anbau von Differentialsortimenten im Feld überprüft. Für $H t 1$ werden die Ergebnisse anhand der im Feld angebauten Linien durch hohe Befallswerte in den Regionen Österreich/Ungarn und der Oberrheinregion bestätigt. Darüber hinaus zeigten die $H t 1$-Linien in den nördlichen Regionen die geringsten Befallswerte. Für HIN wurden die Ergebnisse der Gewächshausversuche ebenfalls durch die höchsten Befallswerte in der Region Südwestfrankreich auf den $H t N$-Linien bestätigt. Die Ergebnisse für die $H t 2$ - und $H t 3$-Linien fielen hingegen uneinheitlicher aus. Die $H t 2$-Linien wiesen generell einen relativ geringen Befall auf, allerdings wurden insbesondere in der Region Norddeutschland und in Südwestfrankreich höhere Befallswerte bonitiert. Es wurde berichtet, dass für Ht2-Linien vor allem in den nördlichen Küstenregionen häufig höhere Befallswerte festgestellt wurden, als es die Ergebnisse aus den Gewächshausversuchen vermuten ließen (Kessel B, pers. Mitteilung). Ähnliche Beobachtungen zu unterschiedlichen Virulenzeigenschaften von Isolaten gegenüber $H t 2$ und $H t 3$ zwischen Gewächshausversuchen und Feldversuchen sind dokumentiert (Leath et al., 1990; Moghaddam \& Pataky, 1994). Um diesen Sachverhalt genauer zu betrachten, wurden im Rahmen der vorliegenden Arbeit spezielle Versuche bezüglich des Temperatureinflusses auf die Wirksamkeit der Resistenzgene durchgeführt. Diese Versuche ergaben insbesondere für das Resistenzgen $H t 2$ einen Einfluss der Temperatur auf die Wirksamkeit. Vor diesem Hintergrund haben Leonard et al. (1989) darauf hingewiesen, dass Virulenzeinstufungen im Pathosystem Mais - E. turcicum generell unter kontrollierten und konstanten Temperaturbedingungen stattfinden sollten. Dieser Sachverhalt ist Gegenstand der Diskussion im nächsten Kapitel. Grundsätzlich bleibt festzuhalten, dass Virulenzeinstufungen für E. turcicum immer mit einer gewissen Unsicherheit behaftet sind. Dies sollte auch für die Ergebnisse dieser Arbeit beachtet werden.

Zusammenfassend können auf Basis der gewonnenen Ergebnisse folgende regionale Empfehlungen für die Nutzung der untersuchten $\mathrm{Ht}$-Resistenzgene gegeben werden: 
In den Regionen Österreich/Ungarn, Zentralfrankreich, der Oberrheinregion und Tschechien/Polen zeigte $H t 1$ zum Teil hohe Wirkungsverluste, wohingegen für die Regionen Niederlande/Belgien, Bretagne/Normandie und Norditalien die Nutzung von Ht1 empfohlen werden kann.

Aufgrund der flächendeckend sehr geringen Virulenzfrequenzen stellt $H$ t2 für alle Regionen eine gute Möglichkeit zur Bekämpfung der Turcicum-Blattdürre dar. Allerdings sollte die Nutzung von $H t 2$ vor dem Hintergrund der in den Kapiteln 4.3 und 4.4 diskutieren Sachverhalte abgewogen werden.

Für $H$ t3 wurden in den Regionen Norditalien, Norddeutschland, Süddeutschland/Österreich und Südwestfrankreich die stärksten Wirkungsverluste aufgezeigt. Eine Empfehlung für die Nutzung von $H t 3$ kann aufgrund der flächendeckend nachgewiesenen Virulenzen für keine der Regionen gegeben werden.

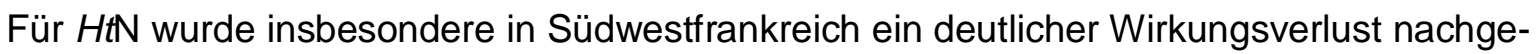
wiesen. In den Regionen Österreich/Ungarn, Norditalien, Bretagne/Normandie und Zentralfrankreich lagen die Virulenzfrequenzen auf einem so geringen Niveau, sodass dort eine Nutzung von $H \mathbb{N}$ zumindest mittelfristig Schutz vor der Turcicum-Blattdürre bieten kann.

Um die Wirksamkeit monogener Resistenzen gegen die Turcicum-Blattdürre für einen möglichst langen Zeitraum zu erhalten, sollte die Basis der Resistenzzüchtung immer eine Kombination von spezifischer qualitativer und breiter quantitativer Resistenz sein. Mehrere Autoren konnten bereits aufzeigen, dass sich die kombinierte Nutzung einzelner $\mathrm{Ht}$-Gene in Genotypen mit breiter qualitativer Resistenz in der Wirkung ergänzt und somit einen besseren und längerfristigen Schutz gegen die Turicucm Blattdürre bietet (Lipps et al., 1997; Pataky \& Ledencan, 2006).

In der praktischen Maiszüchtung werden unter dem Zuchtziel Resistenz neben der Turcicum-Blattdürre noch weitere Blattkrankheiten, wie u. a. die Augenfleckenkrankheit (Kabatiella zeae) oder Maisrost (Puccinia sorghi), aber auch andere Erregergruppen, wie Insekten oder Viren berücksichtigt. Darüber hinaus ergeben sich aus den vielfältigen Nutzungsrichtungen des Maises verschiedene komplexe Zuchtziele, die einerseits auf einen hohen Kornertrag für Körnermaissorten und andererseits auf hohe Biomasseerträge für Energiemaissorten abzielen. Ein weiterer Aspekt, der die Vielfalt der Zuchtziele nochmals erweitert, ist die notwendige Anpassung der Maissorten an klimatisch unterschiedliche Bedingungen. Aufgrund der geringeren Wärmesummen werden in den nördlichen Anbaugebieten frühreife Sorten benötigt, wohingegen in den warmen Regionen im Süden spätreife Sorten bevorzugt werden. Diese vielfältigen Zuchtziele spiegeln sich in der hohen Zahl von aktuell über 430 in Deutschland zugelassenen Maissorten mit jährlich etwa 25 Neuzulassungen 
wider (DMK, 2016). Vor diesem Hintergrund wird deutlich, wie vielfältig die Zuchtziele in der Maiszüchtung sind und die Resistenzzüchtung lediglich einen Aspekt unter vielen darstellt. Deshalb sind die mit der vorliegenden Arbeit bereitgestellten Informationen über die regionale Wirksamkeit der Resistenzgene gegen die Turcicum-Blattdürre umso wichtiger, um eine gezielte und effiziente Resistenzzüchtung gegen E. turcicum im Mais zu ermöglichen.

\subsection{Temperatureinfluss auf die Wirksamkeit der Resistenzgene}

In Klimakammerversuchen konnte gezeigt werden, dass die untersuchten Resistenzgene im genetischen Hintergrund der Linie B37 bei einer Tag/Nacht-Temperatur von $25 / 20^{\circ} \mathrm{C}$ eine konstante Wirksamkeit zeigten. Die Ergebnisse bestätigen, dass die für die Virulenzanalyse gewählte Temperatur von $24 / 20^{\circ} \mathrm{C}$ ideal ist. Einzig die Linie B37- Ht2 zeigte im gewählten Temperaturbereich, abhängig vom Isolat, vereinzelt eine widersprüchliche Resistenzreaktion. Die aufgetretenen Variationen unterstreichen die Notwendigkeit von kontrollierten, konstanten Temperaturen im Bereich von $20^{\circ}$ bis $22^{\circ} \mathrm{C}$ für die Virulenzeinstufung von E. turcicum an Mais.

Insbesondere die Linie B37- $\mathrm{Ht2}$ zeigte bei Temperaturen unter $20^{\circ} \mathrm{C}$ unabhängig vom Isolat eine Verschiebung der Reaktion von resistent zu anfällig, wohingegen bei höheren Temperaturen für B37-Ht2 eine Verschiebung von anfällig zu resistent festgestellt wurde. Im Temperaturbereich unter $15^{\circ} \mathrm{C}$ zeigte die Linie B37-Ht3 ebenfalls eine anfällige Reaktion bei einem avirulenten Isolat. Die Linien B37- $H t 1$ und B37- $H+N$ wiesen über den gesamten Temperaturbereich keine Schwankungen bei den Resistenzreaktionen auf.

Von anderen Autoren wurde in Versuchen mit der Linie H4460-Ht1 eine Verschiebung von anfälliger hin zu resistenter Reaktion bei Temperaturen über $26^{\circ} \mathrm{C}$ nachgewiesen. Im genetischen Hintergrund der Linie B37 zeigte $H t 1$ dagegen über den gesamten Temperaturbereich eine konstante Wirkung (Thakur et al., 1989b). Die Ergebnisse der vorliegenden Arbeit bestätigen diese Aussage für B37. Dennoch zeigten die Ergebnisse von Thakur et al. (1989b), dass die Wirksamkeit von $H t 1$ durch eine Interaktion zwischen dem Resistenzgen, dem genetischen Hintergrund und den Umweltbedingungen beeinflusst werden kann. In weiteren Temperaturversuchen konnten Leath et al. (1990) zeigen, dass vorhandene Virulenzen gegenüber $H t 2$ und $H t 3$ in Gewächshausversuchen bei Temperaturen über $26^{\circ} \mathrm{C}$ nicht mehr nachgewiesen werden konnten. Sie sprechen speziell die im Sommer stark schwankenden Temperaturen in Gewächshäusern von zum Teil deutlich über $26^{\circ} \mathrm{C}$ als Ursache an. Die Verschiebung von anfälligen hin zu resistenten Reaktionen auf den Linien $\mathrm{B} 37-H t 2$ und B37- $H t 3$ bei Temperaturen über $25^{\circ} \mathrm{C}$ in eigenen Versuchen bestätigen diese Ergebnisse. Darüber hinaus beschrieben Leath et al. (1990) und Thakur et al. (1989a) einen 
Wirkungsverlust für Ht2 bei geringen Lichtintensitäten in den Linien B37 und H4460. Der Einfluss der Lichtintensität wurde in der vorliegenden Arbeit nicht näher behandelt.

Für das Resistenzgen $H+N$ beschrieben Thakur et al. (1989a) ebenfalls einen Einfluss der Temperatur. Sie stellten fest, dass die Linie B37- HtN bei Temperaturen von $26^{\circ} \mathrm{C}$ in Kombination mit hohen Lichtintensitäten resistente Befallsreaktionen mit Chlorosen zeigte, wohingegen die Linie bei geringeren Temperaturen von $22^{\circ} \mathrm{C}$ unter Verwendung des gleichen Isolates anfällige Reaktionen ohne Chlorosen aufwies. Allerdings waren diese Befunde inkonsistent zwischen einzelnen Pflanzen bzw. Wiederholungen. Die Wirkung des Resistenzgen $H t N$ zeigte sich in den eigenen Versuchen in der Linie B37 für alle Isolate im gesamten Temperaturbereich als konstant stabil. Die Ergebnisse zu HtN von Thakur et al. (1989a) können also nicht bestätigt werden. Allerdings wurden in den Versuchen der vorliegenden Arbeit für das Resistenzgen $H t 2$ in einigen Fällen inkonsistente Resistenzreaktionen zwischen einzelnen Pflanzen im Temperaturbereich $20 / 15^{\circ} \mathrm{C}$ und $25 / 20^{\circ} \mathrm{C}$ beobachtet. Aufgrund dieser heterogenen Reaktionen zwischen einzelnen Pflanzen ist ein genetischer Effekt wahrscheinlich. In anderen Arbeiten konnte in Rückkreuzungsversuchen gezeigt werden, dass insbesondere der genetische Hintergrund zu Komplikationen beim Transfer von Ht2 führen kann (Ceballos \& Gracen, 1989). Für das Resistenzgen Ht2 wurde ein dominantes Inhibitor Gen (Sht1) beschrieben, das bei gemeinsamem Auftreten die phänotypische Ausprägung der durch Ht2 bedingten Resistenz unterdrückt (Simcox \& Bennetzen, 1993). Darüber hinaus sind Unstimmigkeiten bei Kartierungsexperimenten von $H t 2$ in verschiedenen Kreuzungspopulationen von Mais beschrieben worden, die die Autoren zur Vermutung veranlassten, dass möglicherweise mehrere Gene für die dem Resistenzgen Ht2 zugeordnete Wirkung verantwortlich ist (Wang et al., 2010).

Neben den klassischen Temperaturversuchen, in denen sowohl die Pflanzen als auch der Pilz während des gesamten Versuchszeitraums den verschiedenen Temperaturen ausgesetzt waren, wurden weitere spezifische Temperaturversuche mit den Linien B37 und B37$H t 2$ durchgeführt. Im Rahmen dieser Versuche waren ausschließlich die Pflanzen, nicht aber der Pilz, den verschiedenen Temperaturen ausgesetzt. Auf diese Weise sollten Erkenntnisse darüber gewonnen werden, ob die Verschiebung in der Wirkung des Resistenzgens Ht2 durch die Beeinflussung der Abläufe in der Pflanze oder im Pilz zu erklären ist. Das Virulenzverhalten des virulenten Isolates 48-1 (Rasse 123) unterschied sich nicht zwischen den beiden Versuchen. In beiden Fällen änderte sich die Befallsreaktion in der hohen Temperaturvariante $\left(30 / 25^{\circ} \mathrm{C}\right)$ von anfällig zu resistent. Da der Pilz im zweiten Versuch zu keinem Zeitpunkt hohen Temperaturen ausgesetzt war, liegt es nahe, dass die Ursache des Virulenzverlustes in der Pflanze und nicht im Pilz zu suchen ist. Der Einfluss niedriger 
Temperaturen ausschließlich auf die Pflanze führte hingegen bei dem avirulenten Isolat 76 4 (Rasse 0) nicht zu einer Veränderung der Reaktion von resistent zu anfällig.

Da ein vollständiger Virulenzverlust gegenüber Ht2 ausschließlich in den Fällen nachgewiesen wurde, in denen sowohl der Pilz als auch die Pflanze den niedrigen Temperaturen ausgesetzt waren, könnte die Ursache dafür in der beeinträchtigten Exprimierung des mit $H t 2$ korrespondierenden Avirulenzgens vermutet werden. E. turcicum hat genau wie die Maispflanze ihren Ursprung in tropisch warmen Regionen und ist deshalb möglicherweise nicht optimal an kühlere klimatische Bedingungen angepasst.

Zusammenfassend wurde festgestellt, dass die Virulenz gegenüber Ht2 zunahm, wenn Temperaturen unter $20^{\circ} \mathrm{C}$ sowohl auf die Pflanze als auch auf den Pilz wirken. Wenn allerdings ausschließlich die Pflanzen den geringen Temperaturen ausgesetzt waren, konnte keine Virulenzzunahme beobachtet werden.

Bei Temperaturen über $25^{\circ} \mathrm{C}$ war $H t 2$ voll wirksam gegenüber Isolaten, die unter Standardbedingungen $\left(24 / 20^{\circ} \mathrm{C}, \mathrm{Tag} / \mathrm{Nacht}\right)$ als virulent eingestuft sind und dies unabhängig davon, ob ausschließlich die Pflanze oder die Pflanze und der Pilz den hohen Temperaturen ausgesetzt waren. Die konstant stabile Wirksamkeit des Resistenzgens Ht2 bei hohen Temperaturen in beiden Versuchsvarianten könnte dadurch erklärt werden, dass der optimale Temperaturbereich der aus den Tropen stammenden Maispflanze im Bereich von 25 bis $30^{\circ} \mathrm{C}$ liegt (Bennetzen \& Hake, 2009). Aus diesem Grund könnten die physiologischen Prozesse in der Pflanze in jenem Temperaturbereich ohne Stress ablaufen und damit eine optimale Exprimierung des $H t 2$ Gens ermöglichen. Dieselben Gründe können für die in dieser Arbeit und von anderen Autoren nachgewiesenen Wirkungsverluste für $H t 2$ und $H t 3$ bei Temperaturen unter $20^{\circ} \mathrm{C}$ gesehen werden. Unter Annahme der Hypothese von Wang et al. (2010), wonach mehrere Gene für die als Ht2 bezeichnete Resistenz verantwortlich sind, wäre es vor dem Hintergrund der in dieser Arbeit aufgezeigten heterogenen Reaktionen auf B37- Ht2 bei niedrigen Temperaturen denkbar, dass die beteiligten „Ht2-Gene“ unterschiedlich stark durch niedrige Temperaturen beeinflusst werden. Dadurch könnten letztlich die isolatabhängigen Unterschiede bei niedrigen Temperaturen erklärt werden.

Die hier diskutierten Herausforderungen bei der korrekten Einstufung der Befallsreaktionen auf Genotypen mit $H$ t2 sind insbesondere für die Übertragbarkeit der Ergebnisse auf Feldbedingungen von Bedeutung. Im Vergleich zwischen Feld- und Gewächshausversuchen konnten Moghaddam \& Pataky (1994) deutliche Unterschiede in der Wirkung von Ht2 feststellen. In diesem Fall wurden die unterschiedlichen Temperaturbedingungen als Hauptursache vermutet. Welz \& Geiger (2000) sehen im Temperatureinfluss auf die Wirksamkeit 
monogener Resistenzen gegen die Turcicum-Blattdürre eine Ursache dafür, dass Maiszüchter die Suche nach neuen qualitativen Resistenzen weniger intensiv betreiben.

Neben der qualitativen Beurteilung der Befallsreaktionen im Rahmen der Temperaturversuche wurden ebenfalls quantitative Merkmale als Befallsstärke und durch die Quantifizierung der Pilz-DNA aufgenommen. Diese Daten zeigen wie erwartet für die als virulent eingestuften Isolate im Vergleich zu avirulenten Isolaten die höchsten Befallsstärken auf der Linie B37-Ht2. Überraschend erscheint jedoch, dass sogar in den kompatiblen Interaktionen eine signifikante Reduktion der Befallsstärke durch das vermeintlich unwirksame Resistenzgen $\mathrm{Ht}$ erreicht worden ist. Diese Aussagen werden durch die DNA-Gehalte von E. turcicum im Blattgewebe bestätigt. Dieser Zusammenhang der deutlichen Reduktion der Befallsstärke in kompatiblen Interaktionen untermauert die Notwendigkeit einer klaren Einteilung der Resistenzreaktionen auf $H t 2$ in anfällig bzw. resistent, um aussagekräftige Ergebnisse für eine Rassencharakterisierung zu generieren.

Vor dem Hintergrund der bisher diskutierten Schwierigkeiten bei der Virulenzeinstufung von Isolaten gegenüber $\mathrm{Ht2}$ ist es für die Rassenbestimmung eine Voraussetzung, die Abgrenzung zwischen anfälligen und resistenten Reaktionen auf der Linie B37-Ht2 unter den gewählten Bedingungen zu definieren. Aus diesem Grund wurden für das Resistenzgen Ht2 in verschiedenen genetischen Hintergründen weiterführende Versuche zur Symptomausprägung durchgeführt. Diese sind Gegenstand der Diskussion im folgenden Kapitel.

\subsection{Ht2 Symptomatik und Epidemiepotential}

Das Resistenzgen Ht2 wurde erstmals durch Hooker (1977) als „Chlorotic-Lesion Resistance" benannt und die phänotypische Resistenzreaktion als Chlorosen mit beträchtlichen Nekrosen beschrieben. Die phänotypische Abgrenzung zu den Resistenzreaktionen der Gene Ht1 und Ht3 besteht demnach im Ausmaß der Nekrosen. Im Verlauf des Virulenzscreenings stellte sich heraus, dass die Einstufung der Symptomausprägung auf dem Genotyp B37-Ht2 nicht immer eindeutig einer resistenten oder anfälligen Reaktion zuzuordnen war. Aus diesem Grund wurde das Merkmal Epidemiepotential entwickelt, um eine klare Abgrenzung zwischen den beiden Reaktionstypen auf B37-Ht2 vornehmen zu können. Das Epidemiepotential ergibt sich aus dem relativen Befall multipliziert mit der relativen Sporulation auf der Linie B37-Ht2 im Vergleich zur nah-isogenen Linie B37 (=100). Dieses Merkmal ist aufgrund der aufwändigen Bestimmung nicht dazu geeignet, eine hohe Anzahl an Maisgenotypen, beispielsweise im Rahmen von umfangreichen Resistenztestungen zu untersuchen. Es wurde ausschließlich dafür entwickelt, eine Entscheidungsgrundlage für die in dieser Arbeit genutzten Versuchsbedingungen zu erhalten. 
Die zwei avirulenten Isolate (130-2 \& 186-1) wurden im Ht2-Symptomversuch eindeutig anhand der Befallsreaktionen als avirulent eingestuft. Obwohl das Isolat 186-1 eine Befallsstärke von $12 \%$ aufwies, lag das Epidemiepotential für beide Isolate bei $0,5 \%$ oder geringer. Demnach trägt das Ht2-Gen trotz des hohen Anteils an Nekrosen für diese beiden Isolate zu einer Reduktion des Epidemiepotentials von über 99,5\% bei. Diese Ergebnisse bestätigen die durch Hooker (1977) beschriebene Resistenzreaktion für Ht2. Eine so eindeutige Trennung zwischen anfälligen und resistenten Reaktionen ausschließlich anhand der Qualität der Blattläsionen traf auf weit über $90 \%$ der 559 untersuchten Isolate zu. Vor diesem Hintergrund wird deutlich, dass die Unstimmigkeiten bei der Symptombeurteilung auf $H$ t2 zwar regelmäßig auftraten, aber beim Großteil der untersuchten Isolate nicht zu Problemen führten.

Vier der sechs im Rahmen des Ht2-Versuchs untersuchten Isolate riefen allerdings heterogene Befallsreaktionen hervor (Tab. 22). Das virulente Referenzisolat 28A konnte anhand der Befallsreaktionen nicht eindeutig als virulent eingestuft werden. Daran werden die Herausforderungen für die Virulenzeinstufung der Isolate auf der Linie B37-Ht2 deutlich. Die höchsten Befallswerte zeigten die Isolate 161-1 und 122-2 mit bis zu 39\% nekrotisierter Blattfläche. Trotz dieser beträchtlichen Befallswerte war es nicht möglich, die Qualität der Läsionen eindeutig einer resistenten oder anfälligen Reaktion zuzuordnen. In Kombination mit dem Vermehrungspotential wiesen die beiden Isolate mit 6,4 und $7,8 \%$ ebenfalls die höchsten Werte für das Merkmal Epidemiepotential auf. Im Vergleich dazu zeigte das virulente Isolat $28 \mathrm{~A}$ ebenfalls ein relativ hohes Epidemiepotential von 4,7\%. Dennoch würde man grundsätzlich für ein virulentes Isolat ein deutlich höheres Epidemiepotential erwarten. Denn im klassischen Sinne der qualitativen Resistenz wird in einer kompatiblen Interaktion ein vollständiger oder zumindest nahezu vollständiger Wirkungsverlust des betreffenden Resistenzgens erwartet (Agrios, 2008). Gegenüber dem virulenten Isolat 28A bewirkt das Resistenzgen $H t 2$ hingegen eine sehr hohe Reduktion des Epidemiepotentials um 95,3\%.

Vor dem Hintergrund der in Kapitel 4.3 diskutierten Interaktionen des Resistenzgens Ht2 mit dem jeweiligen genetischen Hintergrund wurden die Versuche zur Ht2-Symptomatik neben dem Genotyp B37 ebenfalls mit den Genotypen Pa91 und KWS durchgeführt. Die Ergebnisse zeigten einen deutlichen Einfluss des genetischen Hintergrundes auf die Wirkung von Ht2. Nur das als avirulent bekannte Isolat 130-2 rief auf allen Genotypen einheitlich resistente Befallsreaktionen hervor. Alle anderen Isolate verursachten je nach genetischem Hintergrund sehr heterogene Befallsreaktionen auf Linien mit $H t 2$ (Tab. 24). Darüber hinaus wurde die unterschiedlich ausgeprägte Wirkung von $H$ t2 in verschiedenen genetischen Hintergründen anhand der Merkmale Befallsstärke und Sporulation sehr deutlich. Das Isolat 28A erreichte auf der Linie Pa91-Ht2 für beide Merkmale ebenso hohe Werte wie auf der 
nah-isogenen Linie Pa91 ohne das Resistenzgen. Diese Werte bestätigen einen vollständigen Wirkungsverlust von Ht2 im Hintergrund der Linie Pa91 gegenüber dem Isolat 28A. Ausgedrückt im Merkmal Epidemiepotential liegt der Wert für das Isolat 28A auf der Linie Pa91-Ht2 bei $152 \%$. Die Linie Pa91 weist generell für alle Isolate den höchsten Befall und die höchste Sporulation auf. Der Vergleich zwischen den getesteten Linien belegt eine vergleichsweise hohe Wirkung für das Resistenzgen Ht2 im genetischen Hintergrund von B37. Nach der Bestätigung der Virulenz von Isolat 28A auf der Linie Pa91-Ht2 dienten die erhobenen Werte auf B37-Ht2 als Richtwerte zur Abgrenzung zwischen anfälliger und resistenter Reaktion. Es konnte kein Zusammenhang zwischen der Befallsstärke einzelner Isolate und deren Sporulation, weder auf B37 noch auf B37-Ht2, nachgewiesen werden. Aufgrund der leicht zu erfassenden Befallsstärke und der signifikanten Korrelation dieses Merkmals mit den Werten des Epidemiepotentials wurde die Befallsstärke als Abgrenzungsmerkmal der Virulenzeigenschaften genutzt. Da ausschließlich die beiden Isolate 161-1 und 122-2 relative Befallsstärken von deutlich über $20 \%$ aufwiesen und sie sich dadurch von den anderen Isolaten absetzen, wurde $20 \%$ Befallsstärke als Abgrenzung zwischen einer anfälligen und resistenten Reaktion herangezogen. Auf dieser Grundlage wurden im Rahmen des $H t 2$ Symptomversuchs die Isolate 161-1 und 122-2 als virulent gegenüber Ht2 eingestuft. Das zunächst in den Virulenzuntersuchungen als avirulent eingestufte Isolat 161-1 konnte durch diese tiefergehenden Untersuchungen nun als virulent beschrieben werden. Alle anderen Isolate $(130-2,127-2,186-1,159-4)$ sind auf Basis dieser Ergebnisse als avirulent auf $H$ t2 eingestuft worden. Die Befallsstärke wurde nur in den Fällen herangezogen, in denen eine eindeutige Abgrenzung zwischen anfällig und resistent anhand der qualitativen Beurteilung auf Basis der Befallsreaktionen nicht möglich war.

Im klassischen Sinne wird angenommen, dass Resistenzen, die eine Sporulation zulassen, nicht rassenspezifisch wirksam sind. Dennoch wurden mit den rassenbildenden Erregern des Schwarzrostes im Weizen (Puccinia graminis var. tritici) oder der Kraut- und Knollenfäule an Kartoffeln (Phytophthora infestans) Pathosysteme beschrieben, in denen in inkompatiblen Interaktionen eine Sporulation in geringem Umfang möglich ist (Johnson \& Taylor, 1976). Diese Beispiele und die hier diskutierten Ergebnisse zeigen, dass eine Vermehrung durch Sporulation auf resistenten Genotypen kein Widerspruch zur rassenspezifischen Resistenz sein muss. Die hier aufgezeigte Wirkung von Ht2 auf die Reduktion, nicht aber vollständige Unterbindung der Sporulation in inkompatiblen Interaktionen ist ebenfalls für $H t 1, H t 3$ und $H t \mathbb{N}$ bekannt (Raymundo \& Hooker, 1982), (Thakur et al., 1989a; Welz \& Geiger, 2000). Der hohe Grad an nekrotisierter Blattfläche in Verbindung mit einer nicht vollständig unterbundenen Sporulation wirft die Frage auf, wie sich dies auf die Verhinde- 
rung von Epidemien im Feld auswirken könnte. Insbesondere durch den diskutierten Einfluss des genetischen Hintergrundes auf $H t 2$ kann dies von großer Bedeutung sein. So berichten Pataky et al. (1986), dass Genotypen mit Ht2 nicht in der Lage waren, die Ausbreitung der Turcicum-Blattdürre in einem Feldbestand zu verhindern, obwohl es sich um eine für Ht2 als avirulent beschriebene E. turcicum Population handelte. Die Autoren vermuteten die Ursache für die drastisch reduzierte Wirkung von Ht2 im genetischen Hintergrund der verwendeten Linie.

Es stellt sich grundsätzlich die Frage, wie wertvoll monogene Resistenzen für den praktischen Anbau sind, wenn sie zwar die Vermehrung des Pathogens auf der Pflanze stark reduzieren, aber dennoch beträchtliche Nekrosen in Verbindung mit Chlorosen auf dem Blattgewebe zulassen. In Versuchen anderer Autoren wurde dieser Frage nachgegangen. Der parallele Anbau von Genotypen mit $H t 1$ und Genotypen mit breiter quantitativer Resistenz, jedoch ohne $H t 1$ an Orten mit avirulenten E turcicum Populationen zeigten diesbezüglich interessante Ergebnisse. In mehreren Fällen konnte nachgewiesen werden, dass Resistenzreaktionen in Form von Nekrosen mit Chlorosen auf $H t 1$-Genotypen bei entsprechend vorhandenem Inokulum zum Absterben großer Teile der Blattfläche führten. Das wurde insbesondere beobachtet, wenn $\mathrm{Ht1}$ in ansonsten anfälligen Genotypen genutzt wurde. Die Blattverluste auf den mit ausschließlich quantitativer Resistenz ausgestatteten Genotypen fielen hingegen deutlich geringer aus. Diese deutlichen Effekte im Blattbefall wirkten sich in Einzelfällen auch negativ auf den Kornertrag aus. (Ullstrup, 1970; Pataky, 1994; Welz \& Geiger, 2000; Pataky et al., 2011). Vor dem Hintergrund der diskutieren Ht2Symptomatik ist dieses Szenario ebenso für das Resistenzgen Ht2 denkbar.

Zusammenfassend stellt die Nutzung einer breiten, quantitativen Resistenz in Kombination mit der gezielten Auswahl monogener Resistenzen die wirkungsvollste und langfristig effektivste Methode für die Resistenzzüchtung gegen die Turcicum-Blattdürre im Mais dar. Diese Aussage ist für keinen Pflanzenzüchter neu. Dennoch wurde in dieser Arbeit neben dem klassischen Argument des Schutzes der monogenen Resistenzen vor dem Hintergrund der beträchtlichen Resistenzreaktion in Form von Nekrosen durch das Resistenzgen $H$ t2 ein weiteres Argument aufgezeigt.

\subsection{Histologische Untersuchungen}

Vergleichende histologische Untersuchungen von kompatiblen mit inkompatiblen Interaktionen bilden die Grundlage für eine Interpretation der genetischen Interaktion zwischen Pathogen und Wirt. Im Rahmen der histologischen Untersuchungen zur Pathogenese von 
E. turcicum in Mais wurden drei Parameter im Zeitverlauf des Infektions- und Besiedlungsprozesses für jedes der vier $\mathrm{Ht}$-Resistenzgene erfasst, nämlich 1. Xylem-Penetrations-Effizienz, 2. Xylem-Besiedlungs-Effizienz und 3. Mesophyll-Besiedlungs-Effizienz. Die Parameter beschränkten sich auf die Abläufe der Besiedlung des Blattgewebes nach Penetration der Epidermis, da die initialen Schritte des Infektionsverlaufs, wie Sporenkeimung, Appressorienbildung und Penetration der Epidermis bereits von (Hilu \& Hooker, 1964; KnoxDavies, 1974) untersucht wurden. Andere Autoren konnten ebenfalls aufzeigen, dass diese Prä-Penetrationsschritte im Verlauf des Infektionsprozesses nicht durch qualitative Resistenz beeinflusst werden (Hilu \& Hooker, 1964; Muiru et al., 2008). Stichprobenartige Testungen im Rahmen der eigenen histologischen Untersuchungen bestätigen diese Aussagen.

Sowohl in den kompatiblen als auch in den inkompatiblen Interaktionen fand nach dem Eindringen in die Epidermiszellen ein verzweigtes, intrazelluläres Hyphenwachstum in Richtung der Leitbündelgefäße statt (Abb. 34). In der näheren Umgebung dieser epidermalen Penetrationsstellen konnten braungefärbte Bereiche sowohl in der Linie B37 als auch in den Linien mit $\mathrm{Ht}$-Gen beobachtet werden. Diese Verfärbungen könnten als Reaktion der Pflanze auf die Zellwandpenetrationen der die Leitbündel umgebenden Mesophyllzellen gedeutet werden, z. B. durch Akkumulation von Phenolen. Eine hypersensitive Reaktion erscheint unwahrscheinlich, da die Braunfärbung auch in Linien ohne $\mathrm{Ht}$-Gene beobachtet werden konnte. Die Ergebnisse der histologischen Untersuchungen zeigen, dass die für die Braunfärbung verantwortlichen Substanzen das Wachstum der Pilzhyphen nicht negativ beeinflussen und nicht auf die $\mathrm{Ht}$-Gene zurückzuführen sind. Die hier beschriebene Reaktion könnte als Ursache für die wenige Stunden nach der Inokulation auftretenden chlorotischen Punkte verantwortlich sein. Welz (1998) hat diese Punkte als 80-100 kollabierte Zellen in der unmittelbaren Umgebung der Penetrationsstelle beschrieben. Im Rahmen der Virulenztestungen diente das Auftreten der chlorotischen Punkte bereits zwölf Stunden nach Inokulation als Indikator für eine erfolgreiche Infektion (Abb. 5). Eine weitere Ursache für die erscheinenden chlorotischen Punkte könnte ein von E. turcicum gebildetes Phytotoxin namens Monocerin sein. Es ist bekannt, dass Monocerin die Chlorophyllsynthese reduziert und auf diesem Weg Chlorosen hervorrufen kann (Cuq et al., 1993). Monocerin wurde ursprünglich nicht in E. turcicum, sondern in E. monoceras beschrieben (Cuq et al., 1993). Demnach handelt es sich um ein unspezifisches Phytotoxin und kann nicht als Virulenzfaktor für eines der $\mathrm{Ht}$-Gene vermutet werden. Da die chlorotischen Punkte sowohl in der hochanfälligen Linie B37 ohne $\mathrm{Ht}$-Gen als auch in inkompatiblen Interaktionen beobachtet werden konnten, erscheinen Phytotoxine als durchaus wahrscheinliche Ursache für die chlorotischen Punkte. 
Ziel der histologischen Untersuchungen war es festzustellen, wo genau und zu welchem Zeitpunkt die Resistenzfaktoren für die einzelnen $\mathrm{Ht}$-Resistenzgene im Blattgewebe vermutet werden müssen.

Das erhobene Merkmal Xylem-Penetrations-Effizienz beschreibt den Anteil an epidermalen Penetrationsstellen, denen ein Eindringen durch Pilzhyphen in das Xylem folgte. Bis drei Tage nach Inokulation konnte in der inkompatiblen Interaktion mit Ausnahme von $H \mathbb{N}$ kein Effekt der Resistenzgene nachgewiesen werden. Erst zwischen dem dritten und sechsten Tag nach Inokulation wurde kein weiteres Eindringen in das Xylem beobachtet. Alle HtGene zeigten also zwischen dem dritten und sechsten Tag in der inkompatiblen Interaktion eine signifikante Reduktion der Xylem-Penetration. Dennoch konnte für alle $\mathrm{Ht}$-Linien in den inkompatiblen Interaktionen ein Eindringen in das Xylem nachgewiesen werden. Diese Beobachtungen zeigen, dass die $\mathrm{Ht}$-Gene in der Linie B37, anders als für eine qualitative Resistenz erwartet, nicht zu einer vollständigen Abwehr der Xylem-Penetration führen.

In der kompatiblen Interaktion zeigten die beiden Linien B37-Ht1 und B37-Ht3 über den gesamten Versuchszeitraum wie erwartet einen vollständigen Wirkungsverlust. Die Linie B37-HtN war nicht durch einen vollständigen Wirkungsverlust gekennzeichnet, sondern verzögerte die Xylem-Penetration lediglich. Dieser Effekt zeigt sich durch einen kontinuierlichen Anstieg der Xylem-Penetrationen im Zeitverlauf. Der Effekt des HtN-Gens gegen die Turcicum-Blattdürre ist in der Literatur als grundlegend verschieden gegenüber denen von $H t 1, H t 2$ und $H t 3$ beschrieben. Bisher ist bekannt, dass $H t N$ nicht die typischen Resistenzreaktionen in Form von chlorotischen Nekrosen hervorruft, sondern eine Verlängerung der Inkubationszeit bewirkt und die Anzahl der auftretenden Läsionen reduziert (Raymundo et al., 1981). Die beschriebenen Eigenschaften von $H \mathbb{N}$ zur verzögerten Befallsentwicklung durch Raymundo et al. (1981) werden anhand der Ergebnisse der histologischen Untersuchungen durch eine verzögerte Xylem-Penetration ergänzt und somit bestätigt. Für die Linie B37-Ht2 konnte erst 18 Tage nach Inokulation ein deutlicher Anstieg der Xylem-Penetrationen in der kompatiblen Interaktion festgestellt werden. Trotz des Anstiegs war zu dem Zeitpunkt aber noch eine deutliche Wirkung von Ht2 vorhanden, die in diesem Ausmaß in einer kompatiblen Interaktion ungewöhnlich hoch erscheint. Wie bereits in Kapitel 4.4 diskutiert, kann die Wirkung von Ht2 durch eine Interaktion mit dem jeweiligen genetischen Hintergrund beeinflusst werden. Durch die histologischen Untersuchungen kann die in Kapitel 4.4 beschriebene fördernde Wirkung des genetischen Hintergrundes auf die Wirkung des Resistenzgens Ht2 bestätigt werden.

Anhand der in dieser Arbeit verwendeten Färbemethode (Chlorazol Black E) konnten im Infektionsverlauf vom Penetrieren der Epidermis bis zum Eindringen in das Xylem in keiner der untersuchten Interaktionen morphologische Veränderungen festgestellt werden, die als 
physische Barriere hätten dienen können. Die entscheidenden Resistenzmechanismen zur Verhinderung des Eindringens in die Xylemgefäße müssen zwischen dem dritten und sechsten Tag nach Inokulation vermutet werden. Da das Gewebe der Xylemwand als physiologisch inaktives Gewebe betrachtet werden kann, müssen die möglichen Abwehrreaktionen in den umliegenden Zellen, beispielsweise den Leitbündelscheidenzellen vermutet werden.

Es ist vor allem ein Sekundärmetabolit allgemein für Gräser und speziell im Mais bekannt, der eine Resistenz gegenüber Schädlingen und Pathogenen bewirkt. Dabei handelt es sich um den Sekundärmetabolit Benzoxazinoid 2,4-Dihydroxy-7-methoxy-1,4-benzoxazin-3one, kurz DIMBOA (Frey, 1997). Bei Versuchen im Mais konnten Courture et al. (1971) bereits eine Wirkung von DIMBOA gegenüber E. turcicum in Linien mit $H t 1$ nachweisen. DIMBOA wird als nicht toxisches Glykosid in den Vakuolen der Pflanzenzellen gespeichert und entwickelt erst nach hydrolytischer Abspaltung durch $\beta$-Glukosidase seine toxische Wirkung (Frey, 1997). In histochemischen Untersuchungen konnte gezeigt werden, dass in den Epidermis- und Mesophyllzellen in Maisblättern keine bzw. nur sehr geringe Gehalte an $\beta$-Glukosidasen vorhanden sind. Mace (1973) beobachtete zudem, dass zwei bis drei Tage nach Besiedlung mit E. turcicum vor allem in unmittelbarer Nähe der Leitbündelgefäße eine höhere DIMBOA-Konzentration als in anderen Zellbereichen zu finden war. Er stellte die Hypothese auf, dass die von E. turcicum synthetisierte $\beta$-Glukosidase die Hydrolyse des im Bereich der Leitbündelgefäße vorhandenen DIMBOA-Glykosids in die toxische Form maßgeblich fördert. Er bekräftigt diese Hypothese damit, dass DIMBOA erst zwei bis drei Tage nach der Epidermis-Penetration und dann lediglich in den Leitbündelgefäßen nachgewiesen werden konnte.

Die Ergebnisse der vorliegenden Arbeit bestätigen diese Hypothese, denn im Mesophyll wurde das Hyphenwachstum weder in der anfälligen noch in der resistenten Variante reduziert und zudem lag der Zeitpunkt des vermehrten Eindringens in die Xylemgefäße ebenfalls um den dritten Tag nach Inokulation. Long et al. (1978) konnten ebenfalls nachweisen, dass die DIMBOA-Konzentration in Maisblättern negativ mit dem Auftreten von E. turcicum Läsionen korreliert. Weitere Autoren konnten für Linien mit $H t 1$ zeigen, dass ab 48 Stunden nach Inokulation vermehrt antimikrobielle Substanzen im Blattgewebe gebildet werden und dadurch eine deutliche Reduktion des Befalls bewirkten. Darüber hinaus konnten sie zeigen, dass die Synthese dieser als antimikrobiell beschriebenen Verbindungen stark vom genetischen Hintergrund der jeweiligen Linie beeinflusst wird (Calub et al., 1974; Obi et al., 1980). Demnach würde das Hyphenwachstum erst ab dem dritten Tag durch die beschriebenen antimikrobiellen Substanzen verhindert bzw. reduziert werden. Diese Hypothese wird durch die histologischen Untersuchungen der vorliegenden Arbeit bestätigt. Da erst 
am sechsten Tag nach Inokulation eine Wirkung der $\mathrm{Ht}$-Gene in der inkompatiblen Interaktion für das Merkmal Xylem-Penetration nachgewiesen werden konnte, muss vermutet werden, dass das Eindringen in das Xylem zwischen dem dritten und sechsten Tag nach Inokulation gestoppt wurde. Da DIMBOA als Sekundärmetabolit auch in Maisgenotypen ohne Ht-Gene auftritt (Frey, 1997), kann dieser Metabolit allerdings nicht als einziger Resistenzfaktor für die hier untersuchten Interaktionen der $\mathrm{Ht}$-Gene gesehen werden.

Die bisher diskutierten Reaktionen betreffen die möglichen Resistenzmechanismen bis zum Zeitpunkt des Eindringens in das Xylem. Der nächste Schritt der Pathogenese betrifft die Besiedlung des Xylems. Ab diesem Schritt haben Metabolite, die außerhalb des Xylems gebildet werden, einen sehr begrenzten Einfluss auf das Hyphenwachstum. Nachdem das Xylem erfolgreich penetriert war, konnte in den kompatiblen Interaktionen ab dem zwölften Tag nach Inokulation eine starke Ausbreitung in den Leitbahnen nachgewiesen werden. Die Ergebnisse für das Merkmal Xylem-Besiedlungs-Effizienz waren denen der Xylem-Penetration sehr ähnlich. Alle Linien mit $\mathrm{Ht}$-Gen zeigten für Xylem-Besiedlung in der inkompatiblen Interaktion wie erwartet eine fast vollständige Reduktion. In der kompatiblen Interaktion konnte für die Linien B37-Ht1 und B37-Ht3 lediglich bis zum zwölften Tag nach Inokulation eine Wirkung der $H t$-Gene nachgewiesen werden. Die Linie B37-HtN fällt auch in diesem Merkmal eher durch eine Verzögerung der Befallsentwicklung als durch eine vollständige Verhinderung auf. Am letzten Boniturtermin zeigte $H \mathbb{N}$ zwar noch signifikante Wirkung, aber es ist anzunehmen, dass im weiteren Zeitverlauf ein kontinuierlicher Anstieg der Xylem-Besiedlung stattgefunden hätte. Die Linie B37-Ht2 zeigte bis 12 dpi eine vollständige Verhinderung der Xylem-Besiedlung, folglich das genaue Gegenteil von dem einer kompatiblen Interaktion. Sogar nach 18 Tagen zeigte $H t 2$ noch eine hoch signifikante Wirkung.

In Einzelfällen konnten in den besiedelten Xylemgefäßen dunkel gefärbte Bereiche beobachtet werden, in denen das Hyphenwachstum unterbunden wurde (Abb. 35). Hierbei handelte es sich nicht um regelmäßig und systematisch auftretende Reaktionen. Diese konnten also weder den inkompatiblen Interaktionen noch einem speziellen $\mathrm{Ht}$-Gen zugeordnet werden.

Die Voraussetzung für eine Vermehrung durch Sporulation stellt für E. turcicum die Besiedlung des Mesophylls dar. Nachdem es in den Xylemgefäßen durch intensives Hyphenwachstum zu einer mechanischen Barriere des Wassertransports in den Maisblättern gekommen ist, beginnen die davon betroffenen Zellbereiche aufgrund von Wassermangel zunächst auszutrocknen und treten als grau-grünliche, dürreähnliche Läsionen in Erscheinung. Die Läsionen breiten sich sehr schnell aus und führen letztlich zum Absterben gröBerer lokal begrenzter Blattbereiche. Diese Symptome waren auf der anfälligen Linie B37 bereits nach acht bis neun Tagen sichtbar (Abb. 5). Nachdem das Zellgewebe nekrotisiert 
ist, beginnen Pilzhyphen, ausgehend vom Xylem, die Mesophyllzellen zu besiedeln. Daraufhin wachsen einzelne Hyphen in Richtung Stomata. Durch die Stomata wachsen die Hyphen nach außen und bilden dort unter feuchten Bedingungen Sporenträger mit Konidiosporen aus. Die Beschreibung der Pathogenese im Blattgewebe verdeutlicht, dass das Ausmaß der Mesophyll-Besiedlung starken Einfluss auf die Sporenbildung hat.

Im Rahmen der histologischen Untersuchungen konnte in den inkompatiblen Interaktionen eine nahezu vollständige Unterbindung der Mesophyll-Besiedlung in den $\mathrm{Ht}$-Linien nachgewiesen werden. In den kompatiblen Interaktionen war die Linie B37-HtN wiederum durch eine verzögernde Wirkung auf die Mesophyll-Besiedlung gekennzeichnet, wohingegen B37-Ht2 wie schon bei den anderen Merkmalen durch eine ungewöhnlich hohe Wirkung in der kompatiblen Interaktion gekennzeichnet war. Spätestens hier stellt sich die Frage, ob es sich bei dem gewählten Isolat und der Linie B37-Ht2 um eine inkompatible Interaktion handelt. Denn bereits bei der Bonitur der Befallsreaktionen traten diesbezüglich Unstimmigkeiten auf. Zum Zeitpunkt 12 dpi waren die Befallsreaktionen auf den Pflanzen als Nekrosen mit Chlorosen zu erkennen und somit als resistent einzustufen. Sechs Tage später waren die Reaktionen hingegen als eindeutig anfällig ohne Chlorosen zu erkennen. In den Versuchen zur Virulenzeinstufung im Rahmen des Rassenscreenings wurde das betreffende Isolat ebenfalls eindeutig als virulent eingestuft. Dieser Sachverhalt unterstützt die Hypothese, dass die Wirkung von $H t 2$ von mehreren Faktoren beeinflusst werden kann. Hier spielen sowohl die Licht- bzw. Temperaturbedingungen (Kapitel 4.3) als auch der genetische Hintergrund, in den $H t 2$ eingebracht wurde, eine Rolle (Kapitel 4.4). Der genetische Hintergrund B37 hat sich in eigenen Versuchen als sehr förderlich für die Ausprägung der durch $H t 2$ verliehenen Resistenz herausgestellt. Dies könnte eine mögliche Erklärung für die hier beschriebene hohe Wirksamkeit von $H t 2$ in einer als inkompatibel definierten Interaktion sein.

Für keines der Resistenzgene konnte im Rahmen der mikroskopischen Untersuchungen in Bezug auf die drei Merkmale Hinweise auf morphologische Veränderungen in der inkompatiblen Interaktion gefunden werden. Diese Erkenntnisse bestätigen frühere Untersuchungen anderer Autoren, die für $\mathrm{Ht1}$ gegen E. turcicum ebenfalls keine morphologischen Barrieren zur Verhinderung bzw. Verminderung des Eindringens von Pilzhyphen in die Xylemgefäße nachweisen konnten (Hilu \& Hooker, 1964).

Die Untersuchungen zur Pathogenese verdeutlichen, dass E. turcicum drei entscheidende Phasen für eine erfolgreiche Besiedlung und Vermehrung im Maisblattgewebe durchlaufen muss: 1. Eindringen in das Xylem (biotrophe Phase), 2. Ausbreitung innerhalb der Xylemgefäße und 3. nekrotrophe Phase beginnend mit dem Austritt aus dem Xylem in das nekrotisierte Mesophyll bis zur Ausbildung von Sporenträgern durch die Stomata. 
An zwei Punkten wird deutlich, dass virulente Isolate von E. turcicum die Fähigkeit besitzen müssen, die Xylemwand aktiv zu durchdringen: zunächst beim Eintritt zwischen dem zweiten und vierten Tag nach Inokulation und danach beim Austritt in das Mesophyll, nachdem das umliegende Gewebe abgestorben ist. Es sind für E. turicucm verschiedene Enzyme und Phytotoxine bekannt, die aber bisher nicht als Virulenzfaktoren in Zusammenhang mit den $\mathrm{Ht}$-Genen gebracht werden konnten. Zum Beispiel sind für $E$. turcicum Genomsequenzen bekannt, die für zwei zellwandabbauende Enzyme codieren, sogenannte Xylanasen (Degefu, 2003). Da die Synthese der Xylanase weder für eines der Ht-Gene noch für $\mathrm{E}$. turcicum spezifisch ist (Mendgen et al., 1996), ist es wenig wahrscheinlich, dass diese Xylanasen als Faktoren für das Penetrieren der Xylemwand eine Rolle spielen. Es kann jedoch angenommen werden, dass diese Xylanasen eine wichtige Rolle in der Besiedlung des Mesophylls sowohl in der biotrophen als auch in der nekrotrophen Phase der Pathogenese spielen und somit als Pathogenitätsfaktoren von Bedeutung sind.

Für das Resistenzgen $H \mathbb{N}$ haben Hurni et al. (2015) nachgewiesen, dass es sich um drei eng gekoppelte Gene am HtN Locus handelt. Diese Ergebnisse können eine Erklärung dafür sein, dass in den histologischen Untersuchungen für $H \mathbb{N}$ in der kompatiblen Interaktion die Wirkung zu keinem Zeitpunkt vollständig verloren war. Vielmehr wirkte $H t N$ verzögernd auf die Xylem-Penetration und die folgende Besiedlung des Blattgewebes. Diese Eigenschaft ist ein klassisches Merkmal einer quantitativen Resistenz. Als solche haben Hurni et al. (2015) die $H t \mathbb{N}-$ Resistenz auf Basis ihrer Ergebnisse zur Kartierung des $H \mathbb{N}$ Locus auch definiert. Die Beobachtungen zur verzögerten Xylem-Penetration und Mesophyll-Besiedlung im Gegensatz zu einem vollständigen Wirkungsverlust für das Resistenzgen $H$ tN bestätigen den quantitativen Charakter der HtN Resistenz.

Zusammenfassend konnte anhand der histologischen Untersuchungen gezeigt werden, dass das Passieren der Xylemwand für alle untersuchten $\mathrm{Ht}$-Gene den entscheidenden Resistenzfaktor darstellt. Dieser Faktor konnte als effektive Barriere gegen die weitere Ausbreitung der Pilzhyphen in den inkompatiblen Interaktionen für jedes Resistenzgen identifiziert werden. Dennoch war keines der $\mathrm{Ht}$-Gene in der Lage, das Passieren der Xylemwand vollständig zu verhindern. Weiterführende Untersuchungen zu den biochemischen Abläufen vor allem in den Leitbündelgefäßen könnten Aufschluss darüber geben, welche Substanzen letztlich dafür verantwortlich sind, das Eindringen der Pilzhyphen in das Xylem zu verhindern. 


\section{Zusammenfassung}

Hintergrund der vorliegenden Arbeit war die seit einigen Jahren zunehmende Bedeutung des pilzlichen Blattdürreerregers Exserohilum turcicum in intensiven Maisanbauregionen. Der Blattbefall durch die Turcicum-Blattdürre reduziert die photosynthetisch aktive Blattfläche und führt somit zu Ertragsverlusten. Als effektivste Maßnahme zur Ertragssicherung werden resistente Sorten mit Hilfe monogen wirkender Resistenzen ( $H t 1, H t 2, H t 3$ und $H t \mathbb{N}$ ) gezüchtet und im praktischen Anbau verwendet. Die Wirksamkeit monogener Resistenzen ist durch die Entstehung virulenter Rassen limitiert. Ein Ziel der Arbeit war es, durch ein Rassen-Monitoring die regionale Wirksamkeit der Resistenzgene zu beurteilen. Auf Basis der gewonnenen Informationen könnten die Nutzung der Resistenzgene in der Sortenzüchtung angepasst und konkrete regionale Sortenempfehlungen ausgesprochen werden. Als Grundlage der Untersuchungen wurden in den Jahren 2011 und 2012 aus zehn europäischen Ländern von 168 Orten befallene Blattproben gesammelt. Insgesamt konnten von diesen Blattproben 559 Einsporisolate gewonnen und deren Virulenz-Eigenschaften charakterisiert werden. Die Rassenbestimmung wurde anhand der Befallsreaktionen nach Ganzpflanzeninokulation an einem Differentialsortiment bestehend aus nah-isogenen Inzuchtlinien durchgeführt. Es wurden die Linien B37 (ohne Resistenzgen), B37-Ht1, B37$H t 2$, B37-Ht3 und B37-HtN verwendet.

Für jedes der untersuchten Resistenzgene konnten virulente Isolate nachgewiesen werden. Insgesamt wurden zwölf verschiedene Rassen charakterisiert. Die vier häufigsten Rassen in beiden Probenahmejahren waren Rasse 0 mit 45\%, die sich avirulent auf den untersuchten Resistenzgenen verhält, Rasse 1 (22\%), Rasse 3 (15\%) und Rasse 3N mit einem Anteil von 14\%. Die Rassen 13, 23, 123, 2, 23N, 12, $1 \mathrm{~N}$ und 13N hatten im Durchschnitt beider Jahre einen kumulierten Anteil von 4\%. Der kumulierte Anteil der drei dominierenden Rassen 1, 3 und 3N lag im Mittel der beiden Jahre 2011 und 2012 bei 52\%. In den nördlichen Küstenregionen Frankreichs, Belgiens und den Niederlanden dominierten avirulente Isolate der Rasse 0 mit einem Anteil von über $75 \%$. In der Oberrheinregion waren 48\% der charakterisierten Isolate virulent auf $H t 1$ und $26 \%$ virulent auf $H t 3$. Sowohl in norddeutschen als auch in süddeutschen Maisanbaugebieten dominierte die Rasse 0. In der Region Niederbayern waren $44 \%$ der untersuchten Isolate virulent auf $H t 3$. In den Maisanbaugebieten von Tschechien und Polen lag der Anteil virulenter Isolate für $H t 1$ bei $37 \%$. Die Virulenzfrequenzen der intensiven Maisanbauregion im südwestlichen Frankreich lagen bei $45 \%$ für $H t 3$ und $38 \%$ für $H+\mathbb{N}$. Der hohe Anteil virulenter Isolate für das Resistenzgen $H \mathbb{N}$ und die Dominanz der Rasse 3N mit einem Anteil von 38\% stellte ein Alleinstellungsmerkmal für die Region Südwestfrankreich dar. Die Region Steiermark im südlichen Österreich ist durch langjährigen intensiven Maisanbau gekennzeichnet. Der Anteil virulenter Isolate für Ht1 lag 
hier bei $83 \%$, was einen Wirkungsverlust dieses Resistenzgens in der Region bedeutet. Darüber hinaus wurde in dieser Region der höchste Anteil der hochkomplexen Rasse 123 nachgewiesen. Die Maisanbauregion in der Po-Ebene Norditaliens war durch eine hohe Virulenzfrequenz von $60 \%$ für $H+3$ gekennzeichnet.

Die E. turcicum Populationen insbesondere in den südlichen Regionen mit intensivem Maisanbau sind durch zum Teil sehr hohe Virulenzfrequenzen für $H t 1$ und $H t 3$ gekennzeichnet. Eine Verwendung dieser monogenen Resistenzen erscheint daher in den entsprechenden Regionen als wenig sinnvoll. In den nördlichen Küstenregionen kann vor allem $H t 1$ mittelfristig einen Schutz vor der Turcicum-Blattdürre bieten. Für die Verhinderung großflächiger E. turcicum-Epidemien bietet eine Kombination aus dauerhafter quantitativer mit qualitativer Resistenz die einzige Möglichkeit, eine hohe Sortenresistenz zu erreichen. Vor dem Hintergrund des ausgedehnten Maisanbaus sowohl in wärmeren Regionen in Südeuropa als auch in kühlen küstennahen Regionen in Nordeuropa war der Einfluss der Temperatur auf die Wirksamkeit der Resistenzgene ein weiterer Untersuchungsschwerpunkt dieses Projektes. Dazu wurden Klimakammerversuche mit dem Differentialsortiment aus nah-isogenen Linien des Genotyps B37 durchgeführt. Die Ergebnisse haben gezeigt, dass das Resistenzgen $H t 2$ durch einen Wirksamkeitsverlust bei Temperaturen unter $20^{\circ} \mathrm{C}$ gekennzeichnet ist. Darüber hinaus zeigte das Resistenzgen $H$ t3 bei Temperaturen unter $15^{\circ} \mathrm{C}$ ebenfalls Wirksamkeitsverluste. Bei Temperaturen über $25^{\circ} \mathrm{C}$ war ein Virulenzverlust der untersuchten Rasse 123 gegenüber den Resistenzgenen $H t 2$ und $H t 3$ zu beobachten. Neben dem Einfluss der Temperatur konnte für das Resistenzgen Ht2 eine deutliche Interaktion mit dem jeweiligen genetischen Hintergrund aufgezeigt werden. Die Nutzung von $H t 2$ in frühreifen Sorten für die kühlen-nördlichen Anbauregionen erscheint aufgrund der Temperatursensitivität wenig sinnvoll.

Im Rahmen vergleichender histologischer Untersuchungen von kompatiblen mit inkompatiblen Interaktionen zur Pathogenese von E. turcicum in Mais wurden im Zeitverlauf des Infektions- und Besiedlungsprozesses für jedes der vier $\mathrm{Ht}$-Resistenzgene drei Parameter erfasst, nämlich 1. Xylem-Penetrations-Effizienz, 2. Xylem-Besiedlungs-Effizienz und 3. Mesophyll-Besiedlungs-Effizienz. Es konnte gezeigt werden, dass die Passage der Xylemwand in den inkompatiblen Interaktionen für jedes der untersuchten $\mathrm{Ht}$-Gene die entscheidende Resistenz-Barriere im Rahmen der Pathogenese von E. turcicum darstellt. Eine vollständige Verhinderung der Xylem-Penetration wurde durch keines der untersuchten HtGene bewirkt. In den kompatiblen Interaktionen war das Resistenzgen $H+\mathbb{N}$ im Vergleich zu den anderen $\mathrm{Ht}$-Genen weniger durch einen vollständigen Wirkungsverlust als durch eine zeitliche Verzögerung der Xylem-Penetration und der Mesophyll-Besiedlung gekennzeichnet. 


\section{Summary}

In the last few years, the importance of Exserohilum turcicum, the causal agent of Northern Corn Leaf Blight (NCLB), has increased in European maize growing regions. The infestation of maize leafs by NCLB reduces the photosynthetically active leaf surface area and thereby leads to considerable yield losses. To ensure high and stable yields therefore, the use of resistant cultivars is the most effective method. The efficiency of monogenic resistances however is restricted, as virulent races of the pathogen which overcome the resistance keep emerging. One of the aims of this work was to determine the regional efficacy of NCLB resistance genes (R-genes) through race monitoring so as to recommend resistant cultivars to specific regions and provide relevant information that can be used in resistance breeding. Infested maize leaf samples were collected from 168 different locations of 10 European countries over the years 2011 and 2012. From these samples, 559 single spore isolates were successfully obtained and their virulence characteristics were thoroughly described. For the race classification, the disease reaction was assessed on a differential set of 5 near isogenic inbred lines: B37- Ht0 (with no $H t$ gene), B37- $H t 1$, B37- Ht2, B37- Ht3 and B37$H \mathbb{N}$.

For each tested R-gene, at least one corresponding virulent isolate was found. In total 12 different races were characterized. Of which, the four dominant races were race 0 (which made up $45 \%$ and is avirulent to all the tested R-genes), race 1 (22\%), race $3(15 \%)$ and race $3 \mathrm{~N}(14 \%)$. The remaining 8 races $(13,123,23,2,23 \mathrm{~N}, 12,1 \mathrm{~N}$ and $13 \mathrm{~N})$ represented a cumulated two years percentage of $4 \%$. The cumulative two years average proportion of the 3 most dominant races (1, 3 and $3 N$ ) was $52 \%$. Interestingly, in the northern and coastal regions of France, Belgium and the Netherlands which are known for their intense maize cultivation, race 0 was predominant making up over $75 \%$. In the Upper Rhine Valley, characterized by higher temperatures and long tradition of maize cultivation, 48 and $26 \%$ of the isolates were found to be virulent on $H t 1$ and $H t 3$, respectively. In the northern and southern regions of Germany, again with a history of intensive maize cultivation, the dominant race was race 0 directly followed by race 3 . In the Inn valley in southeast Germany, $44 \%$ of the tested isolates were virulent on $H t 3$. In maize cultivation regions of Czech Republic and Poland, $37 \%$ of the isolates were virulent on $H t 1$. Isolates collected in south west France showed virulence frequencies of $45 \%$ for $H t 3$ and $38 \%$ for $H t \mathbb{N}$. The unique characteristic of this region, in contrast to the other regions considered in this study, was the high virulence frequency on $H \mathbb{N}$ mainly due to race $3 \mathrm{~N}$ which had a virulence percentage of $38 \%$. In southeast France, especially in the Rhône-Alpes region, the virulence frequency for $H t^{t 1}$ is higher than $50 \%$. The region Steiermark in southern Austria is characterized by an intensive and long tradition of maize cultivation. The percentage of virulent isolates for $H t 1$ in this region 
was higher than $83 \%$, indicating that the $H t 1$ gene is no longer effective in the region. More importantly, the highest proportion of the highly complex race 123 was identified in this region. The maize cultivation region in north Italy was characterized by a high virulence frequency $(60 \%)$ for $H t 3$.

The present study revealed that the European E. turcicum population is characterized by regional very high virulence frequencies particularly against $H t 1$ and $H t 3$ in the southern regions where intensive maize cultivation have been practiced for long period of time. It is thus not worthwhile to use these R-genes in these areas. In the northern coastal regions however, $H t 1$ can probably deliver a medium-term protection against NCLB. Nevertheless, in order to prevent widespread E. turcicum epidemics and further slowdown the emergence of new virulent races, it is advisable to continuously use resistant cultivars that possess a combination of quantitative and qualitative resistance traits.

Like in the colder coastal regions of northern Europe, an extended cultivation of maize is being take place in the warmer regions of southern Europe. Accordingly, the effect of temperature on the efficiency of the R-genes was also a point of interest of this work. Hence, climate chamber experiments were conducted using a differential set of near isogenic lines derived from B37. The results showed that the efficiency of two R-genes, namely Ht2 and $H t 3$, was reduced at temperatures below $20^{\circ} \mathrm{C}$ and $15^{\circ} \mathrm{C}$, respectively. Furthermore, it was found that the race 123 appeared to be less virulent against the R-genes $H t 2$ and $H t 3$ at temperatures above $25^{\circ} \mathrm{C}$. In addition to the temperature effect, the potential role of genetic background was evident. Due to their temperature sensitivity for example, the utilization of $H t 2$ in early ripening cultivars in the cooler northern regions seems to be not helpful.

This study further addressed histological aspects of the compatible and incompatible interactions between E. turcicum and Maize. Efficient parameters (1. Xylem penetration efficiency, 2. Xylem colonization efficiency, 3. Mesophyll colonization efficiency ) that help to compare fungal colonization processes at different stages of infection were established. Using this method, it was found that the xylem wall was the crucial resistance barrier in the incompatible interactions of all the tested $\mathrm{Ht}$ genes. The complete prevention of xylem penetrations was not observed in any of the tested genotypes with $\mathrm{Ht}$ genes. In contrast to the other tested $\mathrm{Ht}$ genes, the $H \mathbb{N} \mathrm{N}$ gene, in the compatible interactions, was characterized by a delayed xylem penetration and mesophyll colonization instead of a total loss of function of the R-gene. 


\section{Literaturverzeichnis}

Abadi R, Y Levy, A Bar-Tsur (1989) Physiological races of Exserohilum turcicum in Israel. Phytoparasitica, 17 (1), 23-30.

AGPM (2016) Association Générale des Producteurs de Maïs, The Maize Market \& Economy in France. Online verfügbar unter http://www.agpm.com/en/generalites.php, zuletzt geprüft am 31.01.2016.

Agrios GN (2008) Plant Pathology, Elsevier Academic Press Amsterdam, 5. Edition 2008.

Andrivon D, C Vallavieille-Pope (1993) Racial diversity and complexity in regional populations of Erysiphe graminis f.sp. hordei in France over a 5-year period. Plant Pathology, 42 (3), 443-464.

Andrivon D, C Vallavieille-Pope (1995) Race diversity and complexity in selected populations of fungal biotrophic pathogens of cereals. Phytopathology, 85 (8), 897-905.

Anonymus 1 (2001) Richtlinie 2001/77/EG des Europäischen Parlaments und des Rates vom 27. September 2001 zur Förderung der Stromerzeugung aus erneuerbaren Energiequellen im Elektrizitätsbinnenmarkt 2001.

Anonymus 2 (2004) Gesetz zur Neuregelung des Rechts der Erneuerbaren Energien im Strombereich, Bundesgesetzblatt, Teil I, Nr. 40, 1918-1930 2004.

Baufeld P (2004) Quantification of maize production in selected EU countries, DIABROTICA Report, Europäische Kommission. Online verfügbar unter http://cordis.europa.eu/result/rcn/33632_en.html, zuletzt geprüft am 31.01.2016.

Beck JJ (1998) Detection of maize fungal pathogens using the polymerase chain reaction, Patentschrift. Veröffentlichungsnr: 5,800,997.

Becker H (1993) Pflanzenzüchtung, Ulmer Verlag Stuttgart 1993.

Bennetzen, Jeff L.; Hake, Sarah C (2009) Chilling Stress in Maize Seedlings; Handbook of Maize: Its Biology, 291 - 310, New York, Springer New York.

Bergquist R, O Masias (1974) Physiologic specialization in Trichometasphaeria turcica f. sp. zea and T. turcica in Hawaii. Phytopathology, 64, 645-649.

Bigirwa G, AM Julian, E Adipala (1993) Characterization of Ugandan isolates of Exserohilum turcicum from maize. African Crop Science Journal, 1 (1), 69-72.

Borchardt DS, HG Welz, HH Geiger (1998a) Genetic structure of Setosphaeria turcica populations in tropical and temperate climates. Phytopathology, 88 (4), 322-329. 
Borchardt DS, HG Welz, HH Geiger (1998b) Molecular marker analysis of European Setosphaeria turcica populations. European Journal of Plant Pathology, 104 (6), 611617.

Bowen KL, WL Pedersen (1988) Effects of northern leaf blight and detasseling on yields and yield components of corn inbreds. Plant Disease, 72, 952-956.

Brandfass C, P Karlovsky (2008) Upscaled CTAB-based DNA extraction and real-time PCR assays for Fusarium culmorum and F. graminearum DNA in plant material with reduced sampling error. International Journal of Molecular Sciences, 9 (11), 23062321.

Brandt J (2014) Charakterisierung der Aggressivität von 12 europäischen Exserohilum turcicum Isolaten mit unterschiedlichen Virulenzeigenschaften. Bachelorarbeit, Georg-August-Universität Göttingen.

Bunkoed W, S Kasam, P Chaijuckam, J Yhamsoongnern, S Prathuangwong (2014) Sexual reproduction of Setosphaeria turcica in natural corn fields in Thailand. Kasetsart Journal (Natural Science) (48), 175-182.

BVL (2016) Bundesamt für Verbraucherschutz und Lebensmittelsicherheit, Liste der zugelassenen Pflanzenschutzmittel in Deutschland mit Informationen über beendete Zulassungen Braunschweig 2016.

Calub A, G Dunn, D Routley, R Couture (1974) Genetic and environmental effects on production of inhibitory compounds in corn resistant to Helminthosporium turcicum. Crop Science, 14 (3), 359-361.

Carson, M L (1999) "Helminthosporium" Leaf Spots and Blights, in Compendium of Corn Diseases, Herausgeber: White DG, 3. Edition, St. Paul, American Phytopathological Society.

Carson ML (1995) A new gene in maize conferring the "chlorotic halo" reaction to infection by Exserohilum turcicum. Plant Disease, 79 (7), 717-720.

Ceballos H, VE Gracen (1989) A dominant inhibitor gene inhibits the expression of $H t 2$ against Exserohilum turcicum race 2 in corn inbred lines related to B14. Plant Breeding, 102 (1), 35-44.

Chung C, JM Longfellow, EK Walsh, Z Kerdieh, G van Esbroeck, P Balint-Kurti, RJ Nelson (2010) Resistance loci affecting distinct stages of fungal pathogenesis: use of introgression lines for QTL mapping and characterization in the maize - Setosphaeria turcica pathosystem. BMC Plant Biology, 10 (103). 
Condon BJ, Y Leng, D Wu, KE Bushley, RA Ohm, R Otillar et al. (2013) Comparative genome structure, secondary metabolite, and effector coding capacity across Cochliobolus pathogens. PLoS Genetics, 9 (1), e1003233.

Courture R, D Routley, G Dunn (1971) Role of cyclic hydroxamic acid in monogenic resistance of maize to Helminthosporium turcicum. Physiological Plant Pathology 1 (4) $515-521$.

Cuq F, M Petitprez, S Herrmann-Gorline, A Klaebe, M Rossignol (1993) Monocerin in Exserohilum turcicum isolates from maize and a study of its phytotoxicity. Phytochemistry, 34 (5), 1265-1270.

Degefu Y (2003) Cloning and characterisation of xylanase genes from phytopathogenic fungi with a special reference to Helminthosporium turcicum, the cause of northern leaf blight of maize. Dissertation, Helsinki

DESTATIS (2016) Statistisches Bundesamt, Wiesbaden. Online verfügbar unter https://www-genesis.destatis.de/genesis/online/link/statistiken/ $41^{*}$, zuletzt geprüft am 08.03.2016.

Dingerdissen AL, HH Geiger, M Lee, HG Welz (1996) Interval mapping of genes for quantitative resistance of maize to Setosphaeria turcica, cause of northern leaf blight, in a tropical environment. Molecular Breeding, 2 (2), 143-156.

DMK (2016) Sortenspiegel der in Deutschland und der EU zugelassenen Maissorten. Deutsches Maiskomitee e.V., Bonn.

Dong J, Y Fan, X Gui, X An, J Ma, Z Dong (2008) Geographic distribution and genetic analysis of physiological races of Setosphaeria turcica in northern China. American Journal of Agricultural and Biological Sciences, 3 (1), 389-398.

Eder B, B Büttner, G Schweizer, J Eder (2015) Bavarian maize landraces: history, agronomic traits and breeding activities. 65. Tagung der Vereinigung der Pflanzenzüchter und Saatgutkauleute Österreichs 2014, 65, 67-70.

EUROSTAT (2016) Statistisches Amt der Europäischen Union. Online verfügbar unter http://appsso.eurostat.ec.europa.eu/nui/show.do, zuletzt geprüft am 08.03.2016.

Fan Y, J Ma, X Gui, X An, S Sun, J Dong (2007) Distribution of mating types and genetic diversity induced by sexual recombination in Setosphaeria turcica in northern China. Frontiers of Agriculture in China, 1 (4), 368-376.

Ferguson LM, ML Carson (2004) Spatial diversity of Setosphaeria turcica sampled from the eastern United States. Phytopathology, 94 (8), 892-900. 
Ferguson LM, ML Carson (2007) Temporal variation in Setosphaeria turcica between 1974 and 1994 and origin of races 1, 23, and 23N in the United States.

Phytopathology, 97 (11), 1501-1511.

Flor HH (1955) Host-parasite interaction in flax rust. Phytopathology, 45, 680-685.

Frey M (1997) Analysis of a chemical plant defense mechanism in grasses. Science, 277 (5326), 696-699.

Freymark LWM (1993) Quantitative and qualitative trait loci affecting host-plant response to Exserohilum turcicum in maize (Zea mays L.). Theoretical and Applied Genetics $87,537-544$.

Gevers HO (1975) New major gene for resistance to Helminthosporium turcicum leaf blight of maize. Plant Disease Reporter, 59 (4), 296-299.

Hallauer AR (2008) Corn Breeding. lowa State Research Farm Progress Reports, 475.

Hilu HM, AL Hooker (1964) Host-pathogen relationship of Helminthosporium turcicum in resistant and susceptible corn seedlings. Phytopathology, 54, 570-575.

Hooker AL (1963) Inheritance of chlorotic-lesion Resistance to Helminthosporium turcicum in seedling corn. Phytopathology, 53, 660-662.

Hooker AL (1977) A second major gene locus in corn for chlorotic-lesion resistance to Helminthosporium turcicum. Crop Science, 17 (1), 132-135.

Hooker AL (1981) Resistance to Helminthosporium turcicum from Tripsacum floridanum incorporated into corn. Maize Genetics Cooperation Newsletter, 55, 87-88.

Hovmøller MS, S Walter, RA Bayles, A Hubbard, K Flath, N Sommerfeldt et al. (2015) Replacement of the European wheat yellow rust population by new races from the centre of diversity in the near-Himalayan region. Plant Pathology, 10.1111/ppa.12433

Hurni S, D Scheuermann, SG Krattinger, B Kessel, T Wicker, G Herren et al. (2015) The maize disease resistance gene $H$ tn 1 against northern corn leaf blight encodes a wallassociated receptor-like kinase. Proceedings of the National Academy of Sciences. 112 (28) 8780-8785.

Imgraben H (2002) Die Turcicum-Blattdürre - ein neues Problem. Innovation (4), 10-11. Johnson R, AJ Taylor (1976) Spore yield of pathogens in investigations of the race-specificity of host resistance. Annual Review of Phytopathology, 14 (1), 97-119. 
Jordan EG, JM Perkins, RA Schall, WL Pedersen (1983) Occurrence of race 2 of Exserohilum turcicum on corn in the central and Eastern United States. Plant Disease, 67 (10), 1163-1165.

Knox-Davies P (1974) Penetration of maize leaves by Helminthosporium turcicum. Phytopathology, 64, 1468-1469.

Krausz JP, RA Fredericksen, OR Rodrigues-Balleseteros (1993) Epidemic of northern corn leaf blight in Texas in 1992. Plant Disease, 77, 1063.

Leath S, W Pedersen (1986) Differences in resistance between maize hybrids with or without $H t 1$ gene when infected with Exserohilum turcicum race 2. Phytopathology, 76 (3), 257-260.

Leath S, R Thakur, K Leonard (1990) Variation in Expression of monogenic resistance in corn to Exserohilum turcicum Race 3 (Today race: 23) under different temperature and light regimes. Phytopathology 80 (3), 309-3013

Leonard KJ, S Leath (1986) Evidence that race 1 of Setosphaeria turcica caused the 1985 northern corn leaf blight epidemic in North Carolina. Plant Disease, 70 (10), 981.

Leonard KJ, Y Levy, DR Smith (1989) Proposed nomenclature for pathogenic races of Exserohilum turcicum on corn. Plant Disease, 73 (9), 776-777.

Levic J, D Ivanovic, S Stankovic (2007) Genetic variability of maize pathogens in Serbia. Genetika, 39 (2), 227-240.

Levy Y (1984) The overwintering of Exserohilum turcicum in Israel. Phytoparasitica, 12 (34), 177-182.

Levy Y, Y Cohen (1983) Biotic and environmental factors affecting infection of sweet corn with Exserohilum turcicum. Phytopathology, 73 (5), 722.

Levy Y, K Leonard (1990) Yield loss in sweet corn in response to defoliation or Infection by Exserohilum turcicum. Journal of Phytopathology, 128 (2), 161-171.

Lipps PE, RC Pratt, JJ Hakiza (1997) Interaction of Ht and partial resistance to Exserohilum turcicum in maize. Plant Disease, 81, 277-282.

Long B, G Dunn, D Routley (1978) Relationship of hydroxamate concentration in maize and field reaction to Helminthosporium turcicum. Crop Science, 18 (4), 573-575.

Mace M (1973) Histochemistry of beta-glucosidase in isolines of Zea mays L. susceptible or resistant to northern corn leaf blight. Phytopathology, 63, 243-245. 
McDonald BA, C Linde (2002) Pathogen population genetics, evolutionary potential and durable resistance. Annual Review of Phytopathology, 40 (1), 349-379.

Meissle M, P Mouron, T Musa, F Bigler, X Pons, VP Vasileiadis et al. (2010) Pests, pesticide use and alternative options in European maize production. Current status and future prospects. Journal of Applied Entomology, 134 (5), 357-375.

Mendgen K, M Hahn, H Deising (1996) Morphogenesis and mechanisms of penetration by plant pathogenic fungi. Annual Review of Phytopathology, 34 (1), 367-386.

Meredith DS (1966) Airborne conidia of Helminthosporium turcicum in Nebraska. Phytopathology, 56, 949-952.

Miedaner T (2011) Resistenzgenetik und Resistenzzüchtung, DLG-Verlag, Frankfurt am Main.

Moghaddam PF, JK Pataky (1994) Reactions of isolates from matings of races 1 an 23N of Exserohilum turcicum. Plant Disease, 78 (8), 767-771.

Muiru WM, B Koopmann, A v Tiedemann, JW Kimenju (2010) Race typing and evaluation of aggressiveness of Exserohilum turcicum isolates of Kenyan, German and Austrian origin. World Journal of Agricultural Sciences, 6 (3), 277-284.

Muiru WM, EW Mutitu, JW Kimenju, B Koopmann, A v Tiedemann (2008) Infectious structures and response of maize plants to invasion by Exserohilum turcicum (Pass). in compatible and incompatible host pathogen systems. Journal of Applied Biosciences, $10(2), 532-537$.

Obi I, A Hooker, S Lim (1980) Phytoalexin production by corn plants with different genetic backgrounds having chlorotic-lesion resistance against Helminthosporium turcicum. Journal of Plant Diseases and Protection, 87 (4), 244-251.

Ogliari JB, MA Guimarães, LEA Camargo (2007) Chromosomal locations of the maize (Zea mays L.) HtP and rt genes that confer resistance to Exserohilum turcicum. Genetics and Molecular Biology, 30 (3), 630-634.

Ogliari JB, MA Guimarães, IO Geraldi, LEA Camargo (2005) New resistance genes in the Zea mays-Exserohilum turcicum pathosystem. Genetics and Molecular Biology, 28 (3), 435-439.

Pataky J (1992) Relatioship between yield of sweet corn and northern leaf blight caused by Exserohilum turcicum. Phytopathology, 82 (3), 370-375. 
Pataky JK (1994) Effects of races 0 and 1 of Exserohilum turcicum on sweet corn hybrids differing for $H t$ and partial resistance to northern leaf blight. Plant Disease, 78 (12), 1189-1193.

Pataky JK, T Ledencan (2006) Resistance conferred by the Ht1 gene in sweet corn infected by mixtures of virulent and avirulent Exserohilum turcicum. Plant Disease, 90 (6), 771-776.

Pataky JK, JM Perkins, S Leath (1986) Effects of qualitative and quantitative resistance on the development and spread of northern leaf blight of maize caused by Exserohilum turcicum Races 1 and 2. Phytopathology, 76, 1349-1352.

Pataky JK, MM Williams, JM Headrick, C Nankam, LJ Du Toit, PM Michener (2011) Observations from a quarter century of evaluating reactions of sweet corn hybrids in disease nurseries. Plant Disease, 95 (12), 1492-1506.

Paul PA, LV Madden, CA Bradley, AE Robertson, GP Munkvold, G Shaner (2011) Metaanalysis of yield response of hybrid field corn to foliar fungicides in the U.S. corn belt. Phytopathology, 101 (9), 1122-1132.

Pedersen WL, JM Perkins, JA Radtke, J Miller (1986) Field evaluation of corn inbreds and selections for resistance to Exserohilum turcicum race 2. Plant Disease, 70 (5), 376377.

Raymundo AD, AL Hooker (1982) Single and combined effects of monogenic and polygenic resistance on certain components of northern corn leaf blight development. Phytopathology (72), 99-103.

Raymundo AD, AL Hooker, JM Perkins (1981) Effect of gene HtN on the development of northern corn leaf blight epidemics. Plant Disease, 65 (4), 327.

Robbins WA, HL Warren (1993) Inheritance of resistance to Exserohilum turcicum in PI 209135, 'Mayorbela' variety of maize. Maydica, 38 (3), 209-213.

Schmidt W (2003) Hybridmaiszüchtung bei der KWS SAAT AG. Bericht über die 54. Tagung der Vereinigung der Pflanzenzüchter und Saatgutkaufleute Österreichs.

Schuhmann P (1986) Kartoffelproduktion in den Niederlanden. agrartechnik, 7 (36), 307308.

Simcox KD, JL Bennetzen (1993) The use of molecular markers to study Setosphaeria turcica resistance in maize. Phytopathology, 83 (12), 1326.

Smith DR, JG Kinsey (1980) Further physiologic specialization in Helminthosporium turcicum. Plant Disease, 64 (8), 779-781. 
Thakur RP, KJ Leonard, RK Jones (1989a) Characterization of a new race of Exserohilum turcicum virulent on corn with resistance gene HtN. Plant Disease, 73 (2), 151.

Thakur RP, KJ Leonard, S Leath (1989b) Effects of temperature and light on virulence of Exserohilum turcicum on corn. Phytopathology, 79 (6), 631.

Ullstrup AJ (1970) A comparison of monogenic and polygenic resistance to Helminthosporium turcicum in corn. Phytopathology, 60, 1597-1599

Vallavieille-Pope C de, S Ali, M Leconte, J Enjalbert, M Delos, J Rouzet (2012) Virulence dynamics and regional structuring of Puccinia striiformis $f$. sp. tritici in France between 1984 and 2009. Plant Disease, 96 (1), 131-140.

Wang H, H Li, Z Zhu, X Wang (2010) Expression of Ht2-related genes in response to the HT-Toxin of Exserohilum turcicum in Maize. Annals of Applied Biology, 156 (1), 111120.

Weiss J (2002) Mais - tiergerecht und qualitätsbewusst veredeln, Deutsches Maiskomitee e.V., Bonn

Welz HG, A Schechert, D Borchardt, H Geiger (1997) Genetische Studien zur Wirtsresistenz und Erregervariabilität im Pathosystem Zea mays / Setosphaeria turcica. Vorträge Pflanzenzüchtung - Angewandte Genetik im Dienst der Welternährung; Forschungsschwerpunkt Biotechnologie und Pflanzenzüchtung, Hohenheim (38), 97127.

Welz HG (1998) Genetics and epidemiology of the pathosystem Zea mays / Setosphaeria turcica. Habilitation, Hohenheim.

Welz HG, P Bassetti, HH Geiger (1996) Turcicum-Blattdürre und Aleppohirse: zwei Schaderreger auf dem Vormarsch. Mais, 24, 66-68.

Welz HG, HH Geiger (1995) Globale Variation und Genetik der qualitativen Virulenz von Setosphaeria turcica, dem Erreger des „Northern corn leaf blight“. Bericht über die 46. Arbeitstagung 1995 der Arbeitsgemeinschaft der Saatzuchtleiter im Rahmen der „Vereinigung österreichischer Pflanzenzüchter“, BAL Gumpenstein.

Welz HG, HH Geiger (2000) Genes for resistance to northern corn leaf blight in diverse maize populations. Plant Breeding, 119 (1), 1-14.

Welz HG, XC Xiao, P Bassetti, AE Melchinger, T Lübberstedt (1999) QTLs for resistance to Setosphaeria turcica in an early maturing Dent $x$ Flint maize population.

Theoretical and Applied Genetics, 99 (3-4), 649-655. 
WIFO (2015) Maisanbau in Österreich - Zahlen \& Fakten. Studie vom Österreichischen Institut für Wirtschaftsforschung. Universität für Bodenkultur Wien

Wilcox HE, LC Marsh (2009) Staining plant tissues with Chlorazol Black E and Pianese IIIB. Stain Technology, 39 (2), 81-86.

Wolfe MS, JM McDermott (1994) Population genetics of plant pathogen interactions. The example of the Erysiphe Graminis-Hordeum vulgare pathosystem. Annual Review of Phytopathology, 32 (1), 89-113. 


\section{Anhang}

Tab. 1A: Alle im Rahmen des Rassen-Monitorings untersuchte Isolate mit Rassencharakterisierung, Herkunftsinformationen und Jahr, sortiert nach Regionen.

\begin{tabular}{|c|c|c|c|c|c|c|}
\hline $\mathrm{Nr}$. & Isolat & Rasse & Standort & Region & Land & Jahr \\
\hline 1 & $15 \_1$ & 0 & Ploudalmézeau & Bretagne/Normandie & Frankreich & 2011 \\
\hline 2 & $15 \_4$ & 0 & Ploudalmézeau & Bretagne/Normandie & Frankreich & 2011 \\
\hline 3 & 39_1 & 0 & Bulat-Pestivien & Bretagne/Normandie & Frankreich & 2011 \\
\hline 4 & 39_2 & 0 & Bulat-Pestivien & Bretagne/Normandie & Frankreich & 2011 \\
\hline 5 & 39_3 & 0 & Bulat-Pestivien & Bretagne/Normandie & Frankreich & 2011 \\
\hline 6 & $39 \_4$ & 0 & Bulat-Pestivien & Bretagne/Normandie & Frankreich & 2011 \\
\hline 7 & $40 \_1$ & 0 & Chákeaulin & Bretagne/Normandie & Frankreich & 2011 \\
\hline 8 & $40 \_2$ & 0 & Chákeaulin & Bretagne/Normandie & Frankreich & 2011 \\
\hline 9 & $46 \_1$ & 3 & Saint-Renan & Bretagne/Normandie & Frankreich & 2011 \\
\hline 10 & $46 \_2$ & 3 & Saint-Renan & Bretagne/Normandie & Frankreich & 2011 \\
\hline 11 & 46_3 & $3 N$ & Saint-Renan & Bretagne/Normandie & Frankreich & 2011 \\
\hline 12 & $46 \_4$ & $3 N$ & Saint-Renan & Bretagne/Normandie & Frankreich & 2011 \\
\hline 13 & $64-1$ & 0 & Fleurigné & Bretagne/Normandie & Frankreich & 2011 \\
\hline 14 & 642 & 0 & Fleurigné & Bretagne/Normandie & Frankreich & 2011 \\
\hline 15 & 643 & 0 & Fleurigné & Bretagne/Normandie & Frankreich & 2011 \\
\hline 16 & $64 \_4$ & 0 & Fleurigné & Bretagne/Normandie & Frankreich & 2011 \\
\hline 17 & 762 & 0 & Les Cresnays & Bretagne/Normandie & Frankreich & 2011 \\
\hline 18 & 763 & 0 & Les Cresnays & Bretagne/Normandie & Frankreich & 2011 \\
\hline 19 & 764 & 0 & Les Cresnays & Bretagne/Normandie & Frankreich & 2011 \\
\hline 20 & $77^{-} 1$ & 0 & Breuville & Bretagne/Normandie & Frankreich & 2011 \\
\hline 21 & $77^{-} 2$ & 0 & Breuville & Bretagne/Normandie & Frankreich & 2011 \\
\hline 22 & $77^{-} 3$ & 0 & Breuville & Bretagne/Normandie & Frankreich & 2011 \\
\hline 23 & $77 \_4$ & 0 & Breuville & Bretagne/Normandie & Frankreich & 2011 \\
\hline 24 & $97 \_1$ & 0 & Guirliliau & Bretagne/Normandie & Frankreich & 2011 \\
\hline 25 & $97 \_2$ & 0 & Guirliliau & Bretagne/Normandie & Frankreich & 2011 \\
\hline 26 & $97 \_3$ & 0 & Guirliliau & Bretagne/Normandie & Frankreich & 2011 \\
\hline 27 & $97 \_4$ & 0 & Guirliliau & Bretagne/Normandie & Frankreich & 2011 \\
\hline 28 & $11 \overline{3} \_3$ & 0 & La Meziere & Bretagne/Normandie & Frankreich & 2011 \\
\hline 29 & $113 \_4$ & 0 & La Meziere & Bretagne/Normandie & Frankreich & 2011 \\
\hline 30 & $145-1$ & 0 & Ploudalmézeau & Bretagne/Normandie & Frankreich & 2012 \\
\hline 31 & $145 \_2$ & 0 & Ploudalmézeau & Bretagne/Normandie & Frankreich & 2012 \\
\hline 32 & $145 \_3$ & 0 & Ploudalmézeau & Bretagne/Normandie & Frankreich & 2012 \\
\hline 33 & $145 \_4$ & 0 & Ploudalmézeau & Bretagne/Normandie & Frankreich & 2012 \\
\hline 34 & 148_3 & 0 & Quimperle & Bretagne/Normandie & Frankreich & 2012 \\
\hline 35 & 1_1 & 0 & Hinx & Südwestfrankreich & Frankreich & 2011 \\
\hline 36 & $1 \_2$ & 0 & Hinx & Südwestfrankreich & Frankreich & 2011 \\
\hline 37 & $1 \_4$ & 0 & Hinx & Südwestfrankreich & Frankreich & 2011 \\
\hline 38 & $2-1$ & 1 & Coublucq Pyrènèes & Südwestfrankreich & Frankreich & 2011 \\
\hline 39 & $2 \_2$ & 1 & Coublucq Pyrènèes & Südwestfrankreich & Frankreich & 2011 \\
\hline 40 & $2 \_4$ & 1 & Coublucq Pyrènèes & Südwestfrankreich & Frankreich & 2011 \\
\hline 41 & $11 \_2$ & $3 \mathrm{~N}$ & Alzonne & Südwestfrankreich & Frankreich & 2011 \\
\hline 42 & 11_3 & $3 \mathrm{~N}$ & Alzonne & Südwestfrankreich & Frankreich & 2011 \\
\hline 43 & $11 \_4$ & 3 & Alzonne & Südwestfrankreich & Frankreich & 2011 \\
\hline 44 & $16 \_1$ & 0 & Sabres & Südwestfrankreich & Frankreich & 2011 \\
\hline 45 & 162 & 0 & Sabres & Südwestfrankreich & Frankreich & 2011 \\
\hline 46 & $25-1$ & $3 \mathrm{~N}$ & Saint Etienne & Südwestfrankreich & Frankreich & 2011 \\
\hline 47 & $25 \_2$ & $3 \mathrm{~N}$ & Saint Etienne & Südwestfrankreich & Frankreich & 2011 \\
\hline 48 & $25 \_3$ & $3 N$ & Saint Etienne & Südwestfrankreich & Frankreich & 2011 \\
\hline
\end{tabular}


49

26_2

3N Saint Etienne

3N Saint Etienne

51263

3N Saint Etienne

52 26_4

$53 \quad 27-1$

54 28_1

55 28_2

56 28_3

$57 \quad 284$

58 29_1

$59 \quad 292$

60 29_3

61294

$62 \quad 342$

$63 \quad 343$

64 34_4

65 35_1

66 35_2

67 35_3

68 36_1

69 36_2

70 36_3

71 44_1

72 44_2

$7344 \_3$

74 44_4

75 101_2

76 101_3

77 101_4

78 102_1

$79 \quad 1022$

$80 \quad 103 \quad 1$

81 103_2

82 103_3

$83 \quad 1034$

84 104 1

$85 \quad 1042$

86 104_3

87 104_4

88 127_1

89 127 2

90 127 3

91 127_4

92 130_1

$93 \quad 1302$

$94 \quad 130 \quad 3$

$95 \quad 1304$

$96 \quad 1312$

97 131_3

98 131_4

99 140_1

$100 \quad 1402$

101 140_3

102 140_4
3N Saint Etienne

3 Saint Etienne

3N Orthevielle

0 Orthevielle

0 Orthevielle

0 Orthevielle

0 Orthevielle

0 Orthevielle

3N Orthevielle

3 Orthevielle

1 Monheurt

1 Monheurt

1 Monheurt

0 Saint Léger

0 Saint Léger

3 Saint Léger

0 Saint Léger

1 Saint Léger

1 Saint Léger

1 Bernac

1 Bernac

1 Bernac

1 Bernac

$3 \mathrm{~N}$ Souprosse

0 Souprosse

$3 \mathrm{~N}$ Souprosse

1 Mau Bourguet

1 Mau Bourguet

3N Tartas

3N Tartas

3N Tartas

3N Tartas

1 südwest Frankreich

1 südwest Frankreich

3N südwest Frankreich

0 südwest Frankreich

3N Peyrehorade

3N Peyrehorade

3N Peyrehorade

3N Peyrehorade

0 Sabres

0 Sabres

0 Sabres

0 Sabres

1 Auch

1 Auch

0 Auch

3 westl. v. Toulouse

$3 \mathrm{~N}$ westl. v. Toulouse

$3 \mathrm{~N}$ westl. v. Toulouse

$3 \mathrm{~N}$ westl. v. Toulouse
Südwestfrankreich

Südwestfrankreich

Südwestfrankreich

Südwestfrankreich

Südwestfrankreich

Südwestfrankreich

Südwestfrankreich

Südwestfrankreich

Südwestfrankreich

Südwestfrankreich

Südwestfrankreich

Südwestfrankreich

Südwestfrankreich

Südwestfrankreich

Südwestfrankreich

Südwestfrankreich

Südwestfrankreich

Südwestfrankreich

Südwestfrankreich

Südwestfrankreich

Südwestfrankreich

Südwestfrankreich

Südwestfrankreich

Südwestfrankreich

Südwestfrankreich

Südwestfrankreich

Südwestfrankreich

Südwestfrankreich

Südwestfrankreich

Südwestfrankreich

Südwestfrankreich

Südwestfrankreich

Südwestfrankreich

Südwestfrankreich

Südwestfrankreich

Südwestfrankreich

Südwestfrankreich

Südwestfrankreich

Südwestfrankreich

Südwestfrankreich

Südwestfrankreich

Südwestfrankreich

Südwestfrankreich

Südwestfrankreich

Südwestfrankreich

Südwestfrankreich

Südwestfrankreich

Südwestfrankreich

Südwestfrankreich

Südwestfrankreich

Südwestfrankreich

Südwestfrankreich

Südwestfrankreich

Südwestfrankreich
Frankreich

2011

Frankreich

2011

Frankreich

2011

Frankreich

2011

Frankreich

2011

Frankreich

2011

Frankreich

2011

Frankreich

2011

Frankreich

2011

Frankreich

2011

Frankreich

2011

Frankreich

2011

Frankreich

2011

Frankreich 2011

Frankreich 2011

Frankreich 2011

Frankreich 2011

Frankreich 2011

Frankreich 2011

Frankreich 2011

Frankreich 2011

Frankreich 2011

Frankreich 2011

Frankreich 2011

Frankreich 2011

Frankreich 2011

Frankreich 2011

Frankreich 2011

Frankreich 2011

Frankreich 2011

Frankreich 2011

Frankreich 2011

Frankreich 2011

Frankreich 2011

Frankreich 2011

Frankreich 2011

Frankreich 2011

Frankreich 2011

Frankreich 2011

Frankreich 2012

Frankreich 2012

Frankreich 2012

Frankreich 2012

Frankreich 2012

Frankreich 2012

Frankreich 2012

Frankreich 2012

Frankreich 2012

Frankreich 2012

Frankreich 2012

Frankreich 2012

Frankreich 2012

Frankreich 2012

Frankreich 2012 


\begin{tabular}{|c|c|c|c|}
\hline 103 & 144_1 & 0 & Meilhan \\
\hline 104 & 144_2 & 0 & Meilhan \\
\hline 105 & 144_3 & 0 & Meilhan \\
\hline 106 & 144_4 & 0 & Meilhan \\
\hline 107 & $164 \_1$ & $3 N$ & Südwestfrankreich \\
\hline 108 & 164_2 & $3 N$ & Südwestfrankreich \\
\hline 109 & 164_3 & $3 N$ & Südwestfrankreich \\
\hline 110 & 164_4 & $3 N$ & Südwestfrankreich \\
\hline 111 & $4 \_4$ & 23 & Codroipo \\
\hline 112 & 5_1 & 0 & Ferrera \\
\hline 113 & $5 \_2$ & 0 & Ferrera \\
\hline 114 & 21_2 & 0 & Monselice \\
\hline 115 & 21_3 & 3 & Monselice \\
\hline 116 & $21 \_4$ & 3 & Monselice \\
\hline 117 & $22 \_1$ & 0 & Monselice \\
\hline 118 & $22 \_3$ & 3 & Monselice \\
\hline 119 & $22 \_4$ & 3 & Monselice \\
\hline 120 & 23_1 & 0 & Monselice \\
\hline 121 & $23 \_2$ & 3 & Monselice \\
\hline 122 & 23_3 & 3 & Monselice \\
\hline 123 & $24 \_1$ & 13 & Monselice \\
\hline 124 & 24_2 & 0 & Monselice \\
\hline 125 & 24_3 & 0 & Monselice \\
\hline 126 & 24_4 & 0 & Monselice \\
\hline 127 & 125_1 & 3 & Udine \\
\hline 128 & 125_2 & $3 \mathrm{~N}$ & Udine \\
\hline 129 & 125_3 & 3 & Udine \\
\hline 130 & $125 \_4$ & 3 & Udine \\
\hline 131 & $65 \_1$ & 0 & Sint-Maria-Lierde \\
\hline 132 & $65 \_2$ & 0 & Sint-Maria-Lierde \\
\hline 133 & 65_3 & 0 & Sint-Maria-Lierde \\
\hline 134 & $65 \_4$ & 0 & Sint-Maria-Lierde \\
\hline 135 & $78 \_1$ & 0 & Wilbertoord \\
\hline 136 & 78_3 & 0 & Wilbertoord \\
\hline 137 & $78 \_4$ & 0 & Wilbertoord \\
\hline 138 & $79 \_1$ & 0 & Postel \\
\hline 139 & $79 \_2$ & 0 & Postel \\
\hline 140 & 79_3 & 0 & Postel \\
\hline 141 & $79 \_4$ & 0 & Postel \\
\hline 142 & 80_1 & 0 & Beervelde \\
\hline 143 & 80_2 & 2 & Beervelde \\
\hline 144 & 80_3 & 0 & Beervelde \\
\hline 145 & $80 \_4$ & 0 & Beervelde \\
\hline 146 & $81 \_1$ & 0 & Wilbertoord \\
\hline 147 & 81_2 & 0 & Wilbertoord \\
\hline 148 & 81_3 & 0 & Wilbertoord \\
\hline 149 & $81 \_4$ & 0 & Wilbertoord \\
\hline 150 & $82 \_1$ & 0 & Postel \\
\hline 151 & $82 \_2$ & 0 & Postel \\
\hline 152 & 82_3 & 0 & Postel \\
\hline 153 & $82 \_4$ & 0 & Postel \\
\hline 154 & 86_1 & 0 & Lochem \\
\hline 155 & 86_2 & 0 & Lochem \\
\hline 156 & 86_3 & 0 & Lochem \\
\hline
\end{tabular}

Südwestfrankreich

Südwestfrankreich

Südwestfrankreich

Südwestfrankreich

Südwestfrankreich

Südwestfrankreich

Südwestfrankreich

Südwestfrankreich

Italien PO Ebene

Italien PO Ebene

Italien PO Ebene

Italien PO Ebene

Italien PO Ebene

Italien PO Ebene

Italien PO Ebene

Italien PO Ebene

Italien PO Ebene

Italien PO Ebene

Italien PO Ebene

Italien PO Ebene

Italien PO Ebene

Italien PO Ebene

Italien PO Ebene

Italien PO Ebene

Italien PO Ebene

Italien PO Ebene

Italien PO Ebene

Italien PO Ebene

Niederlande/Belgien

Niederlande/Belgien

Niederlande/Belgien

Niederlande/Belgien

Niederlande/Belgien

Niederlande/Belgien

Niederlande/Belgien

Niederlande/Belgien

Niederlande/Belgien

Niederlande/Belgien

Niederlande/Belgien

Niederlande/Belgien

Niederlande/Belgien

Niederlande/Belgien

Niederlande/Belgien

Niederlande/Belgien

Niederlande/Belgien

Niederlande/Belgien

Niederlande/Belgien

Niederlande/Belgien

Niederlande/Belgien

Niederlande/Belgien

Niederlande/Belgien

Niederlande/Belgien

Niederlande/Belgien

Niederlande/Belgien
Frankreich

2012

Frankreich

2012

Frankreich

2012

Frankreich

2012

Frankreich

2012

Frankreich

2012

Frankreich

2012

Frankreich

2012

Italien

2011

Italien

2011

Italien

2011

Italien

2011

Italien

2011

Italien

2011

Italien

2011

Italien

2011

Italien

2011

Italien

2011

Italien

2011

2011

2011

Italien

Italien

Italien

Italien

Italien

Italien

Italien

Italien

Belgien

Belgien

Belgien

Belgien

2011

2011

2011

2012

2012

2012

2012

2011

2011

2011

Niederlande

2011

Niederlande

2011

Niederlande

Belgien

Belgien

Belgien

Belgien

Belgien

Belgien

Belgien

Belgien

Niederlande

Niederlande

Niederlande

Niederlande

Belgien

Belgien

Belgien

Belgien

Niederlande

Niederlande

Niederlande
2011

2011

2011

2011

2011

2011

2011

2011

2011

2011

2011

2011

2011

2011

2011

2011

2011

2011

2011

2011

2011 


\begin{tabular}{|c|c|c|c|c|c|c|}
\hline 157 & 86_4 & 0 & Lochem & Niederlande/Belgien & Niederlande & 2011 \\
\hline 158 & $96 \_1$ & 0 & Dronten & Niederlande/Belgien & Niederlande & 2011 \\
\hline 159 & 962 & 0 & Dronten & Niederlande/Belgien & Niederlande & 2011 \\
\hline 160 & 963 & 0 & Dronten & Niederlande/Belgien & Niederlande & 2011 \\
\hline 161 & 964 & 0 & Dronten & Niederlande/Belgien & Niederlande & 2011 \\
\hline 162 & $10 \overline{0} 1$ & 0 & Kamp-Lintfort & Niederlande/Belgien & Deutschland & 2011 \\
\hline 163 & $100-2$ & 0 & Kamp-Lintfort & Niederlande/Belgien & Deutschland & 2011 \\
\hline 164 & 100_3 & 2 & Kamp-Lintfort & Niederlande/Belgien & Deutschland & 2011 \\
\hline 165 & $100 \_4$ & 0 & Kamp-Lintfort & Niederlande/Belgien & Deutschland & 2011 \\
\hline 166 & $105 \_2$ & 0 & Geldern & Niederlande/Belgien & Deutschland & 2011 \\
\hline 167 & 1053 & 0 & Geldern & Niederlande/Belgien & Deutschland & 2011 \\
\hline 168 & 10544 & 0 & Geldern & Niederlande/Belgien & Deutschland & 2011 \\
\hline 169 & $110 \_1$ & 23 & Alpen & Niederlande/Belgien & Deutschland & 2011 \\
\hline 170 & $110 \_2$ & 0 & Alpen & Niederlande/Belgien & Deutschland & 2011 \\
\hline 171 & 110_3 & 0 & Alpen & Niederlande/Belgien & Deutschland & 2011 \\
\hline 172 & 11044 & 3 & Alpen & Niederlande/Belgien & Deutschland & 2011 \\
\hline 173 & $116 \_1$ & 0 & Sint-Maria-Lierde & Niederlande/Belgien & Belgien & 2011 \\
\hline 174 & $116 \_2$ & 0 & Sint-Maria-Lierde & Niederlande/Belgien & Belgien & 2011 \\
\hline 175 & 11644 & 0 & Sint-Maria-Lierde & Niederlande/Belgien & Belgien & 2011 \\
\hline 176 & $151 \_1$ & 0 & Sinaai & Niederlande/Belgien & Belgien & 2012 \\
\hline 177 & 151_2 & 0 & Sinaai & Niederlande/Belgien & Belgien & 2012 \\
\hline 178 & 151_3 & 0 & Sinaai & Niederlande/Belgien & Belgien & 2012 \\
\hline 179 & $151 \_4$ & 0 & Sinaai & Niederlande/Belgien & Belgien & 2012 \\
\hline 180 & $159-1$ & 3 & Lochem & Niederlande/Belgien & Niederlande & 2012 \\
\hline 181 & 15944 & $3 N$ & Lochem & Niederlande/Belgien & Niederlande & 2012 \\
\hline 182 & $160 \_1$ & $3 N$ & Barchem & Niederlande/Belgien & Niederlande & 2012 \\
\hline 183 & $160 \_2$ & $3 N$ & Barchem & Niederlande/Belgien & Niederlande & 2012 \\
\hline 184 & 160_3 & $3 N$ & Barchem & Niederlande/Belgien & Niederlande & 2012 \\
\hline 185 & 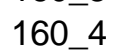 & 3 & Barchem & Niederlande/Belgien & Niederlande & 2012 \\
\hline 186 & 161 & 2 & Dronten & Niederlande/Belgien & Niederlande & 2012 \\
\hline 187 & 161_3 & 0 & Dronten & Niederlande/Belgien & Niederlande & 2012 \\
\hline 188 & $162 \_1$ & 0 & Beervelde & Niederlande/Belgien & Belgien & 2012 \\
\hline 189 & 1622 & 0 & Beervelde & Niederlande/Belgien & Belgien & 2012 \\
\hline 190 & 1623 & 0 & Beervelde & Niederlande/Belgien & Belgien & 2012 \\
\hline 191 & 1624 & 0 & Beervelde & Niederlande/Belgien & Belgien & 2012 \\
\hline 192 & 163 & $3 \mathrm{~N}$ & Sint-Maria-Lierde & Niederlande/Belgien & Belgien & 2012 \\
\hline 193 & 163_3 & 3 & Sint-Maria-Lierde & Niederlande/Belgien & Belgien & 2012 \\
\hline 194 & 163_4 & $3 \mathrm{~N}$ & Sint-Maria-Lierde & Niederlande/Belgien & Belgien & 2012 \\
\hline 195 & 166_1 & $3 \mathrm{~N}$ & Rekken/Enschede & Niederlande/Belgien & Niederlande & 2012 \\
\hline 196 & 166_2 & $3 \mathrm{~N}$ & Rekken/Enschede & Niederlande/Belgien & Niederlande & 2012 \\
\hline 197 & 166_3 & $3 \mathrm{~N}$ & Rekken/Enschede & Niederlande/Belgien & Niederlande & 2012 \\
\hline 198 & 16644 & $3 \mathrm{~N}$ & Rekken/Enschede & Niederlande/Belgien & Niederlande & 2012 \\
\hline 199 & $167 \_1$ & 0 & Breda & Niederlande/Belgien & Niederlande & 2012 \\
\hline 200 & 1673 & 0 & Breda & Niederlande/Belgien & Niederlande & 2012 \\
\hline 201 & 1674 & 0 & Breda & Niederlande/Belgien & Niederlande & 2012 \\
\hline 202 & $168+1$ & 0 & Overloon & Niederlande/Belgien & Niederlande & 2012 \\
\hline 203 & 168_2 & 3 & Overloon & Niederlande/Belgien & Niederlande & 2012 \\
\hline 204 & 168_3 & 0 & Overloon & Niederlande/Belgien & Niederlande & 2012 \\
\hline 205 & $168 \_4$ & 0 & Overloon & Niederlande/Belgien & Niederlande & 2012 \\
\hline 206 & 169 & 0 & Helmond & Niederlande/Belgien & Niederlande & 2012 \\
\hline 207 & 1692 & 0 & Helmond & Niederlande/Belgien & Niederlande & 2012 \\
\hline 208 & 1693 & 0 & Helmond & Niederlande/Belgien & Niederlande & 2012 \\
\hline 209 & $169+4$ & 0 & Helmond & Niederlande/Belgien & Niederlande & 2012 \\
\hline 210 & $170 \_1$ & 0 & Wilbertoord & Niederlande/Belgien & Niederlande & 2012 \\
\hline
\end{tabular}




\begin{tabular}{|c|c|c|c|}
\hline 211 & 170_2 & 0 & Wilbertoord \\
\hline 212 & 170_3 & 0 & Wilbertoord \\
\hline 213 & 170_4 & 0 & Wilbertoord \\
\hline 214 & 171_1 & 0 & Hengelo \\
\hline 215 & 171_2 & 0 & Hengelo \\
\hline 216 & 171_3 & 0 & Hengelo \\
\hline 217 & 171_4 & 0 & Hengelo \\
\hline 218 & $172 \_2$ & 0 & Zwolle \\
\hline 219 & $172 \_3$ & 0 & Zwolle \\
\hline 220 & $172 \_4$ & 0 & Zwolle \\
\hline 221 & $173 \_1$ & 3 & Weert \\
\hline 222 & $173 \_2$ & 3 & Weert \\
\hline 223 & 173_3 & 3 & Weert \\
\hline 224 & 17344 & 0 & Weert \\
\hline 225 & $174 \_1$ & 0 & Weert \\
\hline 226 & 174_2 & 0 & Weert \\
\hline 227 & 174_3 & $3 N$ & Weert \\
\hline 228 & 174_4 & $3 N$ & Weert \\
\hline 229 & 175_1 & $3 N$ & Dessel/Postel \\
\hline 230 & 175_2 & 0 & Dessel/Postel \\
\hline 231 & 176_1 & 0 & Bocholt \\
\hline 232 & 176_2 & 0 & Bocholt \\
\hline 233 & 176_3 & 0 & Bocholt \\
\hline 234 & $176 \_4$ & 0 & Bocholt \\
\hline 235 & 200_2 & 0 & Alpen \\
\hline 236 & 200_3 & 3 & Alpen \\
\hline 237 & $200 \_4$ & 0 & Alpen \\
\hline 238 & 3_1 & $3 \mathrm{~N}$ & Bad Lauchstadt \\
\hline 239 & $17 \_1$ & 0 & Ostbevern \\
\hline 240 & $17 \_2$ & 0 & Ostbevern \\
\hline 241 & 17_3 & 0 & Ostbevern \\
\hline 242 & 17_4 & 0 & Ostbevern \\
\hline 243 & 83_1 & 1 & Einbeck \\
\hline 244 & 83_2 & 1 & Einbeck \\
\hline 245 & 83_3 & 1 & Einbeck \\
\hline 246 & 83_4 & 1 & Einbeck \\
\hline 247 & 91_1 & 1 & Göritz \\
\hline 248 & $91 \_2$ & 1 & Göritz \\
\hline 249 & 91_3 & 13 & Göritz \\
\hline 250 & 91_4 & 13 & Göritz \\
\hline 251 & $10 \overline{9} \_1$ & 0 & Bergen \\
\hline 252 & 109_2 & 0 & Bergen \\
\hline 253 & 109_3 & 0 & Bergen \\
\hline 254 & 133_1 & 3 & Göritz \\
\hline 255 & 133_2 & 3 & Göritz \\
\hline 256 & 133_3 & 3 & Göritz \\
\hline 257 & 133_4 & 3 & Göritz \\
\hline 258 & 137_1 & 3 & Edesheim/Einbeck \\
\hline 259 & 137_2 & 3 & Edesheim/Einbeck \\
\hline 260 & 137_3 & 3 & Edesheim/Einbeck \\
\hline 261 & $137 \_4$ & $3 \mathrm{~N}$ & Edesheim/Einbeck \\
\hline 262 & 142_1 & 3 & Einbeck \\
\hline 263 & 143_1 & 0 & Lorup \\
\hline & 1432 & 0 & Lorup \\
\hline
\end{tabular}

Niederlande/Belgien

Niederlande/Belgien

Niederlande/Belgien

Niederlande/Belgien

Niederlande/Belgien

Niederlande/Belgien

Niederlande/Belgien

Niederlande/Belgien

Niederlande/Belgien

Niederlande/Belgien

Niederlande/Belgien

Niederlande/Belgien

Niederlande/Belgien

Niederlande/Belgien

Niederlande/Belgien

Niederlande/Belgien

Niederlande/Belgien

Niederlande/Belgien

Niederlande/Belgien

Niederlande/Belgien

Niederlande/Belgien

Niederlande/Belgien

Niederlande/Belgien

Niederlande/Belgien

Niederlande/Belgien

Niederlande/Belgien

Niederlande/Belgien

Norddeutschland

Norddeutschland

Norddeutschland

Norddeutschland

Norddeutschland

Norddeutschland

Norddeutschland

Norddeutschland

Norddeutschland

Norddeutschland

Norddeutschland

Norddeutschland

Norddeutschland

Norddeutschland

Norddeutschland

Norddeutschland

Norddeutschland

Norddeutschland

Norddeutschland

Norddeutschland

Norddeutschland

Norddeutschland

Norddeutschland

Norddeutschland

Norddeutschland

Norddeutschland

Norddeutschland
Niederlande

2012

Niederlande

2012

Niederlande

2012

Niederlande

2012

Niederlande

2012

Niederlande

2012

2012

2012

2012

2012

2012

2012

2012

2012

Niederlande

2012

Niederlande

Niederlande

2012

Niederlande

2012

Niederlande

Belgien

Belgien

Belgien

Belgien

Belgien

Belgien

Deutschland

Deutschland

Deutschland

Deutschland

Deutschland

Deutschland

Deutschland

Deutschland

Deutschland

Deutschland

Deutschland

Deutschland

Deutschland

Deutschland

Deutschland

Deutschland

Deutschland

Deutschland

Deutschland

Deutschland

Deutschland

Deutschland

Deutschland

Deutschland

Deutschland

Deutschland

Deutschland

Deutschland

Deutschland

Deutschland
2012

2012

2012

2012

2012

2012

2012

2012

2012

2012

2011

2011

2011

2011

2011

2011

2011

2011

2011

2011

2011

2011

2011

2011

2011

2011

2012

2012

2012

2012

2012

2012

2012

2012

2012

2012

2012 


\begin{tabular}{|c|c|c|c|c|c|c|}
\hline 265 & 143_3 & 0 & Lorup & Norddeutschland & Deutschland & 2012 \\
\hline 266 & 14344 & 0 & Lorup & Norddeutschland & Deutschland & 2012 \\
\hline 267 & 153_1 & 3 & Einbeck & Norddeutschland & Deutschland & 2012 \\
\hline 268 & 153_2 & 3 & Einbeck & Norddeutschland & Deutschland & 2012 \\
\hline 269 & 153_3 & $3 N$ & Einbeck & Norddeutschland & Deutschland & 2012 \\
\hline 270 & $153 \_4$ & 3 & Einbeck & Norddeutschland & Deutschland & 2012 \\
\hline 271 & $156 \_1$ & $3 N$ & Beesten & Norddeutschland & Deutschland & 2012 \\
\hline 272 & $156 \_2$ & $3 N$ & Beesten & Norddeutschland & Deutschland & 2012 \\
\hline 273 & 156_3 & 3 & Beesten & Norddeutschland & Deutschland & 2012 \\
\hline 274 & 1564 & $3 N$ & Beesten & Norddeutschland & Deutschland & 2012 \\
\hline 275 & $177^{-1}$ & 0 & Kiel (SH) & Norddeutschland & Deutschland & 2012 \\
\hline 276 & $177^{-2}$ & 0 & Kiel (SH) & Norddeutschland & Deutschland & 2012 \\
\hline 277 & $177^{-3}$ & 0 & Kiel (SH) & Norddeutschland & Deutschland & 2012 \\
\hline 278 & 1951 & 3 & Bergen & Norddeutschland & Deutschland & 2012 \\
\hline 279 & 1952 & 3 & Bergen & Norddeutschland & Deutschland & 2012 \\
\hline 280 & 195_3 & 3 & Bergen & Norddeutschland & Deutschland & 2012 \\
\hline 281 & 19544 & 3 & Bergen & Norddeutschland & Deutschland & 2012 \\
\hline 282 & $197-1$ & 0 & Einbeck & Norddeutschland & Deutschland & 2012 \\
\hline 283 & $197 \_2$ & 0 & Einbeck & Norddeutschland & Deutschland & 2012 \\
\hline 284 & 197_3 & 0 & Einbeck & Norddeutschland & Deutschland & 2012 \\
\hline 285 & $18-\overline{1}$ & 1 & Hombourg & Oberrheinregion & Frankreich & 2011 \\
\hline 286 & $18 \_2$ & 0 & Hombourg & Oberrheinregion & Frankreich & 2011 \\
\hline 287 & $18 \_3$ & 1 & Hombourg & Oberrheinregion & Frankreich & 2011 \\
\hline 288 & $18 \_4$ & 1 & Hombourg & Oberrheinregion & Frankreich & 2011 \\
\hline 289 & $19-1$ & 1 & Hombourg & Oberrheinregion & Frankreich & 2011 \\
\hline 290 & $19 \_2$ & 1 & Hombourg & Oberrheinregion & Frankreich & 2011 \\
\hline 291 & $19 \_3$ & 1 & Hombourg & Oberrheinregion & Frankreich & 2011 \\
\hline 292 & $20-1$ & 0 & Seebach & Oberrheinregion & Frankreich & 2011 \\
\hline 293 & 20_2 & 0 & Seebach & Oberrheinregion & Frankreich & 2011 \\
\hline 294 & $20 \_4$ & 0 & Seebach & Oberrheinregion & Frankreich & 2011 \\
\hline 295 & 68_1 & 1 & Fessenheim & Oberrheinregion & Frankreich & 2011 \\
\hline 296 & 68_2 & 1 & Fessenheim & Oberrheinregion & Frankreich & 2011 \\
\hline 297 & $68 \_4$ & 1 & Fessenheim & Oberrheinregion & Frankreich & 2011 \\
\hline 298 & $84 \_1$ & 1 & Illarsaz & Oberrheinregion & Schweiz & 2011 \\
\hline 299 & $84 \_2$ & 1 & Illarsaz & Oberrheinregion & Schweiz & 2011 \\
\hline 300 & $84 \_3$ & 1 & Illarsaz & Oberrheinregion & Schweiz & 2011 \\
\hline 301 & $84 \div 4$ & 1 & Illarsaz & Oberrheinregion & Schweiz & 2011 \\
\hline 302 & $88-1$ & 1 & Rustenhart & Oberrheinregion & Frankreich & 2011 \\
\hline 303 & $88 \_2$ & 1 & Rustenhart & Oberrheinregion & Frankreich & 2011 \\
\hline 304 & 88_3 & 1 & Rustenhart & Oberrheinregion & Frankreich & 2011 \\
\hline 305 & $88 \_4$ & 0 & Rustenhart & Oberrheinregion & Frankreich & 2011 \\
\hline 306 & $89 \_1$ & 0 & Rustenhart & Oberrheinregion & Frankreich & 2011 \\
\hline 307 & $89 \_2$ & 1 & Rustenhart & Oberrheinregion & Frankreich & 2011 \\
\hline 308 & 893 & 0 & Rustenhart & Oberrheinregion & Frankreich & 2011 \\
\hline 309 & 89_4 & 0 & Rustenhart & Oberrheinregion & Frankreich & 2011 \\
\hline 310 & $90 \_1$ & 0 & Rustenhart & Oberrheinregion & Frankreich & 2011 \\
\hline 311 & $90 \_2$ & 0 & Rustenhart & Oberrheinregion & Frankreich & 2011 \\
\hline 312 & 90_3 & 0 & Rustenhart & Oberrheinregion & Frankreich & 2011 \\
\hline 313 & $90 \_4$ & 1 & Rustenhart & Oberrheinregion & Frankreich & 2011 \\
\hline 314 & $99 \_3$ & 1 & Marckolsheim & Oberrheinregion & Frankreich & 2011 \\
\hline 315 & $99 \square$ & 1 & Marckolsheim & Oberrheinregion & Frankreich & 2011 \\
\hline 316 & $10 \overline{7} 1$ & 0 & Gondelsheim & Oberrheinregion & Deutschland & 2011 \\
\hline 317 & 119 & 1 & Zürich & Oberrheinregion & Schweiz & 2011 \\
\hline 318 & $136-1$ & 3 & Ottmarsheim/Elsass & Oberrheinregion & Frankreich & 2012 \\
\hline
\end{tabular}




\begin{tabular}{|c|c|c|c|}
\hline 319 & 136_2 & 0 & Ottmarsheim/Elsass \\
\hline 320 & 136_3 & 3 & Ottmarsheim/Elsass \\
\hline 321 & $136 \_4$ & 0 & Ottmarsheim/Elsass \\
\hline 322 & 138_1 & 1 & Fessenheim \\
\hline 323 & 138_2 & 1 & Fessenheim \\
\hline 324 & 138_3 & 1 & Fessenheim \\
\hline 325 & $138 \_4$ & 1 & Fessenheim \\
\hline 326 & 139_1 & 0 & Hombourg \\
\hline 327 & 139_2 & 3 & Hombourg \\
\hline 328 & 139_3 & 0 & Hombourg \\
\hline 329 & $139-4$ & 0 & Hombourg \\
\hline 330 & $152-1$ & $3 N$ & Hombrechtikon \\
\hline 331 & $152 \_2$ & 3 & Hombrechtikon \\
\hline 332 & $152 \_3$ & $3 N$ & Hombrechtikon \\
\hline 333 & $152-4$ & $3 N$ & Hombrechtikon \\
\hline 334 & $154 \_1$ & 1 & Seebach \\
\hline 335 & 1542 & 1 & Seebach \\
\hline 336 & 1543 & 1 & Seebach \\
\hline 337 & $154 \_4$ & $13 N$ & Seebach \\
\hline 338 & $155-1$ & 1 & Breushwickersheim \\
\hline 339 & 1552 & 1 & Breushwickersheim \\
\hline 340 & 1553 & 1 & Breushwickersheim \\
\hline 341 & $155 \_4$ & 1 & Breushwickersheim \\
\hline 342 & $189-1$ & 3 & Dachsen/8447 \\
\hline 343 & 189_2 & 3 & Dachsen/8447 \\
\hline 344 & 189_3 & $3 \mathrm{~N}$ & Dachsen/8447 \\
\hline 345 & $189 \_4$ & $3 \mathrm{~N}$ & Dachsen/8447 \\
\hline 346 & 191_1 & 0 & Rheinau/8462 \\
\hline 347 & 191_2 & 0 & Rheinau/8462 \\
\hline 348 & 191_3 & 0 & Rheinau/8462 \\
\hline 349 & 191_4 & 0 & Rheinau/8462 \\
\hline 350 & $192 \_1$ & $3 \mathrm{~N}$ & Watt/8105 \\
\hline 351 & $192 \_3$ & 3 & Watt/8105 \\
\hline 352 & $192 \_4$ & $3 \mathrm{~N}$ & Watt/8105 \\
\hline 353 & 193_1 & 1 & Ins/3212 \\
\hline 354 & 193_3 & $3 N$ & Ins/3212 \\
\hline 355 & $194 \_1$ & $3 N$ & Birrhard/5244 \\
\hline 356 & 194_2 & $3 N$ & Birrhard/5244 \\
\hline 357 & 194_3 & 3 & Birrhard/5244 \\
\hline 358 & $194 \_4$ & 3 & Birrhard/5244 \\
\hline 359 & $196-1$ & 1 & Colmar \\
\hline 360 & 196_3 & 1 & Colmar \\
\hline 361 & $196 \_4$ & 1 & Colmar \\
\hline 362 & $30 \_\overline{1}$ & 1 & St.Kind \\
\hline 363 & $30 \_2$ & 1 & St.Kind \\
\hline 364 & 30_3 & 1 & St.Kind \\
\hline 365 & $30 \_4$ & 1 & St.Kind \\
\hline 366 & $47 \_1$ & 1 & Groß St. Florian \\
\hline 367 & 472 & 1 & Groß St. Florian \\
\hline 368 & 47_3 & 3 & Groß St. Florian \\
\hline 369 & 47_4 & 1 & Groß St. Florian \\
\hline 370 & 48_1 & 123 & Fehring \\
\hline 371 & 48_2 & 1 & Fehring \\
\hline & 483 & 123 & Fehring \\
\hline
\end{tabular}

Oberrheinregion

Oberrheinregion

Oberrheinregion

Oberrheinregion

Oberrheinregion

Oberrheinregion

Oberrheinregion

Oberrheinregion

Oberrheinregion

Oberrheinregion

Oberrheinregion

Oberrheinregion

Oberrheinregion

Oberrheinregion

Oberrheinregion

Oberrheinregion

Oberrheinregion

Oberrheinregion

Oberrheinregion

Oberrheinregion

Oberrheinregion

Oberrheinregion

Oberrheinregion

Oberrheinregion

Oberrheinregion

Oberrheinregion

Oberrheinregion

Oberrheinregion

Oberrheinregion

Oberrheinregion

Oberrheinregion

Oberrheinregion

Oberrheinregion

Oberrheinregion

Oberrheinregion

Oberrheinregion

Oberrheinregion

Oberrheinregion

Oberrheinregion

Oberrheinregion

Oberrheinregion

Oberrheinregion

Oberrheinregion

Österreich/Ungarn

Österreich/Ungarn

Österreich/Ungarn

Österreich/Ungarn

Österreich/Ungarn

Österreich/Ungarn

Österreich/Ungarn

Österreich/Ungarn

Österreich/Ungarn

Österreich/Ungarn

Österreich/Ungarn
Frankreich

2012

Frankreich

2012

Frankreich

2012

Frankreich

2012

Frankreich

2012

Frankreich

2012

Frankreich 2012

Frankreich 2012

Frankreich 2012

Frankreich 2012

Frankreich 2012

Schweiz 2012

Schweiz 2012

Schweiz 2012

Schweiz 2012

Frankreich 2012

Frankreich 2012

Frankreich 2012

Frankreich 2012

Frankreich 2012

Frankreich 2012

Frankreich 2012

Frankreich 2012

Schweiz 2012

Schweiz 2012

Schweiz 2012

Schweiz 2012

Schweiz 2012

Schweiz 2012

Schweiz 2012

Schweiz 2012

Schweiz 2012

Schweiz 2012

Schweiz 2012

Schweiz 2012

Schweiz 2012

Schweiz 2012

Schweiz 2012

Schweiz 2012

Schweiz 2012

Frankreich 2012

Frankreich 2012

Frankreich 2012

Österreich 2011

Österreich 2011

Österreich 2011

Österreich 2011

Österreich 2011

Österreich 2011

Österreich 2011

Österreich 2011

Österreich 2011

Österreich 2011

Österreich 2011 


\begin{tabular}{|c|c|c|c|c|c|c|}
\hline 373 & 48_4 & 1 & Fehring & Österreich/Ungarn & Österreich & 2011 \\
\hline 374 & 61_1 & 0 & Nak & Österreich/Ungarn & Ungarn & 2011 \\
\hline 375 & 61_2 & 1 & Nak & Österreich/Ungarn & Ungarn & 2011 \\
\hline 376 & 61_3 & 13 & Nak & Österreich/Ungarn & Ungarn & 2011 \\
\hline 377 & 61_4 & 0 & Nak & Österreich/Ungarn & Ungarn & 2011 \\
\hline 378 & 149_1 & 1 & Sankt Kind & Österreich/Ungarn & Österreich & 2012 \\
\hline 379 & $149 \_2$ & 13 & Sankt Kind & Österreich/Ungarn & Österreich & 2012 \\
\hline 380 & 149_3 & 1 & Sankt Kind & Österreich/Ungarn & Österreich & 2012 \\
\hline 381 & 149_4 & $1 \mathrm{~N}$ & Sankt Kind & Österreich/Ungarn & Österreich & 2012 \\
\hline 382 & 150_1 & 1 & Gleisdorf & Österreich/Ungarn & Österreich & 2012 \\
\hline 383 & 150_2 & 0 & Gleisdorf & Österreich/Ungarn & Österreich & 2012 \\
\hline 384 & 150_3 & 1 & Gleisdorf & Österreich/Ungarn & Österreich & 2012 \\
\hline 385 & $150 \_4$ & 1 & Gleisdorf & Österreich/Ungarn & Österreich & 2012 \\
\hline 386 & 114_1 & 0 & Ribadeo & Spanien (Galicien) & Spanien & 2011 \\
\hline 387 & 114_2 & 0 & Ribadeo & Spanien (Galicien) & Spanien & 2011 \\
\hline 388 & 114_3 & 0 & Ribadeo & Spanien (Galicien) & Spanien & 2011 \\
\hline 389 & 115_1 & 0 & Ribadeo & Spanien (Galicien) & Spanien & 2011 \\
\hline 390 & 115_3 & 0 & Ribadeo & Spanien (Galicien) & Spanien & 2011 \\
\hline 391 & 115_4 & 0 & Ribadeo & Spanien (Galicien) & Spanien & 2011 \\
\hline 392 & 6_1 & 1 & Thenn & Süddeutschland/Österreich & Deutschland & 2011 \\
\hline 393 & 6_2 & 1 & Thenn & Süddeutschland/Österreich & Deutschland & 2011 \\
\hline 394 & 7_1 & 13 & Thenn & Süddeutschland/Österreich & Deutschland & 2011 \\
\hline 395 & 8_1 & 23 & Arnstorf-Lindach & Süddeutschland/Österreich & Deutschland & 2011 \\
\hline 396 & 8_2 & 0 & Arnstorf-Lindach & Süddeutschland/Österreich & Deutschland & 2011 \\
\hline 397 & 8_3 & 23 & Arnstorf-Lindach & Süddeutschland/Österreich & Deutschland & 2011 \\
\hline 398 & 8_4 & 0 & Arnstorf-Lindach & Süddeutschland/Österreich & Deutschland & 2011 \\
\hline 399 & $9 \_1$ & 0 & Pocking/Schönburg & Süddeutschland/Österreich & Deutschland & 2011 \\
\hline 400 & 9_2 & 0 & Pocking/Schönburg & Süddeutschland/Österreich & Deutschland & 2011 \\
\hline 401 & 9_3 & 0 & Pocking/Schönburg & Süddeutschland/Österreich & Deutschland & 2011 \\
\hline 402 & 9_4 & 0 & Pocking/Schönburg & Süddeutschland/Österreich & Deutschland & 2011 \\
\hline 403 & $10 \_1$ & 0 & Pocking/Börnau & Süddeutschland/Österreich & Deutschland & 2011 \\
\hline 404 & 10_2 & 0 & Pocking/Börnau & Süddeutschland/Österreich & Deutschland & 2011 \\
\hline 405 & 10_3 & 1 & Pocking/Börnau & Süddeutschland/Österreich & Deutschland & 2011 \\
\hline 406 & $10 \_4$ & 0 & Pocking/Börnau & Süddeutschland/Österreich & Deutschland & 2011 \\
\hline 407 & $12 \_1$ & 3 & Elgersdorf (SN) & Süddeutschland/Österreich & Deutschland & 2011 \\
\hline 408 & $13-1$ & 0 & Welbhausen & Süddeutschland/Österreich & Deutschland & 2011 \\
\hline 409 & $14 \_1$ & 1 & Poching/Eggershaum & Süddeutschland/Österreich & Deutschland & 2011 \\
\hline 410 & $14 \_2$ & 0 & Poching/Eggershaum & Süddeutschland/Österreich & Deutschland & 2011 \\
\hline 411 & 14_3 & 0 & Poching/Eggershaum & Süddeutschland/Österreich & Deutschland & 2011 \\
\hline 412 & $14 \_4$ & 0 & Poching/Eggershaum & Süddeutschland/Österreich & Deutschland & 2011 \\
\hline 413 & 31_1 & 123 & Hartkirchen & Süddeutschland/Österreich & Österreich & 2011 \\
\hline 414 & 31_2 & 3 & Hartkirchen & Süddeutschland/Österreich & Österreich & 2011 \\
\hline 415 & $31 \_4$ & 0 & Hartkirchen & Süddeutschland/Österreich & Österreich & 2011 \\
\hline 416 & $32-1$ & 1 & Gleisdorf & Süddeutschland/Österreich & Österreich & 2011 \\
\hline 417 & $32-4$ & 1 & Gleisdorf & Süddeutschland/Österreich & Österreich & 2011 \\
\hline 418 & $37-1$ & 3 & Künzing & Süddeutschland/Österreich & Deutschland & 2011 \\
\hline 419 & 37_2 & 3 & Künzing & Süddeutschland/Österreich & Deutschland & 2011 \\
\hline 420 & 37_3 & 3 & Künzing & Süddeutschland/Österreich & Deutschland & 2011 \\
\hline 421 & 374 & 3 & Künzing & Süddeutschland/Österreich & Deutschland & 2011 \\
\hline 422 & $38-2$ & 3 & Grucking & Süddeutschland/Österreich & Deutschland & 2011 \\
\hline 423 & 383 & 3 & Grucking & Süddeutschland/Österreich & Deutschland & 2011 \\
\hline 424 & $69-1$ & 3 & Pocking/Maierhof & Süddeutschland/Österreich & Deutschland & 2011 \\
\hline 425 & $69-2$ & 1 & Pocking/Maierhof & Süddeutschland/Österreich & Deutschland & 2011 \\
\hline 426 & 693 & 0 & Pocking/Maierhof & Süddeutschland/Österreich & Deutschland & 2011 \\
\hline
\end{tabular}




\begin{tabular}{|c|c|c|c|c|c|c|}
\hline 427 & $69 \_4$ & 0 & Pocking/Maierhof & Süddeutschland/Österreich & Deutschland & 2011 \\
\hline 428 & $70^{-} 1$ & 3 & Pocking/Maierhof & Süddeutschland/Österreich & Deutschland & 2011 \\
\hline 429 & $70 \_2$ & 3 & Pocking/Maierhof & Süddeutschland/Österreich & Deutschland & 2011 \\
\hline 430 & $70 \_3$ & 3 & Pocking/Maierhof & Süddeutschland/Österreich & Deutschland & 2011 \\
\hline 431 & 704 & 3 & Pocking/Maierhof & Süddeutschland/Österreich & Deutschland & 2011 \\
\hline 432 & 713 & 0 & Pocking/Maierhof & Süddeutschland/Österreich & Deutschland & 2011 \\
\hline 433 & 714 & 0 & Pocking/Maierhof & Süddeutschland/Österreich & Deutschland & 2011 \\
\hline 434 & $72 \_1$ & 0 & Pocking/Maierhof & Süddeutschland/Österreich & Deutschland & 2011 \\
\hline 435 & $72 \_2$ & 0 & Pocking/Maierhof & Süddeutschland/Österreich & Deutschland & 2011 \\
\hline 436 & $73-1$ & 0 & Pocking/Maierhof & Süddeutschland/Österreich & Deutschland & 2011 \\
\hline 437 & $73 \_2$ & 0 & Pocking/Maierhof & Süddeutschland/Österreich & Deutschland & 2011 \\
\hline 438 & 73_3 & 1 & Pocking/Maierhof & Süddeutschland/Österreich & Deutschland & 2011 \\
\hline 439 & $73 \_4$ & 13 & Pocking/Maierhof & Süddeutschland/Österreich & Deutschland & 2011 \\
\hline 440 & $87 \_1$ & $3 N$ & Wilhering & Süddeutschland/Österreich & Österreich & 2011 \\
\hline 441 & $87 \_2$ & 3 & Wilhering & Süddeutschland/Österreich & Österreich & 2011 \\
\hline 442 & $87 \_3$ & $3 N$ & Wilhering & Süddeutschland/Österreich & Österreich & 2011 \\
\hline 443 & $87 \_4$ & $3 \mathrm{~N}$ & Wilhering & Süddeutschland/Österreich & Österreich & 2011 \\
\hline 444 & $92 \_1$ & 0 & Ulm & Süddeutschland/Österreich & Deutschland & 2011 \\
\hline 445 & $92-2$ & 0 & Ulm & Süddeutschland/Österreich & Deutschland & 2011 \\
\hline 446 & 923 & 0 & Ulm & Süddeutschland/Österreich & Deutschland & 2011 \\
\hline 447 & $92 \_4$ & 0 & Ulm & Süddeutschland/Österreich & Deutschland & 2011 \\
\hline 448 & $12 \overline{8} \_1$ & 3 & Tabertshausen & Süddeutschland/Österreich & Deutschland & 2012 \\
\hline 449 & 128_2 & 3 & Tabertshausen & Süddeutschland/Österreich & Deutschland & 2012 \\
\hline 450 & $128 \_3$ & 3 & Tabertshausen & Süddeutschland/Österreich & Deutschland & 2012 \\
\hline 451 & $128+4$ & 0 & Tabertshausen & Süddeutschland/Österreich & Deutschland & 2012 \\
\hline 452 & $132-1$ & 0 & Wenig im Innkreis & Süddeutschland/Österreich & Österreich & 2012 \\
\hline 453 & 132 & 3 & Wenig im Innkreis & Süddeutschland/Österreich & Österreich & 2012 \\
\hline 454 & 1323 & 3 & Wenig im Innkreis & Süddeutschland/Österreich & Österreich & 2012 \\
\hline 455 & 1324 & 0 & Wenig im Innkreis & Süddeutschland/Österreich & Österreich & 2012 \\
\hline 456 & 134 & 3 & Pocking & Süddeutschland/Österreich & Deutschland & 2012 \\
\hline 457 & 134_2 & 1 & Pocking & Süddeutschland/Österreich & Deutschland & 2012 \\
\hline 458 & 1343 & 0 & Pocking & Süddeutschland/Österreich & Deutschland & 2012 \\
\hline 459 & $134 \_4$ & 0 & Pocking & Süddeutschland/Österreich & Deutschland & 2012 \\
\hline 460 & 135_3 & 0 & Pocking & Süddeutschland/Österreich & Deutschland & 2012 \\
\hline 461 & $135 \_4$ & 0 & Pocking & Süddeutschland/Österreich & Deutschland & 2012 \\
\hline 462 & 141_1 & 1 & Gschaid & Süddeutschland/Österreich & Deutschland & 2012 \\
\hline 463 & 141_2 & 0 & Gschaid & Süddeutschland/Österreich & Deutschland & 2012 \\
\hline 464 & 141_3 & 3 & Gschaid & Süddeutschland/Österreich & Deutschland & 2012 \\
\hline 465 & 141_4 & $3 \mathrm{~N}$ & Gschaid & Süddeutschland/Österreich & Deutschland & 2012 \\
\hline 466 & $180 \_1$ & $3 \mathrm{~N}$ & Künzing & Süddeutschland/Österreich & Deutschland & 2012 \\
\hline 467 & 180_2 & 3 & Künzing & Süddeutschland/Österreich & Deutschland & 2012 \\
\hline 468 & 180_3 & 3 & Künzing & Süddeutschland/Österreich & Deutschland & 2012 \\
\hline 469 & $180 \_4$ & 3 & Künzing & Süddeutschland/Österreich & Deutschland & 2012 \\
\hline 470 & 181_1 & 1 & Bad Füssing & Süddeutschland/Österreich & Deutschland & 2012 \\
\hline 471 & 1812 & 0 & Bad Füssing & Süddeutschland/Österreich & Deutschland & 2012 \\
\hline 472 & 181_3 & $3 N$ & Bad Füssing & Süddeutschland/Österreich & Deutschland & 2012 \\
\hline 473 & $181 \_4$ & 1 & Bad Füssing & Süddeutschland/Österreich & Deutschland & 2012 \\
\hline 474 & $182-1$ & 3 & Wartenberg & Süddeutschland/Österreich & Deutschland & 2012 \\
\hline 475 & $182 \_2$ & 0 & Wartenberg & Süddeutschland/Österreich & Deutschland & 2012 \\
\hline 476 & $182 \_3$ & 0 & Wartenberg & Süddeutschland/Österreich & Deutschland & 2012 \\
\hline 477 & 182 & 1 & Wartenberg & Süddeutschland/Österreich & Deutschland & 2012 \\
\hline 478 & $198+1$ & $3 N$ & Rieden a.d. Kötz & Süddeutschland/Österreich & Deutschland & 2012 \\
\hline 479 & 198_2 & $3 N$ & Rieden a.d. Kötz & Süddeutschland/Österreich & Deutschland & 2012 \\
\hline 480 & 1983 & $3 \mathrm{~N}$ & Rieden a.d. Kötz & Süddeutschland/Österreich & Deutschland & 2012 \\
\hline
\end{tabular}




\begin{tabular}{|c|c|c|c|c|c|c|}
\hline 481 & $199 \_2$ & $3 \mathrm{~N}$ & Strasskirchen & Süddeutschland/Österreich & Deutschland & 2012 \\
\hline 482 & 1993 & 0 & Strasskirchen & Süddeutschland/Österreich & Deutschland & 2012 \\
\hline 483 & $199 \_4$ & 1 & Strasskirchen & Süddeutschland/Österreich & Deutschland & 2012 \\
\hline 484 & 1121 & 0 & Gluchow & Tschechien/Polen & Polen & 2011 \\
\hline 485 & 1122 & 0 & Gluchow & Tschechien/Polen & Polen & 2011 \\
\hline 486 & 1123 & 0 & Gluchow & Tschechien/Polen & Polen & 2011 \\
\hline 487 & 178 & 0 & Hrubčice & Tschechien/Polen & Tschechien & 2012 \\
\hline 488 & $178 \_2$ & 0 & Hrubčice & Tschechien/Polen & Tschechien & 2012 \\
\hline 489 & 178_3 & 1 & Hrubčice & Tschechien/Polen & Tschechien & 2012 \\
\hline 490 & 1784 & 0 & Hrubčice & Tschechien/Polen & Tschechien & 2012 \\
\hline 491 & $179^{-} 1$ & 1 & Garzyn & Tschechien/Polen & Polen & 2012 \\
\hline 492 & $179-2$ & 1 & Garzyn & Tschechien/Polen & Polen & 2012 \\
\hline 493 & $179 \_3$ & 1 & Garzyn & Tschechien/Polen & Polen & 2012 \\
\hline 494 & $179 \_4$ & 0 & Garzyn & Tschechien/Polen & Polen & 2012 \\
\hline 495 & $183 \_1$ & 1 & Kojecin & Tschechien/Polen & Polen & 2012 \\
\hline 496 & $183 \_2$ & 0 & Kojecin & Tschechien/Polen & Polen & 2012 \\
\hline 497 & 183_3 & 0 & Kojecin & Tschechien/Polen & Polen & 2012 \\
\hline 498 & $183 \_4$ & 1 & Kojecin & Tschechien/Polen & Polen & 2012 \\
\hline 499 & $184 \_2$ & $3 \mathrm{~N}$ & Velim & Tschechien/Polen & Tschechien & 2012 \\
\hline 500 & $184 \_3$ & $3 \mathrm{~N}$ & Velim & Tschechien/Polen & Tschechien & 2012 \\
\hline 501 & $184 \_4$ & $3 \mathrm{~N}$ & Velim & Tschechien/Polen & Tschechien & 2012 \\
\hline 502 & $185-1$ & 1 & Olomouc & Tschechien/Polen & Tschechien & 2012 \\
\hline 503 & $122-1$ & $3 N$ & Adana & Türkei (Adana) & Türkei & 2012 \\
\hline 504 & $122 \_2$ & $23 N$ & Adana & Türkei (Adana) & Türkei & 2012 \\
\hline 505 & $122 \_3$ & $3 N$ & Adana & Türkei (Adana) & Türkei & 2012 \\
\hline 506 & 12244 & $3 \mathrm{~N}$ & Adana & Türkei (Adana) & Türkei & 2012 \\
\hline 507 & $123 \_1$ & 0 & Adana & Türkei (Adana) & Türkei & 2012 \\
\hline 508 & $123 \_2$ & $3 N$ & Adana & Türkei (Adana) & Türkei & 2012 \\
\hline 509 & 123 & $23 N$ & Adana & Türkei (Adana) & Türkei & 2012 \\
\hline 510 & 12344 & $3 N$ & Adana & Türkei (Adana) & Türkei & 2012 \\
\hline 511 & $124 \_1$ & $3 N$ & Adana & Türkei (Adana) & Türkei & 2012 \\
\hline 512 & 1242 & $3 \mathrm{~N}$ & Adana & Türkei (Adana) & Türkei & 2012 \\
\hline 513 & 124_3 & $3 \mathrm{~N}$ & Adana & Türkei (Adana) & Türkei & 2012 \\
\hline 514 & $41 \overline{1}$ & 1 & Grenoble & Zentralfrankreich/Westschweiz & Frankreich & 2011 \\
\hline 515 & 41_2 & 1 & Grenoble & Zentralfrankreich/Westschweiz & Frankreich & 2011 \\
\hline 516 & 41_3 & 1 & Grenoble & Zentralfrankreich/Westschweiz & Frankreich & 2011 \\
\hline 517 & 42_1 & 0 & José/Avergne & Zentralfrankreich/Westschweiz & Frankreich & 2011 \\
\hline 518 & 42_2 & $3 \mathrm{~N}$ & José/Avergne & Zentralfrankreich/Westschweiz & Frankreich & 2011 \\
\hline 519 & 42_3 & 3 & José/Avergne & Zentralfrankreich/Westschweiz & Frankreich & 2011 \\
\hline 520 & 43_1 & 1 & Lezay & Zentralfrankreich/Westschweiz & Frankreich & 2011 \\
\hline 521 & 43_2 & 12 & Lezay & Zentralfrankreich/Westschweiz & Frankreich & 2011 \\
\hline 522 & 43_3 & 1 & Lezay & Zentralfrankreich/Westschweiz & Frankreich & 2011 \\
\hline 523 & 434 & 1 & Lezay & Zentralfrankreich/Westschweiz & Frankreich & 2011 \\
\hline 524 & $45-1$ & 0 & 03240 Saint-Sornin & Zentralfrankreich/Westschweiz & Frankreich & 2011 \\
\hline 525 & 452 & 1 & 3241 Saint-Sornin & Zentralfrankreich/Westschweiz & Frankreich & 2011 \\
\hline 526 & 453 & 3 & 3242 Saint-Sornin & Zentralfrankreich/Westschweiz & Frankreich & 2011 \\
\hline 527 & $45 \_4$ & $3 \mathrm{~N}$ & 3243 Saint-Sornin & Zentralfrankreich/Westschweiz & Frankreich & 2011 \\
\hline 528 & $66 \_1$ & 1 & Villy le Montier & Zentralfrankreich/Westschweiz & Frankreich & 2011 \\
\hline 529 & 662 & 1 & Villy le Montier & Zentralfrankreich/Westschweiz & Frankreich & 2011 \\
\hline 530 & 663 & 1 & Villy le Montier & Zentralfrankreich/Westschweiz & Frankreich & 2011 \\
\hline 531 & 664 & 1 & Villy le Montier & Zentralfrankreich/Westschweiz & Frankreich & 2011 \\
\hline 532 & $67-1$ & 0 & St Vincent de Mercoze & Zentralfrankreich/Westschweiz & Frankreich & 2011 \\
\hline 533 & $67 \_2$ & 0 & St Vincent de Mercoze & Zentralfrankreich/Westschweiz & Frankreich & 2011 \\
\hline 534 & 673 & 0 & St Vincent de Mercoze & Zentralfrankreich/Westschweiz & Frankreich & 2011 \\
\hline
\end{tabular}




\begin{tabular}{|c|c|c|c|c|c|c|}
\hline 535 & 67_4 & 0 & St Vincent de Mercoze & Zentralfrankreich/Westschweiz & Frankreich & 2011 \\
\hline 536 & $85 \_1$ & 1 & Frenières-sur-Bex & Zentralfrankreich/Westschweiz & Schweiz & 2011 \\
\hline 537 & 85_3 & 3 & Frenières-sur-Bex & Zentralfrankreich/Westschweiz & Schweiz & 2011 \\
\hline 538 & 854 & 3 & Frenières-sur-Bex & Zentralfrankreich/Westschweiz & Schweiz & 2011 \\
\hline 539 & $98+1$ & 1 & Certines & Zentralfrankreich/Westschweiz & Frankreich & 2011 \\
\hline 540 & $98 \_2$ & 1 & Certines & Zentralfrankreich/Westschweiz & Frankreich & 2011 \\
\hline 541 & $98 \_3$ & 1 & Certines & Zentralfrankreich/Westschweiz & Frankreich & 2011 \\
\hline 542 & $98 \_4$ & 1 & Certines & Zentralfrankreich/Westschweiz & Frankreich & 2011 \\
\hline 543 & $14 \overline{6} 1$ & 0 & La Ferté-Hauterive & Zentralfrankreich/Westschweiz & Frankreich & 2012 \\
\hline 544 & 146_2 & 0 & La Ferté-Hauterive & Zentralfrankreich/Westschweiz & Frankreich & 2012 \\
\hline 545 & 146_3 & 0 & La Ferté-Hauterive & Zentralfrankreich/Westschweiz & Frankreich & 2012 \\
\hline 546 & 146_4 & 2 & La Ferté-Hauterive & Zentralfrankreich/Westschweiz & Frankreich & 2012 \\
\hline 547 & $157^{-1}$ & 0 & Viabon & Zentralfrankreich/Westschweiz & Frankreich & 2012 \\
\hline 548 & 158 & 0 & Tignieu & Zentralfrankreich/Westschweiz & Frankreich & 2012 \\
\hline 549 & 1583 & 3 & Tignieu & Zentralfrankreich/Westschweiz & Frankreich & 2012 \\
\hline 550 & 158_4 & 3 & Tignieu & Zentralfrankreich/Westschweiz & Frankreich & 2012 \\
\hline 551 & $186 \_1$ & 1 & Saint Andre de Corcy & Zentralfrankreich/Westschweiz & Frankreich & 2012 \\
\hline 552 & 186_3 & 1 & Saint Andre de Corcy & Zentralfrankreich/Westschweiz & Frankreich & 2012 \\
\hline 553 & $186 \_4$ & 0 & Saint Andre de Corcy & Zentralfrankreich/Westschweiz & Frankreich & 2012 \\
\hline 54 & $187 \_2$ & 1 & Aubigny-sur-Nère & Zentralfrankreich/Westschweiz & Frankreich & 2012 \\
\hline 55 & $187 \_4$ & 1 & Aubigny-sur-Nère & Zentralfrankreich/Westschweiz & Frankreich & 2012 \\
\hline 556 & $188-1$ & $3 N$ & La Côte-Saint-André & Zentralfrankreich/Westschweiz & Frankreich & 2012 \\
\hline 557 & $188 \_2$ & 1 & La Côte-Saint-André & Zentralfrankreich/Westschweiz & Frankreich & 2012 \\
\hline & $188 \_3$ & 1 & La Côte-Saint-André & Zentralfrankreich/Westschweiz & Frankreich & 2012 \\
\hline 559 & 1884 & 1 & La Côte-Saint-André & Zentralfrankreich/Westschweiz & Frankreich & 2012 \\
\hline
\end{tabular}



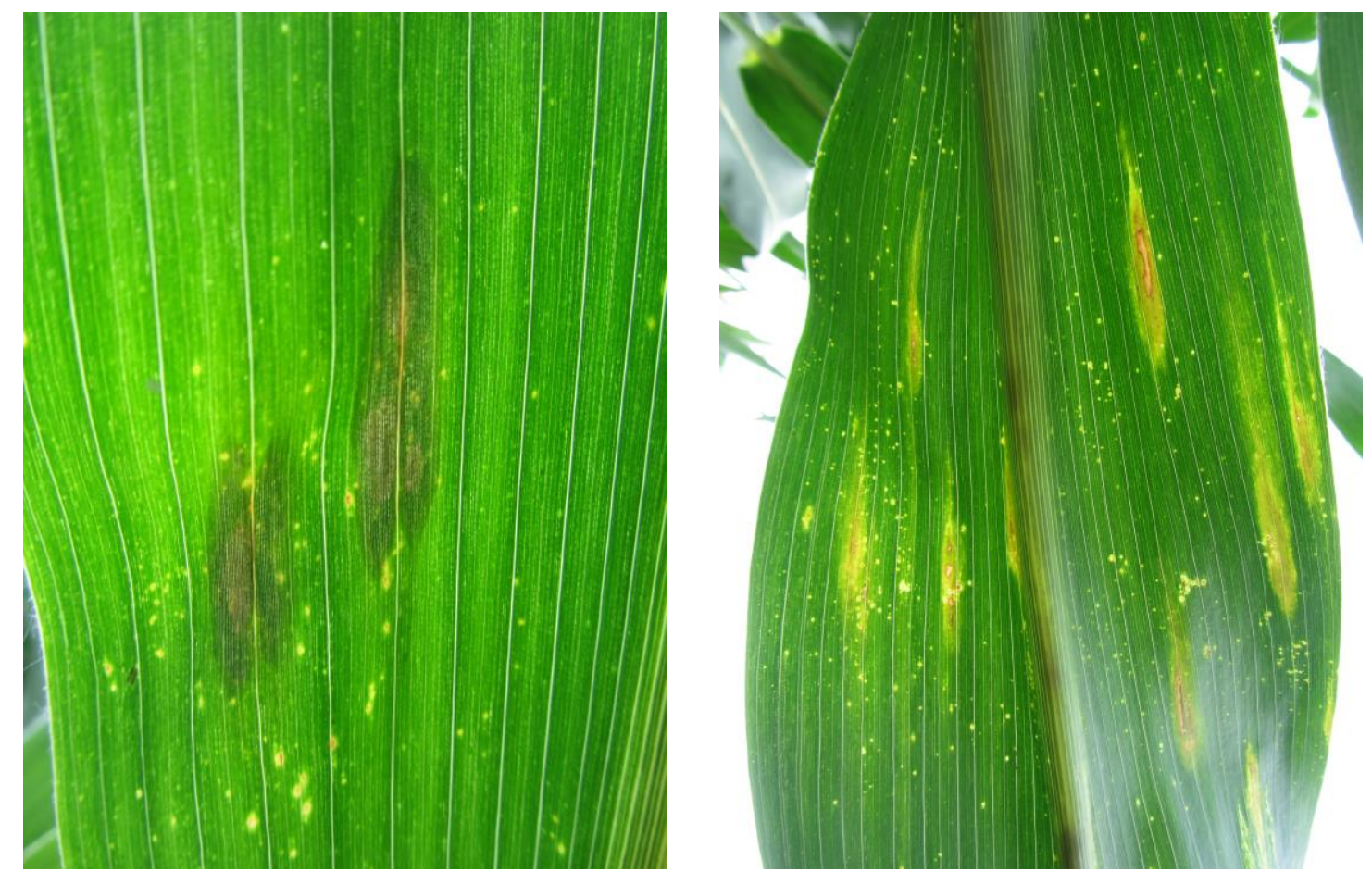

Abb. 1A: Befallsreaktionen im Anfangsstadium an Mais nach E. turcicum Infektion im Freiland mit Gegenlicht, links: kompatible Interaktion grau/grüne Läsionen $(2-3 \mathrm{~cm}$ lang) ohne Cholorsen (anfällig); rechts: inkompatible Interaktion Chlorosen (3-4 cm lang) mit begrenzten Nekrosen (resistent)
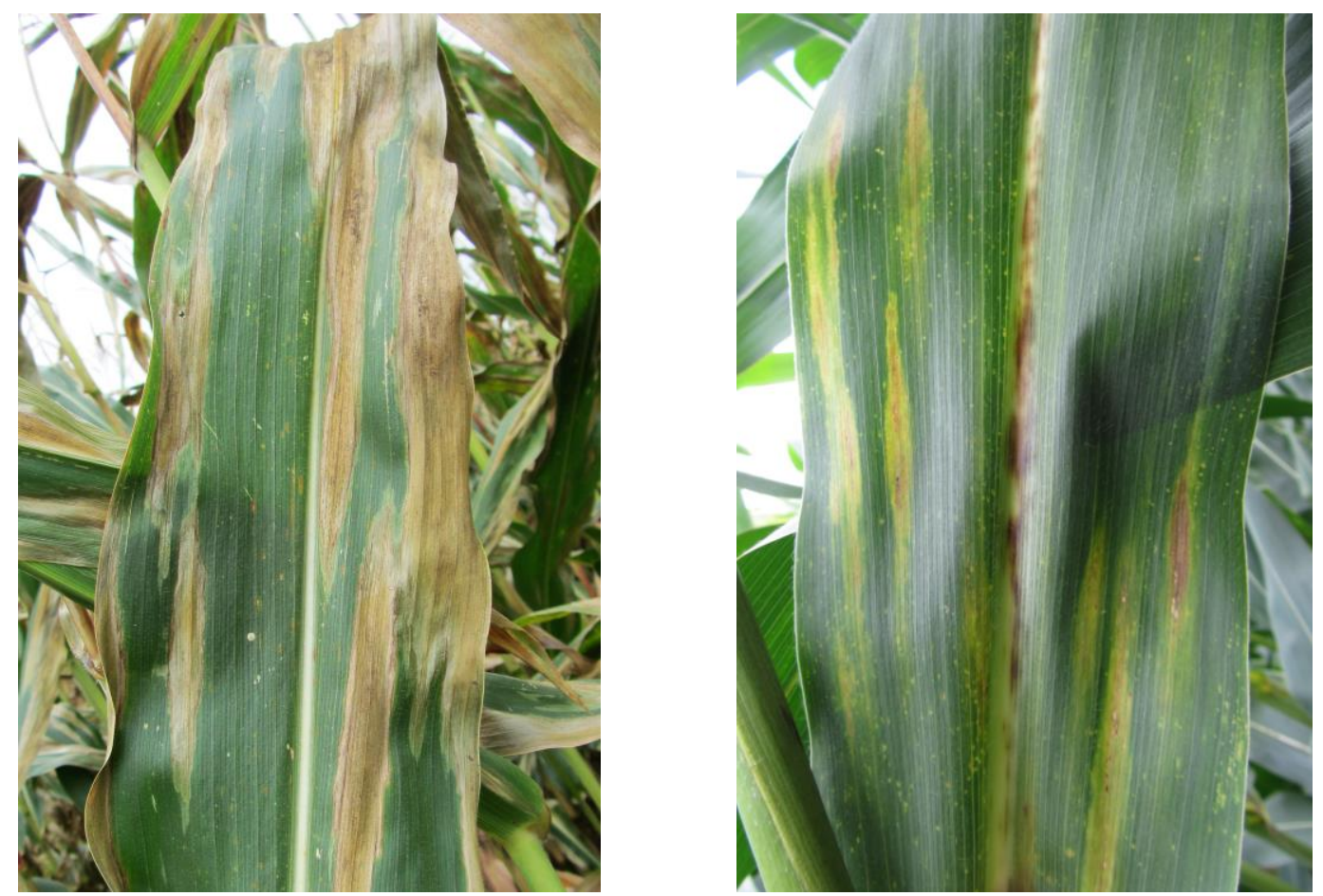

Abb. 1A: Befallsreaktionen an Mais nach E. turcicum Infektion im Freiland, links: kompatible Interaktion braune länglich ovale Läsionen (10 - $15 \mathrm{~cm}$ lang) ohne Cholorsen (anfällig); rechts: inkompatible Interaktion Chlorosen (5 - $10 \mathrm{~cm}$ lang) mit beträchtlichen Nekrosen (resistent) 


\section{Danksagung}

Ich möchte mich besonders bei Prof. Dr. Andreas von Tiedemann für die Überlassung des Themas und die gewährten Freiheiten während der Durchführung und den gezielten Anregungen zur rechten Zeit bedanken.

Herrn Prof. Dr. Heiko Becker danke ich für die Übernahme des Korreferats.

Mein ganz besonderer Dank gilt Herrn Dr. Birger Koopmann. Seine stete Diskussions- und Hilfsbereitschaft in allen Belangen des Projektes während der vierjährigen Laufzeit haben maßgeblich zum erfolgreichen Abschluss der Arbeit beigetragen.

Ganz herzlich möchte ich mich bei Isabel Müller für die sehr verlässliche Zusammenarbeit und die stets angenehme Arbeitsatmosphäre bedanken. Ihre strukturierte Arbeitsweise im Labor und Gewächshaus hat die Durchführung der Versuche im vorgesehenen Zeitrahmen erst möglich gemacht.

Bei Dagmar Tacke bedanke ich mich besonders für die Unterstützung im Rahmen der molekulargenetischen Untersuchungen und die zeitlich flexible Aushilfe in den Gewächshausversuchen.

Bei Evelin Vorbeck und Maik Knobel bedanke ich mich für die verlässliche, pragmatische Hilfsbereitschaft im Rahmen der Labor- und Gewächshausversuche.

Bei Frau Dr. Bettina Kessel, als Projektkoordinatorin der beteiligten Züchterfirmen, möchte ich mich für die stets gute und zuverlässige Zusammenarbeit bedanken. Insbesondere die Bereitstellung des Saatgutes des Differentialsortiments durch die KWS Saat SE, hat über Bettina Kessel während des gesamten Projektzeitraums sehr zuverlässig funktioniert.

Allen anderen Doktoranden, Masterstudenten und Mitarbeitern der Abteilung danke ich für die tolle Arbeitsatmosphäre, die stete Hilfsbereitschaft und auch lustigen Momente sowohl innerhalb als auch außerhalb des Instituts. Es waren vier tolle Jahre.

Bei Dr. Anke Sirrenberg, Fluturë Novakazi, und Jan Picker möchte ich mich für das zügige Gegenlesen großer Teile der Arbeit bedanken.

Bei der FNR bedanke ich mich für die Finanzierung des Projektes (M 36/11 NR) und bei den Züchterfirmen der GFPi Abteilung Mais für die gute Zusammenarbeit.

Ich widme diese Arbeit meinen lieben Eltern, meiner Mutter Elisabeth Hanekamp und meinem Vater Bernhard Hanekamp, der leider viel zu früh verstorben ist. 


\section{Eidesstattliche Erklärung}

Hiermit erkläre ich, dass diese Arbeit weder in gleicher noch in ähnlicher Form bereits anderen Prüfungsbehörden vorgelegen hat.

Weiter erkläre ich, dass ich mich an keiner anderen Hochschule um einen Doktorgrad beworben habe.

Hiermit erkläre ich eidesstattlich, dass diese Dissertation selbständig und ohne unerlaubte Hilfe angefertigt wurde.

Göttingen im März 2016

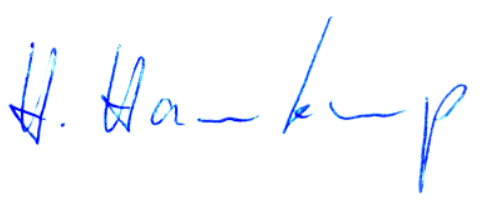




\section{Lebenslauf}

\section{Persönliche Daten}

Name: Hendrik Hanekamp

Geburtsdatum/-ort: 1983 in Löningen

\section{Berufliche Tätigkeit}

Seit 02/2016 Landwirtschaftskammer Niedersachsen, Bezirkstelle Emsland

Leiter Fachgruppe Pflanzenbau und Pflanzenschutz

Pflanzenschutzdienst Niedersachsen

\section{Hochschulausbildung}

10/2011 - 01/2016 Doktorand und Wissenschaftlicher Mitarbeiter am Department für Nutzpflanzenwissenschaften, Abteilung Allgemeine Pflanzenpathologie und Pflanzenschutz der Georg-August-Universität Göttingen.

04/2009 - 09/2011 Masterstudium der Agrarwissenschaften (M. Sc. agr.) an der GeorgAugust-Universität Göttingen, Abteilung Pflanzenzüchtung, Thema der Masterarbeit: „Ascochyta-Resistenz bei Ackerbohnen: Methodische Optimierungen zur Entwicklung eines Tests auf Resistenz in Winterackerbohnen (Vicia faba L.)“.

10/2005 - 04/2009 Bachelor of Science der Agrarwissenschaften (B. Sc. agr.) an der Georg-August-Universität Göttingen, Thema der Bachelorarbeit: „Internationale Wettbewerbsfähigkeit der Putenerzeugung am Standort Deutschland."

09/2007-03/2008 Auslandsstudium an der Universidad de Córdoba, Escuela Técnica Superior de Ingenieros Agronomos y Montes, Spanien.

\section{Berufsausbildung}

08/2003 - 07/2005 Ausbildung zum Landwirt

\section{Zivildienst}

08/2002 - 06/2003 Rettungsdienst, Malteser Hilfsdienst

\section{Schulausbildung}

09/1999-06/2002 Gymnasium der Berufsbildenden Schulen Papenburg, Gewerbliche und kaufmännische Fachrichtung; Abschluss: Abitur 